\title{
Snow Accumulation in the Niaqunguk (Apex) River Watershed near Iqaluit, Nunavut, Canada
}

by

Keegan Smith

A thesis submitted to the Faculty of Graduate and Postdoctoral Affairs in partial fulfillment of the requirements for the degree of

Master of Science

in

Geography

Carleton University

Ottawa, Ontario

(C) 2018

Keegan Smith 


\begin{abstract}
Spring snowmelt is the largest input to Arctic hydrological systems. The spring snow distribution is extremely spatially variable and difficult to quantify. This study used field measurements and models to characterize and quantify the spring snow distribution in the $52 \mathrm{~km}^{2}$ Niaqunguk River watershed near Iqaluit, Nunavut. Three models were assessed for their ability to replicate spatial patterns and estimate total watershed snow storage. Two semi-distributed terrain-based models were calibrated, and a fully distributed process model, SnowModel, was run. All 3 successfully replicated spatial patterns and provided reasonable quantitative estimates, except for SnowModel's poor performance in 2015. SnowModel is useful for studying mid-winter processes, but requires user technical capacity and high-quality meteorological observations lacking for much of the Arctic. By comparison, the semi-distributed models provide an accurate estimate without high technical or meteorological data demands, and provide a framework to guide stratified snow surveying.
\end{abstract}




\section{Acknowledgements}

This research would not have been possible without the dedication of my supervisor, Dr. Murray Richardson. His guidance, patience, and support in field and office were exemplary. At Carleton University, I also thank Drs. Elyn Humphreys and Michael Treberg for their help with field instrumentation. Murray and Elyn also thoroughly reviewed this document, providing valuable editing advice.

In Iqaluit, NU, thanks to project partner and advisor Jamal Shirley, for his support over several field seasons. Jason Carpenter and Daniel Martin coordinated activities with ETP, and generously supplied advice and resources that kept me safe and [relatively] sane. Thanks are due to all NRI/NAC staff, especially Ted Irniq for his advice, humour, and adventure stories, and Sean Guistini for sharing long hours and big ambitions.

For their hard work on our snow surveying program, and for teaching me so much about the Land, I am indebted to the ETP students from the Classes of 2015 - 2017, foremost among them: Peter Aqqaq, Jeremy Fraser, Randy Hinanik, Alex Kilabuk, Tony Lee, Keenan "Nooks" Lindell, Sean Noble-Nowdluk, Nash Panniuq, Angulalik Pedersen, and Daniel Taukie. For their contributions to field and lab work: NRI summer students Jessica Peters (2014-15), Jean Allen (2016) and Anika Bychok (2016-17). Dinos Tikvik gets a warm "thank you" for bannock, tea, and talk on snow while cutting blocks during the 2017 ETP spring field camp.

Gabriel Chiasson-Poirier (U de Montréal) and Michael Bakaic (York U) deserve special mention for friendship, data and advice... and for long days, good cooking, and the dumbest game of Settlers of Catan ever played. For assistance, enthusiasm, and friendship, I thank Tommy Tremblay (CNGO) who edited early work on this manuscript, and Daniel Coulombe (ECCC) who heroically manages the Iqaluit weather station.

For providing his SnowModel software, special thanks are due to Glen Liston (Colorado State U). For his helpful advice on blowing snow modeling, thank you to John Pomeroy (U Saskatchewan). For data and advice on this project, thank you to Hagop Mouradian (ECCC), Jason Friesen (ECCC) and Naomi Short (NRCan).

Most importantly, I thank my loving girlfriend and science superhero, Amy Maclean, for her endless patience and understanding during this project. 
For Frank, Marvin, and Ida Mae. 


\section{Table of Contents}

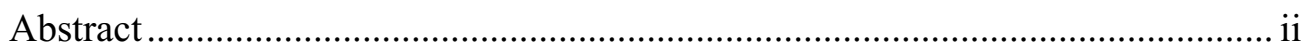

Acknowledgements..........................................................................................ii

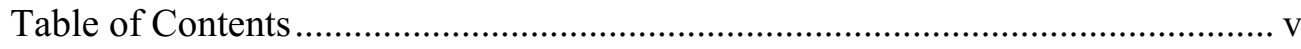

List of Tables ............................................................................................... vii

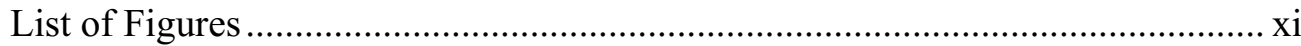

List of Equations .............................................................................................

List of Symbols and Abbreviations Used ........................................................ xviii

1 Chapter: Introduction .......................................................................................

2 Chapter: Literature Review................................................................................... 6

2.1 Blowing Snow Transport …………………………………………………... 6

2.1.1 Boundary Layer Flow and Surface Winds .............................................. 8

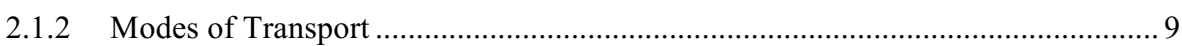

2.1.3 Boundary Layer Separation and Drift Formation ........................................ 14

2.2 Physically-based Blowing Snow Models................................................ 15

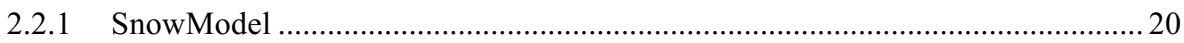

2.3 Review of hydrological studies in the NRW ........................................... 28

3 Chapter: Methods.................................................................................... 31

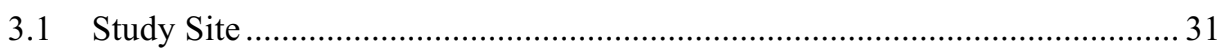

3.2 Field Data Collection ........................................................................... 36

3.3 Terrain Models ................................................................................ 38

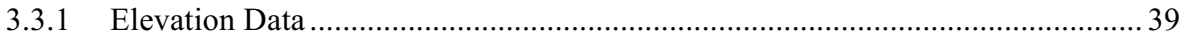

3.3.2 Terrain Variable Calculation ............................................................................ 39

3.3.3 Classification Methods For Semi-Distributed Modeling .................................. 41

3.3.4 Empirical Model Evaluation ................................................................... 44 


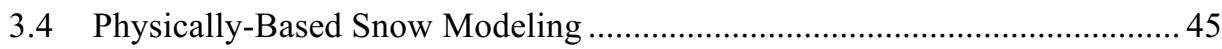

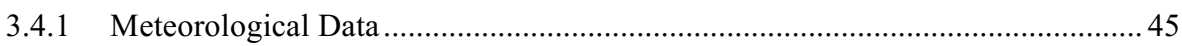

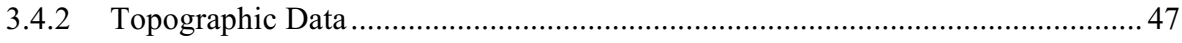

3.4.3 Wind Field Parameter Value Selection ................................................................. 49

3.4.4 SnowModel Sensitivity Analyses......................................................................5 52

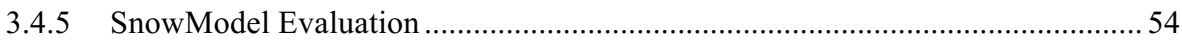

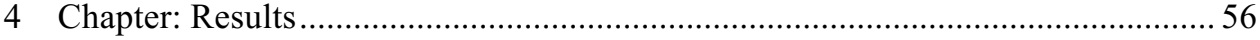

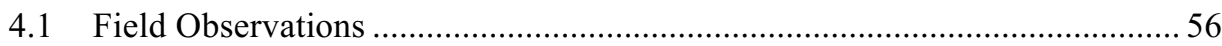

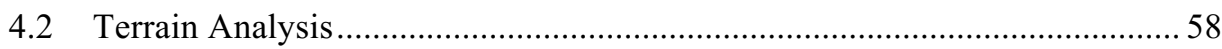

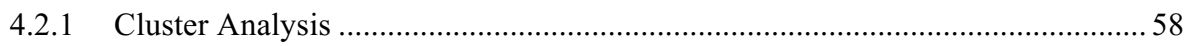

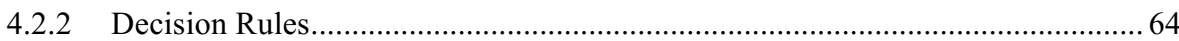

4.2.3 Watershed SWE Estimates from Terrain Models ................................................ 69

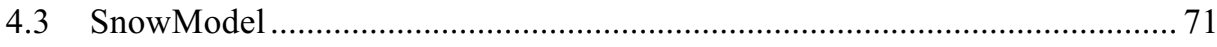

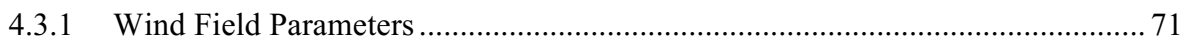

4.3.2 SnowPack Density Evolution ......................................................................... 78

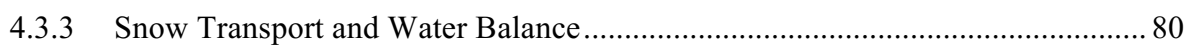

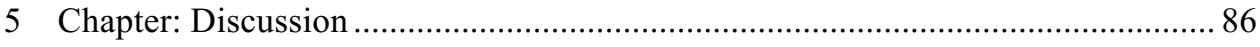

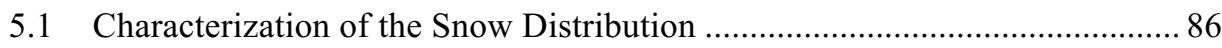

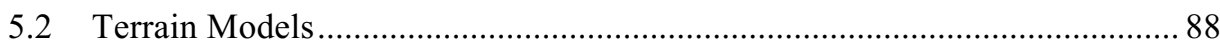

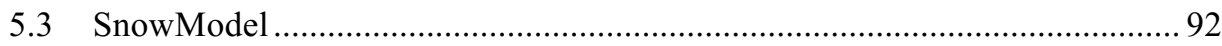

5.3.1 Wind Field Parameters ................................................................................... 93

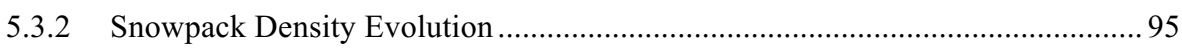

5.3.3 Snow Transport and Water Balance ……………………………………….... 96

5.3.4 SnowModel Performance in Other Studies ....................................................... 97

5.3.5 Potential Shortcomings in the Simulation Inputs ……….....................................99

5.3.6 Uncertainties in Survey Measurements ............................................................. 100

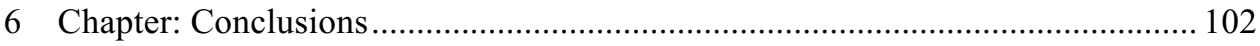




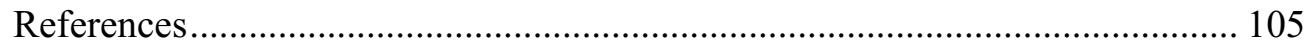

Appendix A - Sources of error in field SWE measurement.............................. 120

Appendix B - Spatial autocorrelation in surveyed snow data........................... 126

Appendix C - Survey Data: Histograms and Linear Model Performance .......... 129

Appendix D - Inuktitut Terminology ............................................................. 133

Appendix E - Terrain Variables Used For Snow Modeling............................. 135

Appendix F -Terrain Unit Model: Supplementary Statistics .......................... 141

Appendix G - Heuristics in Snow and Soil Science ......................................... 142

Appendix H - Decision Rule Model: Supplementary Statistics........................ 147

Appendix I - Meteorological forcing data for 2015 and 2016 ......................... 148

Appendix J - Errors in Arctic Winter Snowfall Measurements ......................... 155

Appendix K - Pre-Processing for the Iqaluit DFAR ........................................ 160

Appendix L - Potential Errors in Iqaluit XFB Measured Data ......................... 172 


\section{List of Tables}

Table 1: Meteorological data summary for the 2 study years, from 2014-10-01 to 201504-18 (200 day period, called " 2015 " throughout this thesis), and from 2015-10-01 to 2016-04-30 (213 day period, called “2016”). PAGE $_{\text {SAre not adjusted for wind-induced }}$ undercatch bias. 47

Table 2: Spring snow survey statistics, with SWE estimated from regression of depth data. Within-sites standard deviation of snow depth $\left(\sigma \mathrm{d}_{\text {within }}\right)$ is calculated from multiple depth measurements at each site, whereas between-sites standard deviation $\left(\sigma \mathrm{d}_{\text {between }}\right)$ is calculated from all site depth averages. Sample sizes for regression SWE are $n=284$ in 2015 and $n=192$ in 2016 .

Table 3: Terrain unit centroids (means) \pm 1 SD. The terrain variables are normalized height $(N H)$, slope $(\beta)$, tangential and longitudinal curvature (CT and $C L$, respectively), topographic openness $\left(O_{+10 K}\right.$ and $\left.O_{-10 K}\right)$, and wind shelter index $\left(W_{30}\right)$

Table 4: Measured SWE partitioned by the 8TU terrain units derived from cluster analysis: sample size (n, with\% of total samples also indicated), mean, standard deviation (SD), and coefficient of variation (CV; SD divided by mean). Pooled mean and SD are averaged from the model classes, using the landscape areas of each class for weighting. Pooled CV is then calculated from the pooled mean and SD.

Table 5: Spatial coverage of the DR snow accumulation classes

Table 6: Measured SWE partitioned by DR classes for both study years: sample size (n, with $\%$ of total samples also indicated), mean, standard deviation (SD), and coefficient of 
variation (CV; SD divided by mean). Pooled mean and SD are averaged from the model classes, using the landscape areas of each class for weighting. Pooled CV is then calculated from the pooled mean and SD. 69

Table 7: Comparison of watershed SWE estimates; unweighted survey mean and model class-weighted means. Model confidence intervals were calculated using pooled standard deviation and sample size. 70

Table 8: Watershed averaged statistics for SnowModel spring SWE from multiple windfield configurations. Mean difference (MD) from survey data was determined for each year. The simulated spring SWE as a fraction of total winter precipitation is given as " $\%$ P”. The survey-measured $\%$ P was 32\% in 2015 and 62\% in 2016.

Table 9: Statistics from point comparison of survey (observed) and SnowModel (predicted) spring SWE over the multiple wind-field configurations. Columns refer to the root-mean square difference (RMSD), mean difference (MD) and coefficient of determination $\left(\mathrm{R}^{2}\right)$ between survey and SnowModel SWE 75

Table 10: All modified SnowModel parameter values used in the final simulations. 78

Table 11: SnowModel water balance fluxes by year (all in mm water equivalent). Water balance elements are defined in Equation 20; $\mathrm{P}=$ precipitation, $\mathrm{Q}_{\mathrm{s}}=$ saltation transport, $\mathrm{Q}_{\mathrm{t}}=$ suspension transport, $\mathrm{Q}_{\mathrm{vs}}=$ in-situ sublimation, $\mathrm{Q}_{\mathrm{vb}}=$ blowing snow sublimation, $\mathrm{M}$ $=$ melt, $\mathrm{SWE}=$ snow water equivalent on the ground by end of simulation. 80

Table 12: (Part I) Error sources, ordered by severity, with compensation techniques. Note that "tare" weighing is subject to all uncertainties normally affecting the spring scale. 124 
Table 13: Mean and standard deviation of field-measured SWE (F-SWE) and regressionmodeled SWE (R-SWE) in the NRW over both study years 130

Table 14: Spearman correlations between measured SWE and the terrain variables used for cluster analysis. Bonferroni-corrected $\alpha=7.1 \times 10^{-3}(0.05 / 7)$. 141

Table 15: Spearman correlations between the measured SWE and the terrain variables used in the decision rules. Bonferroni-corrected $\alpha=1.25 * 10^{-2}(0.05 / 4)$ 147

Table 16: Inventory of currently and historically active ECCC monitoring stations at Iqaluit 160

Table 17: Comparison of winter meteorological variables at Iqaluit XFB and the field tower (FT). Due to an error in the datalogger's averaging procedure, wind direction data is not available for 2016 . 172 


\section{List of Figures}

Figure 1: Niaqunguk River Watershed, showing 2015 survey sampling sites. The river's

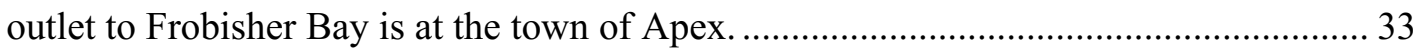

Figure 2: Niaqunguk River Watershed, showing 2016 survey sampling sites. The river's

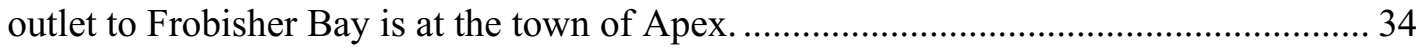

Figure 3: Hydrograph from Apex Hydrometric Station (ECCC), showing the spring melt peak, rapid recession, rapid summer rainfall response, and zero-flow during the winter. 35

Figure 4: Tundra snow cover in the NRW (a) at the end of winter and (b) during the spring freshet. Note the late-lying snowdrifts on leeward slopes in (b). 35

Figure 5: (a) Field survey site sampling strategy - central measurement (SWE or depth) shown with an "O", with 3-4 supporting depth measurements " $\mathrm{X}$ " taken 2 m away in random directions. (b) Nunavut Arctic College student S. Noble-Nowdluk weighing a

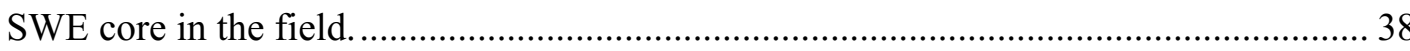

Figure 6: Cumulative water equivalent precipitation from both DFAR and SAGE (not adjusted for wind bias) for the 2014 (top) and 2015 (bottom) study winters. Both y-axes are scaled to the 2014 total.

Figure 7: Exact extent of the full SnowModel domain, showing both SHC classes, with NRW overlaid for reference. Forcing data were collected at Iqaluit XFB (YFB Airport). SnowModel parameters were tested at Lake 1 before being applied to the full domain. . 51

Figure 8: Lake 1 sub-domain, where SnowModel parameters were tested. 52 
Figure 9: SnowModel's spatially-distributed wind-weighting factor at the Lake 1 subwatershed, calculated from multiple curvature length scales and slope/curvature weighting ratios assuming a $340^{\circ}$ (prevailing) wind direction. The colour ramp refers to the wind speed terrain weighting factor $\left(u_{w}\right)$. 53

Figure 10: Terrain units defined by the $8 \mathrm{TU}$ model at the Lake 1 subdomain 61

Figure 11: Measured SWE in 2015 (top) and 2016 (bottom) by terrain unit. Boxes show medians and upper/lower quartiles, with whiskers extending beyond quartiles by 1.5 interquartile ranges and outliers as hollow circles. Colours correspond to Figure 10..... 62

Figure 12: Decision rules for the DR model. Ellipses are conditional tests, with "true" results at left and "false" at right. The final snow accumulation classes are given with bold outlines. The variables are positive and negative openness in a $25 \mathrm{~m}$ radius $\left(\mathrm{O}_{25+}\right.$, $\left.\mathrm{O}_{25-}\right)$, slope $(\beta)$, and wind shelter index at $30 \mathrm{~m}\left(\mathrm{~W}_{30}\right)$

Figure 13: Decision rule snow accumulation classes at the Lake 1 subdomain

Figure 14: Measured SWE in 2015 (top) and 2016 (bottom) by DR snow accumulation class. Boxes show medians and quartiles, with whiskers extending beyond quartiles by 1.5 interquartile ranges, and outliers as hollow circles. Colours correspond to Figure 13.

Figure 15: Fit $\left(\mathrm{R}^{2}\right)$ between surveyed SWE and the wind-speed modifier calculated from a range of slope-curvature weighting ratios. Wind fields were calculated with a constant curvature length scale $(\eta=30 \mathrm{~m})$ and wind direction $\left(340^{\circ}\right)$. 
Figure 16: Wind field sensitivity analysis; SnowModel spring SWE maps for 2015 (top) and 2016 (bottom) simulated using each year's optimal wind-weighting ratios (rather than the "compromise" ratio used in the final simulations), and both of the tested curvature length scales. Compare these to spring SWE maps from the final simulations in Figure 19 (2015) and Figure 20 (2016) 73

Figure 17: SnowModel spring SWE for 2015 (above) and 2016 (below) compared against surveyed SWE. The 1:1 line is shown in red. 76

Figure 18: SnowModel domain-averaged daily snow density over both study years. Gaps occur wherever one or more pixels were snow-free during the day.

Figure 19: Detail of the 2015 SnowModel spring SWE map at the Lake 1 subdomain... 81

Figure 20: Detail of the 2016 SnowModel spring SWE map at the Lake 1 subdomain... 82

Figure 21: Frequency distributions of SnowModel simulated spring SWE in 2015 (above) and 2016 (below) for the whole Niaqunguk River Watershed.

Figure 22: Daily SnowModel statistics for the entire domain over the simulated 2015 winter. (a) snow accumulation, (b) precipitation, (c) sublimation, (d) blowing snow transport (saltation and suspension), and (e) mean daily erosion. The SnowTran-3D Deposition Control Parameter $B$ (indicated in $\mathrm{c}-\mathrm{e}$ ) was used to investigate sensitivity of simulated transport fluxes by decreasing the deposited fraction of the mass flux. 84

Figure 23: Daily SnowModel statistics for the entire domain over the simulated 2016 winter. (a) snow accumulation, (b) precipitation, (c) sublimation, (d) blowing snow 
transport (saltation and suspension), and (e) mean daily erosion. The SnowTran-3D Deposition Control Parameter $B$ (indicated in $\mathrm{c}-\mathrm{e}$ ) was used to investigate sensitivity of simulated transport fluxes by decreasing the deposited fraction of the mass flux. 85

Figure 24: Empirical and fitted-spherical variograms from the 2015 survey data, indicating an $80 \mathrm{~m}$ autocorrelation range. 127

Figure 25: Snow water equivalent (SWE, cm) vs snow depth $(\mathrm{cm})$ for 2015 (top panel, $\mathrm{n}$ $=149$ ) and 2016 (bottom panel, $\mathrm{n}=169$ ). The linear regression models are plotted in red.

Figure 26: Mean site depth - histograms by year.

Figure 27: Snow Water Equivalent (SWE) from survey data - histograms by year..... 132

Figure 28: Snowpack bulk density - histograms by year 132

Figure 29: Daily mean meteorological data during the 2015 study winter. Top to bottom: $T_{a}, R H, u, \theta$. Note common y-axis with plots for 2016 151

Figure 30: Daily mean meteorological data during the 2016 study winter. Top to bottom: $T_{a}, R H, u, \theta$. Note common y-axis with plots for 2015

Figure 31:Daily total water-equivalent precipitation for the 2014 and 2015 study winters. "DFAR" indicates the double-fence gauge, whereas "SAGE" indicates the single-shield gauge, both at XFB. 153

Figure 32: Wind roses for the 2014 (above) and 2015 (below) study winters. 154 
Figure 33: Schematic of the double-fence shielding configuration used in the DFIR/DFAR, and photograph of the DFIR at Hokoriku National Agricultural Experimental Station (Japan). Images from Goodison et al. (1998).............................. 165

Figure 34: Algorithm for pre-processing of Iqaluit DFAR Pluvio data (Part 1). 166

Figure 35: Algorithm for pre-processing of Iqaluit DFAR Pluvio data (Part 2), and processing Iqaluit XFB data to force SnowModel, and for benchmarking XFB precipitation with the final DFAR data 167

Figure 36: Wind roses for the 2016-17 winter at Iqaluit XFB (left, measured at $10 \mathrm{~m}$ height at Iqaluit airport) and the field tower (right). 174 


\section{List of Equations}

Equation 1 ..... Friction velocity, from wind speed and aerodynamic roughness height..... 8

Equation 2 ..... Roughness height during blowing snow over a complete snow cover ....... 9

Equation 3 ..... Equilibrium saltation mass transport rate, from friction velocity for snow covers with exposed non-erodible elements........................................ 9

Equation 4 ..... Equilibrium saltation mass transport rate, from friction velocity for complete snow covers ......................................................................... 10

Equation 5 ..... Snow turbulent suspension mass transport rate .................................... 11

Equation 6 ..... Mass concentration of a particulate cloud in turbulent suspension........... 12

Equation 7 ..... Mass concentration scaling parameter for a suspended particulate cloud 12

Equation 8 ..... Reference level mass concentration in a suspended particulate cloud...... 12

Equation 9 ..... Blowing snow sublimation rate per unit area ...................................... 13

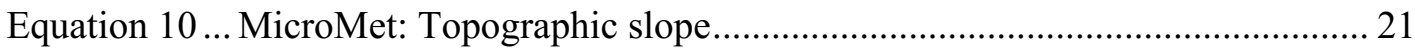

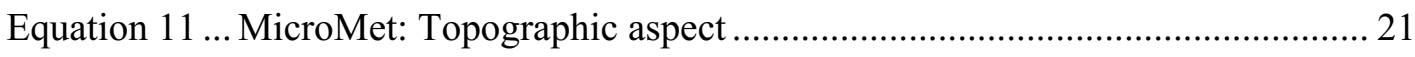

Equation 12 ... MicroMet: Topographic curvature ................................................... 21

Equation 13 ... MicroMet: Standardized topographic curvature ................................... 21

Equation 14 ... MicroMet: Terrain-modified wind direction....................................... 21

Equation 15 ... MicroMet: Wind direction diversion factor ...................................... 22

Equation 16 ... MicroMet: Topographic slope in the wind direction .............................. 22

Equation 17 ... MicroMet: Terrain-modified wind speed ............................................ 22

Equation 18 ... MicroMet: Wind speed terrain weighting factor.................................... 22

Equation 19 ... SnowTran-3D: Fundamental snow depth balance equation..................... 23

Equation 20 ... SnowTran-3D: Water balance equation ............................................ 24

Equation 21 ... SnowTran-3D: saltation mass transport (erosional case) ....................... 25

Equation 22 ... SnowTran-3D saltation mass transport (depositional case) .................... 25

Equation 23 ... SnowTran-3D: "Deposition control” parameter B ................................. 26 


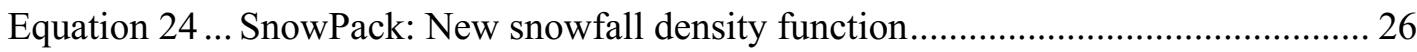

Equation 25 ... SnowPack: Snowfall density wind-offset ...................................... 26

Equation 26 ... SnowPack: Snow density evolution routine........................................ 27

Equation 27 ... SnowPack: Coefficient for snowpack density evolution by wind action.. 27

Equation 28 ... SnowPack: Saltation threshold shear stress for high-density snow ......... 27

Equation 29... SnowPack: Saltation threshold shear stress for low-density snow ........... 27

Equation 30 ... Normalized topographic height ........................................................... 40

Equation 31 ... Weighted mean upslope altitude ...................................................... 136

Equation 32 ... Elevation angle to a distant point, relative to the horizontal .................. 137

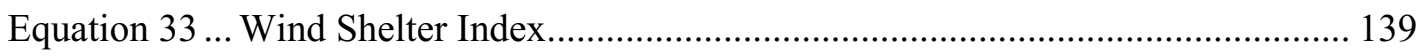

Equation 34 ... Clockwise angular distance between circular measurements ................ 149

Equation 35 ... Shortest angular distance between circular measurements ................... 149

Equation $36 \ldots$ Angular interpolation routine for circular quantities............................ 149

Equation 37 ... General form of precipitation bias-adjustment transfer functions .......... 158 


\section{List of Symbols and Abbreviations Used}

NB: Unless otherwise specified in-text, variables are given in the units denoted here.

\begin{tabular}{|c|c|c|}
\hline Symbol & Unit & Description \\
\hline \multicolumn{3}{|l|}{ Greek } \\
\hline$\beta$ & $\circ$ & topographic slope \\
\hline$\gamma$ & - & wind-weighting factor \\
\hline$\Delta x$ & $\mathrm{~m}$ & horizontal grid increment (in the wind direction) \\
\hline$\zeta$ & $\mathrm{m}$ & snow depth \\
\hline$\eta$ & $\mathrm{m}$ & curvature length scale \\
\hline$\theta$ & $\circ$ & horizontal wind direction \\
\hline$\lambda$ & $\mathrm{J} \mathrm{m}^{-1} \mathrm{~s}^{-1} \mathrm{~K}^{-1}$ & thermal conductivity \\
\hline$\mu$ & - & non-dimensional scaling constant (3.0) \\
\hline$\xi$ & $\circ$ & terrain aspect \\
\hline$\pi$ & - & mathematical constant \\
\hline$\rho$ & $\mathrm{kg} \mathrm{m}^{-3}$ & density \\
\hline$\sigma$ & - & $\begin{array}{l}\text { ambient atmospheric undersaturation of water vapour with } \\
\text { respect to ice }(\sigma=R H / 100-1 \text {, where } R H \text { is relative } \\
\text { humidity in } \%)\end{array}$ \\
\hline$\tau$ & $\mathrm{Pa}$ & shear stress \\
\hline$\psi$ & $\mathrm{s}^{-1}$ & sublimation rate loss coefficient \\
\hline$\phi$ & - & suspension concentration scaling parameter \\
\hline$\Omega$ & - & $\begin{array}{l}\text { topographic variable used to determine wind response to } \\
\text { terrain within SnowModel }\end{array}$ \\
\hline \multicolumn{3}{|l|}{ Roman } \\
\hline$C_{z}$ & - & $\begin{array}{l}\text { proportionality constant, used for calculating aerodynamic } \\
\text { roughness height during blowing snow }\left(C_{z}=0.1203 \text { for }\right. \\
\text { prairie snow covers })\end{array}$ \\
\hline$D$ & $\mathrm{~m}^{2} \mathrm{~s}^{-1}$ & atmospheric water vapour diffusivity \\
\hline$d$ & - & difference between quantity at one increment and the next \\
\hline$f$ & $\mathrm{~m}$ & assumed equilibrium fetch distance (300) \\
\hline$g$ & $\mathrm{~m} \mathrm{~s}^{-2}$ & gravitational acceleration $(9.81)$ \\
\hline$h$ & $\mathrm{MJ} \mathrm{kg}^{-1}$ & latent heat \\
\hline$h^{*}$ & $\mathrm{~m}$ & height of the top of the saltation layer \\
\hline$k$ & - & von Karman's constant (0.4) \\
\hline$M$ & mol & molecular weight \\
\hline$m$ & $\mathrm{~kg}$ & mass of a snow particle in turbulent suspension \\
\hline$P$ & $\mathrm{~mm}$ & precipitation \\
\hline$Q$ & $\mathrm{~kg} \mathrm{~m}^{-1} \mathrm{~s}^{-1}$ & blowing snow mass transport rate \\
\hline
\end{tabular}




$\begin{array}{lll}Q^{*} & \mathrm{~W} \mathrm{~m}^{-2} & \text { shortwave (solar) radiation } \\ R & \mathrm{~J} \mathrm{kmol}^{-1} \mathrm{~K}^{-1} & \text { universal gas constant }(8,313) \\ R H & \% & \text { relative humidity } \\ t & \mathrm{~S} & \text { time } \\ S & \mathrm{~m} \mathrm{~s}^{-1} & \text { particle settling velocity }(0.3) \\ T & \circ \mathrm{C} & \text { temperature } \\ u & \mathrm{~m} \mathrm{~s}^{-1} & \text { horizontal wind speed (at } 2 \mathrm{~m}, \text { unless otherwise specified) } \\ u * & \mathrm{~m} \mathrm{~s}^{-1} & \text { friction velocity } \\ z & \mathrm{~m} & \text { altitude } \\ z_{0} & \mathrm{~m} & \text { aerodynamic roughness height }\end{array}$

\section{Abbreviations}

DFAR

double fence automated [inter-comparison] reference

DFIR

double fence inter-comparison reference

decision rules - (refers specifically to the author's terrain-

DR

based rules for characterizing snow accumulation in the

NRW)

ECCC Environment and Climate Change Canada

FT

MD

field micrometeorological tower (in NRW, near Iqaluit)

mean difference (between observed and predicted

quantities)

NRW

Niaqunguk (commonly: Apex) River Watershed

$\mathrm{Nu}$

Nusselt number

RMSD

root-mean-square-difference (between observed and

predicted quantities)

SAGE

Geonor precipitation gauge in a single-Alter wind-shield

$\mathrm{Sh}$

Sherwood number

SPC

snow particle counter

SWE $\quad \mathrm{mm}$

snow water equivalent

TU

terrain unit; 8TU refers to a models containing eight

terrain units

XFB

short-hand ID for Iqaluit climate monitoring station

Subscripts (unless otherwise stated)

a air

$i \quad$ ice

$p \quad$ for a typical particle undergoing transport

$r \quad$ reference level

$s \quad$ saltation

$s \_$max equilibrium saltation transport rate 
turbulent suspension

vapour

water 


\section{Chapter: Introduction}

Snow is the dominant hydrological input to Arctic systems, accounting for the majority of annual precipitation (Winther and Hall, 1999). Arctic rivers have extremely seasonal flow regimes, with peak discharge during snowmelt and reduced summer/autumn baseflow. Large Arctic rivers may flow under ice if they have southern headwaters and/or groundwater supply in zones of discontinuous permafrost. By contrast, rivers with Arctic headwaters often run dry in autumn or freeze completely in winter, and are "flashy" in summer, responding rapidly to inputs but retaining little baseflow (Woo, 2012, Williams and Smith, 1989, Newbury, 1974, Dingman, 1973). Since snowmelt is the dominant input, water balance calculations for an Arctic river rely on accurate estimates of a watershed's snow storage, which hydrologists refer to as snow water equivalent (SWE, mm), the depth of water per unit area if the snow were melted.

Accurate SWE estimation must account for the spatial heterogeneity of the spring snow cover. This results from extensive redistribution and sublimation by strong winds over open terrain, such as Arctic tundra. Just before spring melt, open tundra retains a shallow snowpack whereas topographic depressions and leeward slopes accumulate deep snowdrifts (Woo, 2012, Pohl and Marsh, 2006, Shook and Gray, 1996, Woo et al., 1983). Drifts cover a small area and thus are challenging to sample representatively, but they contain a large fraction of the total snow mass.

The spatial structure of the spring snow cover is also important for predicting the timing and magnitude of river discharge during melt. Shallow snow melts first, exposing patches of ground which rapidly warm and thaw (Woo, 2012) and transfer heat to nearby snow patches (Marsh and Pomeroy, 1996, Liston, 1995). This creates spatially complex 
melt energetics where many areas undergoing melt are not yet contributing to streamflow (Pohl et al., 2006, Marsh and Pomeroy, 1996, Liston, 1995). Later in the season, drifts continue to provide water for streamflow after most of the snow cover has melted (Woo et al., 2012, Pohl and Marsh, 2006, Pomeroy and Brun, 2000, Shook and Gray, 1997).

The main existing infrastructure to monitor SWE in Arctic Canada is a network of snowfall gauges maintained by Environment and Climate Change Canada (ECCC). These suffer from large wind-induced biases during winter in open environments (Wolff et al., 2015, Theriault et al., 2012, Goodison et al., 1998, Woo, 1983). Furthermore, gaugemeasured snowfall cannot simply be applied uniformly to the landscape, due to the spatially heterogeneous snow cover described above. Modeling techniques are available to simulate snow transport and thus predict complex snow accumulation patterns.

The goal of this study is to develop accurate predictive models for the spatial distribution of the spring snow water equivalent for a small watershed on southern Baffin Island. Extensive spring snow surveys were conducted in 2015 and 2016 in the Niaqunguk River Watershed (NRW) near Iqaluit, Nunavut, to characterize the snowpack and to provide model validation data. Two modeling approaches were employed: (1) a semi-distributed, empirical terrain analysis approach was used to create generalized snow cover classification maps, and (2) a fully-distributed physically-based blowing snow model (SnowModel; Liston and Elder, 2006a) was used to simulate the development of a continuous snow distribution.

In addition to the scientific goal of improving our understanding of blowing snow transport in Arctic environments, motivation for this study comes from the Niaqunguk River's status as a secondary water supply for Iqaluit. Bakaic and Medeiros (2017) 
identified snow water storage estimates to be one of the greatest uncertainties in water supply management for Iqaluit.

Weather data from ECCC's climate station at Iqaluit Airport (WMO ID: 71321, henceforth referred to by Transport Canada ID: "XFB") are of limited use for landscape SWE estimation. At XFB, snowfall is measured by point-based ruler measurements of snow depth on the ground and precipitation gauging. Ruler measurements in exposed sites can lose upward of 50\% of snow to wind action (Pomeroy and Li, 2000), and must be converted to SWE by assuming a "typical" snowfall density (Mekis and Brown, 2010), introducing uncertainty to the SWE estimate. Snowfall gauges require shielding and post-hoc adjustment to reduce wind undercatch, which can be as high as $75 \%$ in arctic tundra (Liston and Sturm, 2004). At XFB, both measurements are made in open terrain at the airport, where their uncertainties are greatest.

Field measurements are one of the best estimates of spring SWE, and are commonly used to validate remotely sensed snow cover products (e.g., Rees et al., 2013). Snow surveys are labour intensive, but extensive coverage is possible through a partnership with the Nunavut Research Institute (NRI) and Nunavut Arctic College (NAC). Researchers from Carleton University provided the study design and training, NRI and NAC provided field support and logistical resources, and students from the NAC Environmental Technology Program were hired to carry out the surveys as field research assistants. This allowed dense survey coverage of the study area before spring melt. In addition to model development, this research developed an efficient sampling approach, minimizing labour required for future surveys. 
SnowModel requires meteorological forcing data but can be run without extensive survey data, and gives valuable insights into winter snow processes. By contrast, the empirical snow maps require field data as a starting point. They provide no new information on mid-winter processes, but may be sufficiently accurate for operational SWE estimation, have far fewer technical requirements, and have no reliance on flawed meteorological inputs. Thus, despite the subjectivity of calibration and the simplification of a semi-distributed result, the empirical models may be more feasible for long-term monitoring in the NRW.

The overarching objective of this thesis is to measure and model the spring snow distribution in a small arctic tundra watershed. This is achieved through three subobjectives:

1. Conduct extensive snow surveys to quantify watershed snow storage, and characterize the spring snow distribution.

2. Use snow survey data and digital terrain analysis to create empirical models of the spring SWE distribution from terrain variables.

3. Parameterize, run, and evaluate the performance of a fully distributed, physicallybased snow transport model.

The best method for estimating spring SWE in the NRW can then be determined by comparing the results from each sub-objective and help improve our understanding of snow processes in this particular Arctic environment.

This thesis follows a traditional structure; Chapter 2 contains a detailed literature review, giving background information on snow transport and accumulation processes. Chapter 3 gives details on field methods and modeling approaches. Chapter 4 presents 
study results, and Chapter 5 contains a discussion of the results. Chapter 6 is a summary of each modeling approach, final conclusions, and suggestions for future work. 


\section{Chapter: Literature Review}

The amount of snow stored on the landscape at the end of winter is a critical variable for Arctic hydrology, since snowmelt is the dominant input to these systems. Landscape SWE is difficult to quantify, however, due to the extreme spatial variability in snow depth. In open environments such as tundra or prairie, a variable snow cover results from wind action as snow is eroded from exposed areas and deposited into sheltered areas (Pomeroy and Gray, 1995).

Thus, the first part of this chapter discusses the physics of blowing snow transport, including snowpack resistance to transport as a result of snowpack metamorphism, the different modes of particle transport and the sublimation of transported particles, and drift formation behind obstacles. Section 2 describes and compares several physically-based blowing snow models, with special emphasis on SnowModel, the model used in this thesis. Section 3 contains a brief overview of hydrological research conducted in the NRW, to give context on the study area.

\subsection{Blowing Snow Transport}

The physical processes of snow transport are similar to those of sediment transport (e.g., Bagnold, 1941, adapted to blowing snow by Dyunin, 1967), with two complicating factors:

1. Interstitial cohesion (i.e., strength) in the snowpack

2. Phase change under ambient conditions

These features are related through snowpack metamorphism - structural changes induced with snowpack age. Metamorphic processes occur stratigraphically (by layer) from initial conditions established at snowfall. Metamorphic processes are driven by 
energy and vapour gradients between the snowpack and the environment. Thus, snowpack metamorphosis results in distinct mid-winter snowpack structures between different geographic areas.

Sturm et al. (1995) described six global classes of snow-cover, based on typical depth, thermal characteristics, and structure. Tundra snow typically contains alternating layers of wind slab and depth hoar. Wind slab is strong, dense and fine-grained, created from crystal sintering after deformation during transport. Depth hoar is a weak, lowdensity structure, which form as vapour moves along temperature gradients within the snowpack (McClung and Schaerer, 1993, Colbeck, 1982).

For transport to occur, the wind must exceed a threshold velocity, which is defined based on snow particle size and density (as in sediment transport), and on the snowpack's surface cohesion (Schmidt, 1982). Snow strength also increases with temperature and density (Abele and Gow, 1975). Li and Pomeroy (1997) determined that cohesion is greater in wet snow, as interstitial water films hold particles together. Greater wind speeds are therefore required to initiate transport from warm snowpack, and the threshold wind speed decreases with temperature down to about $-25^{\circ} \mathrm{C}(\mathrm{Li}$ and Pomeroy, 1997). Once snow is deposited, cohesion increases over time as the snowpack undergoes equitemperature metamorphism, strengthening interstitial bonds (DeWalle and Rango, 2008, Colbeck, 1982).

Cohesion is also modified by shear forces during transport, which destroy delicate structures, allowing particles to pack tightly in drifts. Tabler (1975) calculated that snow particles could melt during transport, despite air temperatures being well below freezing. Refreezing between particles during sintering creates drifts that are stronger and denser 
than the parent material, and resist further erosion (Pomeroy and Gray, 1995, Tabler, 1975). Thus, threshold transport wind speeds vary over a season.

Phase change during snow transport and metamorphism is also important to quantify for closing mass balances of transported snow. Sediment transport is a closed system with respect to mass, but snow typically sublimates in transport. A snow crystal's surface vapour pressure is always saturated at a given temperature, so the vapour gradient favours sublimation to the surrounding (dry) atmosphere (DeWalle and Rango, 2008, Colbeck, 1982). In-situ snowpack sublimation can be a substantial flux, and blowing snow sublimation can be greater in open environments (Pomeroy and Gray, 1995, Pomeroy and Male, 1992). Thus the mass of deposited snow can be much smaller than the eroded mass, with the residual lost to the atmosphere as vapour during transport.

\subsubsection{Boundary Layer Flow and Surface Winds}

Snow transport occurs in the atmospheric boundary layer, where turbulence is induced by the Earth's surface. Under neutral stability conditions in this layer, the friction velocity $\left(\mathrm{m} \mathrm{s}^{-1}\right), u *$, at a given altitude $(z, \mathrm{~m})$ is represented by the logarithmic wind profile, such that:

$$
u^{*}=\frac{u k}{\ln \left(\frac{z}{z_{0}}\right)}
$$

where $u$ is the horizontal wind velocity $\left(\mathrm{m} \mathrm{s}^{-1}\right), k$ is von Karman's constant (0.4), and $z_{0}$ is the roughness length $(\mathrm{m})$.

The roughness length, $z_{0}$, is the intercept of the logarithmic wind profile, and is typically approximated for natural landscapes as $10 \%$ of the average vegetation height. Snow-covered landscapes tend to have lower $z_{0}$, as the snow surface is smooth relative to the underlying surface. Common values for $z_{0}$ over polar snowfields range from $10^{-3}$ to 
$10^{-8} \mathrm{~m}$ (Dingle and Radok, 1961, Liljequist, 1957, Sverdrup, 1936). Pomeroy (1988) found that for blowing snow over complete snow covers with no exposed vegetation, $\mathrm{z}_{0}$ is given by:

$$
z_{0}=\frac{C_{z} u^{2}}{2 g}
$$

where $C_{z}$ is a dimensionless proportionality constant $\left(C_{z}=0.1203\right.$ for prairie snow covers). This proportionality varies with surface condition (Tabler et al., 1990). The dynamic feedback between $u^{*}$ and $z_{0}$ is typically determined by numerical iteration in blowing snow models.

\subsubsection{Modes of Transport}

As in aeolian sediment transport (e.g. Bagnold, 1941), there are 3 main modes of snow transport by wind (Mellor, 1965): creep, saltation, and turbulent suspension. Creep is generally considered unimportant (an extensive discussion can be found in Mellor, 1965), so this section is confined to a discussion of saltation and suspension.

\subsubsection{Saltation}

During saltation, particles lift from the snow surface, following elongated parabolic trajectories before impacting the surface again (Pomeroy and Gray, 1995).

Saltation requires an extensive fetch and exhaustive snow supply to develop. The equilibrium saltation mass transport rate, $Q_{s_{-} \max }\left(\mathrm{kg} \mathrm{m}^{-1} \mathrm{~s}^{-1}\right)$ is given by Pomeroy and Gray (1990):

$$
Q_{s_{-} \max }=\frac{0.68}{u_{*}}\left(\frac{\rho_{a}}{g}\right)\left(u_{*} u_{*}^{2}-u_{*} u_{*_{n}}^{2}-u_{* t}{ }^{3}\right)
$$

where $\rho_{a}$ is the air density $\left(\mathrm{kg} \mathrm{m}^{-3}\right), g$ is gravitational acceleration $\left(9.81 \mathrm{~m} \mathrm{~s}^{-2}\right), u_{*_{n}}$ is the friction velocity exerted against non-erodible elements such as vegetation stalks $\left(\mathrm{m} \mathrm{s}^{-1}\right)$ 
and $u_{*_{t}}$ is the threshold friction velocity for snow transport $\left(\mathrm{m} \mathrm{s}^{-1}\right)$. Kind (1981) estimated $u *_{t}$ on the order of $0.07-0.25 \mathrm{~m} \mathrm{~s}^{-1}$ during and immediately after snowfall when particle cohesion is negligible and $0.25-1.0 \mathrm{~m} \mathrm{~s}^{-1}$ for old, hardened snowpacks.

For complete snow covers without exposed vegetation, Equation 3 simplifies to:

$$
Q_{S_{-} \max }=\frac{0.68}{u_{*}}\left(\frac{\rho_{a}}{g}\right) u_{*}\left(u_{*}^{2}-u_{* t}{ }^{2}\right)
$$

Equation 4 indicates that for a given snowpack, the difference between $u^{*}$ and $u^{*}{ }_{t}$ is the critical variable determining the maximum saltation flux. Pomeroy et al. (1993) note that the relationship between $u *_{t}$ and saltation is not simple; a high threshold condition will prevent transport in low winds, but hard surface snow increases the efficiency of the particle-surface interaction, such that transport at high wind speeds is actually increased if $u_{t}{ }_{t}$ is large.

Researchers have estimated the fetch length required for snow transport to reach equilibrium; Takeuchi (1980) reports $150-350 \mathrm{~m}$ for the first $0.3 \mathrm{~m}$ above the surface, whereas Pomeroy (1988) reports a $500 \mathrm{~m}$ fetch for the first $5 \mathrm{~m}$. The true fetch is variable through time and space, depending on wind speed, surface roughness, and snow supply. The equilibrium concept also underlies the definition of $u{ }_{*}$, which is measured at the cessation of transport to satisfy the equilibrium assumption, rather than at the initiation of blowing snow (Pomeroy and Gray, 1995).

Particle counter measurements during blowing snow have determined that the particle mass and number concentration decreases exponentially with height (Mann et al., 2000, Budd et al., 1966). Mellor (1965) described "streamers" of particles at $10-20 \mathrm{~cm}$, but noted that the saltation layer can reach heights of $1 \mathrm{~m}$. The mass flux gradient is reduced during events with higher wind speed, and the saltation mass flux was 3 - 4 
orders of magnitude higher than in the suspension layer. This supports profiling and particle collector findings by Takahashi (1985) and Takeuchi (1980).

Saltation mass transport increases from initiation until a saturation point is reached. Thus, empirical relationships between blowing snow transport and $u$ defined under equilibrium transport conditions don't apply to non-steady-state events, which are the norm for many events due to flow variance over obstacles and terrain. Mann et al. (2000) noted that there is even disagreement between equations derived from steady-state field measurements, and speculatively attributed this to the fact that relationships between transport and wind speed may have been defined under variable $u_{*_{t}}$ conditions.

\subsubsection{Turbulent Suspension}

Suspension occurs when small particles are held aloft by turbulent eddies. Impacts during saltation shatter particles, supplying fragments for suspension. Suspension also occurs during snowfall, as the falling crystals have a high drag-to-weight ratio and can be easily held aloft. This decreases visibility, creating severe aviation hazards (Rasmussen et al., 1999). As wind speeds increase, suspension rapidly begins to dominate the mass flux (Pomeroy, 1988, Pomeroy and Gray, 1990). Pomeroy and Male (1992) estimated that suspension comprises $75 \%$ of transport at a $10 \mathrm{~m}$ wind speed of $8 \mathrm{~m} \mathrm{~s}^{-1}$, and $>90 \%$ at 17 $\mathrm{m} \mathrm{s}^{-1}$.

The suspended snow mass transport rate $Q_{t}\left(\mathrm{~kg} \mathrm{~m}^{-1} \mathrm{~s}^{-1}\right)$ is given by Pomeroy and Male (1992):

$$
Q_{t}=\int_{h *}^{z t} \phi_{t}(z) d z
$$


where the integration limits are the top of the saltation layer, $h^{*}$ and the top of the suspension layer, $z_{t}$, and $\phi_{t}$ is the mass concentration of the particulate cloud $\left(\mathrm{kg} \mathrm{m}^{-3}\right)$, derived from the concentration $\phi_{r}$ at a reference level $z_{t r}$. Following Kind (1992):

$$
\phi_{t}=\phi_{r}\left[\left(\frac{\phi *}{\phi_{r}} \frac{u *}{s}+1\right)\left(\frac{z}{z_{t r}}\right)^{\frac{-s}{k u *}}-\frac{\phi *}{\phi_{r}} \frac{u *}{s}\right]
$$

where $s$ is the particle-settling velocity $\left(0.3 \mathrm{~m} \mathrm{~s}^{-1}\right.$ per Schmidt, 1982) and $\phi^{*}$ is a concentration scaling parameter, defined by:

$$
\phi^{*}=\beta \frac{u *}{u} \phi_{r}
$$

where $\beta$ is a unitless coefficient (0.5 per Kind, 1992).

Assuming a constant horizontal velocity in the saltation layer $\left(u_{p}, \mathrm{~m} \mathrm{~s}^{-1}\right)$, Pomeroy and Gray (1990) approximated it to be $2.8 u^{*}$. Assuming a constant mass flux in the saltation layer, $\phi_{r}$ is defined by Liston and Sturm (1998) as:

$$
\phi_{r}=\frac{Q_{s}}{h * u_{p}}
$$

The constant flux assumption is questionable, but data from Nishimura and Nemoto (2005) suggest that it may be a reasonable approximation at high wind speeds.

During fully developed snow transport, Pomeroy and Male (1992) found that the suspended mass concentration is sensitive to changes in vertical mass fluxes (snowfall from above, or saltation from below) over short time periods (minutes). Over the hourly periods on which snow transport is typically modeled, however, the concentration gradient is solely a function of height, wind speed, and surface roughness, supporting the use of relatively simple snow transport formulations such as Equations 5 to 8 .

\subsubsection{Sublimation of Transported Snow}


During transport, snow particles are completely ventilated, and the vapour gradient and turbulence around entrained particles are ideal for sublimation. As a result, seasonal water loss from the snowpack by blowing snow sublimation can be large in open environments. Pomeroy and Gray (1995) indicated that $15-41 \%$ of annual SWE is sublimated from the Canadian Prairies, Pomeroy et al. (1997) estimated western Canadian Arctic sublimation losses on the order of 20-47\%, and Liston and Sturm (2004) estimated pan-Arctic sublimation losses up to $50 \%$ of winter precipitation .

When a snow particle is in thermodynamic equilibrium with the surrounding atmosphere, its sublimation rate $(d m / d t)$ was defined by Schmidt $(1991,1972)$. This rate depends on the turbulence characteristics of the atmosphere, and by air temperature $\left(T_{a}\right)$, relative humidity $(R H)$, and solar radiation $\left(Q^{*}\right)$, as well as with wind speed; Pomeroy and Gray (1995) showed that the sublimation rate increased exponentially with wind speed. On the Canadian Prairies, they found that normal diurnal variation in $T_{a}$ and $R H$ caused order-of-magnitude variations in sublimation rate, whereas variations in $Q^{*}$ had a smaller effect. Generalizing the single-particle case to derive a sublimation rate loss coefficient $\left(\Psi, \mathrm{s}^{-1}\right)$, Liston and Sturm (1998) give the blowing snow sublimation rate per unit area as:

$$
Q_{v}=\Psi_{s} \phi_{r} h^{*}+\int_{h *}^{z_{t}} \Psi_{t}(z) \phi_{t}(z) d z
$$

where $s$ and $t$ refer to saltation and suspension, respectively.

The blowing-snow sublimation potential in the NRW has not been investigated. Given the open topography and high wind speeds during extended winter storms, one would expect large sublimation potential on much of southern Baffin Island. However, 
the topography matches Pomeroy et al.'s (1997) description of "highly dissected" terrain, over which unsteady airflow prevents extended transport, reducing potential sublimation.

\subsubsection{Boundary Layer Separation and Drift Formation}

Transport time is limited in complex terrain because snow is often deposited into drifts. In the lee of an abrupt obstacle, airflow slows and then reverses, forming a lee eddy. The position of flow reversal is referred to as the separation point, beyond which eddy rotation dissipates momentum, reducing $u^{*}$ and causing snow to fall out of transport (Mellor, 1965), forming large drifts in the lee of topographic slope breaks, or behind obstacles such as buildings, vegetation, or snow fences. For porous object like fences, flow deceleration deposits snow into a leeward drift, with flow separation behind the drift's peak. Each fence can catch a maximum (or equilibrium) drift, whose size can be predicted from fence geometry (e.g. Tabler 1980a, b, 1990).

For topographic obstructions, the flow separation point is on the topographic feature itself, but Tabler (1975) showed that many of the same concepts apply. Like a fence, topographic catchments retain an equilibrium drift profile, though this cannot usually be achieved due to the limited snow supply. Accumulation begins immediately downwind of the separation point, with most of the initial growth being vertical rather than horizontal. As the drift fills to leeward and its slope decreases, the degree of flow separation and thus the rate of deposition decreases.

Based on extensive measurements, Tabler (1975) developed a model predicting snowdrift geometry in gentle to rolling terrain. The model requires measurements of topographic slopes to windward and leeward of the topographic catchment. Interestingly, when the model was iteratively applied, using its own predicted drift profile as the 
topographic surface during the next iteration, it tended to stabilize toward the observed drift profile. This simple model shows that variation in topographic slope is one of the most important variables for determining snow redistribution depths.

Supporting this observation, Kane et al. (1991) observed as much as 65\% greater accumulation on leeward slopes as low as $2-3^{\circ}$ in Alaska. Pomeroy et al. (1997) delineated drift zones at Trail Valley Creek based on a $9^{\circ}$ threshold from their own findings and those of Tabler (1975). By combining this information with the saltation equilibrium fetch concept described in past sections, the greatest drift potential is likely to be found in the lee of abrupt slope breaks, or in local topographic depressions, where flow separation occurs downwind of long, open fetches.

\subsection{Physically-based Blowing Snow Models}

Blowing snow transport is a complex interaction between the snowpack and atmospheric boundary layer, and topographically induced changes in wind speed create a spatially variable snow distribution. This distribution can be difficult to sample adequately, so models are often used to extend a limited snow survey to the broader landscape. Modeling the spring snow distribution is an important goal of this thesis, and sub-objective three is to use an existing physically-based model.

The physically-based model had to be (1) spatially distributed, (2) capable of handling complex terrain, (3) driven by meteorological measurements available for the study area, and (4) usable without extensive knowledge of advanced computational methods and/or fluid physics. This section gives a brief overview of some of the available modeling methods with consideration of these requirements. 
Given computational limitations and the complexity of the governing physics, blowing snow models must compromise between detail of simulated processes, domain size, and spatio-temporal resolution. Blöschl (1999) discusses these important scaling concerns for snow hydrology studies, concluding that "optimal" model scales may not truly exist and that practical concerns should guide model development. Clark et al. (2011) argue that hillslope-scale processes such as snow drifting are difficult to explicitly model, though their aggregate effects can be estimated from probability functions. However, such parameterizations are only viable when the model resolution can capture hillslope processes in sub-grid space; for the small watershed studied in this thesis, a finer resolution is needed.

The state of the art has advanced with computing power, and computational fluid dynamics (CFD) is increasingly popular for wind-field and particle-trajectory simulation. Gauer (2001) and Naaim et al. (1998) reviewed CFD methods in snow transport modeling. Gauer stated that Lagrangian (i.e., particle-tracking) were too computationally intensive for landscape-scale application, though Eulerian (i.e., particle-concentrationaveraging) were more feasible. Naaim et al. suggested that physically accurate Lagrangian models required data on small-scale grain-bed interactions, which were highly uncertain at that time (and are not fully resolved today).

Recently, CFD simulations have been used to simulate airflow and snow particle trajectories in the limited volumes around precipitation gauges (e.g. Colli et al., 2016a and 2016b, Colli et al., 2015, Theriault et al., 2012). On a larger scale, Comola (2017) modeled snow deposition and redistribution in complex terrain using Lagrangian stochastic modeling of snow particle trajectories and large eddy airflow simulation with 
topographic modification. The model showed coherence to wind tunnel studies when run for a simulated landscape of Gaussian ridges. These test simulations were fully threedimensional, though their areal coverage was limited: $200 \mathrm{~m}$ by $50 \mathrm{~m}$, with a horizontal resolution of $0.6 \mathrm{~m}^{2}$.

Schneiderbauer (2011, with Prokop 2010) used Lagrangian CFD simulations to improve Alpine snowdrift modeling, with applications in avalanche control and highway engineering. The model runs at a high resolution, but with relatively weak performance as a snow depth estimator due to a lack of explicit consideration for the snowpack structure. The model is designed for numerical modeling of single storms, meaning that it is not suitable for the seasonal study period required for this thesis.

Gauer (2001, 1998) described a three-dimensional non-steady-state snow transport model. This avoids the need for parameterization of steady-state equations (e.g. Pomeroy 1989) for non-steady-state conditions in complex terrain, where the long fetches needed for steady-state transport (300 - 500 m; Pomeroy and Gray, 1990) are rarely available. Gauer simulated transport over an Alpine ridge, with a domain $1000 \mathrm{~m}$ by 600 $\mathrm{m}$ and variable horizontal resolution, from $20-300 \mathrm{~m}^{2}$. This model was later combined with the SNOWPACK snow cover model (Lehning and Fierz, 2008, Lehning et al. 2002) for Alpine simulations.

Naaim et al. (1998) used turbulence models in a finite-element mesh, conserving computing power by dynamically adapting the model's spatio-temporal resolution during simulated drift development. Their model assumed particle entrainment by only aerodynamic forces, neglecting important interactions between saltating particles and the 
snow surface. Given computational restrictions it could only be employed over a limited mesh size, restricting it to modeling a single snowdrift.

These advanced models are promising for application in complex terrain, but are underpinned by complex physics and due to computational limitations are too limited in spatial and temporal scale for this thesis. Another approach for detailed process modeling is the "spectral" model. These model blowing snow as a one-dimensional column, relying on assumed particle characteristics with specified distributions of size and mass. Xiao et al. (2000) compare three such models: PIEKTUK-T (Déry et al., 1998), WINDBLAST (Mann, 1998), and SNOWSTORM (Bintanja, 2000a and 2000b), finding that they give similar results for transport but differing sublimation estimates. Such models may be useful for process studies and to represent internally homogenous areas (e.g., open tundra or sub-grid parameterizations for regional-scale models), but their lack of spatial distribution makes them inapplicable for this thesis.

Other models are able to cover longer time scales and larger areas in detail. Alpine3D (Mott et al., 2010) uses an atmospheric turbulence model to simulate wind fields and drive snow transport and preferential deposition in Alpine terrain, and is capable of simulating snow cover development over a large area $\left(7 \mathrm{~km}^{2}\right)$ of complex terrain at high resolution. Mott and Lehning (2010) found that the model performs best at a $5 \mathrm{~m}$ resolution (the finest resolution tested). Given its design for complex terrain, Alpine3D is a strong candidate for this thesis - however, the atmospheric turbulence model is complex, and noted to be computationally inefficient. This is undesirable given that the study watershed in this thesis is much larger than that in Mott et al. (2010). 
The Prairie Blowing Snow Model (PBSM; Pomeroy et al, 1993) is a semidistributed model of snow redistribution, mass, and energy balance. Its semi-distributed structure allows it to be integrated into modeling frameworks based on hydrological response units (HRUs) such as the Cold Regions Hydrological Model (CRHM; Pomeroy et al, 2007). However, PBSM is a steady-state model, meaning that it cannot be applied to areas with fetch distances less than $300 \mathrm{~m}$ (per Takeuchi, 1980). This is unsuitable for the complex terrain in the study area; furthermore, a fully-distributed model is preferable for this thesis.

As an alternative, the Distributed Snow Model (DSM; Essery et al, 1999) is a fully distributed version derived from the PBSM. The DSM is typically used with a wind model valid in gentle terrain (Musselman et al., 2015). The DSM improved over a previous distributed version of the PBSM (Pomeroy et al., 1997) by using 30-minute meteorological data, rather than monthly data. In general, the DSM has shown good performance in both Arctic tundra (Essery et al, 1999) and complex mountain terrain (Musselman et al. 2015), provided a suitable wind model is used.

While Alpine3D and the DSM were both potentially strong options for this research work, their wind models were both noted by their authors to be computationally intensive. By comparison, the simple terrain-based wind model used by SnowModel (Liston et al., 2007) is extremely computationally simple, giving high simulation speeds for the study watershed at a high resolution. Although the wind model is simplistic and noted to be inaccurate in some circumstances (e.g., Musselman et al. 2015), it is intuitive and approachable to the non-expert. Thus, SnowModel was the physically-based snow transport model used in this thesis. 


\subsubsection{SnowModel}

To simulate transport and sublimation processes during the study winters, this study employed SnowTran-3D, a fully distributed, physically-based blowing snow model (Liston and Sturm, 1998). SnowTran-3D is currently implemented in the SnowModel snow evolution modeling system (Liston and Elder, 2006a), developed for Arctic and alpine regions above the tree line (modifications for forest environments have been added over the last 15 years). SnowModel is effectively a suite of 4 sub-models:

1. MicroMet - "Defines meteorological forcing conditions"

2. EnBal - "Calculates surface energy exchanges"

3. SnowPack - "Simulates snow depth and water-equivalent evolution"

4. SnowTran-3D - "Accounts for snow redistribution by wind"

Of these, the physical processes seem to be adequately represented for application in the NRW. However, the performance of three subroutines require closer examination in this study: MicroMet's wind model, SnowTran-3D's mass balance, and SnowPack's density evolution routine.

\subsubsection{MicroMet Wind Model}

Wind observations from ground-based meteorological stations must be spatially interpolated to create a "wind field" covering the entire domain. Liston and Sturm (1998) achieved this with empirical relationships between terrain and airflow, deflecting and scaling wind in response to terrain structure. Digital terrain analysis is less computationally expensive than complex turbulence models.

The required structural parameters are slope, aspect, and curvature. Slope $\left(\beta,^{\circ}\right)$ is the first derivative of elevation with respect to the horizontal, given by: 


$$
\beta=\tan ^{-1}\left[\left(\frac{\delta z}{\delta x}\right)^{2}+\left(\frac{\delta z}{\delta y}\right)^{2}\right]^{\frac{1}{2}}
$$

where $x$ and $y$ are horizontal coordinates. Aspect $\xi\left(^{\circ}\right)$ is the azimuth of the maximum

slope, given by:

$$
\xi=\frac{3 \pi}{2}-\tan ^{-1}\left(\frac{\frac{\partial z}{\partial y}}{\frac{\partial z}{\partial x}}\right)
$$

Curvature $\left(\Omega_{\mathrm{c}}, \mathrm{m}^{-1}\right)$ is the second derivative of elevation, and is defined within MicroMet for a "length scale", $\eta$ and averaged over the 8 primary directions, such that:

$$
\Omega_{C *}=\frac{1}{4}\left(\frac{z-\frac{\left(z_{N}+z_{S}\right)}{2}}{2 \eta}+\frac{z-\frac{\left(z_{E}+z_{W}\right)}{2}}{2 \eta}+\frac{z-\frac{\left(z_{N E}+z_{N W}\right)}{2}}{2 \sqrt{2 \eta}}+\frac{z-\frac{\left(z_{S E}+z_{S W}\right)}{2}}{2 \sqrt{2 \eta}}\right)
$$

where the subscript gives direction, e.g., $\mathrm{z}_{\mathrm{N}}$ is the elevation of a cell $\eta \mathrm{m}$ to North of the target cell. The $\Omega_{\mathrm{c}^{*}}$ values are then scaled by the maximum value in the domain:

$$
\Omega_{c}=\frac{\Omega_{C *}}{2 \Omega_{C * M A X}} \text { and } \therefore-0.5 \leq \Omega_{c} \leq 0.5
$$

The length scale $\eta$ is half the wavelength of topographic features in the domain relevant to snow transport processes. Practically, $\eta$ defines the spatial complexity of the wind field - larger values of $\eta$ ignore smaller topographic features, smoothing the wind field. MicroMet requires a single, time-invariant value of $\eta$, but the authors provide no explicit method for its specification. Topography is comprised of many wavelengths, only some of which are relevant to snow accumulation. Choice of $\eta$ thus seems to be somewhat arbitrary in the literature. Parameter selection for this study, including $\eta$, will be detailed later.

In the MicroMet wind model, the terrain-modified wind direction $\left(^{\circ}\right)$ is:

$$
\theta_{t}=\theta+\theta_{d}
$$

where $\theta_{\mathrm{d}}$ is a "wind diversion factor", after Ryan (1977): 


$$
\theta_{d}=-\frac{1}{2} \Omega_{s} \sin [2(\xi-\theta)]
$$

where $\Omega_{\mathrm{s}^{*}}$ is the surface slope in the direction of the wind $\left(^{\circ}\right)$, calculated as:

$$
\Omega_{S *}=\beta \cos (\theta-\xi)
$$

Finally, $\Omega_{\mathrm{s}^{*}}$ is scaled in the same way as curvature in Equation 13. This conceptual model for topographic flow diversion was originally developed by Ran (1977). The terrain-modified wind speed, $u_{t}$ is then given by:

$$
u_{t}=u u_{w}
$$

where $u_{w}$ is a terrain weighting factor:

$$
u_{w}=1+\gamma_{s} \Omega_{s}+\gamma_{c} \Omega_{c}
$$

where the subscripts $s$ and $c$ refer to windward slope and curvature, respectively, $\Omega$ is the scaled parameter, and $\gamma$ is a weighting coefficient.

MicroMet's wind model was first presented by Liston and Sturm (1998) and refined by Liston and Elder (2006b) and Liston et al. (2007). During a field-validation experiment over tundra at Trail Valley Creek, Pohl et al. (2006) concluded that the wind model accurately simulated $u$ for five sites distributed around a small hill $\left(\mathrm{R}^{2}\right.$ from 0.82 to 0.97 ). Their findings suggested that the model's main shortcoming is its use of slope and curvature alone, excluding a point's position on landform. For example, measured wind speeds were highest at the middle of the hilltop, but the model's highest speeds were at the convex windward edge of the hilltop (Pohl et al., 2006).

The proposed solution was to either (a) increase the curvature length scale to increase the hilltop's relative prominence, or (b) increase $\gamma_{c}$, though the authors noted that this would also cause wind speeds in concavities to become unrealistically low. Default weighting values were also defined by Pohl et al. (2006) and described by Liston and 
Elder (2006b). They found an optimal $\gamma_{\mathrm{s}}: \gamma_{\mathrm{c}}$ ratio of 0.72 , so assuming that $\gamma_{\mathrm{s}}+\gamma_{\mathrm{c}}=1$, the default values are $\gamma_{\mathrm{s}}=0.58$ and $\gamma_{\mathrm{c}}=0.42$.

MicroMet's model preserves computational efficiency and operates with minimal inputs (Liston and Sturm, 1998). To test whether this simple model was sufficient for accurate modeling of blowing snow, Musselman et al. (2015) compared it against other wind models. Simulated wind fields were used to drive their Distributed Snow Model (DSM, Essery et al., 1999), and compared against station observations at (a) a ridgetop, (b) a windward slope, and (c) a leeward slope. MicroMet slightly overestimated wind speed on both windward and leeward slopes. When DSM snow transport was driven by MicroMet, it overestimated accumulation on the ridgetop and the windward slope, and underestimated accumulation on the leeward slope. The MicroMet model led to a smoother (and less accurate) wind field and snow distribution.

Musselman et al. (2015) noted that decreasing $\eta$ might improve the MicroMet model results by allowing greater $u$ changes on a smaller scale, but this might "blind" the model to larger structures, such as slopes accumulating large leeward drifts. The authors concluded that the choice of wind model is critical, and that the increased complexity of the turbulence models is warranted. Given this importance, the simplified empirical wind model is clearly a source of uncertainty in SnowModel results.

\subsubsection{SnowTran-3D Mass Balance}

SnowTran-3D's change in snow depth $(\zeta, \mathrm{m})$ per time step for a given grid cell is given by:

$$
\frac{d \zeta}{d t}=\frac{1}{\rho_{s}}\left[\rho_{w} P-\left(\frac{d Q_{s}}{d x}+\frac{d Q_{t}}{d x}+\frac{d Q_{s}}{d y}+\frac{d Q_{t}}{d y}\right)-Q_{v b}\right]
$$


where $t$ is time (s), $x$ and $y(\mathrm{~m})$ are horizontal spatial coordinates, $\rho_{s}$ and $\rho_{w}\left(\mathrm{~kg} \mathrm{~m}^{-3}\right)$ are the densities of snow and water, $Q_{s}$ and $Q_{t}\left(\mathrm{~kg} \mathrm{~m}^{-1} \mathrm{~s}^{-1}\right)$ are the horizontal mass transport rates from saltation and turbulent suspension, $Q_{v b}\left(\mathrm{~kg} \mathrm{~m}^{-1} \mathrm{~s}^{-1}\right)$ is the blowing snow sublimation rate, $P\left(\mathrm{~m} \mathrm{~s}^{-1}\right)$ is the water-equivalent precipitation rate.

Before snow is available for wind transport, snow depth must first exceed a grid cell's snow-holding capacity (SHC). Once the SHC is exceeded, the snow can also densify (either by SnowPack's density-evolution routine, or by melt or rain-on-snow occurring, which makes the snow "unmovable" in SnowModel's code) and exceed typical transport threshold friction velocities, allowing sustained accumulation greater than the SHC. Liston and Sturm (2002) chose an SHC equal to $80 \%$ of the maximum height for a given vegetation type.

Along with in-situ sublimation $\left(Q_{v s}\right)$ and melt $(M)$, calculated by the EnBal submodel, SnowTran-3D's snow depth balance (Equation 19) is part of the following snowpack water balance (all in $\mathrm{mm}$ ):

$$
S W E=P-\left(Q_{s}+Q_{t}+Q_{v s}+Q_{v b}+M\right)
$$

For winter simulations, melt should be negligible, so for a whole domain, net losses of SWE are only possible by sublimation or horizontal advection (i.e. snow blowing in or out of the domain). An equilibrium-transport upwind boundary condition balances losses from the downwind boundary by importing a (theoretically) similar amount. Most eroded snow will re-deposit elsewhere within the domain, so large advection fluxes are not typically expected, but net import or export is physically realistic, depending on the domain's terrain and winter weather. 
To simulate $Q_{s}, Q_{t}$, and $Q_{v b}$, SnowTran-3D utilizes Equations 1-9. For short fetch distances, Liston and Sturm (1998) discretized the saltation transport rate along the wind direction for location $x$ as:

$$
Q_{s}(x)=Q_{s}(x-\Delta x)+\frac{\mu}{f} \Delta x\left(Q_{S_{-} \max }(x)-Q s(x-\Delta x)\right) \text { for } \frac{d u *}{d x} \geq 0
$$

for the case of constant or increasing shear stress with distance downwind, and:

$$
Q_{s}(x)=\min \left\{\begin{array}{c}
Q s(x-\Delta x) \\
Q_{s_{-} \max }(x)
\end{array}\right\} \quad \text { for } \frac{d u *}{d x}<0
$$

for decreasing shear stress with distance downwind, where $\mu$ is a non-dimensional scaling constant $(\mu=3.0), \Delta x$ is the horizontal distance increment $(\mathrm{m})$, and $f$ is the assumed equilibrium fetch distance (m).

For increasing $u *$ Equation 21 represents the erosional case; the difference between $Q_{s_{-} \max }$ at $x$ and the upwind flux $Q_{s}(x-\Delta x)$ is pro-rated by the scaled fraction of the equilibrium fetch represented by the distance $\Delta x$, and this quantity is added to the upwind flux, reducing the snow depth at $x$ in the process. Conversely, Equation 22 represents the depositional case, where $Q_{s}$ cannot exceed the equilibrium flux at $x$, such that any excess in the upwind flux $Q_{s}(x-\Delta x)$ must be deposited, adding to the snow depth at $x$. If $Q_{s}(x-\Delta x) \leq Q_{s_{-} \max }$, then the entire flux is passed through the cell, and nothing is deposited.

To calculate deposition during saltation, a modified version of Equation 22 is used to correct a deficiency where an unnaturally large fraction of the upwind saltation flux is deposited in a single downwind cell. This results in "peaked" drift profiles with unnaturally steep leeward slopes. In such cases, a deposition control parameter $B$ can be used such that: 


$$
Q_{s}(x)=\max \left\{\begin{array}{c}
B[Q s(x-\Delta x)] \\
Q_{s_{-} \max }(x)
\end{array}\right\}
$$

where $B$ ranges from 0 to 1 , representing the fraction of the upwind flux that would normally be deposited at $x$, but which should instead be transferred further downwind.

This parameter's default value is 0 , which deposits all saltating snow in excess of $Q_{s_{-} \max }$, resulting in deep peaked drifts, whereas longer, smoother drifts will be simulated as $B$ approaches 1 . A value of $B=1$ is a physically unrealistic scenario, where eroded snow cannot be re-deposited. A more recent innovation to correct for this behaviour is the “Tabler Profile" sub-grid parameterization detailed in Liston et al. (2007), which implements a much more realistic drift-adjustment. In this thesis, however, this parameterization was found to be computationally unstable, so the simpler (and nonphysically-based) B parameter was used instead.

\subsubsection{SnowPack Density Evolution}

The SnowPack submodel's snow-density-evolution routine was introduced by Liston et al., 2007, and couples $u^{*}{ }_{t}$ to weather conditions. Given the importance of $u^{*}{ }_{t}$ for determining possible snow transport flux magnitudes, this routine deserves a close examination. The density of new snowfall, $\rho_{n s}$, is given by:

$$
\rho_{n s}=50+1.7\left(T_{w b}-258.16\right)^{1.5}
$$

where $T_{w b}$ is the wet-bulb temperature $(\mathrm{K})$. When precipitation falls with $u>5 \mathrm{~m} \mathrm{~s}^{-1}$, the snowpack density $\rho_{s}$ is determined by adding a wind-related offset, $\rho_{w}$, given by:

$$
\left.\rho_{w}=D_{1}+D_{2}\left[1-e^{-D_{3}\left(u_{t}-5\right)}\right]\right)
$$

where $D_{1}, D_{2}$, and $D_{3}$ are constants, respectively defining (1) the density offset for a $5 \mathrm{~m}$ $\mathrm{s}^{-1} u\left(25 \mathrm{~kg} \mathrm{~m}^{-3}\right),(2)$ the maximum density increase by wind $\left(250 \mathrm{~kg} \mathrm{~m}^{-3}\right)$, and (3) the 
progression from low to high wind speeds $\left(0.2 \mathrm{~m} \mathrm{~s}^{-1}\right)$, and $u_{t}$ is the terrain-modified wind speed, given by Equation 17 .

After snowfall, the density evolution proceeds under the influence of wind speed and temperature, such that:

$$
\frac{d \rho_{s}}{d t}=C A_{1} U \rho_{s} e^{-B\left(T_{f}-T_{S}\right)} e^{-A_{2} \rho_{s}}
$$

where $d t$ is the time step ( $3600 \mathrm{~s}$ in this study), $T_{f}$ is the freezing temperature, $T_{s}$ is the soft snow temperature (the lesser of $T_{a}$ or $T_{f}$ ), $B=0.008 \mathrm{~K}^{-1}, A_{1}=0.0013 \mathrm{~m}^{-1}$ and $A_{2}=$ $0.021 \mathrm{~m}^{3} \mathrm{~kg}^{-1}$, and $C=0.1$. Liston et al.'s wind-speed-related densification parameter $U=$ $1 \mathrm{~m} \mathrm{~s}^{-1}$ for $u<5 \mathrm{~m} \mathrm{~s}^{-1}$, but for $u \geq 5 \mathrm{~m} \mathrm{~s}^{-1}, U$ is given by:

$$
U=E_{1}+E_{2}\left(1-e^{\left[-E_{3}\left(u_{t}-5\right)\right]}\right)
$$

where $E_{1}, E_{2}$, and $E_{3}$ are 5,15 , and $0.2 \mathrm{~m} \mathrm{~s}^{-1}$, respectively. Given a simulated density, $u^{*}{ }_{t}$ is defined by:

$$
u *_{t}=0.005 e^{0.013 \rho_{s}}
$$

for $300<\rho_{s} \leq 450$, and:

$$
u *_{t}=0.1 e^{0.003 \rho_{s}}
$$

for $50<\rho_{s} \leq 300$.

This reasonably captures simulates snowpack bulk densification, but greatly simplifies the dynamic feedback systems of snow metamorphosis. The greatest discrepancy is that the SnowPack submodel does not simulate the formation of depth hoar crystals, which are weaker and less dense than the wind slab above them. This is a major discrepancy between the model and reality, but because depth hoar forms through the movement of vapour within the snowpack, the snowpack's integrated bulk density (i.e. averaged from ground surface to snow surface) is essentially unaffected by depth 
hoar formation. This simplified method is used because the more accurate, but more complex models that simulate snow grain bonding (e.g. Schmidt, 1980, or Lehning et al., 2000) have more strenuous input requirements, which are often unavailable for remote Arctic sites.

\subsection{Review of hydrological studies in the NRW}

Hydrologic research in the NRW was limited until recently. A Water Survey of Canada gauge has been recording river water levels at the town of Apex since 1973 (ECCC, 2016a - record gap from 1997 to 2006), and a geochemical characterization of the watershed was conducted by Obradovic and Sklash (1986), but little other historical hydrological information is available. The lack of baseline knowledge was recently highlighted as a major problem for Arctic water resource management by Bakaic and Medeiros (2017). Recent hydrological research has therefore focused on identifying the magnitude and pathways of streamflow sources to the river.

Snowmelt is the largest contribution to the NRW; meltwater is mostly delivered rapidly during spring melt, though the continued melt of late-lying drifts provides summer streamflow between rainfall events. The active layer is still frozen at the onset of melt, preventing infiltration of meltwater into the ground, which instead tends to refreeze, transferring latent heat to the cold ground as in other permafrost environments (Woo, 2012, Miller et al., 1982, Woo and Heron, 1981). This basal ice layer forms an impermeable barrier to snowmelt infiltration, such that further additions of meltwater from above will either refreeze or flow laterally beneath the snowpack through a slush layer (personal observation, 2015-2017). 
Percolation and refreeze in the snowpack delays the delivery of meltwater to the stream system. In the Mackenzie Delta, NT, Marsh (1988) observed a 4-day lag between surface melt and meltwater arrival to the snowpack base. Once the snowpack is warmed to the melting point, further meltwater leaves the snowpack through the slush layer at its base. By this mechanism, overland flow of snowmelt occurs widely in the watershed during the early melt period, causing a relatively rapid streamflow response.

During the freshet in the NRW, Thiel (2016) identified partial overland flow along the soil--vegetation interface. Measured concentration of dissolved organic carbon decreased and composition changed after the peak discharge period suggesting a switch from surface to subsurface pathways and an increasing importance of baseflow to the total stream discharge.

As snowmelt continues and patches of bare ground open, soil thaw can begin, allowing some infiltration and moderating the streamflow response to inputs of rainfall or snowmelt (Dingman, 1973; Church, 1974). Rivers underlain by continuous permafrost show higher peaks and lower base flows relative to those underlain by discontinuous or sporadic permafrost (Newbury, 1974). This is true of the NRW even after thaw throughout the summer; Kjikjerkovska (2016) showed that the NRW remains highly responsive to large rain events throughout the summer.

During the summer baseflow period, specific conductance (Obradovic and Sklash, 1986; Chiasson-Poirier, 2016) and total dissolved solids (Rusk, 2016) increase, indicating increased groundwater contributions. The contribution of stored lake water to annual streamflow is not known. Richardson and Shirley (2016) determined that snowmelt and soil water mixed before entering lakes in the NRW, but mixing between this streamflow 
and the lake water column is limited. This suggests that stored lake water does not become an important component of river flow until after snowmelt has concluded.

Estimates of evapotranspiration have been limited to isotopic (e.g. Kjikjerkovska, 2016) or modeling (e.g., Bakaic and Mediros, 2017) studies, while estimates of spring snow sublimation are non-existent. Field observation and preliminary modeling suggest, however, that spring snow sublimation may constitute a substantial loss of stored water to the atmosphere. To support investigation of this process, an eddy covariance tower capable of directly measuring the latent heat flux has been installed in the NRW as of 2017 (Richardson et al., unpublished).

A community-based water quality monitoring campaign has been conducted by the Nunavut Research Institute in the NRW since 2009 (Shirley, 2014) and long-term monitoring at Tasiluk (Crazy) Lake has been conducted by students from the Nunavut Arctic College's Environmental Technology Program for over a decade (Dyck, 2007). Collaborations between these monitoring projects and southern researchers, such as the study described here, have been vital for increasing research capacity in the NRW.

This thesis describes the first study to attempt to quantify the spring SWE storage in the watershed, to describe the spring snow distribution, and to estimate midwinter transport and sublimation fluxes using a physically-based snow transport model. Given the recent hydrological activity in this watershed, there is a need for spring SWE to support water balance calculations and snowmelt studies. 


\section{Chapter: Methods}

This chapter is ordered according to the sub-objectives of this thesis, which were to (1) conduct snow surveys in the NRW to quantify SWE storage, (2) use survey data and digital terrain analysis to create empirical models of the SWE distribution, and (3) prepare and run a physically-based snow transport model. The chapter begins with a brief introduction to the study site followed by the research methods used to address each subobjective.

Note on terminology: Snow surveys were conducted in the springs of 2015 and 2016. The snow accumulation period for each survey includes the winter and autumn of the previous calendar year, i.e., October 2014 - May 2015 and October 2015 - May 2016. The convention in this thesis is to refer to these as 2015 and 2016, referring both to the year in which the survey was conducted and to the water year of interest (USGS, 2016).

\subsection{Study Site}

This study was carried out in the $52.3 \mathrm{~km}^{2}$ Niaqunguk River Watershed near Iqaluit, Nunavut (Figure 1). The river's flow regime is typical for an Arctic river, dominated by a nival discharge peak in June, followed by a rapid recession (Figure 3). Summer and autumn base-flow is low, with occasional large rainfall peaks. There is no flow during the winter (Environment and Climate Change Canada, 2016a).

The watershed is characterized by continuous permafrost, with rugged to rolling terrain arranged in parallel ridges running to the northwest. Surficial materials are glacial till with granite/granitoid rock outcrops (Blackadar, 1967; St-Onge et al., 1999; Hodgson, 2005; Allard et al., 2012; Tremblay et al., 2015), though boulder fields and other glacial 
deposits (Squires, 1984) are also common. Vegetation is limited to tundra grasses, dwarf shrubs and forbs less than $5-10 \mathrm{~cm}$ tall. This low vegetation provides little interception of blowing snow, unlike shrub tundra or taiga landscapes.

The 1981 - 2010 Iqaluit climate normal shows precipitation of $404 \mathrm{~mm} \mathrm{y}^{-1}$, with $57 \%$ received as snow. The snowfall fraction may, in fact, be much greater, as snowfall is underestimated by standard gauges (see Appendix J), and precipitation type has not been recorded at XFB since 1997. Snowfall occurs year-round, with accumulation from October to May. Most (96.5\%) daily snowfall totals are less than $10 \mathrm{~cm}$, though daily events up to $32 \mathrm{~cm}$ have been recorded (Environment and Climate Change Canada, 2016b). Rainfall dominates when average air temperatures rise above $0^{\circ} \mathrm{C}$ (June to September).

Prevailing winds are from the NNW, channeled by the surrounding topography. Average annual wind speeds at Iqaluit are $15.7 \mathrm{~km} \mathrm{~h}^{-1}$, though winter storms can bring gusts well over $100 \mathrm{~km} \mathrm{~h}^{-1}$ (Environment and Climate Change Canada, 2016b). Storms associated with the largest snowfalls originate over the Great Lakes, Hudson's Bay, and the Atlantic Ocean (Gascon et al., 2010). Frequent blowing snow events are hazards for aviation in Arctic communities (Gordon et al., 2010), and redistribute snow from exposed to sheltered areas. This results in a variable snow depth distribution before spring melt (Figure 4a), promoting the development of a patchy snow cover during melt (Figure 4b). 


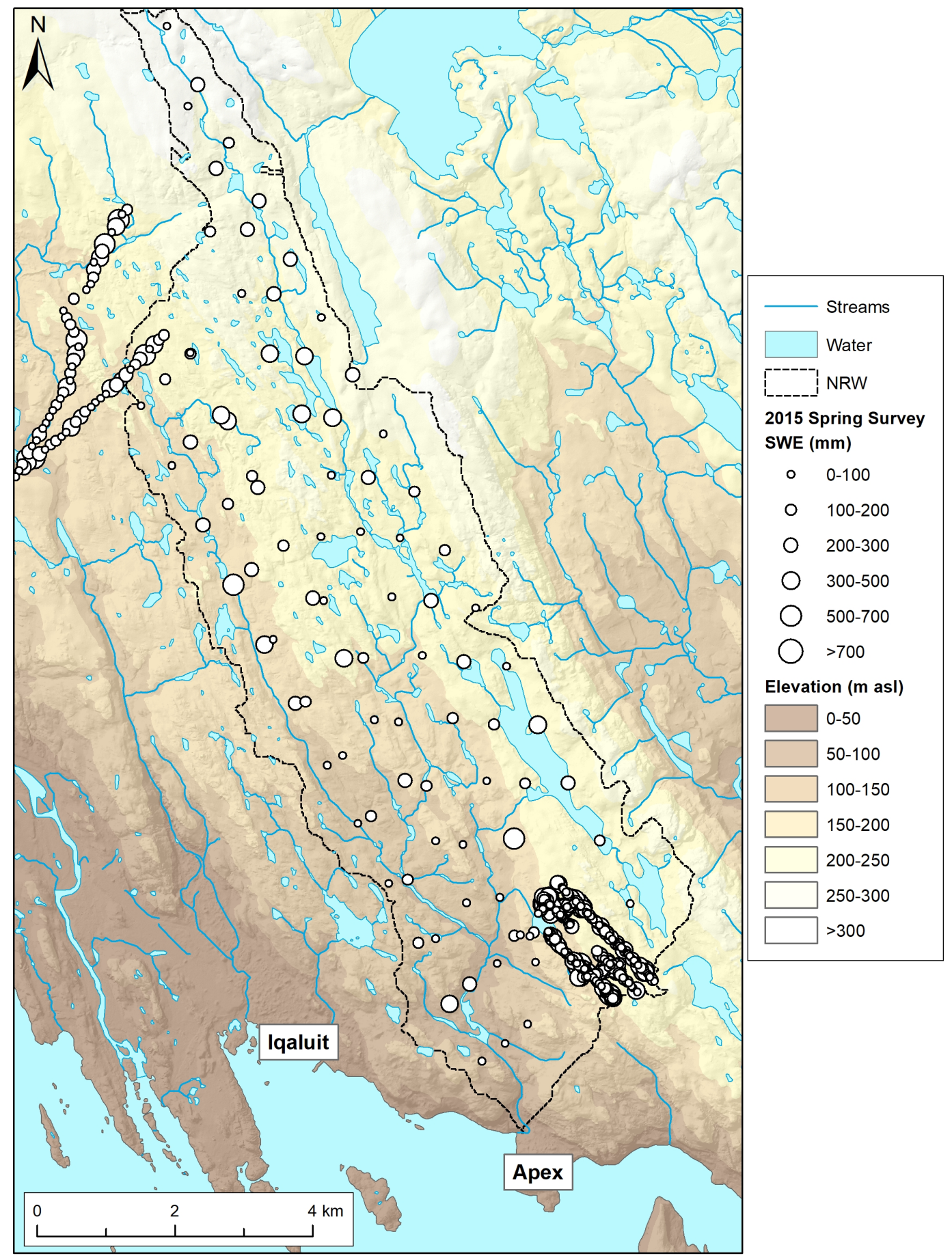

Figure 1: Niaqunguk River Watershed, showing 2015 survey sampling sites. The river's outlet to Frobisher Bay is at the town of Apex. 


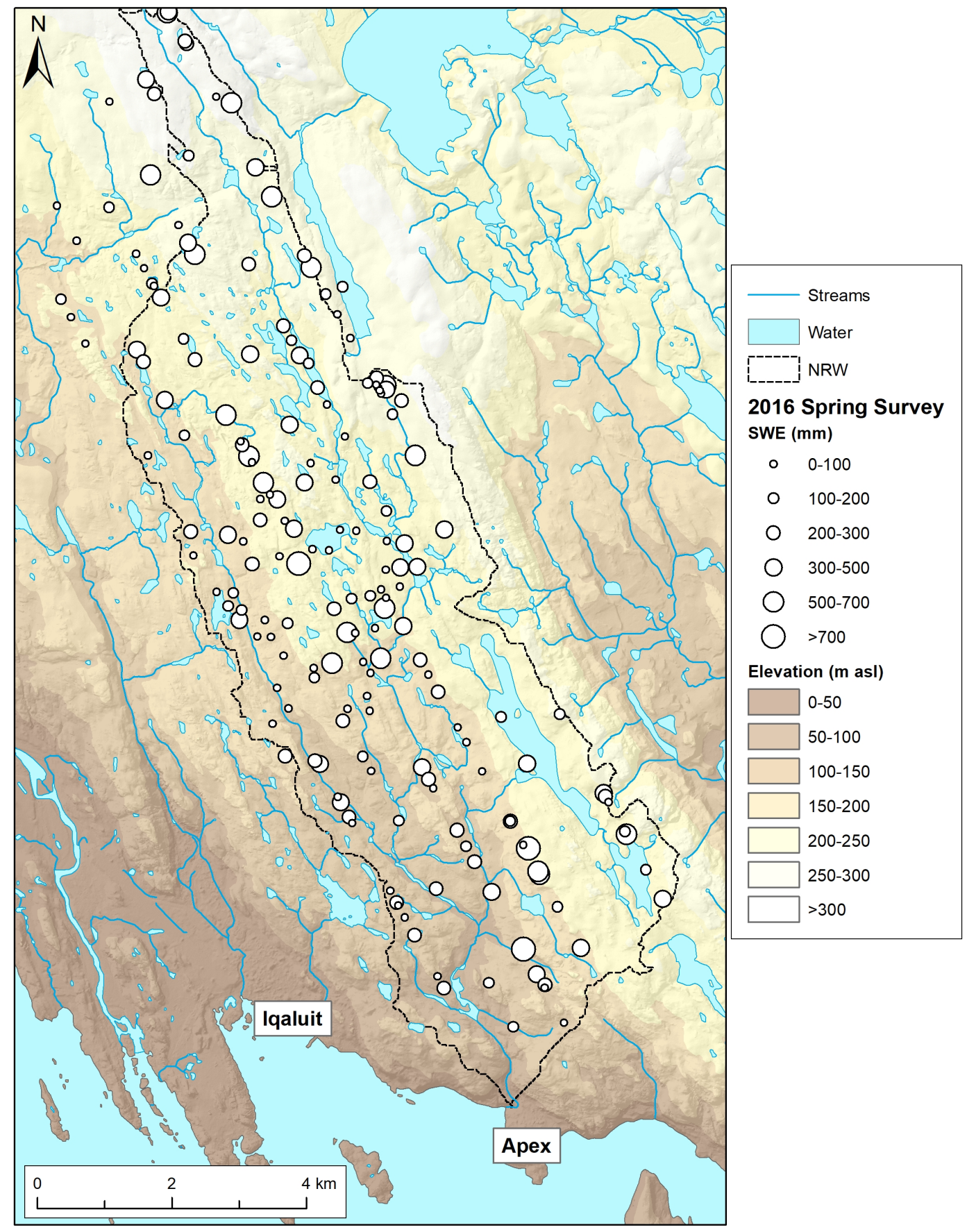

Figure 2: Niaqunguk River Watershed, showing 2016 survey sampling sites. The river's outlet to Frobisher Bay is at the town of Apex. 


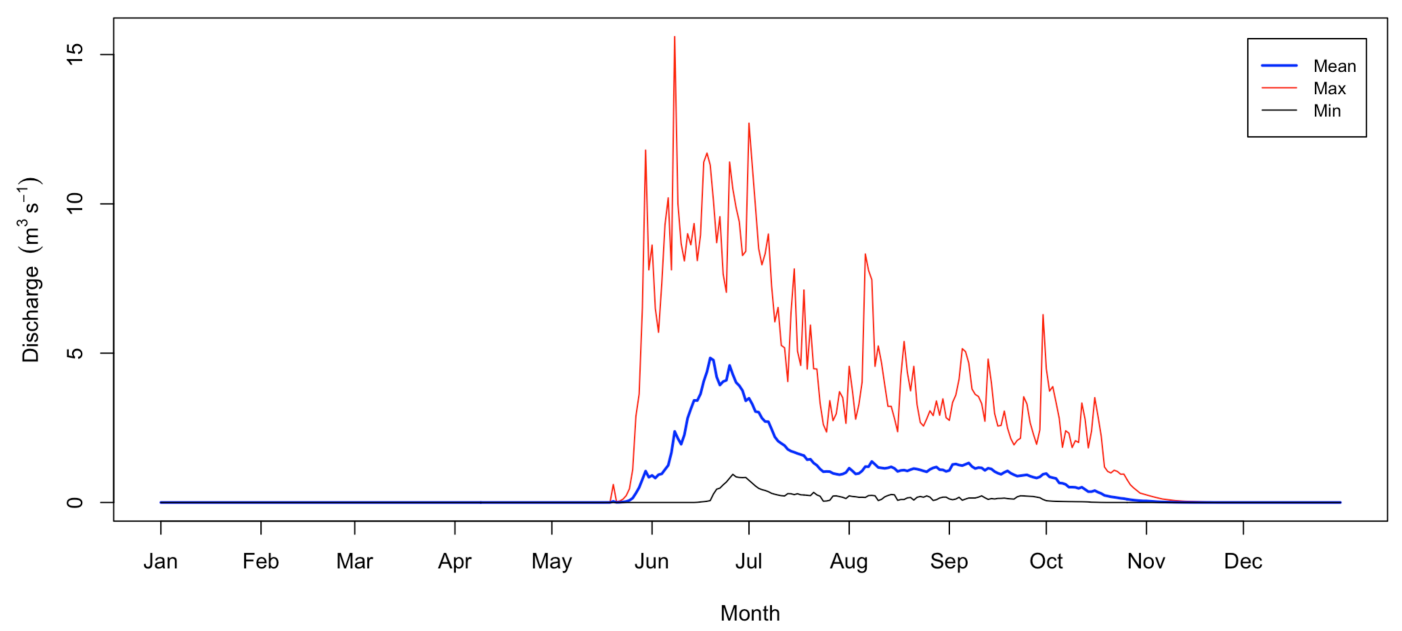

Figure 3: Hydrograph from Apex Hydrometric Station (ECCC), showing the spring melt peak, rapid recession, rapid summer rainfall response, and zero-flow during the winter.
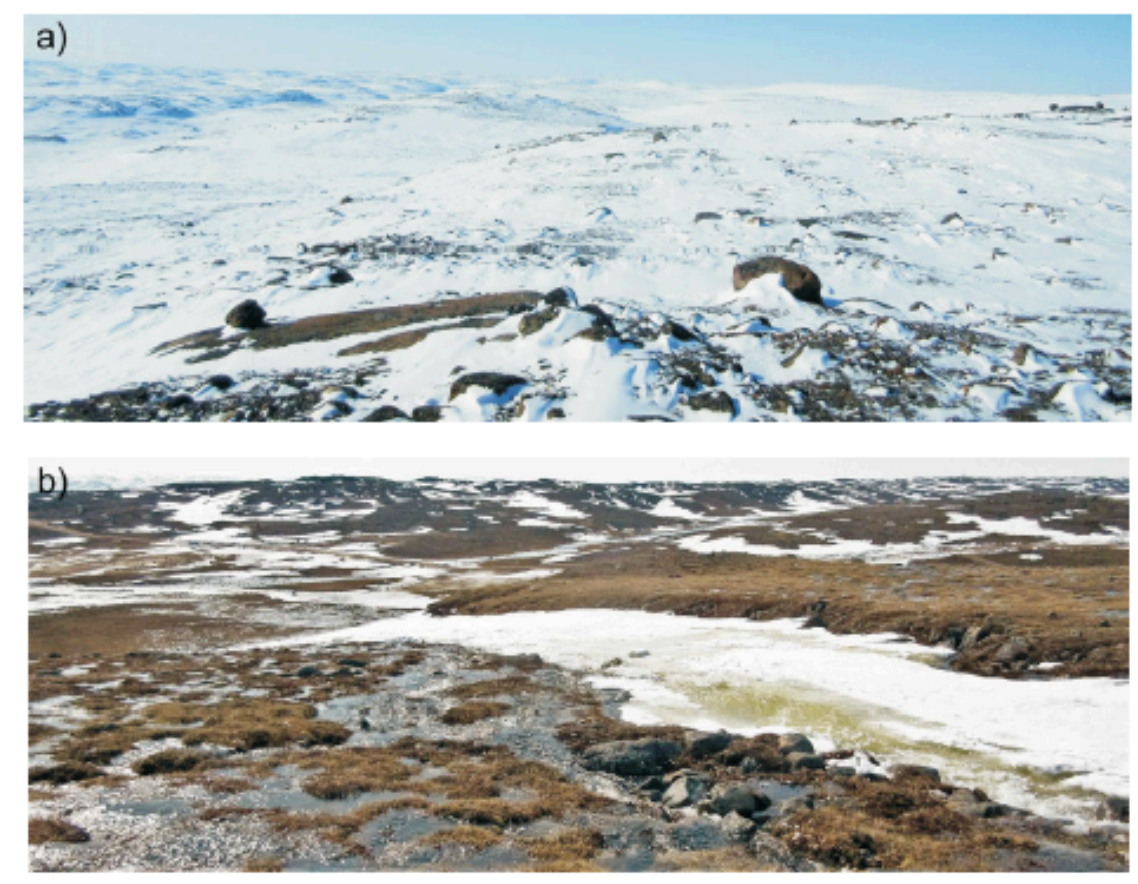

Figure 4: Tundra snow cover in the NRW (a) at the end of winter and (b) during the spring freshet. Note the late-lying snowdrifts on leeward slopes in (b). 


\subsection{Field Data Collection}

To quantify watershed SWE storage and characterize the spring snow distribution (sub-objective 1), extensive snow surveys of the NRW were conducted by snowmobile and on foot in April-May of 2015 and 2016. At each site, a depth measurement was taken with an aluminum snow probe (SnowMetrics), with at least 3 supporting depth measurements within $2 \mathrm{~m}$ of this central point (Figure 5). This $2 \mathrm{~m}$ distance was chosen to characterise the site scale because it was close enough to the central point to be representative, and because it approximately corresponds to the uncertainty associated with our handheld GPS. Snow water equivalent cores were taken using a Federal sampling tube (Geo Scientific Ltd.) at approximately $1 / 3$ of the sites in 2015, and at every site in 2016. For more details on sampling technique in the field, see Appendix A.

Sampling locations were predetermined, with different sampling strategies employed in each year. In 2015 (Figure 1), 391 samples were taken. Of these, 87 were taken in the NRW every $1 \mathrm{~km}$, along seven randomly placed transects running the length of the watershed (not shown on the map). The remaining samples were taken in two lake sub-watersheds were also sampled along transects (also not shown on map), with sites spaced at 30 and $100 \mathrm{~m}$. These measurements were used to determine the range of spatial autocorrelation in snow depth in the NRW (found to be $\sim 80 \mathrm{~m}$, see Appendix B), and to calibrate a terrain-based snow distribution model for the 2015 season.

In 2016 (Figure 2), samples were taken along six randomly placed transects running the length of the watershed (not shown on the map). Sites were separated from one another by a minimum distance of $100 \mathrm{~m}$, and were randomly placed within the snow depth classes identified in the 2015 data. Some opportunistic random samples increased 
coverage at the end of the surveying period. The total sample size was limited in 2016 by ice layers in the snow, which had to be punched through with force, slowing the procedure and stressing the equipment.

The 2015 method should be seen as a minor variation on other systematic sampling strategies (such as grid or spiral sampling), whereas the 2016 method was an attempt at stratified sampling (similar to other authors who stratify their sampling by terrain unit). Other sampling methods are common; in particular, the use of long lines of closely spaced samples taken by foot is common. Given the autocorrelation length observed in snow data ( $\sim 80 \mathrm{~m}$ in the NRW in 2015 , see Appendix B), closely spaced samples are not statistically independent. Instead, the majority of data collected by this method constitutes pseudoreplication, and so should not be correlated collectively to terrain data, as was the goal in this study. Winstral et al., 2002, argued against discarding data to account for spatial correlation, but the survey in this study was designed to avoid this problem entirely.

For sites where only depth was measured, SWE was estimated from depth using linear regressions. An alternative to this method would be to use an average density to calculate SWE from each depth. Sturm et al. (2010) found that linear regressions were an effective tool for predicting SWE from depth, noting that the functional relationship between them is nonlinear - that is, the slope of the regression line is not equal to the bulk density. This was also observed in this study (Appendix C). 


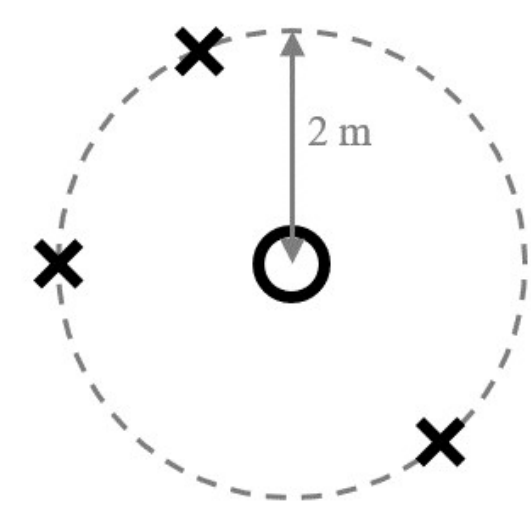

(a)

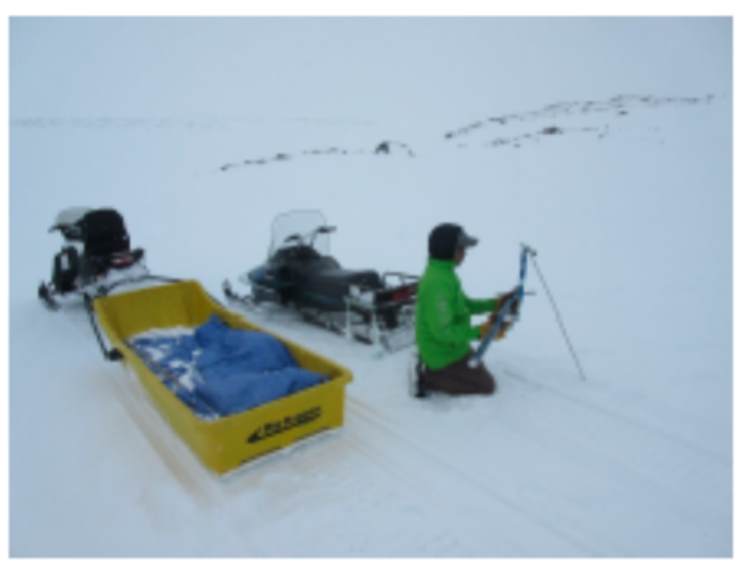

(b)

Figure 5: (a) Field survey site sampling strategy - central measurement (SWE or depth) shown with an "O", with 3-4 supporting depth measurements " $\mathrm{X}$ " taken $2 \mathrm{~m}$ away in random directions. (b) Nunavut Arctic College student S. Noble-Nowdluk weighing a SWE core in the field.

\subsection{Terrain Models}

Following Pomeroy et al. (1997), the tundra snow distribution can be broadly characterized by three different depositional or erosional regimes: (1) areas strongly exposed to wind, which are scoured of snow, (2) areas mildly exposed to wind, which are a source of snow for wind transport, but remain snow-covered during the winter, and (3) areas sheltered from the wind, which act as "sinks" for the snow transported from (1) and (2). These drift areas occur on the lee slopes of hills, and in local depressions like gullies and stream channels. Since these regimes are defined by their exposure to wind, it should be possible to model the spring snow distribution from quantitative measures of terrain form (i.e., terrain variables).

To create empirical models of the snow distribution (sub-objective 2), terrain variables related to snow distribution were used to divide the watershed into SWE 
classes. These variables were calculated using SAGA-GIS software (Conrad et al., 2015), based on a $1 \mathrm{~m}$ digital elevation model (DEM) of the study area, derived from WorldView-1 stereo-optical data collected in August 2008, was provided by Natural Resources Canada (Short et al., 2013), with planimetric accuracy $<40 \mathrm{~cm}$, and vertical accuracy $<50 \mathrm{~cm}$ for $72 \%$ of tested locations (Budkewitsch et al., 2009).

\subsubsection{Elevation Data}

Before processing, the DEM was resampled from a $1 \mathrm{~m}$ spacing to $5 \mathrm{~m}$. This improved computational efficiency and reduced random noise in sensitive parameters like curvature. Mott et al. (2011) suggested that a $5 \mathrm{~m}$ resolution fails to capture fine-scale snow transport processes, which was supported during the snow surveys in this thesis by the large site-scale snow depth variance. However, analysis at a finer scale was precluded by positional uncertainty in the survey data, as our handheld GPS units typically indicated precision of $2-3 \mathrm{~m}$. This results in a 4-6 m "footprint" of uncertainty at each sample site. A $5 \mathrm{~m}$ resolution is largely confined to this footprint, reduces uncertainty associated with site-scale variations in snow depth, and allows terrain variable calculation at scales from 5 to $250 \mathrm{~m}$ without computational limitations.

\subsubsection{Terrain Variable Calculation}

The terrain variables of interest for this thesis are: (1) slope, (2 and 3) longitudinal and tangential curvature, (4) normalized height, (5 and 6) positive and negative topographic openness, and (7) a wind shelter index. This section provides a very brief description of each variable, including their calculation. For further background on these variables, see Appendix E. 
Slope and curvature are well-established topographic variables used to describe a pixel's surface (e.g., Hengl and Reuters, 2008, Wood, 1996, Zevenbergen and Thorne, 1987, Evans, 1972). Slope $\left(\beta,^{\circ}\right)$ is the angle between a grid cell's highest and lowest edges. Curvature is the radius of a curve defined by the intersection of the terrain surface with a plane, usually defined by the slope normal and a second axis. For longitudinal curvature (CL, $\mathrm{m}^{-1}$; Wood, 1996), the second axis is along the slope direction, whereas for tangential curvature (CT, m${ }^{-1}$; Schmidt et al., 2003, Krcho, 1991), the second axis is perpendicular to the slope direction.

Normalized height ( $\mathrm{NH}$, no unit; Böhner and Selige, 2006) is a hydrologically oriented metric of a grid cell's height within its local context. Specifically, $N H$ indicates a grid cell's position between the bottom $\left(z_{d}\right.$, where $\left.N H=0\right)$ and top $\left(z_{s}\right.$, where $\left.N H=1\right)$ of its catchment area. These altitudes are then normalized:

$$
N H=\frac{1}{2}\left(1+\frac{z_{d}-z_{S}}{z_{d}+z_{s}}\right)
$$

Topographic openness relates a grid cell to its surrounding relief, from two perspectives: positive openness $\left(O_{+},{ }^{\circ}\right)$ indicates a cell's dominance above the surrounding terrain, whereas negative openness $\left(O_{-},{ }^{\circ}\right)$ represents its enclosure within the terrain. To calculate openness for a grid cell $A$, a radial distance is defined. In each of the 8 primary directions, this distance away from $A$ is searched and the highest (for $O_{+}$) and lowest (for $O_{-}$) points are retained. For $O_{+}$, the angle between $A$ and the highest point is subtracted from $90^{\circ}$ to give the zenith angle, whereas for $O$, , the lowest points are used, and the resulting angles are added to $90^{\circ}$ to give the nadir angle. The average zenith and nadir angles give $O_{+}$and $O_{\text {-, }}$ respectively. In this research, the radial distances used were $10 \mathrm{~km}\left(O_{10 K}\right.$, for cluster analysis $)$ and $25 \mathrm{~m}\left(O_{25}\right.$, for the decision rule method $) ; 10 \mathrm{~km}$ 
seemed to be the optimal radius to differentiate landforms such as plateaus and valleys in the NRW without subdividing them further, whereas $25 \mathrm{~m}$ was the optimal radius to replicate patterns of wind-scour on hilltops and ridgelines.

Finally, the wind shelter index $\left(W{ }^{\circ}\right.$, developed by Winstral et al, 2002) indexes a grid cell's topographic sheltering by upwind slope breaks. A wind direction and search distance are specified, and the slope between the target grid cell and the cells within the search distance upwind is calculated. The largest slope is retained, with positive values indicating greater wind sheltering at the target cell by some upwind obstacle, whereas negative values indicate exposure at the target cell. To account for flow diversion around complex terrain, this process is repeated for other directions within a specified angular tolerance, and the mean value is assigned to $W$. In this research, the prevailing wind direction $\left(340^{\circ}\right)$ was specified, with a $\pm 10^{\circ}$ tolerance and a search distance of $30 \mathrm{~m}$ $\left(W_{30}\right)$.

\subsubsection{Classification Methods For Semi-Distributed Modeling}

Two different classification methods were used for modeling. The first method is cluster analysis, which is used to identify "terrain units". These units are natural groupings in the first six terrain variables, which are then subdivided according to the final variable $\left(W_{30}\right)$. Given the importance of terrain in determining the snow distribution, these units should correspond closely to spring SWE patterns.

The second method is a decision rule approach, which splits a subset of the terrain variables $\left(\beta, O_{+25}, O_{-25}, W_{30}\right)$ using rules defined from direct reference to snow transport principles and field observations. Defining these rules relied on first principles derived from the literature, as well as from heuristics derived from field experience. Heuristic 
applications are relatively uncommon in the geosciences, but have been used in soil type and ecological mapping - for a review of these applications, see Appendix G.

\subsubsection{Method 1: Cluster Analysis}

Cluster analysis, a well-established family of unsupervised classification methods (Forgy, 1965, MacQueen, 1967, Thorndike, 1953), was used to identify natural groups in the terrain variables, under the assumption that these groupings should correspond to terrain units (TUs) such as "ridge" or "valley". As an unsupervised method, clustering does not use SWE to refine clusters, avoiding the problem of over-fitting the SWE data to survey data.

In this study, the "hill-climbing method" of cluster analysis (Rubin, 1967) was applied to all of the terrain variables except for $W_{30}$. Given a multivariate dataset, the hillclimbing algorithm specifies random centroids in data space, clusters the nearest neighbours, and then iteratively moves observations between clusters to minimize withingroup variance. Because the clusters are sensitive to initial centroid placement, the process is repeated with different initial centroids, and the result that minimizes withincluster variance is retained.

The number of possible terrain units is large, but the resulting maps and centroid statistics suggested that 4 was the largest number of meaningful TUs, without creating ambiguous classes by over-splitting. Since wind direction and exposure are critical factors for drift development, the $30 \mathrm{~m}$ index of wind shelter $\left(W_{30}\right)$ was used to split the 4-TU model into "sheltered" and "exposed" areas, yielding an 8-TU model. 


\subsubsection{Method 2: Decision Rules}

The cluster analysis method identifies landforms and uses these directly as the basis for modeling the snow distribution. In contrast, the second method makes direct reference to the principles by defining a set of decision rules. These rules divided the NRW into "sub-classes" by splitting terrain variables at critical values, then merging subclasses with common snow accumulation regimes into final classes. The variables and split values were chosen from review of the literature and from heuristics developed through field experience, and were assessed by visualizing the snow accumulation classes in a GIS.

Where patterns corresponded to observations and photographs from the surveys, the decision rules were finalized. The final rules used four terrain variables: slope $(\beta)$, both perspectives of topographic openness at a $25 \mathrm{~m}$ radius $\left(O_{+25}\right.$ and $\left.O_{-25}\right)$ and wind shelter index at a $30 \mathrm{~m}$ distance $\left(W_{30}\right)$. These rules defined three final snow classes: Scour, Drift, and Tundra.

Scour was the shallowest class, defined by exposure to wind from all directions this was selected with the rule: $\mathrm{O}_{+25} \geq 90^{\circ}$. The spatial pattern of Scour closely matches the distribution of bare rock on ridges and hilltops observed in the field. This class also covers the centres of large lakes, which are usually scoured during winter.

The deepest class was named Drift, and is aggregated from 2 sub-classes:

Catchment and Sheltered Slope. The first sub-class was Catchment, defined by topographic enclosure $\left(\mathrm{O}_{-25}>90^{\circ}\right)$, which accounts for snow settling in locally enclosed terrain, a phenomenon referred to as the "diffusion effect" by Ohara (2014). The second 
sub-class is Sheltered Slope. This was aggregated from a Slope sub-class, defined by $\beta>$ $9^{\circ}$ following Essery and Pomeroy (2004) and Pomeroy (1997), and a Sheltered class, defined by $W_{30}>0$.

The final class was called Tundra, and was composed of all sub-classes not assigned to Scour or Drift. These areas are mildly exposed to the wind and act as a source area for blowing snow. Observations in the field suggested that most of the NRW falls under this snow accumulation regime.

\subsubsection{Empirical Model Evaluation}

The overarching objective of this thesis was to determine a suitable method for estimating spring SWE. To meet this objective, evaluation criteria were needed to determine whether the empirical models developed in this section were accurate representations of the snow distribution. The models are evaluated on how well they (1) correspond to observed spatial patterns of snow accumulation, (2) reproduce the survey estimate of watershed SWE, and (3) represent distinct classes of SWE, indexed by within-class variance.

This last criterion assesses a model's validity; it may coincidentally meet criteria (1) and (2), but it may not partition the variability in the snow distribution in a meaningful way. If class means are similar and within-class variance is so large that classes are indistinguishable, then the model is not a useful improvement over a systematic full-watershed snow survey. By contrast, an effective model would clearly distinguish between snow accumulation classes. This could be used to stratify future snow surveys and improve confidence in the final SWE estimate as a result of increased sampling of classes with higher internal variance. 


\subsection{Physically-Based Snow Modeling}

As described in Chapter 2, this study used the SnowModel snow evolution modeling system (Liston and Elder, 2006a) to simulate snow accumulation in the NRW. SnowModel requires meteorological and topographic input data and user-selected parameter values for the wind field. This section details data sources and preparation techniques, as well as a sensitivity analysis of the simulated transport fluxes to parameter values. The model evaluation criteria are also described at the end of this section.

\subsubsection{Meteorological Data}

Hourly measurements of air temperature, humidity, precipitation, wind speed and direction were downloaded from Environment and Climate Change Canada's (ECCC) Iqaluit airport climate station (XFB). Two of the standard measurements were inspected and replaced; in both cases an alternative data source was available at the same location.

The first replaced measurement was wind speed and direction. The $10 \mathrm{~m}$ anemometer showed evidence of icing during mid-winter, so wind measurements were instead taken from a secondary $2 \mathrm{~m}$ anemometer at the same location (which did not seem to be affected by icing). Since SnowModel takes a $2 \mathrm{~m}$ wind speed by default, this also avoids the need to convert $10 \mathrm{~m}$ wind speeds using the log wind profile.

The second replaced sensor was the station's single-Alter-shielded Geonor T200B precipitation gauge $\left(\mathrm{P}_{\mathrm{SAGE}}\right)$. Snowfall measurements from these gauges suffer from extreme wind bias in open environments (see Appendix J), so snowfall measurements were also taken from an OTT Pluvio ${ }^{2}$ double fence automatic reference gauge at Iqaluit $\left(\mathrm{P}_{\mathrm{DFAR}}\right)$. The Pluvio performs onboard noise filtering and quality control before datalogging, but these data still required quality checks and aggregation from the original 
6 s sampling rate to an hourly interval (see Appendix K for complete details of the preprocessing performed on this dataset).

Initial runs with $\mathrm{P}_{\mathrm{SAGE}}$ as the snowfall forcing could not reproduce the observed snow distributions, so $\mathrm{P}_{\mathrm{DFAR}}$ was used as the forcing in this study. To use SnowModel for simulations near other Nunavut communities (which lack DFAR gauges), or near Iqaluit before 2008 (the date of the Iqaluit DFAR installation - H. Mouradian, personal communication), standard gauge data should be adjusted for wind bias using transfer functions (e.g., Wolff et al., 2015, Smith, 2009). The P PAGE measurements presented in this thesis have not been bias-adjusted.

All meteorological datasets were examined for missing data. Since most gaps in the input data were short (1-3 hours typical, with some gaps up to 7 hours), all variables except wind direction were gap-filled by linear interpolation. A modified interpolation technique was used to handle wind direction as a circular quantity (see Appendix I). The 2015 and 2016 winters had similar average meteorological conditions (Table 1), though the 2015 winter was slightly colder with a lower mean wind speed.

Precipitation was detected more often with the DFAR; 32 and 19\% of the total hours in 2015 and 2016, respectively, compared to 5 and 10\% for SAGE. For hours with recorded precipitation, hourly $\mathrm{P}_{\mathrm{DFAR}}$ and $\mathrm{P}_{\mathrm{SAGE}}$ were similar in both years (averaging 0.33 and 0.34 $\mathrm{mm}$ in 2015 , compared to 0.40 and $0.36 \mathrm{~mm}$ in 2016), but given the large differences in total recorded precipitation hours, daily and seasonal accumulations showed strong differences (Figure 6, see also Appendix I). 
Table 1: Meteorological data summary for the 2 study years, from 2014-10-01 to 201504-18 (200 day period, called "2015" throughout this thesis), and from 2015-10-01 to 2016-04-30 (213 day period, called "2016”). P PAGE are not adjusted for wind-induced undercatch bias.

\begin{tabular}{lcccccc}
\hline & $\begin{array}{c}\mathbf{P}_{\text {DFAR }} \\
(\mathbf{m m})\end{array}$ & $\begin{array}{c}\mathbf{P}_{\text {SAGE }} \\
(\mathbf{m m})\end{array}$ & $\begin{array}{c}\boldsymbol{u}_{\mathbf{2 m}} \\
\left(\mathbf{m ~ s}^{-\mathbf{1}}\right)\end{array}$ & $\begin{array}{c}\boldsymbol{\theta}_{\mathbf{2 m}} \\
\left({ }^{\circ}\right)\end{array}$ & $\begin{array}{c}\boldsymbol{T}_{\boldsymbol{a}} \\
\left({ }^{\circ} \mathbf{C}\right)\end{array}$ & $\begin{array}{c}\boldsymbol{R} \boldsymbol{H} \\
(\mathbf{\%})\end{array}$ \\
\hline $\mathbf{2 0 1 5}$ & 502.6 & 82.7 & 3.3 & 339 & -20.0 & 76.4 \\
$\mathbf{2 0 1 6}$ & 389.2 & 190.3 & 4.1 & 337 & -17.4 & 78.6 \\
\hline
\end{tabular}
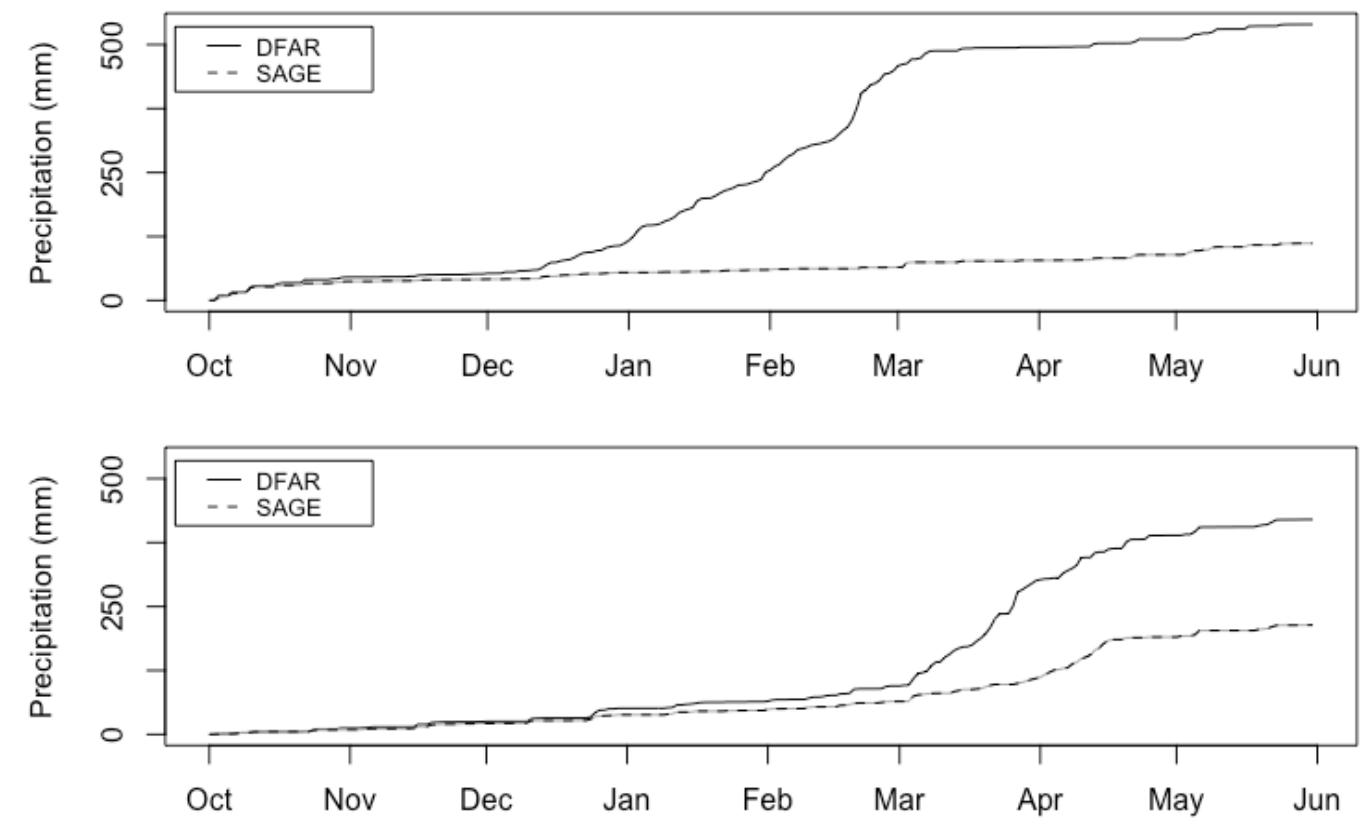

Figure 6: Cumulative water equivalent precipitation from both DFAR and SAGE (not adjusted for wind bias) for the 2014 (top) and 2015 (bottom) study winters. Both y-axes are scaled to the 2014 total.

\subsubsection{Topographic Data}

SnowModel requires two spatial data grids to run: (1) a DEM, and (2) a snowholding capacity (SHC) grid. Elevation data from the DEM are required to distribute 
meteorological data, including topographically induced changes in wind speed, which are critical for snow transport modeling. Snow holding capacity is the depth of snow accumulating on a grid cell before snow can be transported out of that cell by SnowModel.

The DEM was the same as that used for terrain variable calculation in the previous section, resampled to $10 \mathrm{~m}$. The distributions and statistics from simulations with finer grid spacings were not substantially different from the $10 \mathrm{~m}$ simulations, while requiring much greater computational resources (e.g., 18 hour run-time at $10 \mathrm{~m}$ versus a 3.5 day run-time at $5 \mathrm{~m}$ ). This DEM was clipped to a $12.65 \times 18.20 \mathrm{~km}$ area. This was done to improve efficiency by minimizing the portion of the domain outside of the study watershed, though small buffers were preserved to prevent boundary effects from causing errors in the simulated NRW snow accumulation.

For the SHC grid, two terrain types were defined: tundra and ice (Figure 7, Figure 8). Tundra SHC was $5 \mathrm{~cm}$, the lower bound of typical accumulation in an exposed (though not wind-scoured) location. At a $10 \mathrm{~m}$ grid resolution, average catchment by hummocky tundra microtopography might be greater $(10-20 \mathrm{~cm})$, but this was a conservative estimate for the watershed as a whole, and agrees with Liston and Sturm's (2002) value of $5 \mathrm{~cm}$ for barrens.

Ice comprises $7.6 \%$ of the total area of the NRW and $16.5 \%$ of the SnowModel domain. This includes large lakes, such as Tasiluk to the northeast, as well as Frobisher Bay to the south. To delineate ice for the SHC grid, water body GIS polygons were downloaded from GeoGratis (NRCAN, 2015). The coarse polygon edges were edited to 
match the real shorelines of waterbodies, determined from satellite imagery

(GoogleEarth, 2017) and a hillshade of the DEM, visually scanned at a 1:10,000 scale.

The ice SHC was assumed to be $1 \mathrm{~cm}$, as rough ice can catch some snow (though ice roughness was not measured during fieldwork). Ice may not have been fully formed at the simulation start (October 1), but was observed in the field in early October in 2015 and 2016, suggesting that complete lake freeze would soon follow. Therefore it was decided that simulating snow accumulation on ice for a few days in October, when it realistically might have fallen into water, would have a negligible effect on the simulation. Certainly, this effect would be no larger than the uncertainties introduced by modeling ice formation from limited data, without validating observations.

Sea ice is more problematic, typically forming in December (M. Thomas, 2016 pers. comm.). SnowModel requires a rectangular grid and does not allow missing topographic data, so it was impossible to completely exclude Frobisher Bay from the SnowModel domain. Since the prevailing wind is from the northeast, typical snow transport should be from the NRW towards the Bay. Thus the simplification of assuming sea ice presence on October 1 was considered unlikely to have a large effect on the SnowModel simulation of snow transport and accumulation. Any effect would be further minimized by the fact that the bulk of $\mathrm{P}_{\mathrm{DFAR}}$ fell after December in both years.

\subsubsection{Wind Field Parameter Value Selection}

SnowModel distributes the wind field with the MicroMet submodel. Calculation of the wind field requires a curvature length scale $(\eta)$ and a weighting ratio for slope and curvature $\left(\gamma_{\mathrm{s}}: \gamma_{\mathrm{c}}\right)$. The default values for these are $500 \mathrm{~m}$ and 0.58:0.42 (determined by Pohl et al., 2006), respectively, but are modified depending on the terrain in the 
SnowModel domain, as well as on the scale of interest - for example, snow drifts on lee slopes might best be characterized by $\eta$ from $100-1000 \mathrm{~m}$, whereas stream channel drifts might take $\eta$ from $10-100 \mathrm{~m}$.

The simulated wind field is highly sensitive to these parameters. Initial "test" simulations run with multiple curvature length scales and slope/curvature weighting ratios showed large variations in the spatial distribution of terrain-modified wind speed (Figure 9). The accuracy of the wind field is the most important part of snow transport modeling, so selecting appropriate values for these parameters is critical.

At $\eta=500 \mathrm{~m}$, wind speeds continuously accelerated over large features such as the moraine that forms the NRW's northeast boundary. In reality, deceleration occurs within this moraine, as large snowdrifts are found behind topographic features approximately $200-250 \mathrm{~m}$ long. Liston and Elder (2006b) recommend that $\eta$ be "half the wavelength of the topographic features within the domain", which in this case corresponds to approximately $100 \mathrm{~m}$. This choice is reasonably well supported by the 80 $\mathrm{m}$ autocorrelation range calculated from the 2015 snow data.

This method is subjective; natural terrain is complex and contains multiple wavelengths, and the $\gamma_{s}: \gamma_{c}$ ratio is abstract and difficult to conceptualize. Two steps were used to test this choice more objectively. First, curvature fields were calculated for a range of $\eta$ values from $0-250 \mathrm{~m}$, and the $\eta$ value providing the closest match to the observed spatial pattern of SWE was selected. Second, this $\eta$ value was used to calculate wind fields with a range of $\gamma_{s}: \gamma_{c}$ ratios, and the ratio providing the closest match to the observed spatial pattern of SWE was selected. 


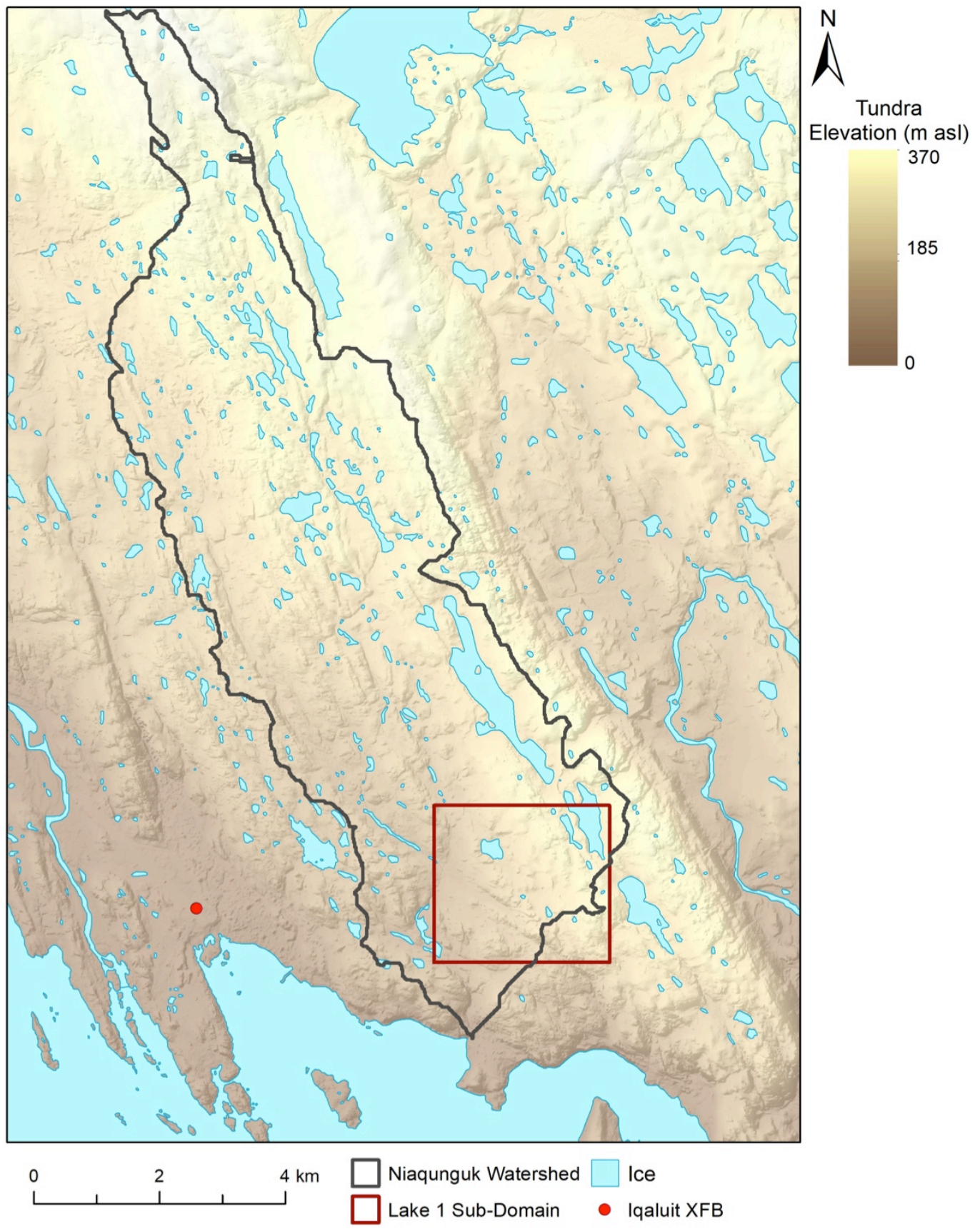

Figure 7: Exact extent of the full SnowModel domain, showing both SHC classes, with NRW overlaid for reference. Forcing data were collected at Iqaluit XFB (YFB Airport). SnowModel parameters were tested at Lake 1 before being applied to the full domain. 


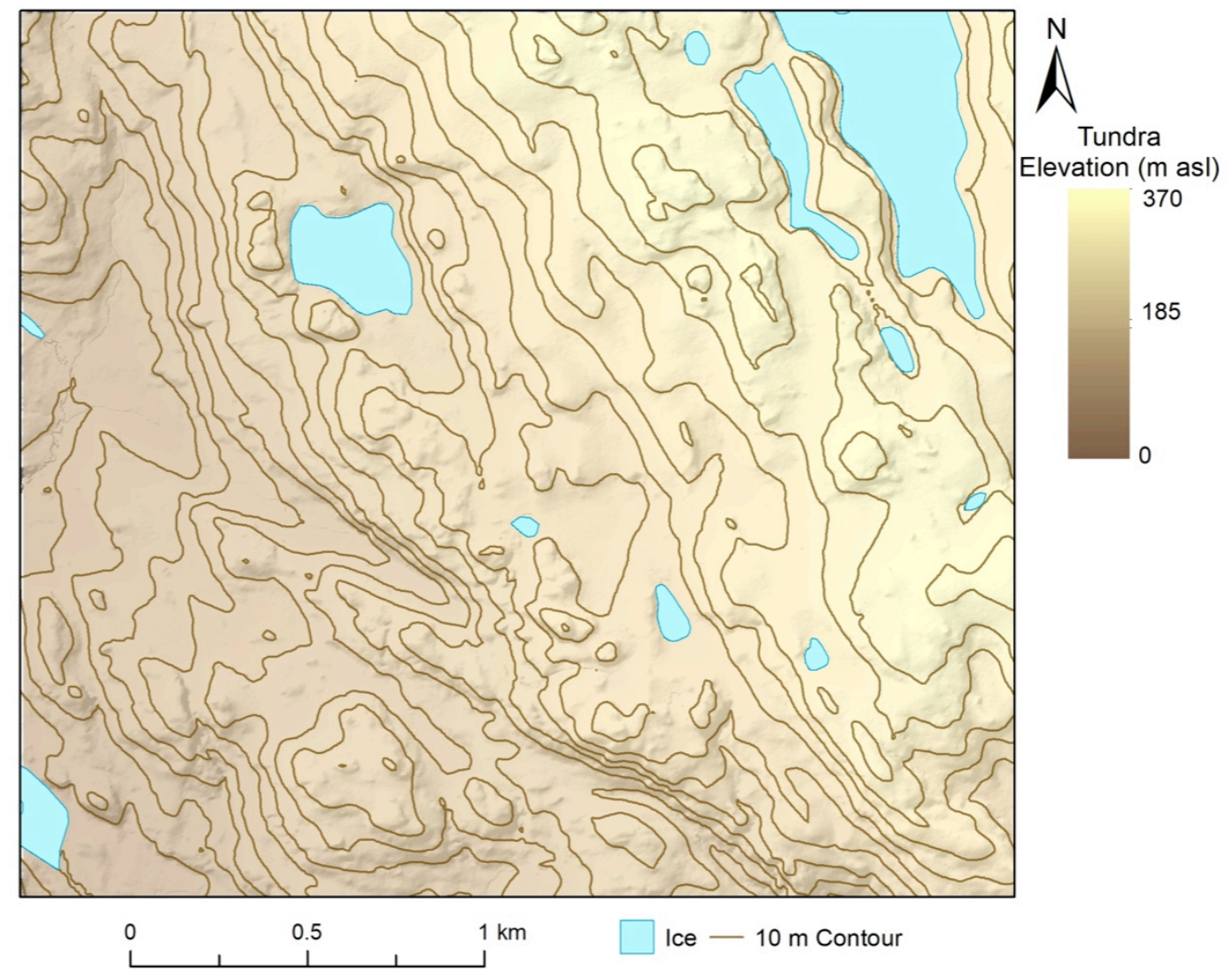

Figure 8: Lake 1 sub-domain, where SnowModel parameters were tested.

\subsubsection{SnowModel Sensitivity Analyses}

SnowModel parameter values were chosen based on the best available information. To verify these choices, three sensitivity analyses were performed to investigate the effect of parameter values on the simulated snow transport fluxes, and thus the spring SWE estimate.

First, the wind field was tested as described in Section 3.4.3. If permuting the wind model parameters has a large effect on the simulation, these parameters may be responsible for errors in the simulated spring SWE. 


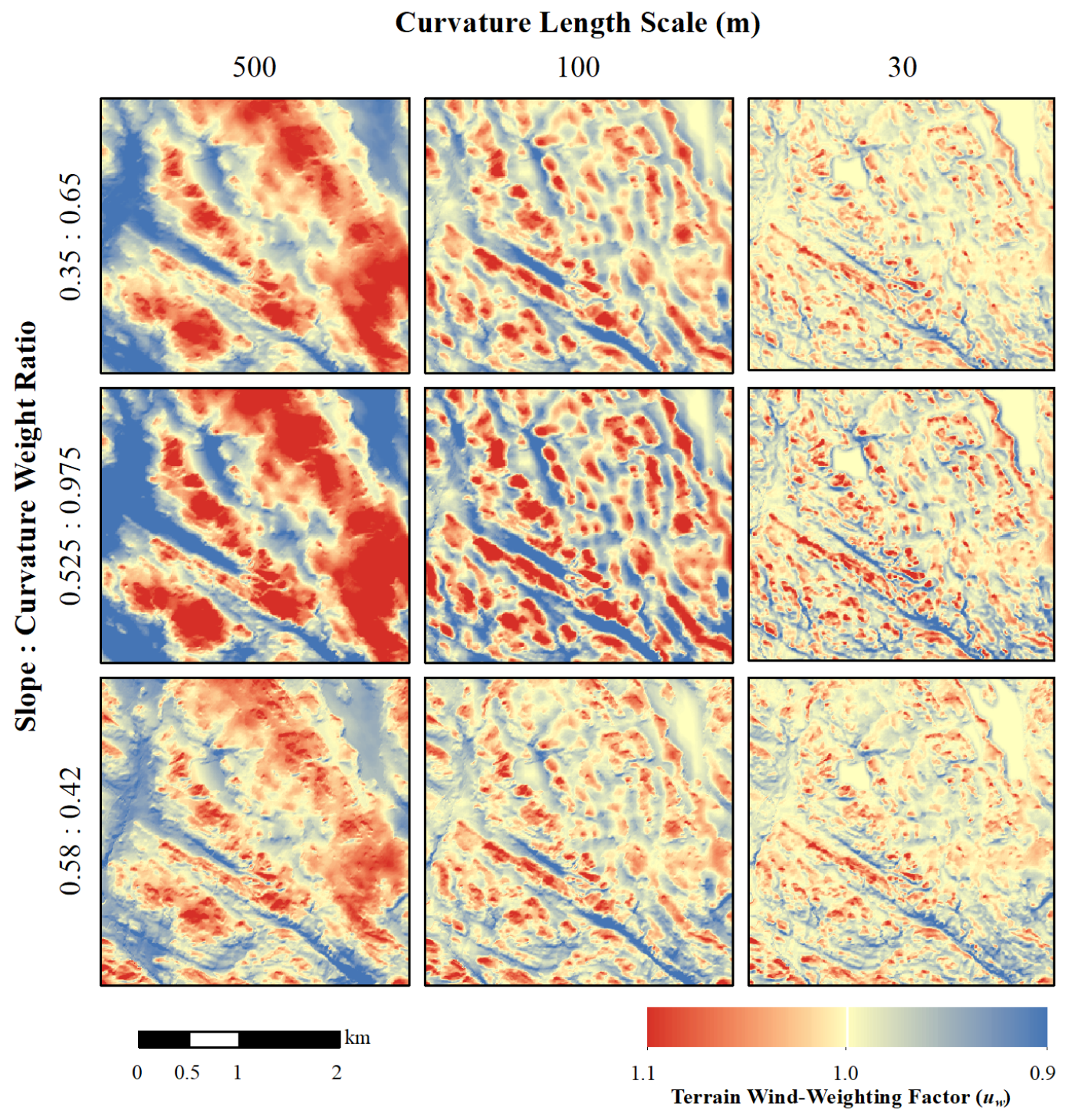

Figure 9: SnowModel's spatially-distributed wind-weighting factor at the Lake 1 subwatershed, calculated from multiple curvature length scales and slope/curvature weighting ratios assuming a $340^{\circ}$ (prevailing) wind direction. The colour ramp refers to the wind speed terrain weighting factor $\left(u_{w}\right)$. 
Second, SnowModel's snow erosion was tested by changing the SnowTran-3D deposition control parameter $B$ (Equation 23) from 0 to 1 . This keeps snow in transport until it reaches either (a) the domain's downwind edge, or (b) a location with low enough wind speeds for transport to cease. If this effect is large, SnowModel could be overestimating deposition. Liston et al. (2007) addressed this with a "subgrid parameterization" to move excess snow further downwind. However, every attempt to use their parameterization routine for this study resulted in a software crash, so the older $B$ parameter was used instead.

Third, for 2015, $u^{*}{ }_{t}$ was uncoupled from $\rho_{s}$ and set to a constant value of $0.135 \mathrm{~m}$

$\mathrm{s}^{-1}$, corresponding to $\rho_{s}=100 \mathrm{~kg} \mathrm{~m}^{-3}$ (i.e., fresh snowfall). This corresponds to a threshold transport wind speed of $2.63 \mathrm{~m} \mathrm{~s}^{-1}$, well below documented transport wind speeds. This test bypasses the density routine's role in snow transport altogether, so a large effect on the simulation suggests that this routine may be overestimating snow density in normal simulations. This would result in unrealistically high threshold wind speeds, limiting snow erosion and thus inflating SWE accumulation.

\subsubsection{SnowModel Evaluation}

To meet the overarching thesis objective of finding an optimal spring SWE model, SnowModel's simulated snow cover was evaluated for accuracy. The model was benchmarked against field observations of snow distribution patterns and quantitative survey measurements, with three indicators of model accuracy: (1) visual assessment of the SWE distribution patterns, (2) comparison of simulated and observed watershed SWE averages, and (3) point comparison between simulated and observed SWE. These performance indicators were also used during initial testing and SnowModel sensitivity 
analyses. If SnowModel's performance improved with a changed forcing or parameter value, the improved input was retained for the final SnowModel run.

Each indicator tests SnowModel in a different way. (1) Visual assessment is a qualitative comparison based on field experience and the physical principles of snow transport, and determines SnowModel's ability to reproduce observed patterns of erosion and deposition using the modeled wind field. (2) Watershed assessment is a quantitative comparison of survey and SnowModel mean SWE. SnowModel's simulated water balance was also compared to those in other studies, as errors in the magnitude of simulated mid-winter snow transport and ablation fluxes could account for inaccuracies in the simulated spring snow distribution. Finally, (3) point comparison is a quantitative comparison of SnowModel's simulated SWE to measured SWE at the same location, assessing the model's spatial accuracy and identifying biases in the simulated SWE. 


\section{Chapter: Results}

This chapter follows the order of the sub-objectives of this thesis. First, snow survey results are presented, with SWE data estimated from a linear relationship to snow depth. Second, the structure of two semi-distributed terrain models is described, and their modeled snow distributions are evaluated. Third, the parameter values for SnowModel are given, and the simulated fluxes and snow distribution are evaluated.

\subsection{Field Observations}

Extensive snow surveys were conducted in each study year, with 391 depth measurement sites in 2015 (152 of which included SWE measurement) and 192 sites in 2016 (all of which included SWE). Snow depth was highly variable, with between-sites standard deviations $75-95 \%$ the size of the mean. Density was less variable, with a standard deviation $22-24 \%$ of the mean. This justifies the high depth-to-density sampling ratio, especially given the longer sampling process for SWE (Appendix A). In each year, a linear regression model was fit between depth and SWE and used to estimate SWE for all sites. Detail on these models is given in Appendix C.

Table 2 gives measured depth and density and regression-modeled SWE. Snow depth was slightly greater in 2016 than 2015, whereas density was much greater. Measured SWE followed the same trend, with $16.6 \mathrm{~cm}$ in 2015 and $24.1 \mathrm{~cm}$ in 2016. Snow water equivalent is even more variable than depth, with a standard deviation within $1 \mathrm{~cm}$ the mean in both years. Depth samples outside the watershed boundary, or those that were spatially autocorrelated (see Appendix B) were removed, leaving 284 samples in 2015 and 192 in 2016. These samples were used to benchmark model performance in later sections. 
Strong wind during the 2015 winter eroded the shallow snow cover in exposed locations, and formed prominent sastrugi, which are peaked ridges aligned to the wind direction and formed by erosion of snowdrifts during windy conditions (AMS 2012). Snow density was strongly stratified with depth in the snowpack; high-density wind slab was observed near the surface, with low-density depth hoar below (see Chapter 2 for details of Arctic snow layers).

In 2016 late-winter storms and freezing-rain events formed heavy ice layers in the snow (see Appendix A). These layers increased the snow's surface cohesion, reducing erosion of deeper snow in exposed areas of the watershed. They also increased the time needed for sampling and caused equipment damage.

Table 2: Spring snow survey statistics, with SWE estimated from regression of depth data. Within-sites standard deviation of snow depth $\left(\sigma \mathrm{d}_{\text {within }}\right)$ is calculated from multiple depth measurements at each site, whereas between-sites standard deviation $\left(\sigma \mathrm{d}_{\text {between }}\right)$ is calculated from all site depth averages. Sample sizes for regression SWE are $n=284$ in 2015 and $n=192$ in 2016.

\begin{tabular}{|c|c|c|c|c|c|c|}
\hline Winter & $\begin{array}{c}n \\
\left(\mathbf{n}_{\text {SWE }}\right)\end{array}$ & $\begin{array}{c}\text { SWE }[ \pm \sigma] \\
(\mathbf{m m})\end{array}$ & $\begin{array}{c}\rho[ \pm \sigma] \\
\left(\mathrm{kg} \mathrm{m}^{3}\right)\end{array}$ & $\begin{array}{l}d_{\text {avg }} \\
(\mathrm{cm})\end{array}$ & $\begin{array}{c}\sigma d_{\text {within }} \\
\text { (cm) }\end{array}$ & $\begin{array}{c}\sigma d_{\text {between }} \\
\text { (cm) }\end{array}$ \\
\hline 2015 & $\begin{array}{c}391 \\
(152)\end{array}$ & 173 [139] & $336[75]$ & 52.3 & 19.4 & 39.1 \\
\hline 2016 & $\begin{array}{c}193 \\
(193)\end{array}$ & 242 [232] & 460 [109] & 57.2 & 12.0 & 54.4 \\
\hline
\end{tabular}




\subsection{Terrain Analysis}

\subsubsection{Cluster Analysis}

The terrain variables analysed were slope, longitudinal and tangential curvature, normalized height $(\mathrm{NH})$, and topographic openness $\left(\mathrm{O}_{+10 \mathrm{~K}}\right.$ and $\left.\mathrm{O}_{-10 \mathrm{~K}}\right)$. Four terrain units were identified by cluster analysis, representing Plateaus, Valley Floors, Midslopes, and Toeslopes. Plateaus possess high $\mathrm{NH}$, low slope, convex curvature, and high $O_{+10 \mathrm{~K}}$. Valley Floors have generally low $\mathrm{NH}$ and slope, concave curvature, and high $\mathrm{O}_{-10 K}$. Upper and middle slopes (Midslopes) possess moderately high $\mathrm{NH}$, strong slope, and convex. The fourth terrain unit represents strong curvatures, such as stream channels or Toeslopes at the base of hills, and is distinguished by moderate slope and strongly concave curvature.

These initial 4 units are discussed in Appendix F. Since wind drives the snow distribution, wind-exposed and wind-sheltered terrain were distinguished by dividing each unit in two according to the wind sheltering index $\left(W_{30}\right)$. The centroids for this 8TU model are presented in Table 3. 
Table 3: Terrain unit centroids (means) $\pm 1 \mathrm{SD}$. The terrain variables are normalized height $(N H)$, slope $(\beta)$, tangential and longitudinal curvature (CT and $C L$, respectively), topographic openness $\left(O_{+10 K}\right.$ and $\left.O_{-10 K}\right)$, and wind shelter index $\left(W_{30}\right)$.

\begin{tabular}{|c|c|c|c|c|c|c|c|c|}
\hline Terrain Unit & $\begin{array}{l}\text { Coverage } \\
\left(\mathbf{k m}^{2}\right)(\%)\end{array}$ & NH & $\begin{array}{c}\beta \\
\left({ }^{\circ}\right)\end{array}$ & $\begin{array}{c}C T \\
\left(\mathbf{m}^{-1}\right)\end{array}$ & $\begin{array}{c}C L \\
\left(\mathbf{m}^{-1}\right)\end{array}$ & $\begin{array}{c}O_{+10 K} \\
\left(^{\circ}\right)\end{array}$ & $\begin{array}{c}O_{-10 K} \\
\left(^{\circ}\right)\end{array}$ & $\begin{array}{l}W_{30} \\
\left({ }^{\circ}\right)\end{array}$ \\
\hline $\begin{array}{l}\text { Sheltered } \\
\text { Plateaus }\end{array}$ & $\begin{array}{c}12.8 \\
(24.4)\end{array}$ & $\begin{array}{c}0.71 \\
\pm 0.16\end{array}$ & $\begin{array}{c}5.6 \\
\pm 2.8\end{array}$ & $\begin{array}{l}1.3 \mathrm{E}^{-4} \\
\pm 7.8 \mathrm{E}^{-4}\end{array}$ & $\begin{array}{l}4.2 \mathrm{E}^{-4} \\
\pm 1.8 \mathrm{E}^{-3}\end{array}$ & $\begin{array}{c}87 \\
\pm 1.1\end{array}$ & $\begin{array}{c}85 \\
\pm 1.5\end{array}$ & $\begin{aligned} & 5.4 \mathrm{E}^{-2} \\
\pm & 4.0 \mathrm{E}^{-2}\end{aligned}$ \\
\hline $\begin{array}{l}\text { Exposed } \\
\text { Plateaus }\end{array}$ & $\begin{array}{c}6.2 \\
(11.9)\end{array}$ & $\begin{array}{c}0.73 \\
\pm 0.16\end{array}$ & $\begin{array}{c}5.3 \\
\pm 2.7\end{array}$ & $\begin{array}{l}4.1 \mathrm{E}^{-4} \\
\pm 8.9 \mathrm{E}^{-4}\end{array}$ & $\begin{array}{c}8.1 \mathrm{E}^{-4} \\
\pm 2.1 \mathrm{E}^{-3}\end{array}$ & $\begin{array}{c}87 \\
\pm 1.1\end{array}$ & $\begin{array}{c}85 \\
\pm 1.5\end{array}$ & $\begin{array}{l}-4.0 \mathrm{E}^{-2} \\
\pm 3.3 \mathrm{E}^{-2}\end{array}$ \\
\hline $\begin{array}{c}\text { Sheltered } \\
\text { Valley Floors }\end{array}$ & $\begin{array}{c}14.9 \\
(28.6)\end{array}$ & $\begin{array}{c}0.21 \\
\pm 0.13\end{array}$ & $\begin{array}{c}3.7 \\
\pm 2.5\end{array}$ & $\begin{array}{l}-1.3 \mathrm{E}^{-4} \\
\pm 7.6 \mathrm{E}^{-4}\end{array}$ & $\begin{array}{l}-5.4 \mathrm{E}^{-4} \\
\pm 2.1 \mathrm{E}^{-3}\end{array}$ & $\begin{array}{c}86 \\
\pm 1.2\end{array}$ & $\begin{array}{c}88 \\
\pm 1.1\end{array}$ & $\begin{aligned} & 4.4 \mathrm{E}^{-2} \\
\pm & 3.8 \mathrm{E}^{-2}\end{aligned}$ \\
\hline $\begin{array}{c}\text { Exposed } \\
\text { Valley Floors }\end{array}$ & $\begin{array}{c}7.6 \\
(14.4)\end{array}$ & $\begin{array}{c}0.17 \\
\pm 0.12\end{array}$ & $\begin{array}{c}2.5 \\
\pm 2.6\end{array}$ & $\begin{array}{l} \\
4.3 \mathrm{E}^{-5} \\
\pm 5.7 \mathrm{E}^{-4}\end{array}$ & $\begin{array}{l}-2.0 \mathrm{E}^{-4} \\
\pm 1.7 \mathrm{E}^{-3}\end{array}$ & $\begin{array}{c}86 \\
\pm 1.1\end{array}$ & $\begin{array}{c}88 \\
\pm 1.1\end{array}$ & $\begin{array}{l}-1.5 \mathrm{E}^{-2} \\
\pm 2.1 \mathrm{E}^{-2}\end{array}$ \\
\hline $\begin{array}{l}\text { Sheltered } \\
\text { Midslopes }\end{array}$ & $\begin{array}{c}3.3 \\
(6.4)\end{array}$ & $\begin{array}{c}0.58 \\
\pm 0.21\end{array}$ & $\begin{array}{c}15 \\
\pm 4.4\end{array}$ & $\begin{array}{c}6.8 \mathrm{E}^{-4} \\
\pm 1.5 \mathrm{E}^{-3}\end{array}$ & $\begin{array}{c}2.3 \mathrm{E}^{-3} \\
\pm 3.9 \mathrm{E}^{-3}\end{array}$ & $\begin{array}{c}84 \\
\pm 1.9\end{array}$ & $\begin{array}{c}82 \\
\pm 1.9\end{array}$ & $\begin{array}{l}1.0 \mathrm{E}^{-1} \\
\pm 7.3 \mathrm{E}^{-2}\end{array}$ \\
\hline $\begin{array}{l}\text { Exposed } \\
\text { Midslopes }\end{array}$ & $\begin{array}{c}2.2 \\
(4.2)\end{array}$ & $\begin{array}{c}0.64 \\
\pm 0.21\end{array}$ & $\begin{array}{c}14 \\
\pm 4.6\end{array}$ & $\begin{array}{l}1.2 \mathrm{E}^{-3} \\
\pm 1.8 \mathrm{E}^{-3}\end{array}$ & $\begin{aligned} & 2.9 \mathrm{E}^{-3} \\
\pm & 4.8 \mathrm{E}^{-3}\end{aligned}$ & $\begin{array}{c}84 \\
\pm 2.0\end{array}$ & $\begin{array}{c}81 \\
\pm 2.1\end{array}$ & $\begin{array}{l}-8.8 \mathrm{E}^{-2} \\
\pm 6.6 \mathrm{E}^{-2}\end{array}$ \\
\hline $\begin{array}{l}\text { Sheltered } \\
\text { Toeslopes }\end{array}$ & $\begin{array}{c}4.0 \\
(7.6)\end{array}$ & $\begin{array}{c}0.29 \\
\pm 0.19\end{array}$ & $\begin{array}{c}12 \\
\pm 4.5\end{array}$ & $\begin{array}{l}-8.2 \mathrm{E}^{-4} \\
\pm 1.7 \mathrm{E}^{-3}\end{array}$ & $\begin{array}{l}-4.1 \mathrm{E}^{-3} \\
\pm 5.0 \mathrm{E}^{-3}\end{array}$ & $\begin{array}{c}83 \\
\pm 2.0\end{array}$ & $\begin{array}{c}85 \\
\pm 1.9\end{array}$ & $\begin{array}{c}1.1 \mathrm{E}^{-1} \\
\pm 8.2 \mathrm{E}^{-2}\end{array}$ \\
\hline $\begin{array}{l}\text { Exposed } \\
\text { Toeslopes }\end{array}$ & $\begin{array}{c}1.3 \\
(2.5)\end{array}$ & $\begin{array}{c}0.33 \\
\pm 0.18\end{array}$ & $\begin{array}{c}12 \\
\pm 4.2\end{array}$ & $\begin{array}{l}-4.2 \mathrm{E}^{-4} \\
\pm 1.9 \mathrm{E}^{-3}\end{array}$ & $\begin{array}{l}-3.6 \mathrm{E}^{-3} \\
\pm 5.5 \mathrm{E}^{-3}\end{array}$ & $\begin{array}{c}83 \\
\pm 1.7\end{array}$ & $\begin{array}{c}84 \\
\pm 1.7\end{array}$ & $\begin{array}{l}-5.3 \mathrm{E}^{-2} \\
\pm 4.3 \mathrm{E}^{-2}\end{array}$ \\
\hline
\end{tabular}


The terrain unit model is shown at the Lake 1 subdomain (Figure 10). Lakes fall within Exposed Valley Floors. The positions of Sheltered Midslopes and Toeslopes correspond to the locations of large drifts in the field. Subdividing terrain units by wind exposure improves the representation of complex terrain, for example by differentiating windward/leeward slopes on hills and valleys in the southwest corner of the Lake 1 subdomain. However for rolling terrain, such as the northeast corner of the subdomain, sections of open fetch are unrealistically treated as different accumulation environments.

Snow accumulation differences by exposure were small for Plateaus and Valley Floors, but larger for Midslopes and Toeslopes (Table 4, Figure 11). Terrain unit SWE varied between years. In 2015, exposed units were shallower than their sheltered counterparts in all cases. In contrast, in 2016 Toeslopes showed almost no difference between exposures, whereas Midslopes accumulated greater SWE in exposed units than sheltered ones. In 2016 Plateaus and Valley Floors were strongly distinguished by wind exposure, with greater accumulations on sheltered units than in 2015.

Mean SWE differed strongly between exposed and sheltered slope classes in 2015 but barely differed in 2016. Kruskal-Wallis tests (Kruskal and Wallis, 1952) indicate significant differences in measured SWE between the 8TU terrain units in both years, with $\mathrm{K}-\mathrm{W} X^{2}=29.0$ and 42.8 in 2015 and 2016, respectively $(d f=7, p<0.05)$. Dunn's post-hoc test (Dunn 1964, 1961) indicates significant differences between Exposed Plateaus and Sheltered Valley Floors in $2015\left(z=-3.15, p=8.5 \times 10^{-4}\right)$. Results differed in 2016 with significant differences between Exposed Plateaus, Sheltered Valley Floors, and Sheltered Midslopes, between Exposed Valley Floors and Sheltered Midslopes, and between Sheltered Plateaus and Sheltered Midslopes. 

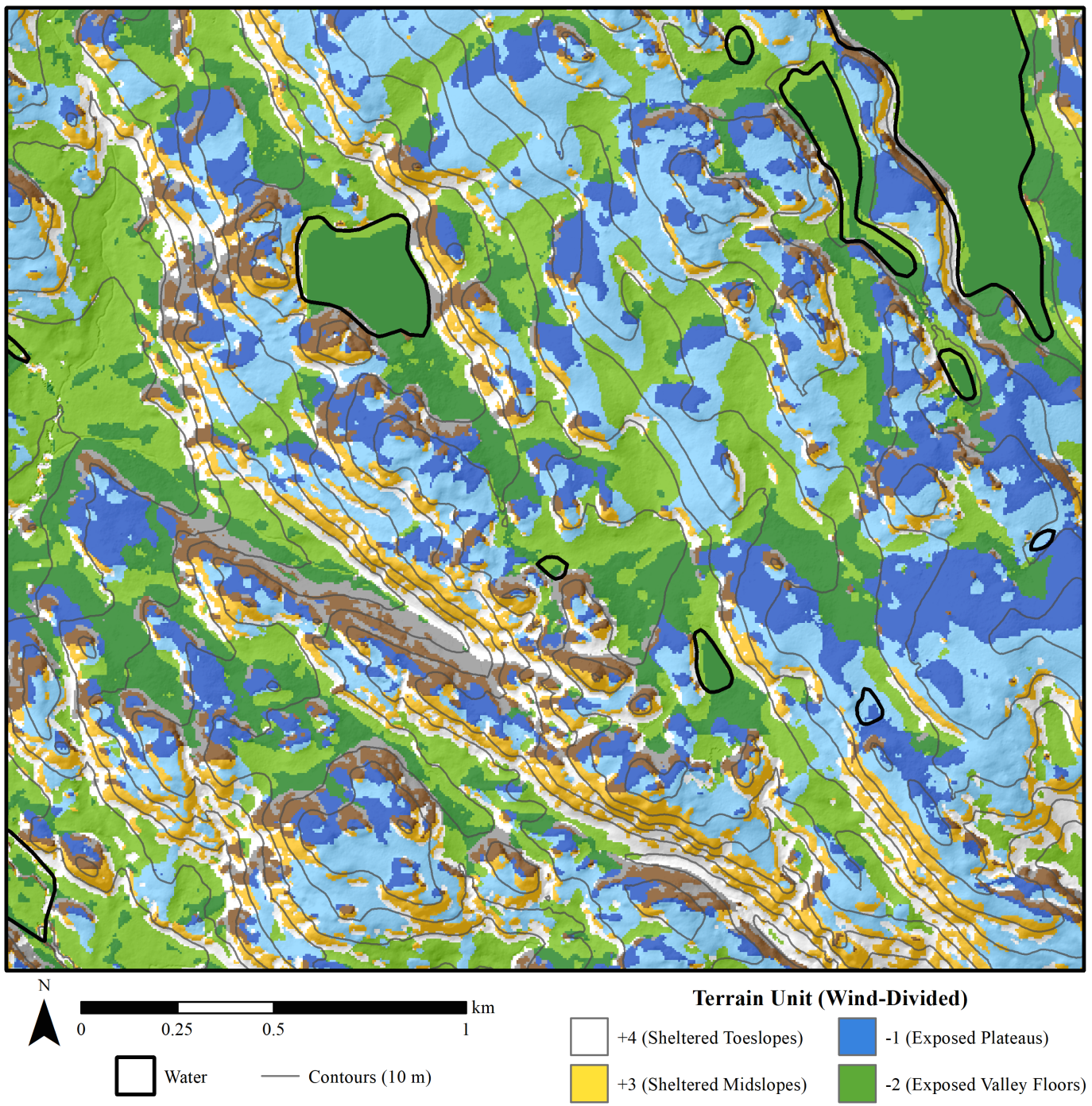

Terrain Unit (Wind-Divided)

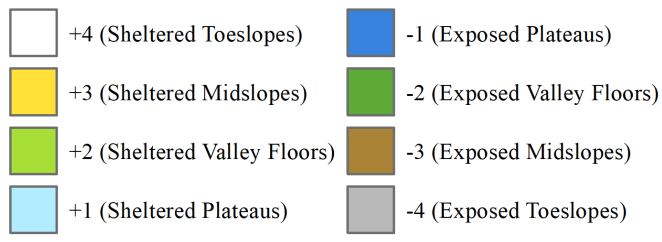

Figure 10: Terrain units defined by the 8TU model at the Lake 1 subdomain. 

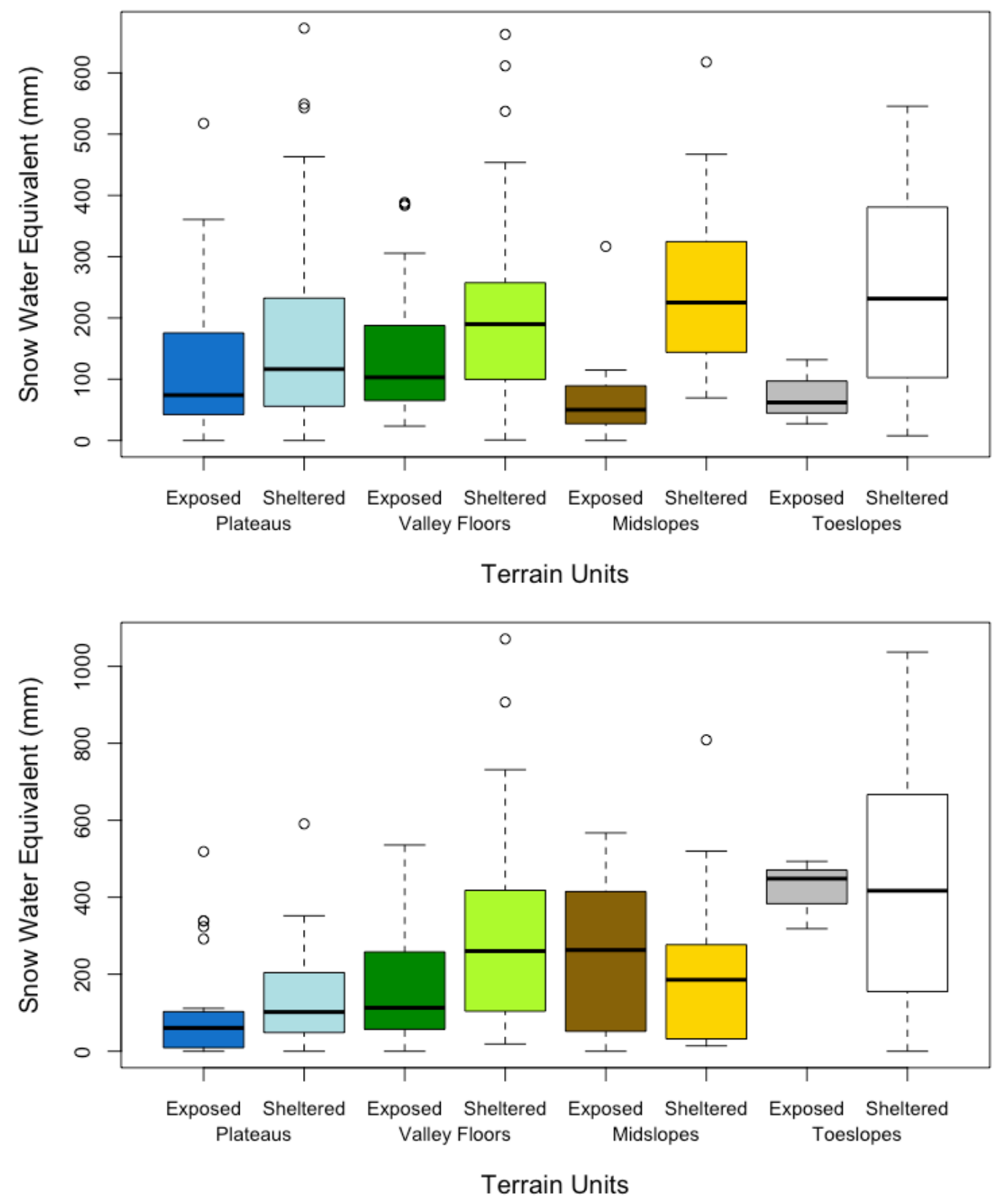

Figure 11: Measured SWE in 2015 (top) and 2016 (bottom) by terrain unit. Boxes show medians and upper/lower quartiles, with whiskers extending beyond quartiles by 1.5 interquartile ranges and outliers as hollow circles. Colours correspond to Figure 10. 
Table 4: Measured SWE partitioned by the 8TU terrain units derived from cluster analysis: sample size ( $\mathrm{n}$, with\% of total samples also indicated), mean, standard deviation (SD), and coefficient of variation (CV; SD divided by mean). Pooled mean and SD are averaged from the model classes, using the landscape areas of each class for weighting. Pooled CV is then calculated from the pooled mean and SD.

\begin{tabular}{|c|c|c|c|c|}
\hline TU & n (\%) & Mean SWE (mm) & $\mathrm{SD}(\mathbf{m m})$ & CV \\
\hline \multicolumn{5}{|c|}{2015} \\
\hline Exposed Plateaus & $27(10)$ & 128 & 127 & 0.99 \\
\hline Sheltered Plateaus & $77(27)$ & 164 & 148 & 0.90 \\
\hline Exposed Valley Floors & 54 (19) & 135 & 94 & 0.70 \\
\hline Sheltered Valley Floors & $89(31)$ & 205 & 137 & 0.67 \\
\hline Exposed Midslopes & $7(3)$ & 86 & 109 & 1.27 \\
\hline Sheltered Midslopes & $12(4)$ & 259 & 161 & 0.62 \\
\hline Exposed Toeslopes & $3(1)$ & 74 & 53 & 0.72 \\
\hline Sheltered Toeslopes & $15(5)$ & 247 & 185 & 0.75 \\
\hline Pooled & 284 & 147 & 117 & 0.80 \\
\hline \multicolumn{5}{|c|}{2016} \\
\hline Exposed Plateaus & $26(13)$ & 103 & 138 & 1.34 \\
\hline Sheltered Plateaus & $38(20)$ & 142 & 129 & 0.91 \\
\hline Exposed Valley Floors & $20(10)$ & 170 & 164 & 0.96 \\
\hline Sheltered Valley Floors & $64(33)$ & 293 & 222 & 0.76 \\
\hline Exposed Midslopes & $7(4)$ & 252 & 230 & 0.91 \\
\hline Sheltered Midslopes & $9(5)$ & 253 & 262 & 1.04 \\
\hline Exposed Toeslopes & $3(2)$ & 420 & 91 & 0.22 \\
\hline Sheltered Toeslopes & $25(13)$ & 448 & 316 & 0.71 \\
\hline Pooled & 192 & 204 & 168 & 0.82 \\
\hline
\end{tabular}




\subsubsection{Decision Rules}

The decision rules used to define snow accumulation classes are shown schematically in Figure 12. The resulting spatial distribution is shown at Lake 1 in Figure 13. The Tundra class dominates the landscape, covering $74 \%$ of the NRW (Table 5), covering multiple landform elements. The decision rules predominantly classify smooth terrain in the NW corner of the Lake 1 subdomain as Tundra. This overcomes the shortcoming in the 8TU model where low-relief areas are heavily subdivided according to landform characteristic, despite the fact that they constitute a single "open fetch" environment for snow redistribution processes. Due to its extensive coverage, the tundra class was the most heavily sampled in both years, though a greater proportion of samples were collected in the other classes in 2016 than 2015 (Table 6).

Generally, deep snow accumulation zones follow a similar spatial pattern between the decision rule (DR) Drift class and the 8TU model's deep snow classes, Sheltered Midslopes and Sheltered Toeslopes. Total coverage of the DR Drift class was $18.8 \%$, whereas coverage by Sheltered Midslopes and Sheltered Toeslopes together was $14.0 \%$. Some areas of the Toeslopes unit are represented in the DR Tundra class, since this terrain unit was defined by lower slopes and strong curvature, the latter of which is not accounted for by the DR model. 


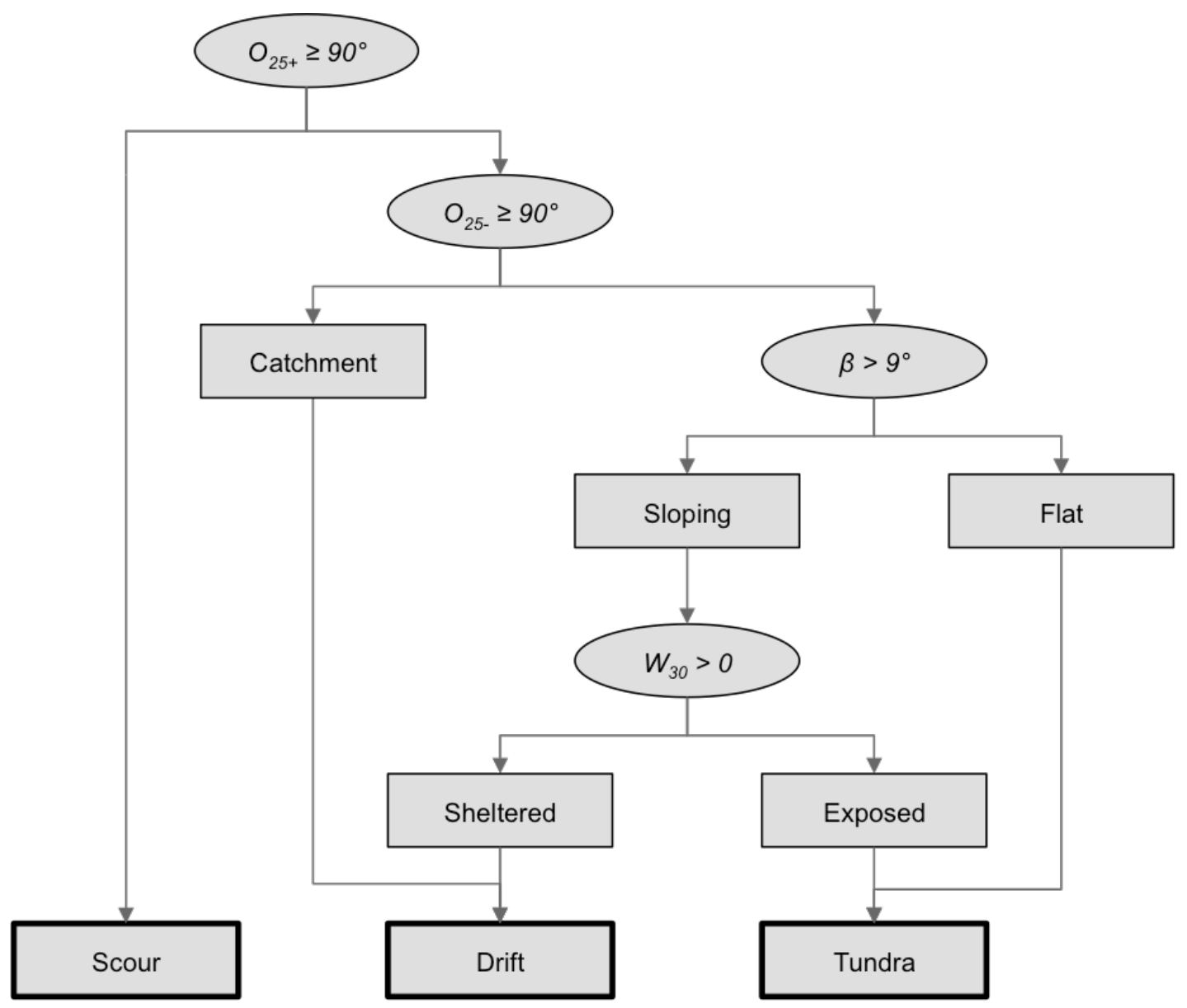

Figure 12: Decision rules for the DR model. Ellipses are conditional tests, with "true" results at left and "false" at right. The final snow accumulation classes are given with bold outlines. The variables are positive and negative openness in a $25 \mathrm{~m}$ radius $\left(\mathrm{O}_{25+}\right.$, $\left.\mathrm{O}_{25-}\right)$, slope $(\beta)$, and wind shelter index at $30 \mathrm{~m}\left(\mathrm{~W}_{30}\right)$.

Table 5: Spatial coverage of the DR snow accumulation classes

\begin{tabular}{lcc}
\hline & Coverage $\left(\mathbf{k m}^{\mathbf{2}}\right)$ & Coverage $\mathbf{( \% )}$ \\
\hline Drift & 9.8 & 18.8 \\
Tundra & 38.7 & 74.0 \\
Scour & 3.8 & 7.2 \\
Total & 52.3 & 100 \\
\hline
\end{tabular}




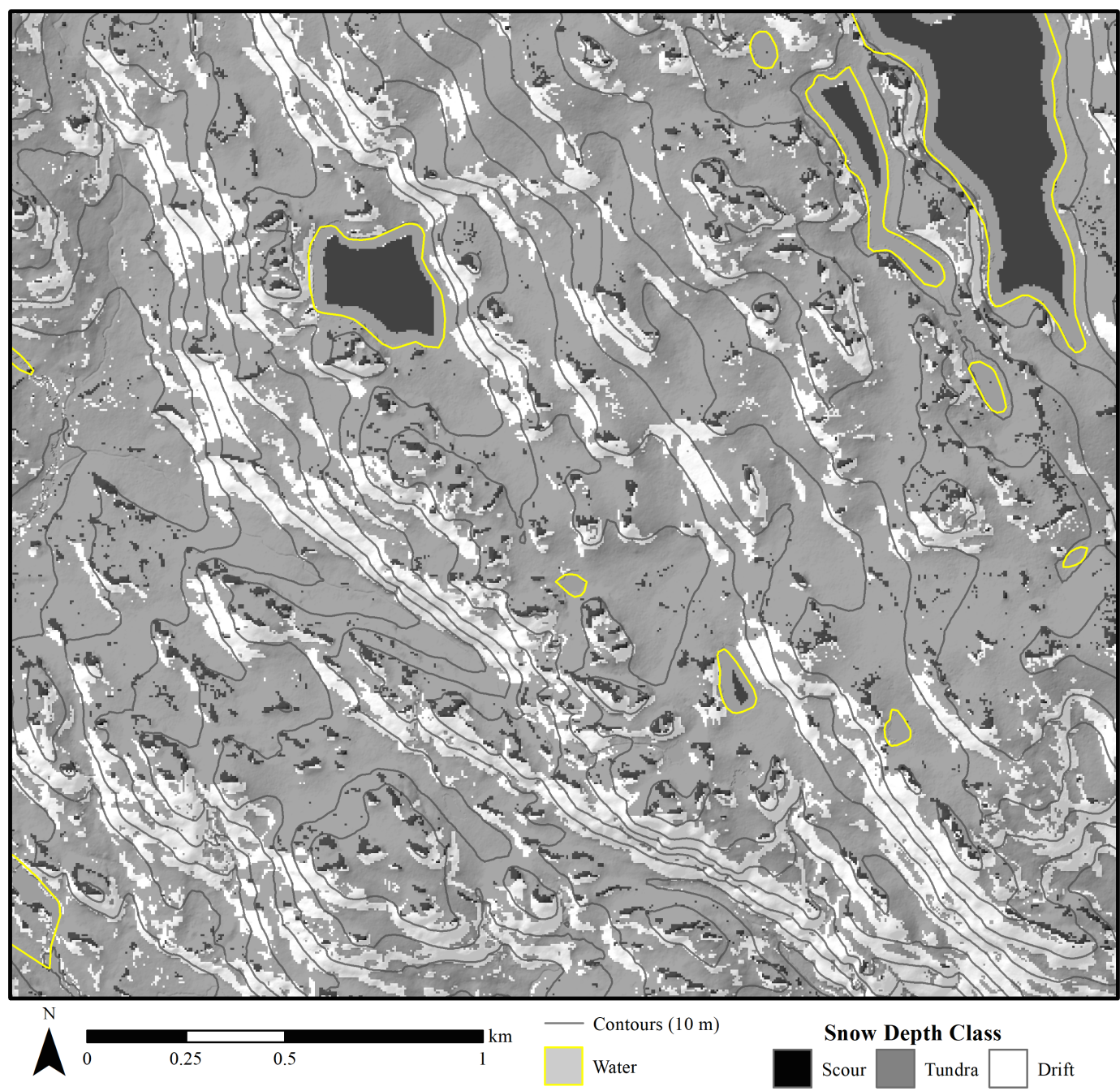

Figure 13: Decision rule snow accumulation classes at the Lake 1 subdomain.

Scour covers only $7.2 \%$ of the NRW, with the largest areas on the centers of large lakes. The remaining Scour locations are comprised of small, exposed hilltops or ridges, and the brows of large hills. The pattern of bare rock observed during spring surveys matches the mapped Scour pattern quite well, lending confidence to the definition of this class. 
The relative differences in median SWE accumulation among the DR classes are similar in 2015 and 2016 (Figure 14). Variability in SWE for the Drift and Tundra classes was similar in both years though the Drift class was more heavy-tailed in 2016; i.e., the deepest drifts were deeper. By contrast, the Scour class was much less variable in 2016 with fewer deep locations than in 2015 . This suggests that snow was more aggressively transported from Scour areas into Drift areas in 2016, which is supported by the higher wind speeds observed in that year.

In both years, the separation between DR classes was clearer than for the TU models. This is supported by the results from Kruskal-Wallis and Dunn's post-hoc tests (Appendix H), which indicated significant differences between all classes in both years with one exception: Scour was not significantly different from Tundra in 2015. This was likely due to the small sample sizes in the Scour class, and the greater variability in SWE within the class in 2015. These factors, and the conservative Bonferroni $p$-adjustment, reduce the power of Dunn's Test. The 2015 Scour class is clearly distinct, but its higher variability and large outliers suggest that this class is less robust in 2015. 

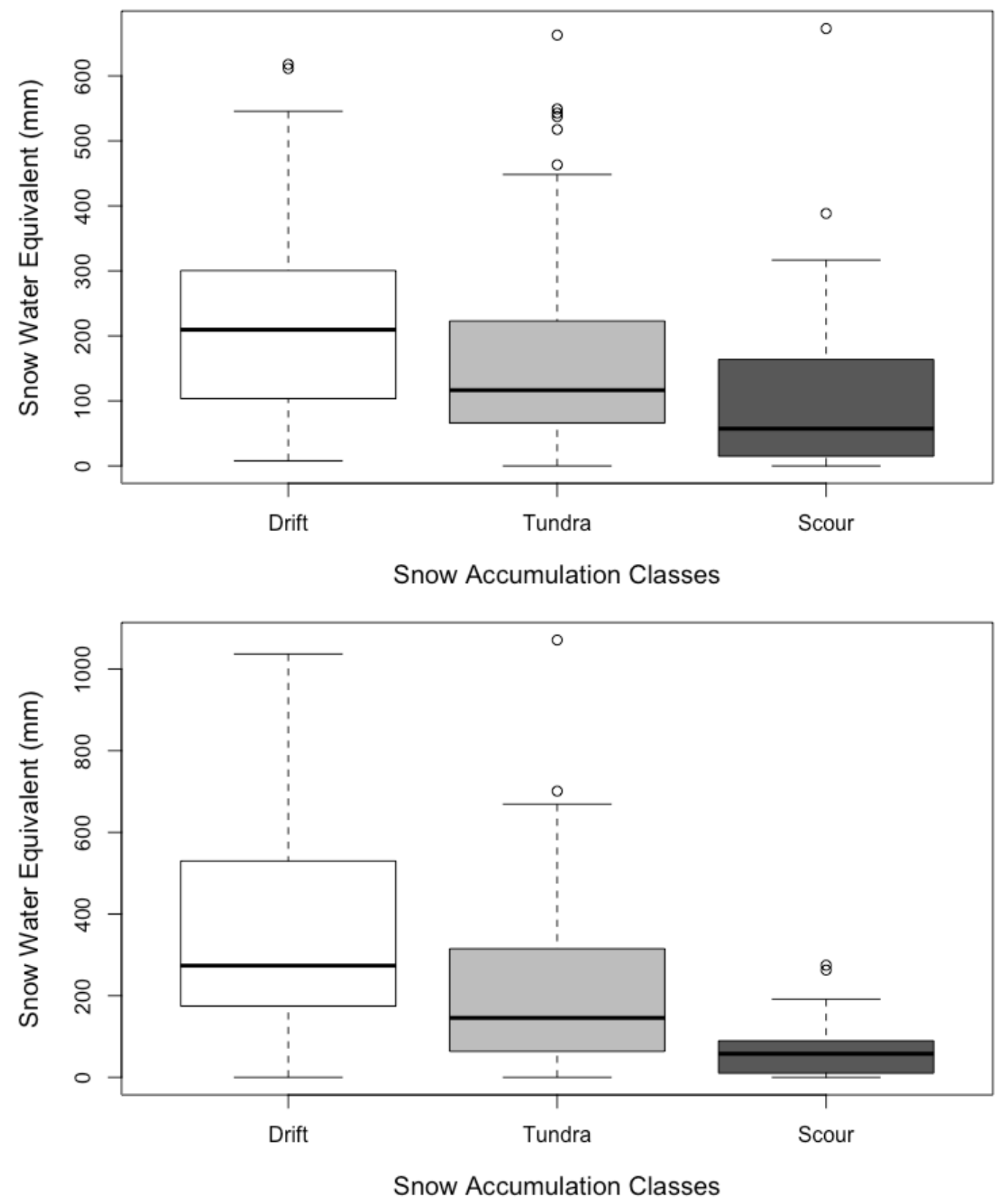

Figure 14: Measured SWE in 2015 (top) and 2016 (bottom) by DR snow accumulation class. Boxes show medians and quartiles, with whiskers extending beyond quartiles by 1.5 interquartile ranges, and outliers as hollow circles. Colours correspond to Figure 13. 
Table 6: Measured SWE partitioned by DR classes for both study years: sample size (n, with $\%$ of total samples also indicated), mean, standard deviation (SD), and coefficient of variation ( $\mathrm{CV}$; SD divided by mean). Pooled mean and SD are averaged from the model classes, using the landscape areas of each class for weighting. Pooled CV is then calculated from the pooled mean and SD.

\begin{tabular}{lcccc}
\hline DR Class & n (\%) & Mean SWE $(\mathbf{m m})$ & SD $(\mathbf{m m})$ & CV \\
\hline Drift & $79(28)$ & 218 & 146 & 0.67 \\
Tundra & $183(64)$ & 160 & 129 & 0.81 \\
Scour & $22(8)$ & 120 & 163 & 1.36 \\
Pooled & 284 & 168 & 135 & 0.80 \\
\hline \multicolumn{5}{c}{$\mathbf{2 0 1 5}$} \\
Drift & $59(31)$ & 357 & 274 & 0.77 \\
Tundra & $111(58)$ & 216 & 198 & 0.92 \\
Scour & $22(11)$ & 76 & 84 & 1.11 \\
Pooled & 192 & 232 & 204 & 0.88 \\
\hline
\end{tabular}

\subsubsection{Watershed SWE Estimates from Terrain Models}

The overarching objective of this thesis was to identify the best method for estimating spring SWE by comparing the results from each sub-objective. To do this, the unclassified survey mean SWE for the watershed was compared to the weighted mean SWE from each terrain model.

In both study years, the weighted mean from each model was less than the unweighted mean SWE, and within-class variances were larger in 2016 (Table 7), reducing confidence in the SWE estimates in that year. The DR model was closer to the unweighted mean than the $8 \mathrm{TU}$ model in both years. This model was also more stable; if ordered according to SWE accumulation, the DR classes would be ordered identically in 
both years. By comparison, the 8TU terrain units were not ordered consistently between the two years.

Both models had narrower $95 \%$ confidence intervals than the unweighted survey data, and $8 \mathrm{TU}$ had the best confidence of any method. Both models had narrower $95 \%$ confidence intervals than the unweighted survey data, and 8TU had the best confidence of any method. Increased confidence is not synonymous with improved accuracy, but indicates that the snow distribution's variability can be compartmentalized in a useful way. Stratified surveying with increased focus in more variable snow classes can give greater confidence in the result per unit investment of time and labour, without biasing the watershed mean (which would result from an unweighted mean of the same data).

Table 7: Comparison of watershed SWE estimates; unweighted survey mean and model class-weighted means. Model confidence intervals were calculated using pooled standard deviation and sample size.

\begin{tabular}{lccc}
\hline & $\mathbf{2 0 1 5}$ & $\mathbf{2 0 1 6}$ \\
\hline Unweighted Mean SWE $(\mathbf{m m}) \pm \mathbf{9 5 \%}$ CI & $173 \pm 16$ & $242 \pm 33$ \\
& $\mathbf{8 T U}$ & & $204 \pm 24$ \\
Weighted Mean SWE $(\mathbf{m m}) \pm \mathbf{9 5 \%}$ CI & $147 \pm 14$ & -38 \\
$\begin{array}{l}\text { Difference from Unweighted (mm) } \\
\text { DR }\end{array}$ & -26 & $232 \pm 29$ \\
$\begin{array}{l}\text { Weighted Mean SWE (mm) } \pm \mathbf{9 5 \%} \text { CI } \\
\text { Difference from Unweighted (mm) }\end{array}$ & $168 \pm 16$ & -10 \\
\hline
\end{tabular}




\subsection{SnowModel}

The accuracy of a SnowModel simulation was evaluated using the three performance indicators described in Section 3.4.5. The same metrics were also used to determine optimal parameter values during sensitivity analyses.

\subsubsection{Wind Field Parameters}

A 100 m curvature length scale $(\eta)$ was hypothesized based on field observation and the autocorrelation range in the survey data. A two-step procedure (described in Section 3.4.3) was used to test this choice. First, a range of curvature fields were compared to survey data, with a best-fit at $\eta=30 \mathrm{~m}\left(\mathrm{R}^{2}=0.13\right)$.

Second, wind fields with $\eta=30 \mathrm{~m}$ and a range of slope-curvature weighting ratios $\left(\gamma_{s}: \gamma_{c}\right)$ were compared to surveyed SWE data. The best-fit ratios were very different between the two years: 0.5:0.5 $\left(\mathrm{R}^{2}=0.19\right)$ in 2015 and 0.2:0.8 $\left(\mathrm{R}^{2}=0.33\right)$ in 2016 (Figure 15). This parameter is terrain based and theoretically should not vary between years, so a compromise ratio $(0.35: 0.65)$ was used for both simulations.

In addition to the objectively selected $\eta=30 \mathrm{~m}, \gamma_{\mathrm{s}}=0.35$, and $\gamma_{\mathrm{c}}=0.65$, additional simulations were run to test SnowModel's sensitivity to the wind-field parameters (Table 8, Table 9). To test whether snow transport could be increased without altering the relative weighting of slope and curvature, the compromise ratio was increased to $0.525: 0.975$. To test whether slope-curvature weighting ratios should be allowed to change between years, the best-fit ratio for each year was also tested. To test the validity of the shorter curvature length scale, all of the above were also run with $\eta=$ $100 \mathrm{~m}$. 


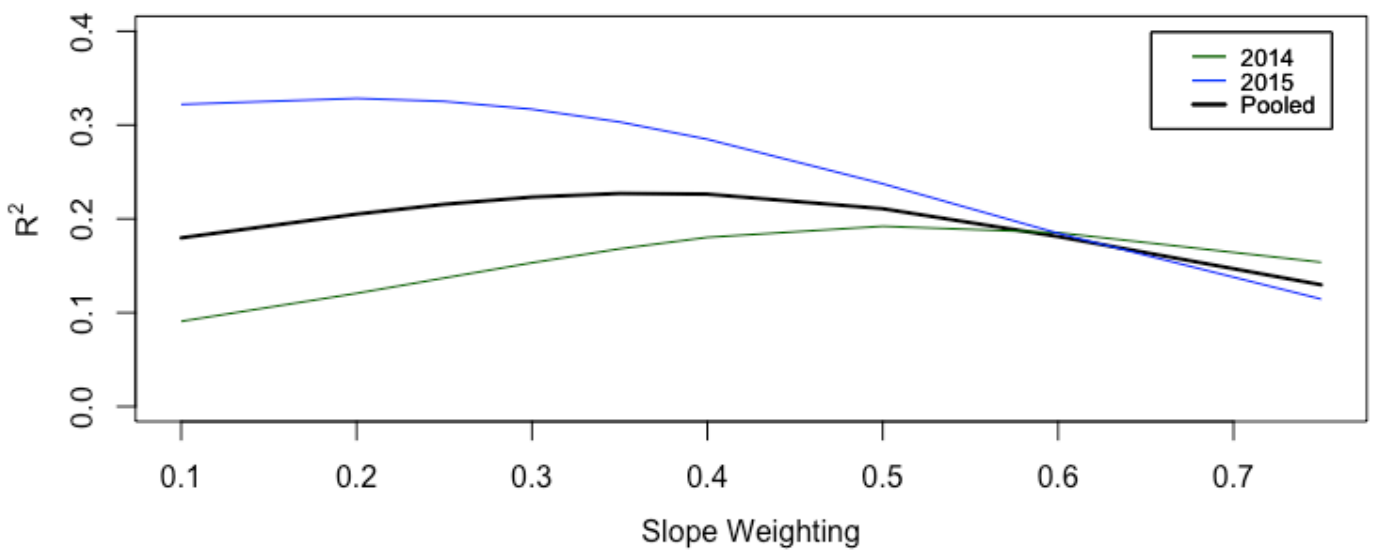

Figure 15: Fit $\left(\mathrm{R}^{2}\right)$ between surveyed SWE and the wind-speed modifier calculated from a range of slope-curvature weighting ratios. Wind fields were calculated with a constant curvature length scale $(\eta=30 \mathrm{~m})$ and wind direction $\left(340^{\circ}\right)$. 


\section{Curvature Length Scale}

100

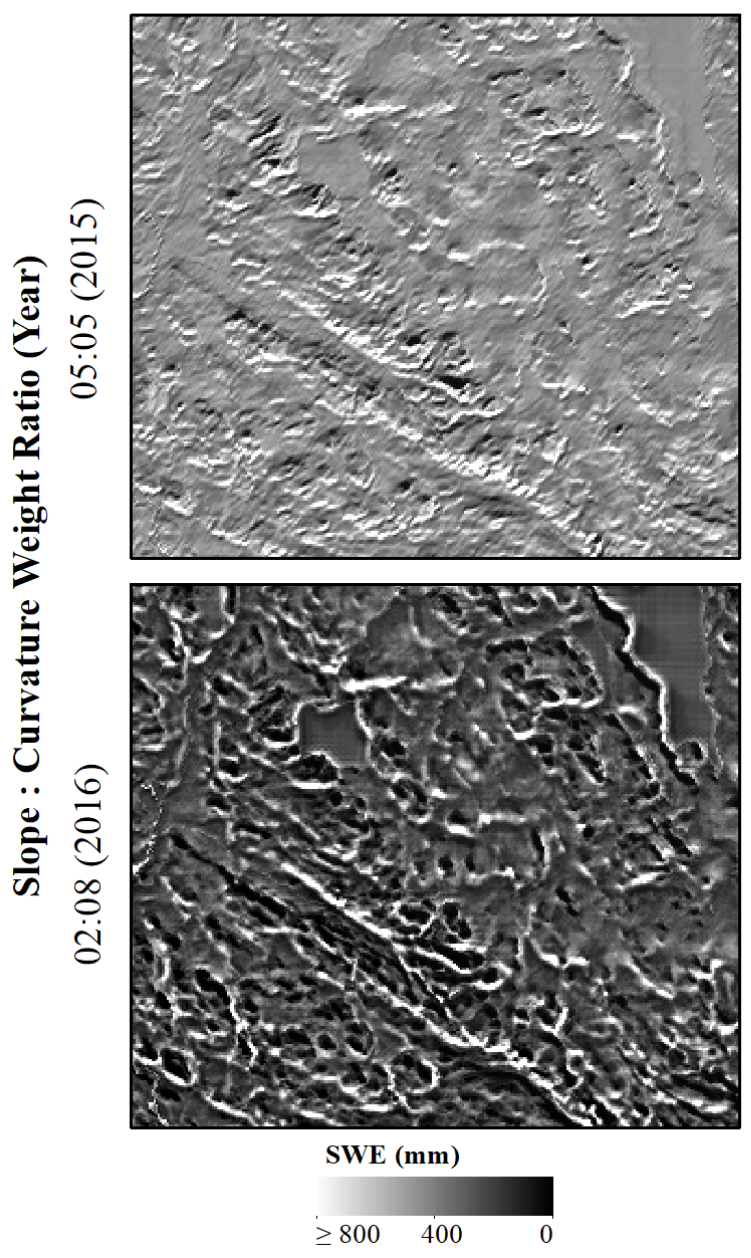

30
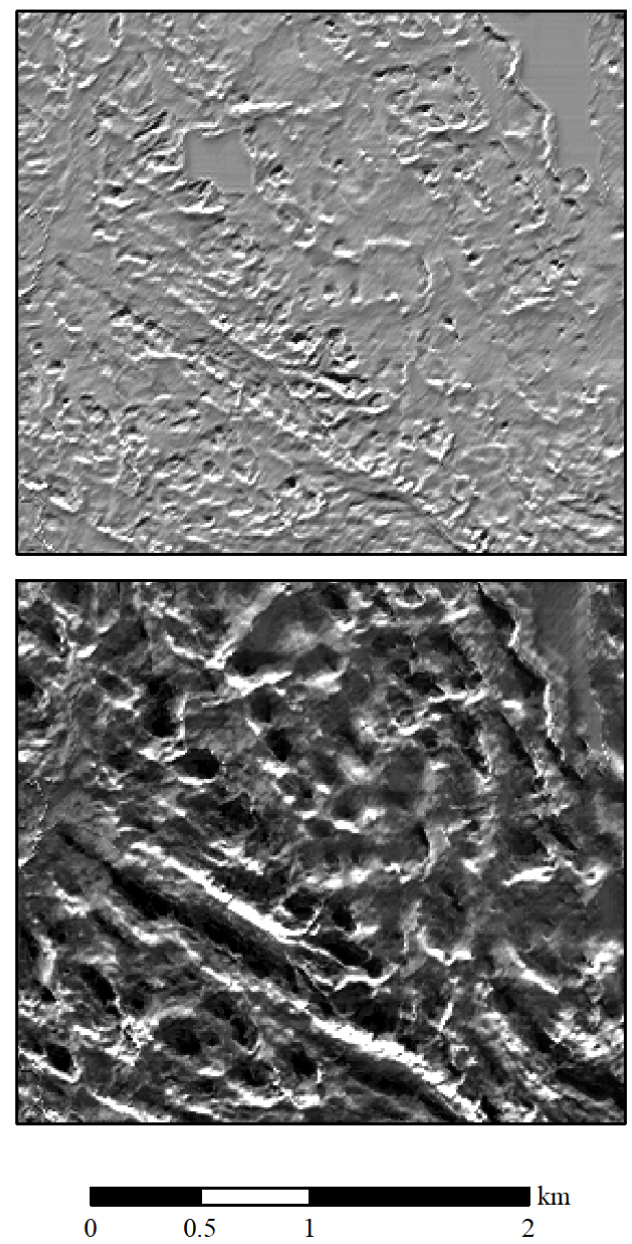

Figure 16: Wind field sensitivity analysis; SnowModel spring SWE maps for 2015 (top) and 2016 (bottom) simulated using each year's optimal wind-weighting ratios (rather than the "compromise" ratio used in the final simulations), and both of the tested curvature length scales. Compare these to spring SWE maps from the final simulations in Figure 19 (2015) and Figure 20 (2016). 
Table 8: Watershed averaged statistics for SnowModel EOW SWE from multiple wind-field configurations. Mean difference (MD) from survey data was determined for each year. The simulated EOW SWE as a fraction of total winter precipitation is given as “\% P".

The survey-measured \% P was $32 \%$ in 2015 and $62 \%$ in 2016.

\begin{tabular}{|c|c|c|c|c|c|c|c|c|c|c|c|}
\hline \multirow[b]{2}{*}{$\begin{array}{c}\eta \\
(\mathbf{m})\end{array}$} & \multirow[b]{2}{*}{$\gamma_{s}: \gamma_{c}$} & \multicolumn{3}{|c|}{ Depth (cm) } & \multicolumn{3}{|c|}{$\rho_{s}\left(\mathrm{~kg} \mathrm{~m}^{-3}\right)$} & \multicolumn{4}{|c|}{ SWE (mm) } \\
\hline & & $\begin{array}{c}\text { Mean } \\
\pm \text { SD }\end{array}$ & Range & $\begin{array}{l}\text { MD } \\
(\%)\end{array}$ & $\begin{array}{c}\text { Mean } \\
\pm \text { SD }\end{array}$ & Range & $\begin{array}{l}\text { MD } \\
(\%)\end{array}$ & $\begin{array}{c}\text { Mean } \\
\pm \text { SD }\end{array}$ & Range & $\begin{array}{l}\text { MD } \\
(\%)\end{array}$ & $\% \mathbf{P}_{\text {sim }}$ \\
\hline \multicolumn{12}{|c|}{2015} \\
\hline \multirow{3}{*}{30} & $0.5: 0.5$ & $129 \pm 28$ & $77-478$ & 147 & $353 \pm 13$ & $179-443$ & 5 & $460 \pm 118$ & $19-2116$ & 166 & 91 \\
\hline & $0.35: 0.65$ & $129 \pm 26$ & $75-460$ & 147 & $354 \pm 13$ & $195-444$ & 5 & $460 \pm 109$ & $18-2043$ & 166 & 92 \\
\hline & $0.525: 0.975$ & $130 \pm 25$ & $74-523$ & 148 & $354 \pm 12$ & $134-454$ & 5 & $462 \pm 107$ & $16-2368$ & 167 & 92 \\
\hline \multirow{3}{*}{100} & $0.5: 0.5$ & $129 \pm 28$ & $82-470$ & 147 & $353 \pm 14$ & $147-441$ & 5 & $461 \pm 120$ & $18-2065$ & 166 & 92 \\
\hline & $0.35: 0.65$ & $129 \pm 35$ & $67-454$ & 147 & $353 \pm 18$ & $148-440$ & 5 & $461 \pm 145$ & $17-1998$ & 167 & 92 \\
\hline & $0.525: 0.975$ & $130 \pm 35$ & $61-533$ & 148 & $353 \pm 19$ & $129-453$ & 5 & $463 \pm 149$ & $16-2398$ & 168 & 92 \\
\hline \multicolumn{12}{|c|}{2016} \\
\hline \multirow{3}{*}{30} & $0.2: 0.8$ & $79 \pm 49$ & $0-706$ & 37 & $366 \pm 40$ & $300-550$ & -20 & $285 \pm 200$ & $0-3396$ & 18 & 73 \\
\hline & $0.35: 0.65$ & $75 \pm 47$ & $0-691$ & 31 & $362 \pm 38$ & $295-550$ & -21 & $270 \pm 189$ & $0-3337$ & 11 & 69 \\
\hline & $0.525: 0.975$ & $77 \pm 55$ & $0-871$ & 34 & $365 \pm 42$ & $292-550$ & -21 & $280 \pm 225$ & $0-4338$ & 16 & 71 \\
\hline \multirow{3}{*}{100} & $0.2: 0.8$ & $75 \pm 46$ & $0-754$ & 31 & $368 \pm 44$ & $298-550$ & -20 & $270 \pm 183$ & $0-3664$ & 12 & 69 \\
\hline & $0.35: 0.65$ & $73 \pm 55$ & $0-876$ & 28 & $370 \pm 49$ & $303-550$ & -20 & $267 \pm 224$ & $0-4303$ & 10 & 69 \\
\hline & $0.525: 0.975$ & $75 \pm 67$ & $0-1202$ & 31 & $376 \pm 56$ & $294-550$ & -18 & $278 \pm 283$ & $0-6193$ & 15 & 72 \\
\hline \multicolumn{12}{|c|}{$2015\left(u_{t}^{*}=0.135\right)$} \\
\hline 30m & $0.35: 0.65$ & $129 \pm 28$ & $78-4700$ & 147 & $353 \pm 14$ & $182-445$ & 5 & $459 \pm 117$ & $18-2093$ & 166 & 91 \\
\hline
\end{tabular}


Table 9: Statistics from point comparison of survey (observed) and SnowModel (predicted) spring SWE over the multiple wind-field configurations. Columns refer to the root-mean square difference (RMSD), mean difference (MD) and coefficient of determination $\left(\mathrm{R}^{2}\right)$ between survey and SnowModel SWE.

\begin{tabular}{|c|c|c|c|c|c|c|}
\hline$\eta$ & $\gamma_{s}: \gamma_{c}$ & $\begin{array}{c}\text { Survey } \\
\text { SWE (mm) }\end{array}$ & $\begin{array}{l}\text { SnowModel } \\
\text { SWE (mm) }\end{array}$ & $\begin{array}{c}\text { RMSD } \\
(\mathrm{mm})\end{array}$ & $\begin{array}{c}\text { MD } \\
(\mathbf{m m})\end{array}$ & $\mathbf{R}^{2}$ \\
\hline \multicolumn{7}{|c|}{2015} \\
\hline & $0.5: 0.5$ & 173 & 465 & 333 & 292 & 0.02 \\
\hline \multirow[t]{3}{*}{30} & $0.35: 0.65 *$ & 173 & 466 & 331 & 293 & 0.06 \\
\hline & $0.525: 0.975$ & 173 & 467 & 310 & 294 & 0.07 \\
\hline & $0.5: 0.5$ & 173 & 464 & 337 & 291 & 0.02 \\
\hline \multirow[t]{4}{*}{100} & $0.35: 0.65$ & 173 & 463 & 327 & 289 & 0.05 \\
\hline & $0.525: 0.975$ & 173 & 465 & 338 & 292 & 0.06 \\
\hline & \multicolumn{6}{|c|}{$\begin{array}{r}405 \\
2016\end{array}$} \\
\hline & $0.2: 0.8$ & 242 & 306 & 243 & 64 & 0.26 \\
\hline \multirow[t]{3}{*}{30} & 0.35:0.65 * & 242 & 276 & 237 & 34 & 0.22 \\
\hline & $0.525: 0.975$ & 242 & 281 & 262 & 38 & 0.25 \\
\hline & $0.2: 0.8$ & 242 & 283 & 218 & 41 & 0.29 \\
\hline \multirow[t]{2}{*}{100} & 0.35:0.65 & 242 & 293 & 313 & 51 & 0.02 \\
\hline & $0.525: 0.975$ & 242 & 319 & 365 & 76 & 0.14 \\
\hline \multicolumn{7}{|c|}{$2015\left[u *_{t}=0.135\right]$} \\
\hline 30 & $0.35: 0.65$ & 173 & 464 & 337 & 291 & 0.05 \\
\hline
\end{tabular}

Visual assessment determined that SnowModel's spring snow pattern matches that observed in the field - shallow snow in exposed locations and drifted snow in sheltered areas (concavities and leeward slopes). However SnowModel underestimated the difference between these areas. For example, the model predicted shallow snow cover in many areas that were scoured to bare rock in the field. This problem was more severe for the 2015 simulation. 

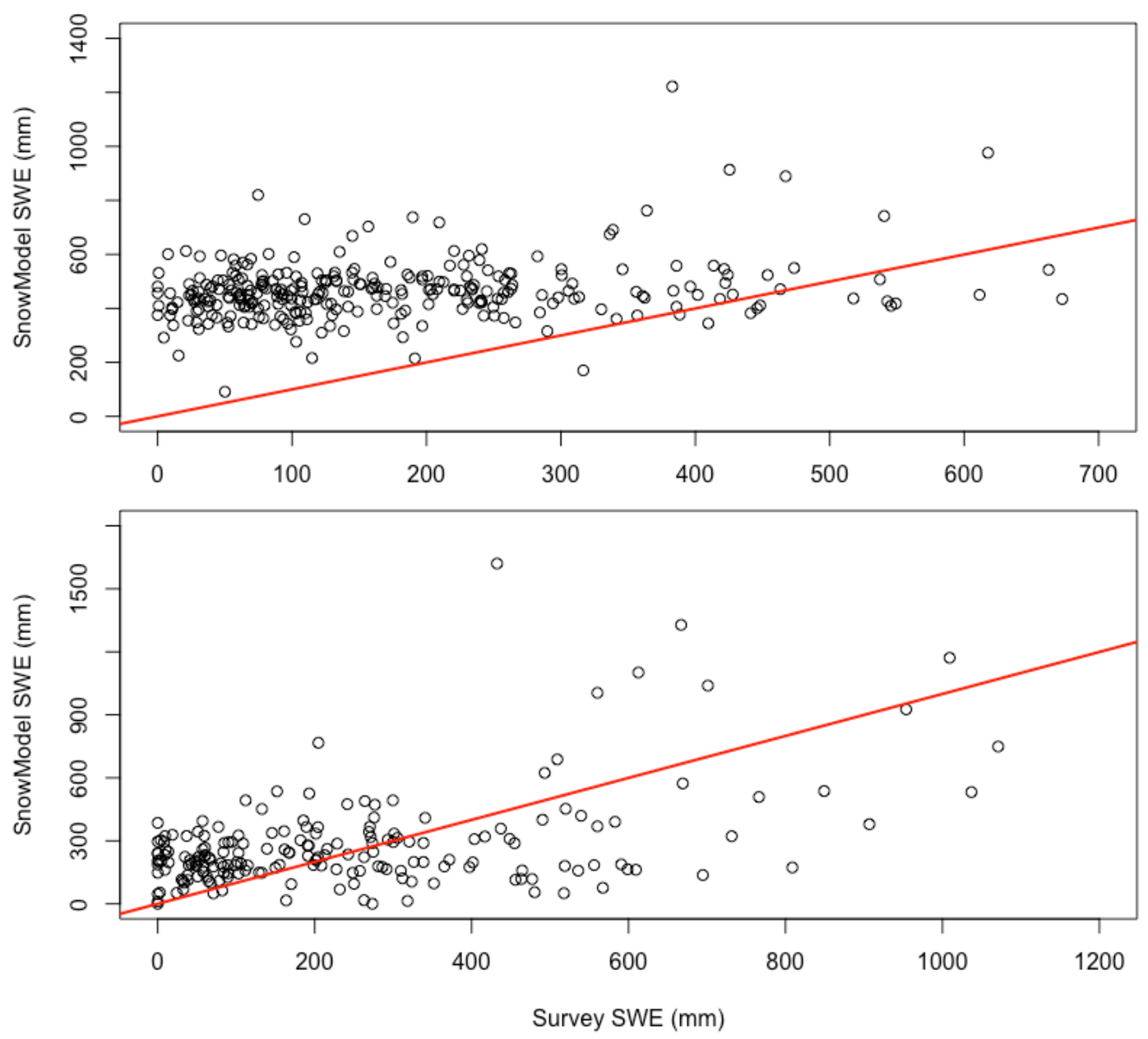

Figure 17: SnowModel spring SWE for 2015 (above) and 2016 (below) compared against surveyed SWE. The 1:1 line is shown in red.

This is supported by point comparisons, which demonstrate overestimation of shallow snow and underestimation of deep snow. This is evident in the flat relationship between predictions and observations in Figure 17. Again, poorer performance is evident in 2015. Table 9 shows that the difference between the 2015 SnowModel and survey SWE estimates was so large that it exceeded the survey SWE estimate, with poor fit 
exemplified by $\mathrm{R}^{2}$ less than 0.1 . By comparison, the 2016 simulations had much smaller differences and $\mathrm{R}^{2}$ as high as 0.29 .

When comparing watershed averages (Table 8), SnowModel overestimated all variables in $2015 ; 92 \%$ of the total $\mathrm{P}_{\mathrm{DFAR}}$ remained on the ground in spring, in contrast to the survey estimate of $32 \%$. This and the small variability in simulated SWE (SD $=109$ $149 \mathrm{~mm}$; Table 8) relative to those observed in the field (Table 2) suggest that SnowModel underestimated wind transport in 2015. The 2016 simulations were more reasonable, as they overestimated SWE by only $10-18 \%$, resulting from cancelation of snow depth overestimation by $28-37 \%$ and density underestimation by $18-21 \%$. SWE variability was higher, much closer to the observed variability.

The wind field parameters had limited effect on the simulated spring snow, especially in 2015. Choice of curvature length scale was a tradeoff; $\eta=100 \mathrm{~m}$ improved the spatial patterns of large drifts, whereas $\eta=30 \mathrm{~m}$ improvde small-scale patterns of erosion and deposition. Whole-watershed estimates from simulations with $\eta=30 \mathrm{~m}$ had larger MD (Table 8), and less variable SWE . Furthermore, point comparison (Table 9) showed that $\eta=30 \mathrm{~m}$ resulted in a higher spatial accuracy (lower MD and RMSD, higher $\mathrm{R}^{2}$ ) than $\eta=100 \mathrm{~m}$ in all but one case.

For the slope-curvature weighting ratio, higher curvature weighting resulted in larger drifts in channels and toeslopes, but reduced the importance leeward hillslope drifts. Both drift types occur in the study area, suggesting that the "compromise" ratio $(0.35: 0.65)$ is more accurate. This is supported by the watershed average SWE from runs with this ratio, which were the most similar to the survey average (Table 8), and were associated with low MD and RMSD, and high $\mathrm{R}^{2}$ (Table 9). 
Allowing the slope-curvature weighting ratio to exceed one generated a more variable wind field and thus more snow transport, apparent from the greater variability in SWE across the watershed (Table 8). This configuration had high $\mathrm{R}^{2}$ (Table 9), but high RMSD in 2016; transport was increased at the cost of spatial accuracy.

No single configuration of wind field parameters improved SnowModel's spring SWE estimate under all performance indicators for both years. However, this evidence suggests that the best overall performance was by simulations with $\eta=30 \mathrm{~m}$ and $\gamma_{s}: \gamma_{c}=$ 0.35:0.65. The final user-modified SnowModel parameters are given in Table 10 .

Table 10: All modified SnowModel parameter values used in the final simulations.

\begin{tabular}{lc}
\hline SnowModel Parameter & Value \\
\hline Grid Spacing $(\mathrm{m})$ & 10 \\
Domain Size $(x, y)$ & {$[1265,1820]$} \\
Timestep $(\mathrm{s})$ & 3600 \\
$\eta(\mathrm{m})$ & 30 \\
$\gamma_{\mathrm{s}}$ & 0.35 \\
$\gamma_{\mathrm{c}}$ & 0.65 \\
Precipitation Adjustment Factor & 0 \\
Upwind Boundary Condition & Equilibrium flux \\
Snow-Holding Capacity $(\mathrm{m})$ & 0.05 (tundra) \\
\end{tabular}

\subsubsection{SnowPack Density Evolution}

With only spring density measurements, it is difficult to accurately assess the snow density evolution simulated by SnowModel. The expected general trend of densification throughout the winter was successfully simulated (Figure 18), though the evolution is highly variable as new snow reduces the bulk density with each precipitation event. 


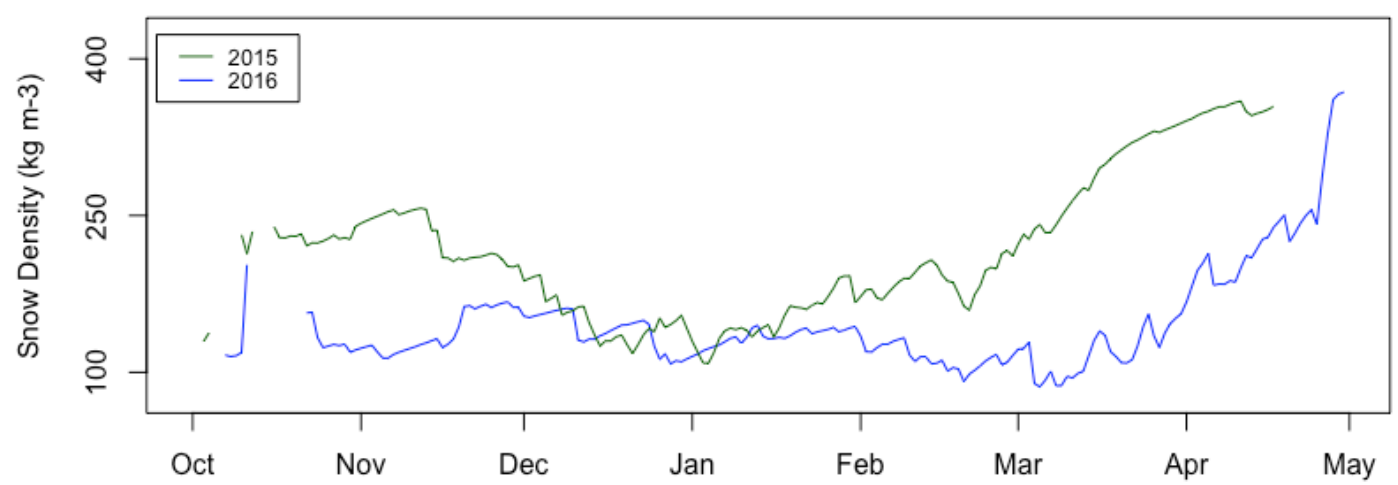

Figure 18: SnowModel domain-averaged daily snow density over both study years. Gaps occur wherever one or more pixels were snow-free during the day.

For most of the 2015 simulation, snow density exceeded $200 \mathrm{~kg} \mathrm{~m}^{-3}$, with a spring density of $354 \mathrm{~kg} \mathrm{~m}^{-3}$ (Figure 18), which corresponded well to the observed spring density of $336 \mathrm{~kg} \mathrm{~m}^{-3}$. Point comparison to survey data indicated that spatial variability in density was poorly represented, with an RMSD of $76 \mathrm{~kg} \mathrm{~m}^{-3}$.

In 2016, density remained low until air temperatures rose above $0{ }^{\circ} \mathrm{C}$ in late April. For most of the winter, the simulated snowpack density was below $200 \mathrm{~kg} \mathrm{~m}^{-3}$. The simulated 2016 spring density was simulated at $362 \mathrm{~kg} \mathrm{~m}^{-3}$, a substantial underestimate from the measured value of $460 \mathrm{~kg} \mathrm{~m}^{-3}$. Spatial variability in the simulated density was greater and the locational accuracy of simulated snow density was poor, with an RMSD of $152 \mathrm{~kg} \mathrm{~m}^{-3}$.

The effect of decoupling snowpack density evolution was from $u_{*}$, and setting $u_{*}$ $=0.135 \mathrm{~m} \mathrm{~s}^{-1}$ was negligible. The variability in watershed spring SWE was slightly higher than the equivalent density- $u *_{t}$ coupled run (Table 8 ), indicating slightly higher overall transport rates. However the fit to survey data was worse (Table 9), indicating that the small increase in observed snow erosion did not occur at the correct locations. 


\subsubsection{Snow Transport and Water Balance}

The selected wind field parameters were used to generate final snow distributions (Figure 19 - Figure 21), and time series of snow accumulation, transport and ablation (Figure 22, Figure 23). The water balance (Table 11) was dominated by sublimation, with blowing snow sublimation providing the single largest flux in both years. In 2015, in-situ sublimation was a larger fraction of the total sublimation flux (37\%, as opposed to $27 \%$ in 2016).

In both years, net transport was out of the domain. Only $8 \mathrm{~mm}$ SWE were transported out of the domain in 2015, but $54.3 \mathrm{~mm}$ were transported out in 2016. Melt was negligible in both years, mainly occurring during warm periods in the fall of 2014 and spring of 2016. In 2015, the blowing snow sublimation flux exceeded all other fluxes combined, whereas in 2016, it was of comparable magnitude to domain export, with a moderate contribution by in-situ sublimation.

Table 11: SnowModel water balance fluxes by year (all in mm water equivalent). Water balance elements are defined in Equation 20; $\mathrm{P}=$ precipitation, $\mathrm{Q}_{\mathrm{s}}=$ saltation transport, $\mathrm{Q}_{\mathrm{t}}=$ suspension transport, $\mathrm{Q}_{\mathrm{vs}}=$ in-situ sublimation, $\mathrm{Q}_{\mathrm{vb}}=$ blowing snow sublimation, $\mathrm{M}$ $=$ melt, $\mathrm{SWE}=$ snow water equivalent on the ground by end of simulation.

\begin{tabular}{cccccccc}
\hline & $\mathrm{P}$ & $\mathrm{Q}_{\mathrm{s}}$ & $\mathrm{Q}_{\mathrm{t}}$ & $\mathrm{Q}_{\mathrm{vs}}$ & $\mathrm{Q}_{\mathrm{vb}}$ & $\mathrm{M}$ & $\mathrm{SWE}$ \\
\hline 2015 & 502.6 & -5.5 & -2.5 & -9.2 & -24.9 & -2.0 & 458.5 \\
2016 & 389.2 & -23.1 & -31.1 & -14.8 & -54.1 & -1.9 & 264.2 \\
\hline
\end{tabular}




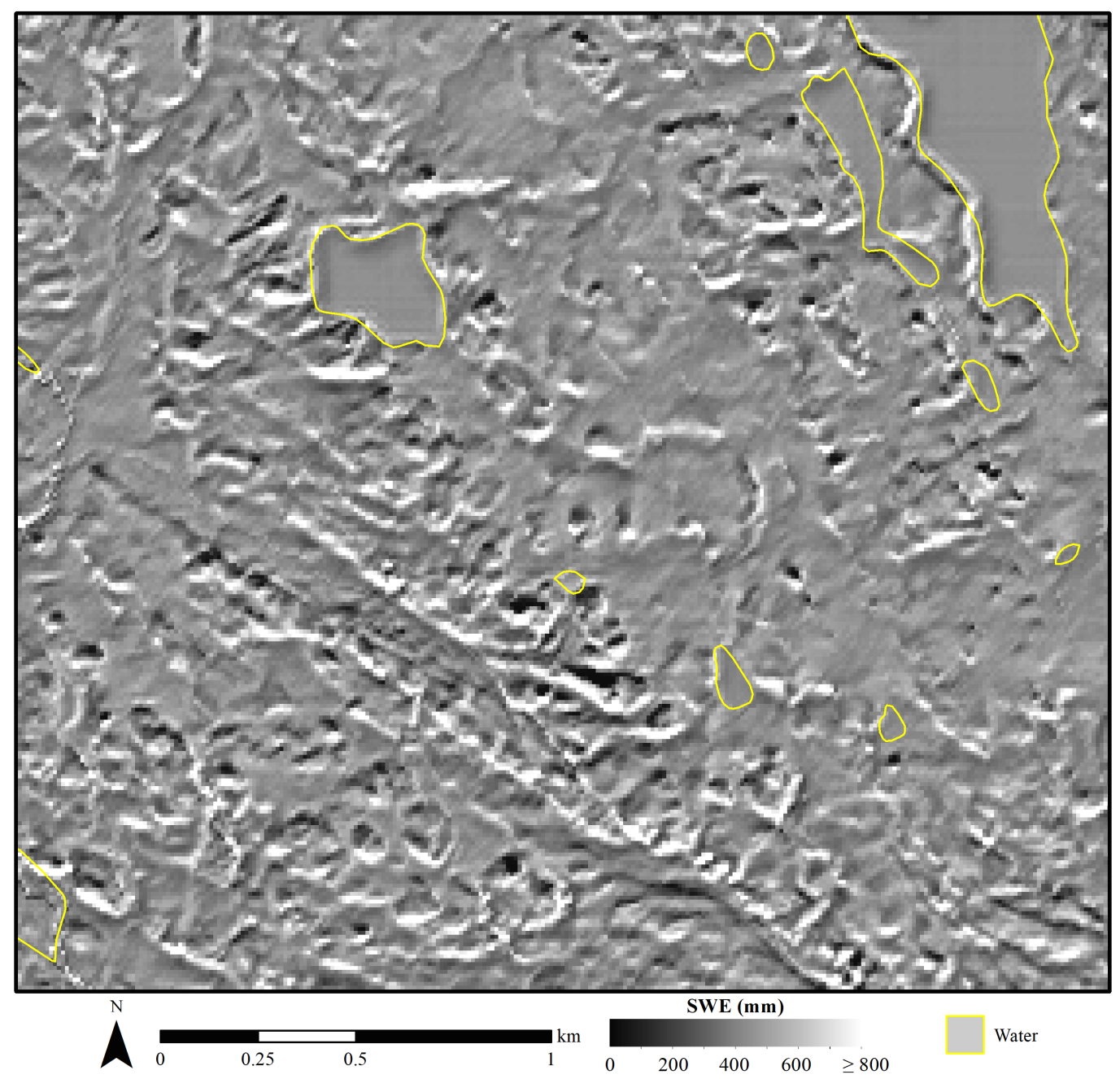

Figure 19: Detail of the 2015 SnowModel spring SWE map at the Lake 1 subdomain 


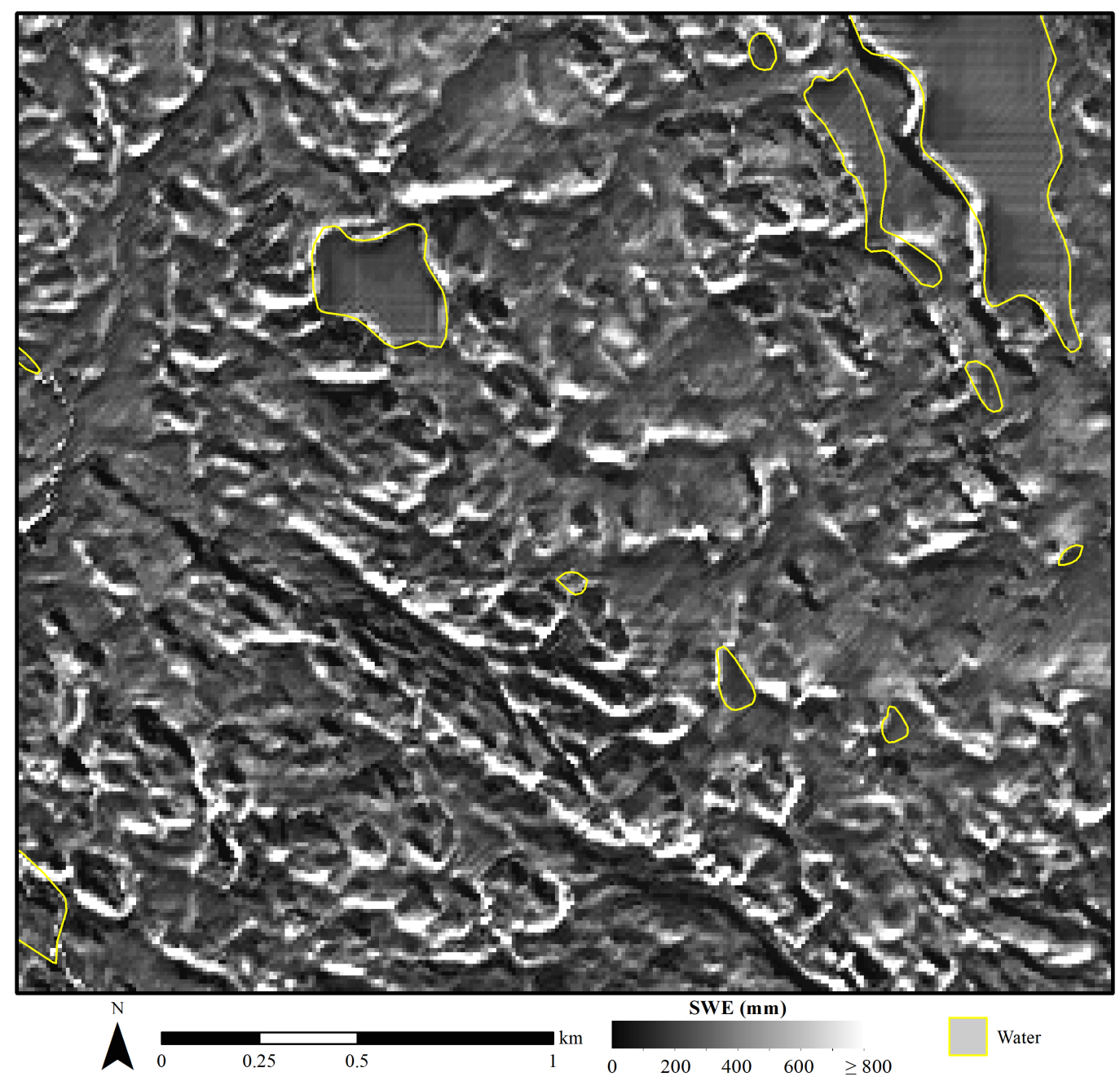

Figure 20: Detail of the 2016 SnowModel spring SWE map at the Lake 1 subdomain 

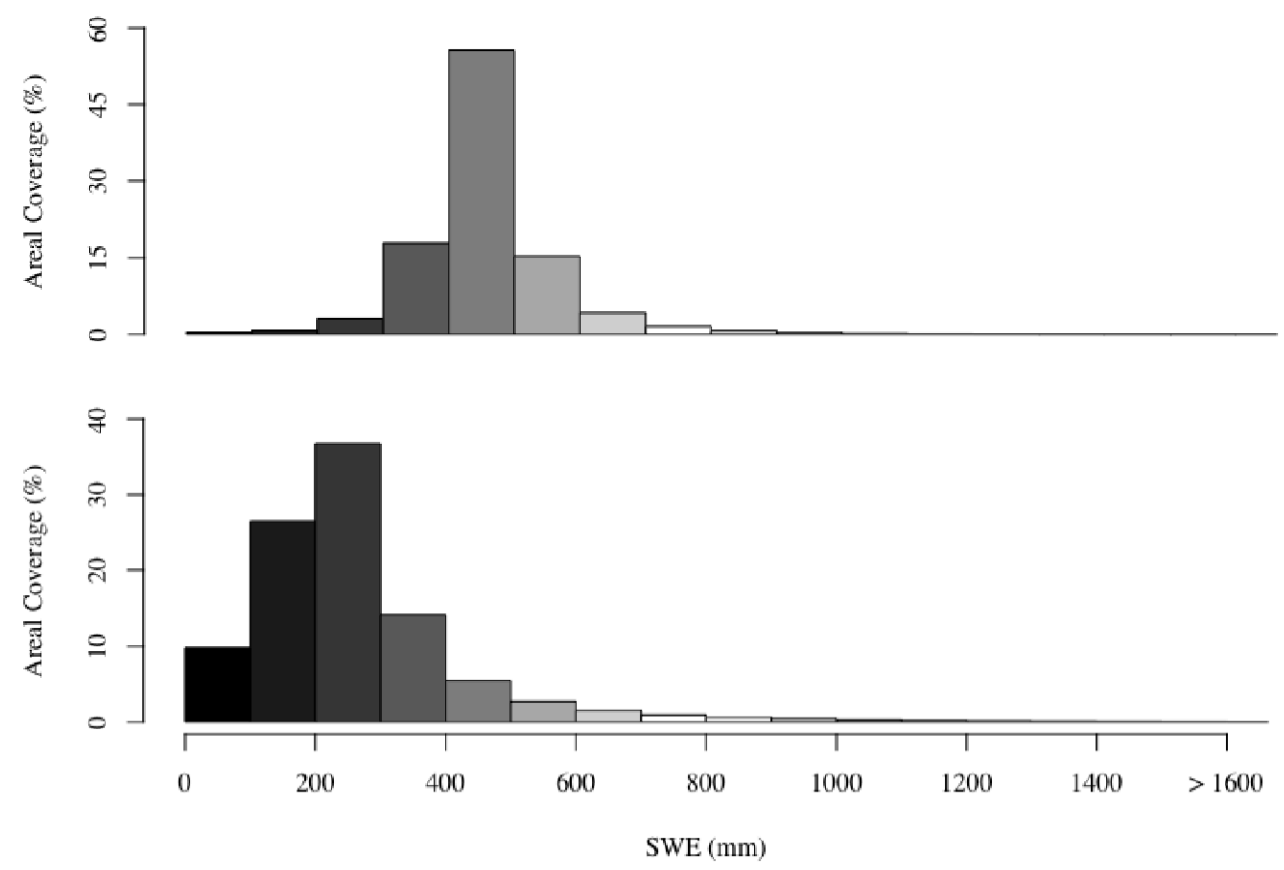

Figure 21: Frequency distributions of SnowModel simulated spring SWE in 2015 (above) and 2016 (below) for the whole Niaqunguk River Watershed. 


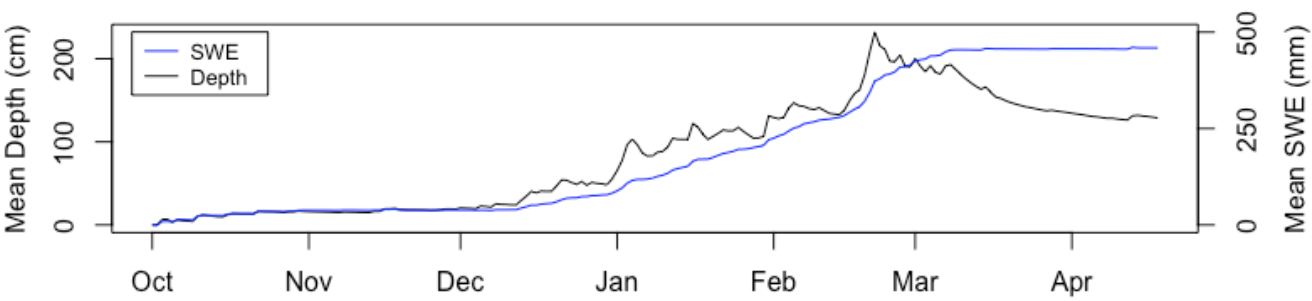

(a)

(b)

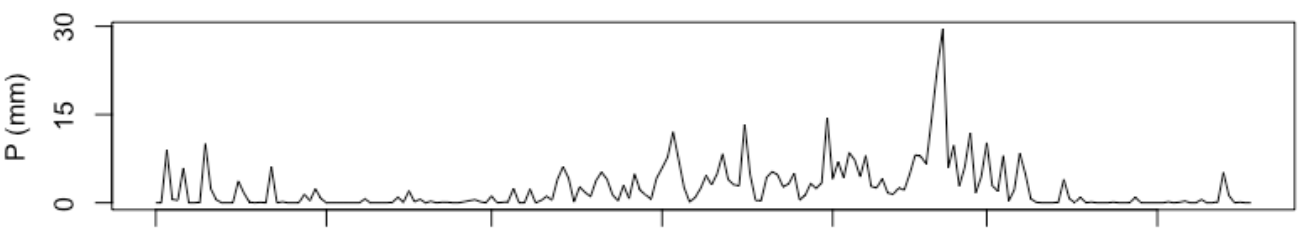

(c)

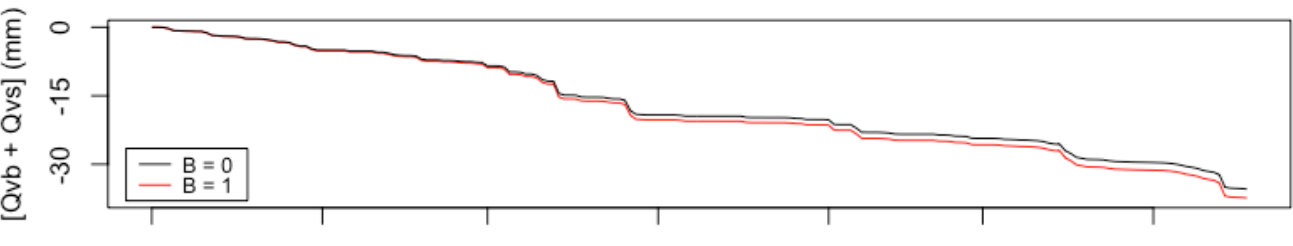

(d)
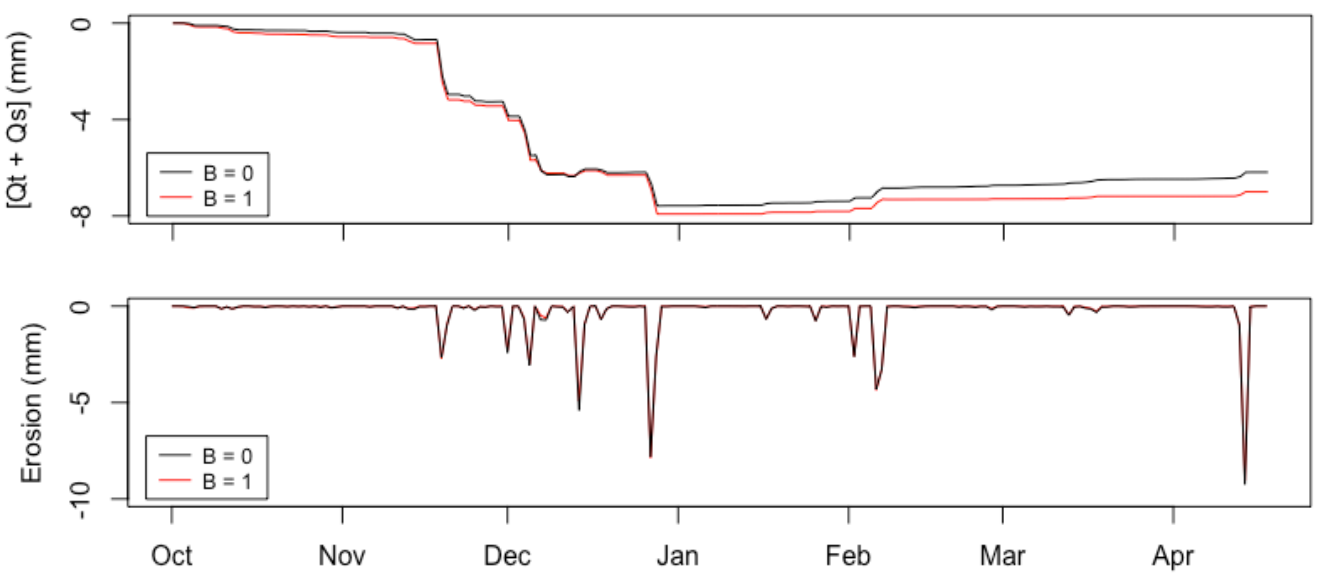

(e)

Figure 22: Daily SnowModel statistics for the entire domain over the simulated 2015

winter. (a) snow accumulation, (b) precipitation, (c) sublimation, (d) blowing snow transport (saltation and suspension), and (e) mean daily erosion. The SnowTran-3D Deposition Control Parameter $B$ (indicated in $\mathrm{c}-\mathrm{e}$ ) was used to investigate sensitivity of simulated transport fluxes by decreasing the deposited fraction of the mass flux. 
(a)

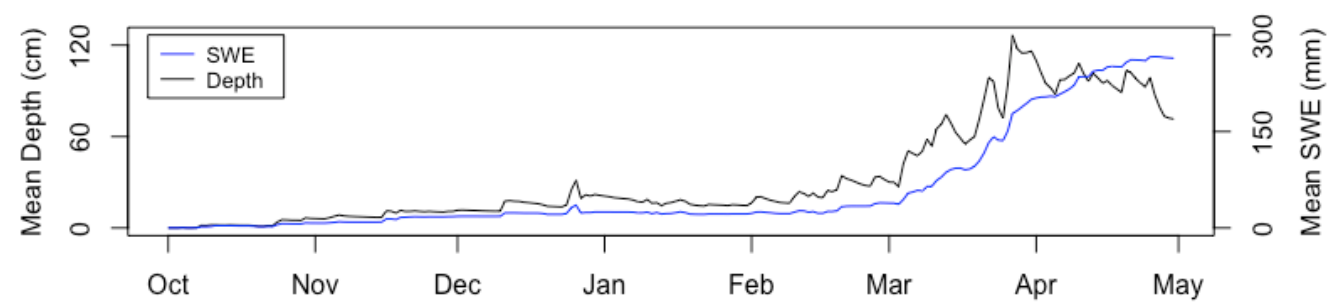

(b)

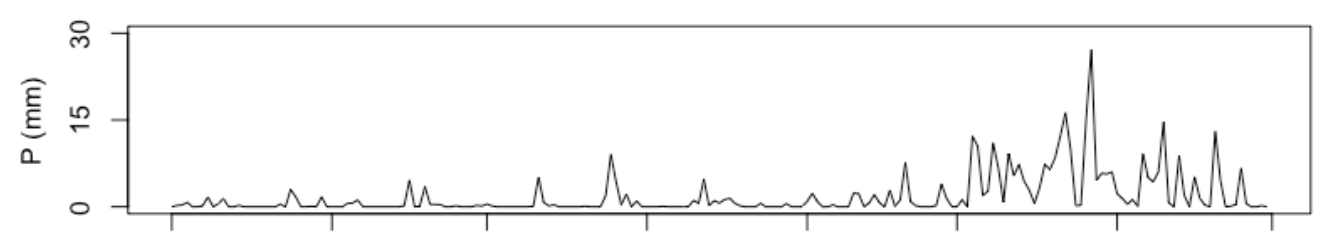

(c)

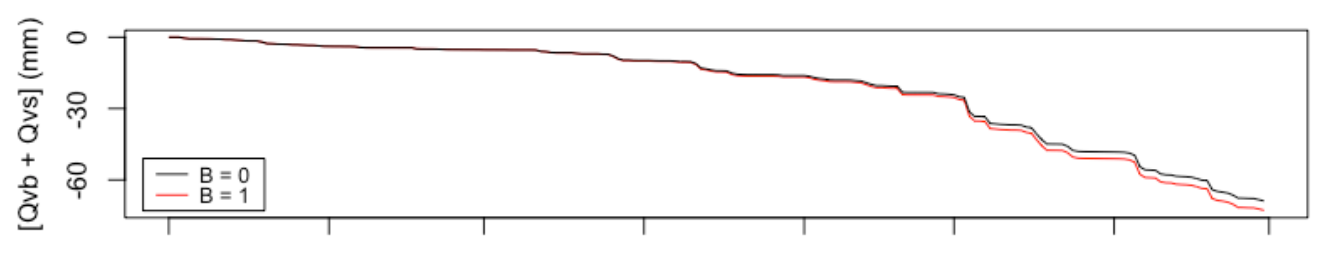

(d)

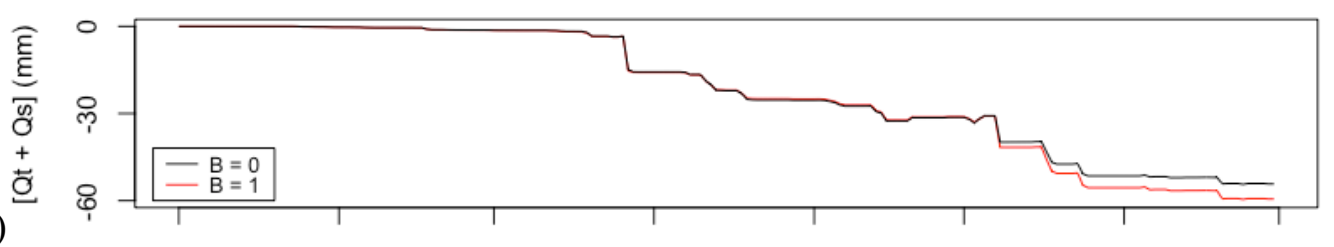

(e)

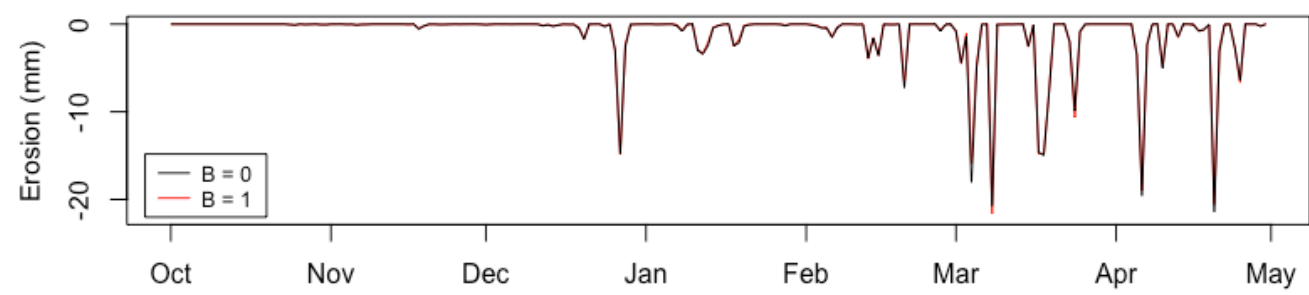

Figure 23: Daily SnowModel statistics for the entire domain over the simulated 2016

winter. (a) snow accumulation, (b) precipitation, (c) sublimation, (d) blowing snow transport (saltation and suspension), and (e) mean daily erosion. The SnowTran-3D Deposition Control Parameter $B$ (indicated in $\mathrm{c}-\mathrm{e}$ ) was used to investigate sensitivity of simulated transport fluxes by decreasing the deposited fraction of the mass flux. 


\section{Chapter: Discussion}

This section discusses the snow distribution as characterized by field observations and surveying. Model performance, both of the empirical terrain models and the physically-based SnowModel, is also discussed. Potential shortcomings of the data and models in this study are also detailed.

\subsection{Characterization of the Snow Distribution}

This section characterizes the spring snow distribution in the study watershed based on field observations, with references to the literature to explain some observations. Particular emphasis is placed on characterizing two scales of spatial variation relevant to snow distribution modeling.

The snow distribution was similar between the two study years. Most of the watershed is covered by a thin snowpack, as snow is eroded by wind action during the winter. The eroded snow is deposited into sheltered areas, such as leeward slopes or stream channels, and can form very large drifts covering very little total area. Over several years of surveying, these drifts were observed in the same locations each year. This is due to the persistence of the prevailing winds, and has been observed by authors in many landscapes that experience snow drifting (e.g. Woo 2012, Schirmer et al. 2011, Winstral et al. 2002, Pomeroy and Gray, 1995).

Other snowpack properties were very different between the 2015 and 2016 surveys, which can be attributed to the winter weather patterns. The 2015 snowpack was shallower with a density and layering pattern typical for Arctic tundra (e.g., Sturm et al., 2010). These features resulted from extensive redistribution of new snow, which has low cohesion in the cold winter air temperatures (Li and Pomeroy, 1997). Once re-deposited, 
wind-transported particles sintered together into a dense wind slab, and the underlying snow metamorphosed into depth hoar due to the strong temperature gradient in the snowpack.

By comparison, the 2016 snowpack was slightly deeper, with remarkably high density. This was due to thick ice layers, which formed during storms in March and April when wet snow fell and refroze on the snow surface. Snowfall from such storms may be referred to as mangusait (D. Tikvik, pers. comm., 2017 - see Appendix D). Severe storms with wet precipitation are increasing at polar latitudes (Ye et al. 2008), though it would be extremely difficult to predict the effect of such weather events on snowpack density using currently available snow models. These conditions also limited the number of samples taken that year, as the snowpack was more difficult to sample.

The snow distribution varies at multiple spatial scales. This phenomenon has been extensively discussed by authors like Clark et al. (2011), Blöschl (1999), Shook and Gray (1996), and McKay and Gray (1981) in the context of sampling or modeling the snow distribution. In this study, there are two scales of interest: the site scale (less than $5 \mathrm{~m}$ ) and the landform scale $(50-250 \mathrm{~m})$.

At the site scale, variations in snow depth were mainly due to the underlying microtopography, such as hummocks or boulders. These variations are essentially random noise in a larger-scale survey. Site scale variations were therefore controlled by the sampling strategy in this study by averaging multiple measurements at a single site.

At the landform scale, variations in snow depth were controlled by interactions of wind and topography. Unlike the site scale, variations at the landform scale are predominantly due to predictable physical processes, which can be modeled. For 
example, shallow snow in hilltops results from wind acceleration, eroding the snow cover. The eroded snow is then deposited on the downwind slope due to wind deceleration, reducing the shear stress and dropping some of the transported mass. The snow surveys therefore covered the watershed as extensively as possible with independent samples at the landform scale, to provide data for model creation and validation.

\subsection{Terrain Models}

The relationship between snow distribution and topography in open environments is well established (e.g., Clark 2011, Woo 1997, Pomeroy and Gray 1995). Modeling snow distribution from terrain variables is therefore a common approach. Earlier researchers used aerial photographs, validated in the field, to define terrain units heuristically (e.g. Woo and Marsh 1978). Since GIS has become readily accessible, quantitative definitions of terrain units have become more common - often using terrain variables (e.g. Lapen and Martz 1996), possibly with remote sensing data to account for vegetation patterns (e.g. Pomeroy et al. 1997).

In this study, terrain variables were calculated in a GIS, and used to define terrainbased models of snow accumulation by two methods: cluster analysis and heuristic decision rules. Qualitatively, these models match observed snow depth patterns - visual assessment indicated that areas of deep snow accumulation are similar between the two terrain models, though they handle open tundra slightly differently.

Quantitatively, these terrain-based models seem to be reasonable approximations of mean watershed SWE; mean differences from survey data range from $-5 \mathrm{~mm}$ or $\sim 2 \%$ (DR 2015) to $-38 \mathrm{~mm}$ or $\sim 16 \%$ (8TU 2016), and the $95 \%$ confidence intervals around the 
weighted mean SWE were equal to or narrower than the confidence intervals around the unweighted survey data. The 8TU model had the highest confidence, but the terrain units varied in their relative SWE accumulations between the two study years, reducing this model's reliability for future years. By comparison, the DR model had lower confidence, but class order was stable between the study years. This may be because DR has fewer classes than 8TU, resulting in larger sample sizes within each DR class and thus reducing the influence of outliers on the classes.

The terrain units identified by cluster analysis are similar to those described in open environments by other authors. For a small basin near Resolute (NU) in the High Arctic, Woo and Marsh (1978) defined terrain units from air photos, stating that subdividing the basin into Hilltops, Flats, Slopes, and Gullies was sufficient to minimize error in the basin SWE estimate. Woo's (1997) recommendation to employ terrainstratified surveying are still used for survey design in Arctic landscapes (e.g., Assini and Young, 2012).

While Woo and Marsh's terrain units were not mathematically defined, and thus are challenging to reproduce, the descriptions of their terrain units correspond closely to the 8TU units of Plateaus, Valley Floors, Midslopes, and Toeslopes. Given the similar topographic and climatic conditions between their study basin and the NRW, the snow distribution is likely governed by the same relationships between accumulation and terrain variables.

At an agricultural site on the Canadian Prairies, Lapen and Martz (1996) defined 6 terrain units to model spatial patterns of snow depth. The authors used a Fortran program to calculate terrain variables such as slope gradient, plan and profile curvature, fetch 
distance, local sheltering, etc. Terrain units were split using a decision rule structure similar to the DR model in this study. Lapen and Martz used topographic indices and agricultural land cover types to divide their terrain into fallow or stubble upland, strongly or moderately sheltered lowland, and fallow or stubble exposed lowland. Although their terrain units are different from those in this study due to their use of vegetation, their topographic indices divide the landscape in essentially the same way, based on topographic position and sheltering. As one of the earliest uses of explicitly defined terrain variables in semi-distributed snow modeling, Lapen and Martz (1996) provided an important contribution to this field.

On western Arctic shrub-tundra at Trail Valley Creek (TVC), Pomeroy et al. (1997) defined landscape units to apply a physically-based model requiring blowing snow "source" and "sink" areas as an input. These were mainly defined by vegetation type using Landsat imagery; tundra is a source of blowing snow, whereas forest and shrub tundra are sinks. Of greater relevance to this thesis was an additional sink class, "Drift", was defined by low tundra vegetation and topographic context: slopes greater than $9^{\circ}$ or stream channels. These correspond reasonably well to the 8TU Midslopes and Toeslopes respectively, and Pomeroy et al.'s "Drift" class partially inspired the DR Drift class.

The landscape of TVC is mostly flat tundra plateau, with steeply incised stream channels. The "Drift" class covered $8.2 \%$ of TVC's area, but contained $27 \%$ of the total basin snow. The deep snow classes in this study covered 14.3 (8TU) or 18.8 (DR)\% of the landscape, and held $15-28 \%$ of the total snow in a given year. Given the larger drift area, a larger fraction of watershed snow might be expected in these drifts. However, the 
rougher terrain in the NRW constitutes what Pomeroy et al. (1997) refer to as "highly dissected fetch". Given the shorter fetch distances, fewer transport events achieve equilibrium flux in landscapes like the NRW than TVC.

The terrain models described in this thesis are a good representation of the spatial distribution of snow at the landform scale. From an operational perspective, they provide maps for stratifying future surveys to optimize labour requirements. For further hydrological studies, they allow the application of a semi-distributed hydrological modeling structure, such as that employed by the Cold Regions Hydrological Model (Pomeroy et al., 2007) or the Raven model (Craig et al., 2017, Chernos et al., 2017), with snow depth classes for snowmelt simulation.

Although they provide similar estimates, the conceptual basis for these models are distinct. The $8 \mathrm{TU}$ model provides an automated technique for defining readily identifiable terrain units and relating them to snow distribution. By contrast, the DR model characterizes the snow distribution using a set of simple rules, allowing experience from extensive observations to be passed to the non-expert without demanding a significant technical background.

Despite their acceptable performance, there are several shortcomings to these terrain models. One is their semi-distributed structure; in applying a constant value to an entire area, the model is able to reproduce the watershed mean, but is a poor predictor of snow depth at a given point. For water supply prediction, this is inconsequential, but for studies where fine-scale spatial accuracy is important (such as vegetation or permafrost studies using snow depth as a predictor) this could be a major problem with these models. 
Another shortcoming of terrain models is their complete reliance on survey data to provide the SWE estimate. With further analysis, it may be possible to forecast SWE in each zone as a fraction of winter precipitation. This "precipitation index" approach is common in the use of terrain metrics to capture snowdrift patterns (e.g., Winstral et al., 2002, Prasad et al., 2001).

In comparison to numerical approaches like SnowModel, another major shortcoming of terrain models is temporal; by limiting the models' scope to the spring, they provide little insight into winter processes. This makes it difficult to speculate on the model's sensitivities to variations in winter weather. It also means that these models cannot be used to estimate the mid-winter snow distribution.

The terrain models might be applicable in other Arctic communities, as the terrain variables can be calculated by anyone with a digital elevation model, and compared against snow survey data from their study area. Some of these variables would require careful assessment before being applied to a new area, however; for example, the prevailing wind direction will need to be defined and the wind shelter index recalculated accordingly. Furthermore, the response of these models to changing climatic conditions is outside the scope of the current work, but this may require re-assessment of terrain variable validity in the future.

\subsection{SnowModel}

Three indicators were used to evaluate SnowModel's performance: visual assessment of the spatial distribution of snow, comparison of modeled and surveyed watershed averages, and point comparison between individual survey sites and SnowModel data at the same locations. This section discusses SnowModel's performance 
when run with various parameter values, and compares the results from this study to SnowModel applications in other environments.

\subsubsection{Wind Field Parameters}

There are no well-established methods for selecting parameter values for the MicroMet wind model, so several parameter values were tested in this thesis. The final parameters were a curvature length scale of $30 \mathrm{~m}$ and slope-curvature weighting ratio of

0.35:0.65. The 2015 simulated SWE was insensitive to these parameter changes, likely because SnowModel underestimated wind transport in that year. However, the 2016 simulation was moderately sensitive to the parameter changes.

Shorter $\eta$ increased the small-scale variability in snow accumulation but could not adequately simulate the spatial variability of wind speed (and thus friction velocity) over these small scales. This suggests that only longer curvature length scales are able to generate the wind speeds required for accurate transport, at the cost of small-scale accuracy. Variability in friction velocity in the wind direction $(d u * / d x)$ is critical for determining whether snow will erode or deposit at appropriate locations. Musselman et al. (2015) noted that the modeled wind fields are not spatially variable enough to accurately represent flow over an Alpine ridge, resulting in an erroneous simulated snow distribution.

The relative distances between erosion areas and downwind deposition areas were slightly increased with $\eta=100 \mathrm{~m}$ as opposed to $\eta=30 \mathrm{~m}$. This implies that total transport distances (and therefore times) are reduced at the shorter $\eta$. This is supported by the Pomeroy et al. (1997) concept of the "highly dissected fetch", where blowing snow sublimation is reduced in rough terrain due to the reduced transport durations. 
Variations in the slope-curvature weighting ratios resulted in changing emphasis on drift development in certain areas. Increasing the curvature weighting to $80 \%$ increased the prominence of drifts in concave areas like toeslopes and gullies. Simulated SWE from these runs corresponded well to survey SWE in 2016, suggesting that these drifts were an important element of the snow distribution in that year. However, erosion on windward slopes and deposition on leeward slopes were reduced under the higher curvature weightings. These are prominent features of the NRW snow distribution, so increasing their weighting in the compromise ratio (35\% slope weighting, $65 \%$ curvature weighting) improved the watershed averaged SWE estimate.

This choice of weighting ratio gives insight into snow deposition processes. To characterize topographic drivers of snow deposition, Ohara (2014) distinguished between the "downwind effect" and the "diffusion effect". The downwind effect is the most commonly cited driver of snow accumulation, causing accumulation on leeward slopes or behind obstacles. The diffusion effect causes snow accumulation in concavities, such as in slope saddles or between soil hummocks. These correspond to the slope and curvature weighting factors in the MicroMet wind model, which reduce wind speed on leeward slopes and in concavities, respectively. Based on the high performance of simulations with increased curvature weighting, it seems that overall snow deposition in the NRW is dominated by the diffusion effect. This explains why toeslopes were such an important feature in the empirical terrain models described in this thesis.

The "best fit" method for objectively choosing parameter values was not ideal. While true wind speed changes occur over small spatial scales, resulting in a fine-scale snow depth variability, the terrain-based wind definition seems to require a larger 
curvature length scale in order to simulate large transport and sublimation fluxes. In recent work, Liston et al. (2007) implied that this problem had been overcome with the new "Tabler profile" subgrid parameterizations, which allow snow redistribution within and between grid cells to improve fine-scale accuracy. However, this parameterization caused a software crash whenever it was used, preventing its assessment for this thesis.

\subsubsection{Snowpack Density Evolution}

The negligible effect of running SnowModel with $\rho_{s}-u{ }_{t}$ uncoupled indicates that the density routine is not the source of the error in the 2015 simulation. Furthermore, the density routine cannot reasonably be blamed for the discrepancy between measured and simulated snow density in 2016 . The unusually high measured density was caused by ice layers in the snow, which formed wet snowfalls while mean hourly air temperatures were below $0{ }^{\circ} \mathrm{C}$ in March and April. SnowPack can simulate surface ice formation by rain-onsnow or surface melt (increasing density and preventing wind transport from that layer), but these are modeled from surface meteorological conditions and thus were "blind" to these storms.

Indeed the simulated density evolution over both winters seems reasonable based on conversations with community members regarding seasonal uses of snow. Further assessment is difficult due to a lack of comprehensive data on the mid-winter evolution of Arctic tundra snow. Some models have been applied to density evolution in Arctic environments. For example, Sturm et al. (2010) analysed a large snow survey dataset from across the northern hemisphere to calibrate an empirical density-evolution function. This estimates snow density as a nonlinear function of day of year, initial density at time of deposition, snow depth, and climatic context. The function's maximum density for 
tundra snow is $363 \mathrm{~kg} \mathrm{~m}^{-3}$ however, and its reliance on climatic conditions makes it even less responsive to unusual weather events such as the 2016 storms.

Alternatively, physically-based snowpack evolution models are used for avalanche forecasting, which requires detailed knowledge of snowpack structure. One example is Crocus (Brun et al. 1992), a one-dimensional snowpack model that simulates snowpack evolution from mass and energy exchanges between the snowpack and its surroundings. This has been coupled with atmospheric models to simulate blowing snow transport and snowpack evolution in three dimensions (Vionnet et al. 2014). This is a promising option for alpine studies, but Crocus' applications at High Arctic sites suggest that it is currently unable to model the unique temperature gradients and vapour fluxes in Arctic snowpacks (Barrere et al. 2017, Domine et al. 2016).

The lack of midwinter tundra snow density data makes it difficult to assess the performance of a seasonal snow evolution model. This is clearly an area for further work in Arctic snow studies.

\subsubsection{Snow Transport and Water Balance}

The snowpack water balance was very different between study years. The 2015 water balance (Table 11) indicates that snow transport was underestimated in that year. Compared to 2016, net transport out of the domain boundaries was much smaller in that year, the blowing snow sublimation flux was much smaller, and in-situ sublimation was relatively more important - all of which suggest a smaller mass transport with less opportunity for blowing snow sublimation losses. The sensitivity analysis suggested that meteorological inputs were the most likely cause of the poor performance in the 2015 
simulation, rather than deficiencies in the modeled processes. The discussion of SnowModel's performance will therefore focus on the 2016 simulation.

In contrast, the 2016 magnitudes of the transport and sublimation fluxes seem reasonable from typical values reported for snow transport and sublimation fluxes in open environments. In Arctic Alaska, Liston and Sturm (2002) used SnowTran-3D to simulate fluxes for a large domain, predicting 29 - $52 \mathrm{~mm}$ of blowing snow sublimation (15 $34 \%$ of the estimated winter precipitation). Pomeroy and Gray (1995) described transport fluxes from fallow fields on the Canadian Prairies on the order of 4.5 to $39.4 \mathrm{~mm}$, accounting for the removal of $13-36 \%$ of annual precipitation, and blowing snow sublimation fluxes of 7.6 to $63.8 \mathrm{~mm}$, comprising $23-41 \%$ of the annual precipitation. At Trail Valley Creek in the Western Canadian Arctic, Pomeroy et al. (1997) observed found that $11 \mathrm{~mm}(5.8 \%$ of snowfall) were transported out of the study area, while 37 $\mathrm{mm}(19.5 \%$ of snowfall) were sublimated.

\subsubsection{SnowModel Performance in Other Studies}

This study's findings with regards to the performance of SnowModel/SnowTran3D differ from some studies and are similar to others. The study area falls within the range of typical domain sizes (ranging from $<1 \mathrm{~km}^{2}$ to $>20,000 \mathrm{~km}^{2}$ ), grid spacings ( 5 to $100 \mathrm{~m}$ ), and regional meteorological conditions for Arctic applications. The main difference is in topography - the rugged tundra of the NRW occupies a "middle ground" between the complex Alpine terrain and low-relief tundra that account for most past model applications.

In Alpine terrain (e.g. Hasholt et al., 2003, Prasad et al., 2001, Greene et al., 1999) major differences in wind speed are observed on the windward or leeward side of 
large mountain features such as ridges. The wind model used by SnowModel is based on approaches originally designed for the Rocky Mountains (Ryan, 1977), and in this terrain type it can perform well if parameters are carefully defined for a single feature $(e . g$.

Greene et al., 1999).

In low-relief tundra, wind flow is less spatially variable than in Alpine terrain and the NRW. SnowTran-3D was successfully used by Liston and Sturm (1998) and Liston and Sturm (2002) on "gently rolling" terrain north of the Brooks Range in Alaska, and by Pohl and Marsh (2006) on "gently rolling” terrain at Trail Valley Creek, NWT. During their original paper documenting SnowTran-3D, Liston and Sturm (1998) identified this shortcoming, stating that the wind model "may be inadequate for many topographic profiles", and that "a more sophisticated model, that could handle flow over a range of topographic configurations", would improve the model's performance.

Having said this, the spring SWE estimate seems robust to the choice of wind field parameter values based on the results of the 2016 simulation, with changes to mean difference from the survey average less than $10 \%$ when a given parameter is changed. Furthermore, the location of modeled drifts matched observed patterns. The performance metrics in this study are in good agreement with the findings of Prasad et al. (2001) who applied SnowTran-3D to a small Alpine catchment in the Idaho Rockies. Their basinaveraged simulated SWE overestimated measured SWE by only $51 \mathrm{~mm}$; by comparison, our study overestimated by only $28 \mathrm{~mm}$ in the 2016 simulation. As in this study, Prasad et al. concluded that the simulated drift patterns corresponded to observed drifting patterns, but the point comparison against surveyed SWE provided a poor fit $\left(\mathrm{R}^{2}=0.19\right)$. Similarly, the 2016 simulation in this study gave $\mathrm{R}^{2}=0.22$. 
Applying SnowTran-3D at Libby Flats, an Alpine ridge in Wyoming, Hiemstra et al. (2006) found that the simulated spatial patterns of accumulation appeared correct from field experience, but in point comparisons against surveyed SWE, the $\mathrm{R}^{2}$ ranged from $0.14-0.18$. As in our study, they found that SnowModel overestimated shallow snow depths and underestimated drift depths. An earlier study of the area by Hiemstra et al. (2002) had similar conclusions, with $\mathrm{R}^{2}$ for the relationship between predicted and observed SWE ranging from $0.13-0.33$.

During an application of SnowTran-3D in Alpine terrain in Greenland, Hasholt et al. (2003) found that mean SWE for Mittivakkat Glacier was underestimated by only 10 $\mathrm{mm}$, and the model reproduced observed snow accumulation patterns well. Compared to these and other studies, the transport and sublimation estimates for 2016 are within the typical ranges reported for open Prairie or Arctic Tundra environments (Liston and Sturm, 2002, Pomeroy et al., 1997, Pomeroy and Gray, 1995, Benson and Sturm, 1993).

\subsubsection{Potential Shortcomings in the Simulation Inputs}

The unrealistically low transport and sublimation fluxes simulated by SnowModel in 2015 indicate that the XFB wind speed may be too low to represent conditions in the NRW. Test simulations determined that the most likely cause is insufficient erosion, which can be explained by underestimated wind speed. Measurements taken at a field tower $\sim 6 \mathrm{~km}$ east of XFB suggest that the wind speeds measured at XFB are lower than at that location (Appendix I).

The field tower also suggests that the wind directions at XFB may not be as variable as those observed in the complex terrain of the NRW. Because the field tower was installed after the 2015 survey and did not incorporate measurements of wind 
direction until after the 2016 survey, these measurements could not be used to drive SnowModel.

Another possibility is that DFAR snowfall is overestimated due to blowing snow catch (Yang et al., 1998). Without observer notes on the timing of blowing snow events at the XFB site, it is difficult to estimate the magnitude of this error. Liston and Sturm (2002) used measured SWE and simulated sublimation to estimate winter precipitation. When their simulated precipitation was compared to data from a gauge with similar wind response to the DFAR, it was found to over- or underestimate snowfall in different areas at different times. This stochasticity in the relationship between gauge catch and landscape SWE accumulation reduces confidence in gauge-forced snow models in general.

\subsubsection{Uncertainties in Survey Measurements}

Finally, the shortcomings in the validation data must be considered. SWE measurements are prone to multiple errors (see Appendix A). Snow depth measurements may be over-estimated due to penetration of the probe tip between boulders or into soft substrates. Farnes et al. (1983) noted that narrow snow tubes, such as the Federal sampler used in this study, tend to overestimate snow density. However loose depth hoar crystals tend to fall out of the tube in Arctic snow packs such as in this study, leading to underestimation of SWE. These are noted challenges in Arctic environments by Berezovskaya and Kane (2007) and Woo (1997). Given the opposite directions of these errors, their net effect should be small.

Spatial variability at the site scale is large (Table 2), which makes it challenging to evaluate SnowModel's performance. Two depth measurements inside a $10 \mathrm{~m}$ grid 
square could be very different, so it is unreasonable to expect a perfect fit between SnowModel and survey SWE at a given point. This site-scale variability was somewhat controlled by averaging multiple depth measurements. Spatial uncertainty from the limited (2-3 $\mathrm{m}$ at best) accuracy of our handheld GPS units is largely controlled by the use of a $10 \mathrm{~m}$ modeling grid. Together, these techniques improve confidence in survey measurements as a validation set for SnowModel, but they also set a lower limit on modeling resolution; to model at a finer scale would require averaging depths from a smaller site, and would require more precise field positioning systems.

Despite these controls on uncertainty, the watershed average snow accumulation is still likely underestimated because we were unable to properly sample the deepest drifts in the watershed. In 2016 this was partly due to time constraints and challenges with the icy snowpack, but field conditions will limit deep drift measurements during any survey in the NRW for safety reasons. The largest drifts are found in extreme terrain where overhanging cornices could give way underfoot or overhead. This danger is exacerbated by frequent overcast conditions during sampling, which cast indirect ("flat") light and make it difficult to detect shapes in the snow such as cornices. Accordingly, these sites were not given the field priority that their snow accumulation might deserve. Thus, there may be less SWE overestimation by SnowModel than the survey results suggest. 


\section{Chapter: Conclusions}

Snow accumulation in the NRW is characterized by a predominantly shallow snowpack, with exposed areas often scoured to bare ground, and sheltered areas accumulating large drifts. To replicate the observed spring snow patterns, a semidistributed terrain unit model, a semi-distributed heuristic decision-rule model, and a fully distributed physically-based blowing snow model were compared.

These models performed well qualitatively, predicting similar areas for drift development, which matched observed drift zones in the field. Areas of shallow snow, particularly areas eroded due to wind exposure, proved more difficult to predict. The models varied in the coverage and SWE accumulation of their respective shallow zones.

Quantitatively, the models showed mixed performance in their estimates of watershed SWE. The lowest difference from survey data in both years was observed in the DR model, and the DR classes showed similar and predictable behaviour between the two study years, suggesting that it is an accurate and effective way of subdividing the landscape to estimate spring SWE.

The 8TU model showed larger differences from survey data when subdivided according to wind exposure, but this subdivision was required to accurately reproduce the spatial patterns of snow accumulation. The resulting model had narrower confidence intervals around its spring SWE estimates than the DR model, suggesting that a combination of automated landform element identification and segmentation by wind direction is a powerful technique for modeling the tundra snow distribution.

SnowModel showed relatively low mean difference from survey SWE in 2016, though this was partly due to the fact that the model significantly underestimated snow 
density and overestimated snow depth for that year. Furthermore, SnowModel significantly underestimated snow transport in the 2015 winter, leading to extreme overestimation of 2015 SWE. This variability in performance seems to be attributable to the meteorological inputs, with the possibility that wind speed was artificially low due to anemometer freezing, and/or that precipitation was artificially high due to DFAR catch of blowing snow.

Further work is needed to improve the usefulness of these models. The terrain models could provide a map for future snow surveying efforts in the NRW. Resampling simulations of the study years could be used to determine whether a minimum sample number exists for the NRW, to reduce labour requirements in surveying. The models could also be extended to other areas, and used in future years, to check its spatial and temporal robustness. Further extension could be achieved by relating zonal SWE accumulation to winter precipitation, to create an "index" predictive model that does not require such extensive field calibration.

To improve SnowModel's performance, efforts should focus on the development of a suitable bias-adjustment transfer function for the Iqaluit DFAR gauge. This process should involve careful quality-control of the DFAR, as it may catch blowing snow during the frequent transport events, and may itself require adjustment. Wind data from the nearby field tower could also be incorporated into the model using the MicroMet Barnes Interpolation routine, reducing the importance of the seemingly erroneous airport anemometer.

SnowModel's simulation of mid-winter processes is one of its greatest advantages over the terrain models, which provide limited insight into these processes. To maximize 
SnowModel's usefulness, these process simulations should also be validated against midwinter measurements of snow depth and density. These data need not be nearly as extensive as the spring surveys in this study, and could be collected on multiple dates during the winter and could be passed to SnowModel's data assimilation routine, which calibrates the model during a run. By examining deficiencies in the model's performance, it may be possible to identify errors in the underlying physical assumptions.

Alternative methods of assessing the snow distribution could also be attempted. One possible method is the use of a UAV to gather high-resolution snow depth data, creating a "surface" for model validation, rather than a series of isolated points. Another method is drift mapping. The geometry of a drift could be determined by intensive measurement, to create a 3D mesh model of the drift. The growth and ablation of these models could then be simulated, and spatial patterns of drift ablation could be empirical modeled. This concept of identifying and modeling specific drifts is supported by a number of CFD modeling studies and by the empirical work of Tabler (1975).

Up to this point, estimates of watershed snow accumulation in the NRW have been sorely lacking. The measurements and models in this study provide such an input to the water balance. The next step for this work is to determine the fate of accumulated SWE during snowmelt; this includes snow sublimation, transport pathways, and the correspondence between predicted melt volumes and timing of discharge in the Niaqunguk River. 


\section{References}

Adams, W., Barr, D. 1974. Techniques and equipment for measuring snowcover, including stratigraphy. Trent University Occasional Papers, Volume 3:

Measurement in Physical Geography, p. 11-26

Allard, M., Doyon, J., Mathon-Dufour, V., LeBlanc, A.-M., L’Hérault, E., Mate, D., Oldenborger,G., Sladen,W. 2012. Surficial geology, Iqaluit, Nunavut. Geological Survey of Canada: Canadian Geoscience Map 64 (preliminary version), 1:15000

American Meteorological Society. 2012. Meteorology Glossary: "sastrugi”. URL: http://glossary.ametsoc.org/wiki/Sastrugi. Accessed March 2018.

Anders, N., Seijmonsbergen, A., Bouten, W. 2011 (a). Optimizing object-based image analysis for semi-automated geomorphological mapping. Proceedings of Geomorphometry 2011: 117-120

Anders, N., Seijmonsbergen, A. Bouten, W. 2011 (b). Segmentation optimization and stratified object-based analysis for semi-automated geomorphological mapping. Remote Sensing of Environment. 115(12): 2976-2985

Anders, N., Seijmonsbergen, A., Bouten, W. 2009. Multi-scale and object-oriented image analysis of high-res LiDAR data for geomorphological mapping in Alpine mountains. Proceedings of Geomorphometry 2009: 61-65.

Assini, J., Young, K. 2012. Snow cover and snowmelt of an extensive High Arctic wetland: spatial and temporal seasonal patterns. Hydrological Sciences Journal, 57(4): 738-755

Bagnold, R. 1941. The physics of blown sand and desert dunes. Methuen Publishing Ltd., London, $266 \mathrm{p}$.

Bakaic, M., Medeiros, A. 2017. Vulnerability of northern water supply lakes to changing climate and demand. Arctic Science. 3: 1-16

Barnes, S. 1973. Mesoscale objective analysis using weighted time-series observations. NOAA Tehnical Memorandum: ERL NSSL-62, National Severe Storms Laboratory, Norman, OK, $60 \mathrm{p}$.

Barnes, S. 1964. A technique for maximizing details in numerical weather map analysis. Journal of Applied Meteorology, 3: 396-409

Barrere, M., Domine, F., Decharme, B., Morin, S., Vionnet, V., Lafaysse, M. 2017. Evaluating the performance of coupled snow-soil models in SURFEXv8 to simulate the permafrost thermal regime at a high Arctic site. Geoscientific Model Development, 10: 3461-3479 
Benson, C., Sturm, M. 1993. Structure and wind transport of seasonal snow on the Arctic slope of Alaska. Annals of Glaciology. 18: 161 - 267

Benson, C. 1982. Reassessment of winter precipitation on Alaska's Arctic slope and measurement of the flux of wind blown snow. UAG-R22. Geophyiscal Institute, University of Alaska Fairbanks. Fairbanks, AK. 26 p.

Berezovskaya, S., Kane, D. 2007. Measuring snow water equivalent for hydrological applications: part 1, accuracy of observations. $16^{\text {th }}$ International Northern Research Basins Symposium and Workshop. Petrozavodsk, Russia, 29-35

Bintanja, R. 2000a. Snowdrift suspension and atmospheric turbulence. Part I: Theoretical background and model description. Boundary-Layer Meteorology. 95: 343-368

Bintanja, R. 2000b. Snowdrift suspension and atmospheric turbulence. Part II: Results of Model Simulations. Boundary-Layer Meteorology. 95: 369-395

Blackadar, R. 1967. Geological reconnaissance, southern Baffin Island, District of Franklin. Geological Survey of Canada: Paper no. 66-47, 39 p.

Blöschl, G. 1999. Scaling issues in snow hydrology. Hydrological Processes. 13: 21492175

Böhner, J., Selige, T. 2006. Spatial prediction of soil attributes using terrain analysis and climate regionalisation. In: SAGA - Analysis and Modelling Applications (Boehner, J., McCloy, K., Strobl, J. - eds). Goettingen. 13-28

Box, G., Jenkins, G. 1976. Time Series Analysis, Forecasting, and Control. Holden-Day, San Francisco, CA, 575 p.

Brenning, A. 2008. Statistical geocomputing combining R and SAGA: The example of landslide susceptibility analysis with generalized additive models. SAGASeconds out. Hamburger Beiträge Zur Physischen Geographie Und Landschaftsökologie, Hamburg:19: p. 23-32

Brun, E., David, P., Sudul, M., Brunot, G. 1992. A numerical model to simulate snow cover stratigraphy for operational avalanche forecasting. Journal of Glaciology, 38: $13-22$

Budd., W., Dingle, W., Radok, U. 1966. The Byrd Snow Drift Project: Outline and basic results. In: Studies in Antarctic Meteorology (Rubin, M. - ed). AGU Antarctic Research Series, Washington, D.C. 9: 71-134

Budkewitsch, P., Pavlic, G., Pregitzer, M., Prevost, C., Zhang, Y., Lavergne, J., Sauve, P. 2009. Iqaluit WorldView-1 DEM Accuracy Assessment, Draft Report on Preliminary Results. Canada Centre for Remote Sensing, Ottawa (Internal Report)

Bui, E. 2004. Soil survey as a knowledge system. Geoderma. 120: 17-26 
Chalmers, A. 1999. What is this thing called science? University of Queensland Press, St. Lucia, Australia. 266 p.

Chernos, M., MacDonald, R., Craig, J. 2017. Efficient semi-distributed hydrological modelling workflow for simulating streamflow and characterizing hydrologic processes. Confluence: Journal of Watershed Science and Management. 1(3): 113

Church, M. 1974. Hydrology and permafrost with reference to northern North America. Permafrost Hydrology: Proceedings of the Workshop Seminar, 1974, Canadian National Committee for the International Hydrological Decade, Environment Canada: $7-20$

Clark, M., Hendrikx, J., Slater, A., Kavetski, D., Anderson, B., Cullen, N., Kerr, T., Hreinsson, E., Woods, R. 2011. Representing spatial variability of snow water equivalent in hydrologic and land-surface models: A review. Water Resources Research. 47: W07539

Colbeck, S. 1982. An overview of seasonal snow metamorphism. Reviews of Geophysics and Space Physics. 20(1): 45-61

Colli, C., Lanza, L., Rasmussen, R., Theriault, J. 2016a. The collection efficiency of shielded and unshielded precipitation gauges. Part I: CFD airflow modeling. Journal of Hydrometeorology. 17: 231-243

Colli, C., Lanza, L., Rasmussen, R., Theriault, J. 2016b. The collection efficiency of shielded and unshielded precipitation gauges. Part II: Modeling particle trajectories. Journal of Hydrometeorology. 17: 245-255

Colli, M., Rasmussen, R., Theriault, J., Lanza, L., Baker, C., Kochendorfer, J. 2015. An improved trajectory model to evaluate the collection performance of snow gauges. Journal of Applied Meteorology and Climatology. 54: 1826-1836

Comola, F. 2017. Stochastic modeling of snow transport and hydrologic response in alpine terrain. Ph.D. Dissertation, Swiss Federal Institute of Technology in Lausanne, Lausanne, Switzerland. 139 p.

Conrad, O., Bechtel, B., Bock, M., Dietrich, H., Fischer, E., Gerlitz, L.,Wehberg, J.,Wichmann, V., Böhner, J. 2015. System for Automated Geoscientific Analyses (SAGA) v. 2.1.4; Geoscientific Model Development. 8: 1991-2007

Craig, J., Huang, S., Khedr, A., Pearson, S., Spraakman, S., Stonebridge, G., Werstruck, C., Zhang, C. 2017. Raven: user's and developer's manual. Raven Version 2.7. URL: http://www.civil.uwaterloo.ca/jrcraig/Raven/Main.html (Accessed October 2017) 
Déry, S., Taylor, P., Xiao, J. 1998. The thermodynamic effects of sublimating, blowing snow in the atmospheric boundary layer. Boundary-Layer Meteorology. 89: 251283

DeWalle, D., Rango, A. 2008. The Principles of Snow Hydrology. Cambridge University Press, Cambridge, UK

Dietrich, H., Böhner, J., 2008. Cold air production and flow in a low mountain range landscape in Hessia (Germany). SAGA-Seconds Out. Hamburger Beiträge Zur Physischen Geographie Und Landschaftsökologie, Hamburg: p. 37-48

Dingle, W., Radok, U. 1961. Antarctic snow drift and mass transport. International Association of Scientific Hydrology, Publication no. 55, p. 77-81

Dingman, S. 1973. Effects of permafrost on stream flow characteristics in the discontinuous permafrost zone of central Alaska. Proceedings of the North American Contribution to the Permafrost Second International Conference, July 13-28, 1973, Yukutsk, USSR, National Academy of Sciences: 447-453.

Domine, F., Barrere, M., Sarrazin, D. 2016. Seasonal evolution of the effective thermal conductivity of the snow and the soil in high Arctic herb tundra at Bylot Island, Canada. The Cryosphere, 10: 2573-2588

Dunn, O. 1964. Multiple comparisons using rank sums. Technometrics. 6(3): 241-252

Dunn, O. 1961. Multiple comparisons among means. Journal of the American Statistical Association. 56(293): 52-64

Dyunin, A. 1967. Fundamentals of the mechanics of snow storms. Proceedings of the International Conference on Low Temperature Science: Physics of Snow and Ice. Oura, H. (ed). 1(2): 1065-1073

Environment and Climate Change Canada. 2016 (b). Canadian climate normals 19812010. URL: http://climate.weather.gc.ca/climate_normals/index_e.html

Environment and Climate Change Canada. 2016 (b). Water Survey of Canada, Environment and Climate Change Canada, web: https://www.ec.gc.ca/rhc-wsc/

Essery, R., Li, L., Pomeroy, J. 1999. A distributed model of blowing snow over complex terrain. Hydrological Processes. 13: 2423-2438

Essery, R., Pomeroy, J. 2004. Vegetation and topographic controls of wind-blown snow distributions in distributed and aggregated simulations for an Arctic tundra basin. Journal of Hydrometeorology (Special Section). 5: 735-744

Evans, I. 1972. General geomorphometry, derivatives of altitude, and descriptive statistics. In: Spatial Analysis in Geomorphology (Chorley, R. - ed). Methuen, London. 17-90 
Farnes, P., Peterson, N., Goodison, B., Richards, R. 1983. Metrication of manual snow sampling equipment by Western Snow Conference Metrication Committee. Proceedings of the $39^{\text {th }}$ Eastern Snow Conference / Proceedings of the $50^{\text {th }}$ Western Snow Conference. Reno, NV. 120-132

Forgy, E. 1965. Cluster analysis of multivariate data: efficiency versus interpretability of

Gascon, G., Stewart, R., Hension,W. 2010: Major cold-season precipitation events at Iqaluit, Nunavut. Arctic. 63(3): 327-337

Gauer, P. 2001. Numerical modeling of blowing and drifting snow in Alpine terrain. Journal of Glaciology. 47(156): 97-110

Gauer, P. 1998. Numerical snow drift modeling in complex alpine terrain and comparison with field measurements. International Snow Science Workshop, Sunriver, OR, 98: $60-66$

Gigerenzer, G. 2008. Why heuristics work. Perspectives on Psychological Science. 3(1): 20-29

Google Earth (V 7.3.0.3832). Image date: July 20, 2015. Southern Baffin Island, Nunavut. $63^{\circ} \mathrm{N}, 68^{\circ} \mathrm{W}$, Eye altitude $200-300 \mathrm{~m}$, DigitalGlobe, 2017. URL $<$ http://www.earth.google.com $>$ [August 31, 2017]

Gordon, M., Biswas, S., Taylor, P., Hanesiak, J., Albarran-Melzer, M., Fargey, S. 2010. Measurements of drifting and blowing snow at Iqaluit, Nunavut, Canada, during the STAR project. Atmosphere-Ocean. 48(2): 81-100

Greene, E., Liston, G., Pielke, R. 1999. Simulation of above treeline snowdrift formation using a numerical snow-transport model. Cold Regions Science and Technology. (30): $135-144$

Hasholt, B., Liston, G., Knudsen, N. 2003. Snow-distribution modelling in the Ammassalik Region, South East Greenland. Nordic Hydrology. 34(1/2): 1 - 16

Hengl, T., Reuter, H. (eds). 2008. Geomorphometry: Concepts, Software, Applications. Developments in Soil Science: Volume 33. Elsevier. 1-772

Hiemstra, C., Liston, G., Reiners, W. 2006. Observing, modeling, and validating snow redistribution by wind in a Wyoming upper treeline landscape. Ecological Modelling (197): 35 - 51

Hiemstra, C., Liston, G., Reiners, W. 2002. Snow redistribution by wind and interactions with vegetation at upper treeline in the Medicine Bow Mountains, Wyoming, USA. Arctic, Antarctic, and Alpine Research. 34(3): 262 - 273

Hodgson, D. 2005. Quaternary geology of western Meta Incognita peninsula and Iqaluit area, Baffin Island, Nunavut. Geological Survey of Canada, Bulletin 582: 74 p. 
Hudson, B.D., 1992. The soil survey as a paradigm-based science. Soil Science Society of America Journal 56, 836-841

Iacozza, J., Barber, D. 1999. An examination of the distribution of snow on sea-ice. Atmosphere-Ocean. 37(1): 21-51

Iacozza, J. 1997. Models of snow distribution patterns for various types of sea ice in the Canadian High Arctic, M.A. thesis, University of Manitoba,Winnipeg, 183 pp.

Isaaks, E., Srivastava, R. 1989. An Introduction to Applied Geostatistics. Oxford University Press, New York, 552 pp.

Kane, D., Hinzman, L., Benson, C., Liston, G. 1991. Snow hydrology of a headwater arctic basin. 1. Physical measurements and process studies. Water Resources Research. 27: 1099-1109

Kind, R. 1992. One-dimensional Aeolian suspension above beds of loose particles - A new concentration-profile equation. Atmospheric Environment. 26A(5): 927-931

Kind, R. 1981. Snow Drifting. Handbook of Snow: Principles, Processes, Management, and Use. Gray, D., Male, D. (eds). Pergamon. 338-359

Krcho, J. 1991. Georelief as a subsystem of landscape and the influence of morphometric parameters of georelief on spatial differentiation of landscape-ecological processes. Ecology (CSFR). 10: 115-157

Kjikjerkovska, E. 2016. Long-term hydroclimatic change and interannual variability in water sources, Apex River (Iqaluit), Baffin Island, Nunavut. M.Sc. thesis, Queen's University, Kingston, Ontario. 107 p.

Koen, B. 1985. Definition of the Engineering Method. American Society for Engineering Education, Washington, DC. 79 p.

Kruskal, W., Wallis, A. 1952. Use of ranks in one-criterion variance analysis. Journal of the American Statistical Association. 47(260): 583-621

Kuhn, T. 1970. The structure of scientific revolutions $\left(2^{\text {nd }}\right.$ Ed. $)$. University of Chicago Press, Chicago. 226 p.

Lapen, D., Martz, L. 1996. An investigation of the spatial association between snow depth and topography in a Prairie agricultural landscape using digital terrain analysis. Journal of Hydrology, 184: 277-298

Lehning, M., Doorschot, J., Fierz, C., Raderschall, N. 2002. A 3D model for snow drift and snow cover development in steep alpine terrain. Proceedings of the International Snow Science Workshop 2002 Penticton, British Columbia: 579586 
Lehning, M., Lowe, H., Ryser, M., Raderschall, N. 2008. Inhomogeneous precipitation distribution and snow transport in steep terrain. Water Resources Research. 44: W07404

Lehning, M., Doorschot, J., Raderschall, N. and Bartelt, P., 2000. Combining snow drift and SNOWPACK models to estimate snow loading in avalanche slopes. In: Snow Engineering 2000: Recent Advances and Developments. Hjorth-Hansen, E., Holand, I., Loset, S., Norem, H. - eds. CRC Press. 113-122

Li, L., Pomeroy, J. 1997. Estimates of threshold wind speeds for snow transport using meteorological data. Journal of Applied Meteorology. 36: 205 - 213

Liljequist, G. 1957. Energy exchange of an Antarctic snowfield. Norwegian-BritishSwedish Antarctic Expedition, 1949-52, Scientific Results, Volume 2, Part 1. Norsk Polarinstitut, Oslo, 298 p.

Liston, G. 1995. Local advection of momentum, heat, and moisture during the melt of patchy snow covers. Journal of Applied Meteorology. 34: 1705-1715

Liston, G., Elder, K. 2006a. A distributed snow-evolution modeling system (SnowModel). Journal of Hydrometeorology, 7: 1259-1276

Liston, E., Elder, K. 2006b. A meteorological distribution system for high-resolution terrestrial modeling (MicroMet). Journal of Hydrometeorology, 7: 218-234

Liston, G., Haehnel, R., Sturm, M., Hiemstra, C., Berezovskaya, S., Tabler, R. 2007. Simulating Complex snow distributions in windy environments using SnowTran3D. Journal of Glaciology: Instruments and Methods. 53(181): 241-256

Liston, G., Sturm, M. 2004. The role of winter sublimation in the Arctic moisture budget. Nordic Hydrology. 35(4-5): 325-334

Liston, G., Sturm, M. 2002. Winter precipitation patterns in Arctic Alaska determined from a blowing-snow model and snow-depth observations. Journal of Hydrometeorology. 3(6): $646-659$

Liston, G., Sturm, M. 1998. A snow-transport model for complex terrain. Journal of Glaciology. 44(148): 498-516

MacQueen, J. 1967. Some methods for classification and analysis of multivariate observations. Proceedings of the $5^{\text {th }}$ Berkeley Symposium on Mathematical Statistics and Probability. 281-297

Mann, G. 1998. Surface Heat and Water Vapour Budgets over Antarctica. Ph.D. Dissertation, University of Leeds, Leeds, UK. 279 p.

Mann, G., Anderson, P., Mobbs, S. 2000. Profile measurements of blowing snow at Halley, Antarctica. Journal of Geophysical Research. 105(D19): 24,491-24,508 
Marsh, P. 1988. Soil infiltration and snow-melt run-off in the Mackenzie Delta, N.W.T. Proceedings of the 5th International Conference on Permafrost, Trondheim. 1: $618-621$

Marsh, P., Pomeroy, J. 1996. Meltwater fluxes at an Arctic forest-tundra site. Hydrological Processes. 10: 1383-1400

McClung, D., Schaerer, P. 1993. The Avalanche Handbook. The Mountaineers Books, Seattle, USA

McKay, G., Gray, D. 1981. The distribution of snowcover. Handbook of Snow: Principles, Processes, Management, and Use. Gray, D., Male, D. (eds). Pergamon Press, p. 153-190

Meek, D., Hatfield, J. 1994. Data quality checking for single station meteorological variables. Agricultural and Forest Meteorology. 69: 85-109

Mekis, E. 2005. Adjustments for trace measurements in Canada. $15^{\text {th }}$ Conference on Applied Climatology, Savannah, GA. J3.7.

Mekis, E., Brown, R. 2010. Derivation of an adjustment factor map for the estimation of the water equivalent of snowfall from ruler measurements in Canada. Atmosphere-Ocean. 48(4): 284-293

Mekis, E., Hogg, D. 1999. Rehabilitation and analysis of Canadian daily precipitation time series. Atmosphere-Ocean. 37(1): 53-85

Mellor, M. 1965. Blowing Snow. CRREL Monograph, Part 3, Section A3c, United States Army Cold Regions Research and Engineering Laboratory, Hanover, NH. 79 p.

Miller F., Edmonds E., Gunn A. 1982. Foraging behavior of Peary Caribou in response to springtime snow and ice conditions. Canadian Wildlife Service: Occasional Paper no. 48, Ministry of Supply and Services, Canada

Mott, R., Lehning, M. 2010. Meteorological modeling of very high-resolution wind fields and snow deposition for mountains. Journal of Hydrometeorology. 11: 934-949

Mott, R., Schirmer, M., Bavay, M., Grunewald, T., Lehning, M. 2010. Understanding snow-transport processes shaping the mountain snow cover. The Cryosphere, 4: 545-559

Mott, R., Schirmer, M., Lehning, M. 2011. Scaling properties of wind and snow depth distribution in an Alpine catchment. Journal of Geophysical Research. 116(D06106): 1-8

Musselman, K., Pomeroy, J., Essery, R., Leroux, N. 2015. Impact of windflow calculations on simulations of alpine snow accumulation, redistribution and ablation. Hydrological Processes. 29(18): 3983-3999 
Naaim, M., Naaim-Bouvet, F., Martinez, H. 1998. Numerical simulation of drifting snow: erosion and deposition models. Annals of Glaciology. 26: 191-196

Natural Resources Canada. 2015. CanVec. NRCAN, topographic reference digital product, URL < http://geogratis.gc.ca/api/en/nrcan-rncan/ess-sst/23387971-b6d34ded-a40b-c8e832b4ea08.html $>$ [October, 2015]

Newbury, R. 1974. River hydrology in permafrost areas. Permafrost Hydrology: Proceedings of the Workshop Seminar, 1974, Canadian National Committee for the International Hydrological Decade, Environment Canada: 31-37

Nishimura, K., Nemoto, M. 2005. Blowing snow at Mizuho Station, Antarctica. Philosophical Transactions of the Royal Society A: Mathematical, Physical, and Engineering Sciences. 363(1832): 1647-1662

Obradovic, M., Sklash, M. 1986. An isotopic and geochemical study of snowmelt runoff in a small Arctic watershed. Hydrological Processes. 1: 15-30

Ohara, N. 2014. A practical formulation of snow surface diffusion by wind for watershed-scale applications. Water Resources Research. 50: 5074-5089

Plattner, C., Braun, L., Brenning, A. 2004. Spatial variability of snow accumulation on Vernagtferner, Austrian Alps, in winter 2003/2004. Zeitschrift fuer Gletscherkunde und Glazialgeologie. 39: 43-57

Podobnikar, T., Szekely, B. 2015. Towards the automated geomorphometric extraction of talus slopes in Martian landscapes. Planetary and Space Science. 105: 148-158

Pohl, S., Marsh, P. 2006. Modelling the spatial-temporal variability of spring snowmelt in an arctic catchment. Hydrological Processes, 20: 1773-1792

Pohl, S., Marsh, P., Liston, G. 2006. Spatial-temporal variability in turbulent fluxes during spring snowmelt. Arctic, Antarctic, and Alpine Research, 38(1): 136-146

Polanyi, M. 1966. The tacit dimension. Doubleday, Garden City. 108 p.

Pomeroy, J. 1989. A process-based model of snow drifting. Annals of Glaciology. 13: 237-240

Pomeroy, J. 1988. Wind Transport of Snow. Ph.D. Thesis, Division of Hydrology, University of Saskatchewan, Saskatoon. 226 p.

Pomeroy, J., Brun, E. 2001. Physical Properties of Snow. In: Snow Ecology (H. G. Jones et al.., eds), Cambridge University Press, 45-118

Pomeroy, J., Gray, D. 1995. Snowcover accumulation, relocation, and management. National Hydrology Research Institute Science Report No. 7. Environment Canada, Saskatoon, SK. 144 p. 
Pomeroy, J., Gray, D. 1990. Saltation of snow. Water Resources Research. 26(7): 15831594

Pomeroy, J., Gray, D., Brown, T., Hedstrom, N., Quinton, W., Granger, R., Carey, S. 2007. The cold regions hydrological model: a platform for basing process representation and model structure on physical evidence. Hydrological Processes. 21(19): 2650-2667

Pomeroy, J., Gray, D., Hedstrom, N., Janowicz, J. 2002. Prediction of seasonal snow accumulation in cold climate forests. Hydrological Processes. 16: 3543-3558

Pomeroy, J., Gray, D., Landine, P. 1993a. The Prairie Blowing Snow Model: Characteristics, validation, operation. Journal of Hydrology. 144: 165-192

Pomeroy, J., Li, L. 2000. Prairie and arctic areal snow cover mass balance using a blowing snow model. Journal of Geophysical Research. 105(D21): 26,619 26,634

Pomeroy, J., Male, D. 1992. Steady-state suspension of snow. Journal of Hydrology. 136: 275-301

Pomeroy, J., Marsh, P., Gray, D. 1997. Application of a distributed blowing snow model to the Arctic. Hydrological Processes. 11: 1451-1464

Pomeroy, J., Marsh, P., Lesack, L. 1993b. Relocation of major ions in snow along the tundra-taiga ecotone. Nordic Hydrology. 24: 151-168

Prasad, R., Tarboton, D., Liston, G., Luce, C., Seyfried, M. 2001. Testing a blowing snow model against distributed snow measurements at Upper Sheep Creek, Idaho, United States of America. Water Resources Research, 37(5): 1341-1350

Prima, O., Yoshida, T. 2010. Characterization of volcanic geomorphology and geology by slope and topographic openness. Geomorphology. 118(1-2): 22-32

Prima, O., Echigo, A., Yokoyama, R., Yoshida, T. 2006. Supervised landform classification of Northeast Honshu from DEM-derived thematic maps. Geomorphology. 78(3-4): 373-386

Qin, C.-Z., Jiang, J.-C.,Zhan, L.-J., Lu, Y.-J., Zhu, A.-X. 2013. A browser/server-based prototype of heuristic modelling environment for digital terrain analysis. Proceedings of Geomorphometry 2013: Conference and Workshops, October 1620, Nanjing, China. O-27: 4 p.

Rasmussen, R., Baker, B., Kochendorfer, J., Meyers, T., Landolt, S., Fischer, A.P., Black, J., Thériault, J.M., Kucera, P., Gochis, D., Smith, C. 2012. How well are we measuring snow: The NOAA/FAA/NCAR winter precipitation test bed. Bulletin of the American Meteorological Society. 93(6): 811-829. 
Rasmussen, R., Vivekanandan, J., Cole, J., Meyers, B., Masters, C. 1999. The estimation of snowfall rate using visibility. Journal of Applied Meteorology. 38: 1542-1563

Ribeiro, P., Diggle, P. 2001. geoR: a package for geostatistical analysis. R-NEWS. $1(2): 15-18$

Richardson, M. Shirley, J. 2016. Metal loading and retention in Arctic tundra lakes during spring runoff. Indigenous and Northern Affairs Canada, Northern Contaminants Program Synopsis Report. 11 p.

Rubin, J. 1967. Optimal classification into groups: An approach for solving the taxonomy problem. Journal of Theoretical Biology. 15: 103-144

Rusk, B. 2016. Characterization of the geochemical processes and importance of subsurface water input at the confluence of the Apex River in Iqaluit, NU. B.Sc. Honours thesis, Queen's University, Kingston, Ontario. 37 p.

Ryan, B. 1977. A mathematical model for diagnosis and prediction of surface winds in mountainous terrain. Journal of Applied Meteorology, 16: 571-584

Schirmer, M., Lehning, M. 2011. Persistence in intra-annual snow depth distribution: 2. Fractal analysis of snow depth development. Water Resources Research. 47(W09517): 1-14

Schirmer, M., Wirz, V., Clifton, A., Lehning, M. 2011. Persistence in intra-annual snow depth distribution: 1. Measurements and topographic control. Water Resources Research. 47(W09516): 1-16

Schmidt, R. 1991. Sublimation of snow intercepted by an artificial conifer. Agricultural and Forest Meteorology. 54(1): 1-27

Schmidt, R. 1982. Properties of blowing snow. Reviews of Geophysics. 20(1): 39-44

Schmidt, R. 1980. Threshold wind-speeds and elastic impact in snow transport. Journal of Glaciology. 26(94): 453-467

Schmidt, J., Evans, I., Brinkmann, J. 2003. Comparison of polynomial models for land surface curvature calculation. International Journal of Geographic Information Science. 17(8): 797-814

Schneiderbauer, S. 2010. Computational fluid dynamics (CFD) simulation of snow transport, erosion and sedimentation in Alpine environments and in the vicinity of massive obstacles. Ph.D. Dissertation, Johannes Kepler University, Linz, Austria. $203 \mathrm{p}$.

Schneiderbauer, S., Prokop, A. 2011. The atmospheric snow-transport model: SnowDrift3D. Journal of Glaciology. 57(203): 526- 
Shirley, J. 2014. Microbial water quality in Apex River from 2009 to 2012: insights from community based monitoring. Proceedings of Arctic Change 2014: Oral Presentation Abstracts, December 8-12, 2014, Ottawa: p. 168-169

Short, N., LeBlanc, A., Sladen, W., Oldenborger, G., Mathon-Dufour, V., Brisco, B. 2014. RADARSAT-2 D-InSAR for ground displacement in permafrost terrain, validation from Iqaluit Airport, Baffin Island, Canada. Remote Sensing of Environment. 141: 40-51

Shook, K., Gray, D. 1997. Synthesizing shallow seasonal snow covers. Water Resources Research. 33(3): 419-426

Shook, K., Gray, D. 1996. Small-scale spatial structure of shallow snowcovers. Hydrological Processes. 10: 1283-1292

Skidmore, A. 1989. An expert system classifies eucalypt forest types using Landsat Thematic Mapper and a digital terrain model. Photogrammetric Engineering and Remote Sensing. 55: 1449-1464

Smith, K. 2016. Preliminary findings on snow accumulation in the Niaqunguk River watershed near Iqaluit, Baffin Island, Nunavut. Summary of Activities 2016, Canada-Nunavut Geoscience Office: 89-104

Sturm, M., Taras, B., Liston, G., Derksen, C., Jonas, T., Lea, J. 2010. Estimating snow water equivalent using snow depth data and climate classes. Journal of Hydrometeorology. 11: 1380-1394

Sturm, M., Holmgren, J., Liston, G. 1995. A seasonal snow cover classification system for local to global applications. Journal of Climate. 8: 1261-1283

Squires, C. 1984. The late Foxe deglaciation of the Burton Bay area, southeastern Baffin Island, N.W.T. M.A. thesis, Windsor University, Windsor, Ontario. 115 p.

St-Onge, M., Scott, D. Wodicka, N. 1999. Geology, Frobisher Bay, Nunavut. Geological Survey of Canada, “A” Series Map 1979A, scale 1:100 000

Sverdrup, H. 1936. The eddy conductivity of air over a smooth snow field. Results of the Norwegian-Swedish Spitsbergen Expedition in 1934, Geofysiske Publikasjoner, 9(7): $69 \mathrm{p}$.

(a) Tabler, R. 1980. Self-similarity of wind profiles in blowing snow allows outdoor modeling. Journal of Glaciology. 26(94): 421-434

(b) Tabler, R. 1980. Geometry and density of drifts formed by snow fences. Journal of Glaciology. 26(94): 405-419

Tabler, R. 1975. Predicting profiles of snowdrifts in topographic catchments. Proceedings of the $43^{\text {rd }}$ Annual Western Snow Conference, p. 87-97 
Tabler, R., Benson, C., Santana, B., Ganguly, P. 1990. Estimating snow transport from wind speed records: Estimates versus measurements at Prudhoe Bay, Alaska. Proceedings of the $58^{\text {th }}$ Annual Meeting of the Western Snow Conference, p. 6178

Takahashi, S. 1985. Characteristics of drifting snow at Mizuho Station, Antarctica. Annals of Glaciology, 6: 71-75

Takeuchi, M. 1980. Vertical profile and horizontal increase of drift-snow transport. Journal of Glaciology, 26(94): 481-492

Theriault, J., Rasmussen, R., Ikeda, K., Landolt, S. 2012. Dependence of snow gauge collection efficiency on snowflake characteristics. Journal of Applied Meteorology and Climatology. 51: 745-762

Thiel, G. 2016. Investigating seasonal hydrology and its relationship with microbiological indicators in the Apex River watershed (Iqaluit, Nunavut); B.Sc. Honours thesis, Queen's University, Kingston, Ontario. 57 p.

Thorndike, R. 1953. Who belongs in the family? Psychometrika. 18(4): 267-276

Tremblay, T., Day, S., McNeil, R., Smith, K., Richardson, M., Shirley, J. 2015. Overview of surficial geology mapping and geochemistry in the Sylvia Grinnell Lake area, Baffin Island, Nunavut. Summary of Activities 2015, Canada-Nunavut Geoscience Office. p. 107-120

United States Geological Survey. 2016. Explanations for the National Water Conditions. Web: https://water.usgs.gov/nwc/explain_data.html

Valentine, A., Kalnins, L. 2016. An introduction to learning algorithms and potential applications in geomorphometry and Earth surface dynamics. Earth Surface Dynamics. 4: 445-460

Vionnet, V., Martin, E., Masson, V., Guyomarc'h, G., Naaim-Bouvet, F., Prokop, A., Durand, Y., Lac, C. 2014. Simulation of wind-induced snow transport and sublimation in alpine terrain using a fully coupled snowpack/atmosphere model. The Cryosphere, 8, 395-415

Walton, T. 1996. Fill-in of missing data in univariate coastal data. Journal of Applied Statistics. 23: 31-39

Williams, P.J. and Smith, M.W. 1989. The Frozen Earth: Fundamentals of Geocryology. Cambridge University Press, Cambridge: 202-236

Winstral, A., Elder, K., Davis, R. 2002. Spatial snow modeling of wind-redistributed snow using terrain-based parameters. Journal of Hydrometeorology. 3: 524-538 
Winstral, A., Marks, D., Gurney, R. 2013. Simulating wind-affected snow accumulations at catchment to basin scales. Advances in Water Resources. 55: 64-79

Winstral, A., Marks, D. 2002. Simulating wind fields and snow redistribution using terrain-based parameters to model snow accumulation and melt over a semi-arid mountain catchment. Hydrological Processes. 16: 3585-3603

Wolff, M., Isaksen, K., Petersen-Øverleir, A., Ødemark, K., Reitan, T., Brækkan, R. 2015. Derivation of a new continuous adjustment function for correcting windinduced loss of solid precipitation: results of a Norwegian field study. Hydrology and Earth System Sciences. 19: 951-967. DOI: 10.5194/hess-19-951-2015

Woo, M. 2012. Permafrost Hydrology. Springer-Verlag, Berlin. 519 p.

Woo, M. 1997. A guide for ground based measurement of the arctic snow cover. Report for the Climate Research Branch, Atmospheric Environment Service. 30 p.

Woo M., Heron R. 1981. Occurrence of ice layers at the base of High Arctic snowpacks. Arctic Alpine Research.13: 225-230

Woo M., Heron R., Marsh P. 1982. Basal ice in High Arctic snowpacks. Arctic and Alpine Research.14: 251-260

Woo, M., Heron, R., Marsh, P., Steer, P. 1983. Comparison of weather station snowfall with winter snow accumulation in high arctic basins. Atmosphere-Ocean. 21(3): 312-325

Woo, M., Marsh, P. 1978. Analysis of error in the determination of snow storage for small high arctic basins. Journal of Applied Meteorology, 17: 1537 - 1541

Wood, J. 1996. The Geomorphological Characterisation of Digital Elevation Models. PhD Thesis, Department of Geography, University of Lancaster, UK

Xiao, J., Bintanja, R., Déry, S., Mann, G., Taylor, P. 2000. An intercomparison among four models of blowing snow. Boundary-Layer Meteorology. 97: 109-135

Yang, D. 2014. Double fence intercomparison reference (DFIR) vs. bush gauge for "true" snowfall measurement. Journal of Hydrology. 509: 94-100

Yang, D., Goodison, B., Metcalfe, J., Golubev, V., Bates, R., Pangburn, T., Hanson, C. 1998. Accuracy of NWS 8" standard nonrecording precipitation gauge: results and application of WMO intercomparison. Journal of Atmospheric and Ocean Technology. 15: $54-68$

Yang, D., Metcalfe, J., Goodison, B., Mekis, E. 1993. An evalution of the double fence intercomparison reference gauge. Proceedings of the $50^{\text {th }}$ Eastern Snow Conference, Quebec City: 105 - 111 
Ye, H., Yang, D., Robinson, D. 2008. Winter rain on snow and its association with air temperature in Northern Eurasia. Hydrological Processes, 22(15): 2728-2736

Yokoyama, R., Shirawasa, M., Pike, R. 2002. Visualizing topography by openness: a new application of image processing to digital elevation models. Photogrammetric Engineering and Remote Sensing. 68: 257-265

Zevenbergen, L, Thorne, C. 1987. Quantitative analysis of land surface topography. Earth Surface Processes and Landforms. 12: 47-56 


\section{Appendix A - Sources of error in field SWE measurement}

This section details the surveying procedures employed during this study, and the "workarounds" for some challenges are given in Table 12. Operational guides have focused on snow course surveys (e.g., Adams and Barr, 1974); for a review of errors associated with SWE coring equipment, see Sturm et al. (2010), Woo (1997), or Farnes et al. (1983).

At each site, 3-4 "supporting" depth measurements were made within $2 \mathrm{~m}$ of a central point. Central measurements were either depth ( 75\%) or SWE ( 25\%) measurements in 2015; the choice of an optimal sampling ratio is discussed in detail below. In 2016, all central measurements were taken as SWE, as ice layers in the snow, decreased our confidence in our density measurements. Surveys in 2017 took the " $1: 3$ " approach again, due to the relative labour-intensiveness of SWE coring; depth measurement takes a single operator less than 30 seconds, requiring negligible skill or experience.

By comparison, snow coring requires 2-3 people for 3-5 minutes (longer if sampling very deep and/or dense snow). On warm days, coring can be delayed by meltrefreeze inside the corer. This can be minimized by handling equipment with gloves, but if $T_{a}>0{ }^{\circ} \mathrm{C}$, it cannot be fully avoided, requiring the operator to plunge water and ice from the barrel with a cleaning rod. For shallow-to-moderate snow with significant depth hoar, Woo (1997) recommended digging around the corer base and holding the core in place from the bottom (e.g. with a hand or shovel blade), noting that this was standard in Scandinavia at that time. All of these techniques consume valuable sampling time. 
Sturm et al. (2010) state that since SWE measurement takes approximately 20 times longer, a ratio of at least 20 depth measurements per SWE measurement optimizes data collection. This premise is sound, though their ratio is derived from depth measurement with an automatic "MagnaProbe" sensor. By our estimates using a typical measuring rod, and with driving between survey sites providing the greatest logistical burden, a number closer to $10: 1$ seems fair. Since depth is more spatially variable than density, maximizing spatial coverage by depth measurement will also yield a more complete dataset. All of this assumes some minimum number of density measurements to provide an accurate estimate for SWE modeling, given the errors inherent in SWE measurement (especially with the high wind speeds and prominent depth hoar in the snowpacks of southern Baffin Island - see Table 12 below). Our chosen ratio could likely be optimized by a larger number of depth samples.

Costs are also a significant factor; a SWE tube costs 4 or 50 times more than an aluminum "scientific" depth probe or folding avalanche probe, respectively. Where soft snow can be measured with a ruler, the cost difference may be a factor of $>600$. In 2016 , heavy ice layers in the snow of southern Baffin Island damaged our aluminum probe, and would likely have destroyed an avalanche probe outright. Since weight is not a large factor for survey by skidoo, stainless steel probes have since been fabricated to act as an "ice punch" for future surveys. These probes follow the design suggested in Woo (1997).

To place our snow data in the wider context, Sturm et al. (2010) provide a summary of a meta-dataset of $>13,500$ measurements taken by varying methods across the North American Arctic between 1935 and 2004. They determined that tundra snow has a mean depth of $34.6 \mathrm{~cm}(\mathrm{SD}=28.8)$ and a mean density of $278 \mathrm{~kg} \mathrm{~m}^{-3}(\mathrm{SD}=85)$. 
Compared to 5 other "classes" of snowpack found globally (Sturm et al. 1995), tundra snow is the shallowest by a significant margin, with bulk density near the global mean. Given the substantial density stratification between wind slab $\left(\rho>400 \mathrm{~kg} \mathrm{~m}^{-3}\right.$ in some cases) and depth hoar ( $\rho$ from $150-250 \mathrm{~kg} \mathrm{~m}^{-3}$ ), the density variation in tundra snowpacks is typically greater than taiga snow at similar latitudes. In the NRW, the author has observed incredible variation in density within a single drift, and within drifts at the same location between multiple years.

At Eureka and Resolute in 1982, Woo (1997) compared 3 SWE samplers (MSC, ESC-30, and Federal - the latter being the model used in this study) in $340-345 \mathrm{~kg} \mathrm{~m}^{-3}$, $60 \mathrm{~cm}$ deep snow, with $T_{a}<-20{ }^{\circ} \mathrm{C}$. The Federal sampler was found to overestimate density by $>10 \%$, the largest of the 3 samplers. Farnes et al. (1983) found similar errors and attributed them to edge effects (per Bindon, 1964) exacerbated by the smaller crosssectional area of the Federal. However Woo (1997) noted that this same small-cross section made it the fastest sampler to use, and more useful in deep snow.

Berezovskaya and Kane (2007) found that in northern Alaska SWE was overestimated from $4-20 \%$. The main error sources were soft organic materials overlying hard-frozen soil, which allowed probe penetration and thus overestimation of snow depth by $11-31 \%$, and depth hoar at the snowpack base, which caused losses from snow tubes and thus underestimation of SWE. From a large snow measurement dataset, Sturm et al. (2010) concluded that core-based snow densities underestimate by $7.1 \%$. These findings conflict with those of Woo (1997) and Farnes et al. (1983).

Woo (1997) stated that for very shallow snow, SWE coring error is large relative to the sample volume, and recommended that manual cutting and weighing of snow 
volumes be used. At deep drifts where depth or core sampling may not be reasonable $(d>$ 2-3 m, depending on equipment), the snow depth may be determined by difference of theodolite-surveyed elevations in spring and post-melt. This method is more timeconsuming, but has the added advantage of being non-destructive, allowing repeat surveying of a transect if required. Drone-based surveying could be a viable alternative for such transects. 
Table 12: (Part I) Error sources, ordered by severity, with compensation techniques. Note that "tare" weighing is subject to all uncertainties normally affecting the spring scale.

\begin{tabular}{|c|c|c|}
\hline Error & Field Compensation Technique & Severity \\
\hline $\begin{array}{l}\text { Wind pumping of } \\
\text { the snow tube, } \\
\text { causing the spring } \\
\text { scale to bounce }\end{array}$ & $\begin{array}{l}\text { Weigh tube behind wind shelter, e.g. } \\
\text { snowmobile; average measurements over } \\
5 \text { seconds; take more depth/fewer SWE } \\
\text { measurements on windy days }\end{array}$ & $\begin{array}{l}\text { Severe; compensation in } \\
\text { light winds is effective, } \\
\text { but impossible in winds } \\
>8 \mathrm{~m} \mathrm{~s}^{-1}\end{array}$ \\
\hline $\begin{array}{l}\text { Snow loss from } \\
\text { coring tube (due } \\
\text { to, e.g., extensive } \\
\text { depth hoar } \\
\text { formation, esp. on } \\
\text { ice) }\end{array}$ & $\begin{array}{l}\text { Gentle removal; check for loss by } \\
\text { recording external (snowpack depth) and } \\
\text { internal (core length) depth } \\
\text { measurements. If a large discrepancy is } \\
\text { noted, or if loss is evident, repeat core; } \\
\text { on soft substrates, core into soil/organic } \\
\text { material; on hard substrates, dig around } \\
\text { the corer to expose the cutter, and use } \\
\text { shovel blade to hold core in place. } \\
\text { Alternatively: Don't use the corer - take } \\
\text { depth measurements only, or dig a } \\
\text { snowpit to take density measurements. }\end{array}$ & $\begin{array}{l}\text { Severe on hard } \\
\text { substrates where the } \\
\text { corer can't "bite" the } \\
\text { surface, especially on } \\
\text { lake ice; compensation } \\
\text { can reduce this to } \\
\text { negligible, but requires } \\
\text { operator care and } \\
\text { experience, and is time } \\
\text { consuming }\end{array}$ \\
\hline $\begin{array}{l}\text { Snow compaction } \\
\text { in the tube by } \\
\text { dense layers, } \\
\text { preventing lower } \\
\text { snow from } \\
\text { entering the tube }\end{array}$ & $\begin{array}{l}\text { Avoid "ramming" - use cutter and C- } \\
\text { clamp handles to twist the tube into the } \\
\text { snowpack; check the snow tube for } \\
\text { evidence of compaction (smooth, hard } \\
\text { snow inside cutter); take depth } \\
\text { measurement instead in extreme cases }\end{array}$ & $\begin{array}{l}\text { Usually minimal. Severe } \\
\text { if ice layers present (e.g. } \\
\text { mid-winter freezing rain, } \\
\text { significant melt- } \\
\text { refreeze); compensation } \\
\text { reduces this, but it's still } \\
\text { a problem for icy sites }\end{array}$ \\
\hline $\begin{array}{l}\text { Ice/water } \\
\text { remaining inside } \\
\text { tube between sites }\end{array}$ & $\begin{array}{l}\text { Shake out all snow after measurement; } \\
\text { mop water from tube before } \\
\text { measurement; take a "tare" weight every } \\
\text { time; keep scale and corer covered } \\
\text { between sites (minimize exposure to sun } \\
\text { and snow); handle equipment with } \\
\text { gloves (minimize heat transfer) }\end{array}$ & $\begin{array}{l}\text { Minimal, given operator } \\
\text { care; if unchecked, may } \\
\text { build up, becoming more } \\
\text { severe over a sampling } \\
\text { day }\end{array}$ \\
\hline $\begin{array}{l}\text { Subjectivity in } \\
\text { reading spring } \\
\text { scale }\end{array}$ & Same operator always reads scale & $\begin{array}{l}\text { Minimal; reduced to } \\
\text { negligible by careful } \\
\text { operators }\end{array}$ \\
\hline
\end{tabular}


Table 12 (Part II): Error sources, ordered by severity, with compensation techniques.

Note that "tare" weighing is subject to all uncertainties normally affecting the spring scale.

\begin{tabular}{|c|c|c|}
\hline Error & Field Compensation Technique & Severity \\
\hline $\begin{array}{l}\text { Spring scale } \\
\text { calibration drift }\end{array}$ & $\begin{array}{l}\text { Verify scale calibrations in the field; } \\
\text { send scale for periodic } \\
\text { recalibration/servicing }\end{array}$ & $\begin{array}{l}\text { Minimal; fully } \\
\text { compensated if drifted } \\
\text { calibration factors are } \\
\text { determined }\end{array}$ \\
\hline $\begin{array}{l}\text { Diurnal } \\
\text { temperature } \\
\text { fluctuations - } \\
\text { affect spring scale } \\
\text { elastic response }\end{array}$ & $\begin{array}{l}\text { Tare weights; cover scale and corer; only } \\
\text { handle equipment with gloves }\end{array}$ & $\begin{array}{l}\text { Negligible in most cases, } \\
\text { but air temperature may } \\
\text { fluctuate }>20 \text { degrees on } \\
\text { calm, sunny days, which } \\
\text { may have a small effect }\end{array}$ \\
\hline
\end{tabular}




\section{Appendix B - Spatial autocorrelation in surveyed snow data}

Spatial autocorrelation is commonly reported from snow surveys, with ranges on the order of 10-100 m in open environments (Lapen and Martz, 1996, Shook and Gray, 1996, Pomeroy, 2016, personal communication). On the open tundra, site-scale depth variability is large, dominated by microtropography such as hummocks or boulders. At moderate $(10-100 \mathrm{~m})$ scales, snow depth is predominantly driven by wind exposure. Autocorrelation occurs if snowpack exposure is determined by a common topographic element (e.g. many samples behind one ridge).

At the watershed scale, snow accumulation is related to these topographic elements; however, if autocorrelated data are used to derive predictive relationships, the statistical assumption of independence is violated. In such a case, the apparent goodnessof-fit from any relationship will be artificially inflated.

Winstral et al. (2002) argue that snow survey data should not be discarded to account for autocorrelation, as a large and representative sample outside the autocorrelation range is non-feasible without sacrificing statistical power. Given the high variability in snow data, this may be true for small watersheds and foot-based sampling. However, this study used snowmobile-based sampling for a moderately sized watershed, so therefore altering the survey design to account for autocorrelation was feasible.

Variograms were computed from data collected at multiple spacings in 2015, and these suggested an autocorrelation range of approximately $80 \mathrm{~m}$ - in good agreement with the findings of other authors (Figure A2.1). Further sampling in 2016 and 2017 was thus conducted at a minimum spacing of $100 \mathrm{~m}$, to ensure independence in snow data. 
Variography was conducted using the R spatial-statistics package "geoR" (Ribeiro and Diggle, 2001).

For further discussion of variography, see Isaaks and Srivastava (1989). Many authors explore snowpack spatial structures; Shook and Gray (1996) employ fractal analysis for terrestrial snowpacks in open environments, Hiemstra et al. (2006) and Schirmer and Lehning (2011) use them in Alpine environments, and Iacozza (1997, with Barber: 1999) do the same for sea ice.

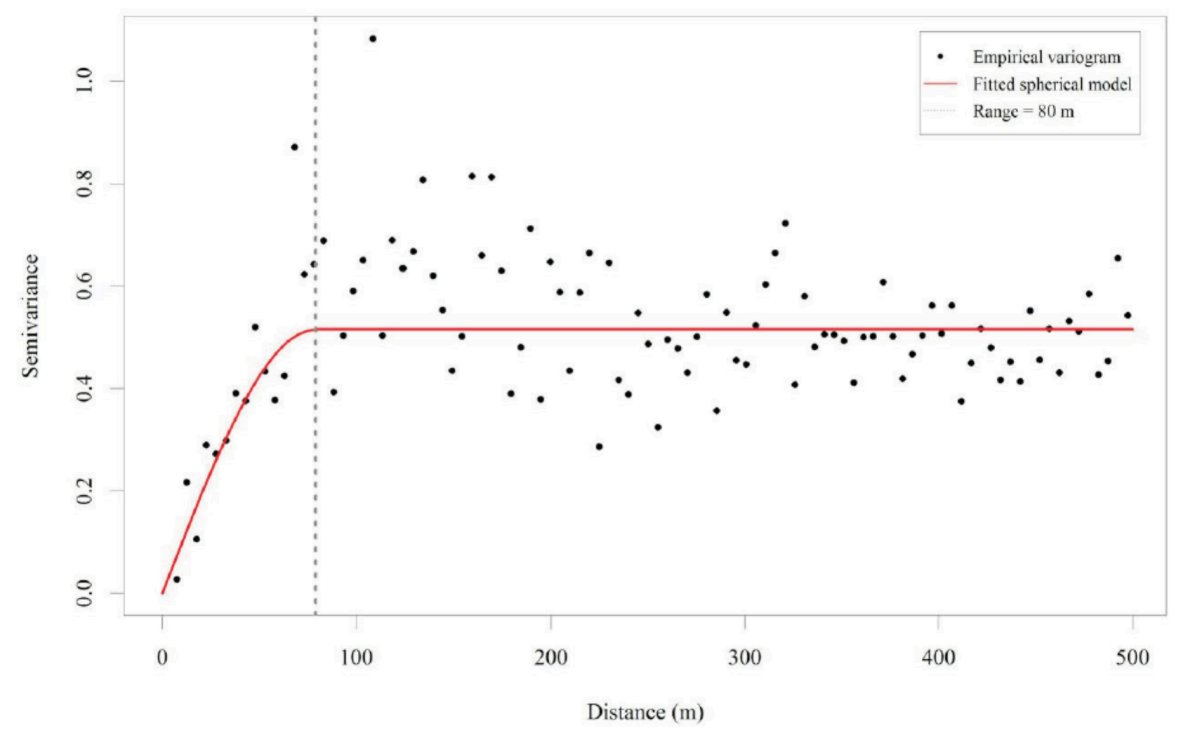

Figure 24: Empirical and fitted-spherical variograms from the 2015 survey data, indicating an $80 \mathrm{~m}$ autocorrelation range.

To handle autocorrelation during future snow surveys north of treeline, I propose techniques that may be used for 2 topographic regimes: for flat areas where microtopography dominates the accumulation patterns, snow depth might be considered a random field, with an identifiable autocorrelation range. Random sampling outside of this range should thus yield a reasonable sample. For leeward slopes or river channels, where 
landforms induce flow separation and significant drifting, the entire structure is autocorrelated, but the location of a single "representative" sample is unknown. In such cases, a 3-D model of the drift could be generated by identifying the drift's edges, and measuring drift depth at a high resolution (e.g. by theodolite or drone-based surveying, per the recommendations of Woo, 1997).

Statistical models of drift form could then be derived (i.e., a 3-D version of Tabler's 1975 drift profile model), which would allow object-oriented drift modeling from terrain morphometry, as an efficient and accurate alternative to a simple grid model like those employed in spatially-distributed snow models. As proposed, this technique would be explicitly empirical, and given the consistent locations of large drifts between years, this could greatly improve the accuracy of operational water resource studies. Further development of this technique could lead to an explicitly physically-based model of greater applicability in scientific snow hydrology. 


\section{Appendix C - Survey Data: Histograms and Linear Model Performance}

Pomeroy and Gray (1995) suggested that drifts $(>60 \mathrm{~cm})$ be modeled with a nonlinear relationship where SWE increases with depth at a diminishing rate. In this study, residuals from the predictive regressions indicated that a linear approximation for the SWE-to-depth relationship was reasonable (Figure 25). The variability in drift density with depth manifested as heteroscedasticity in the linear model residuals, and model predictive accuracy decreased with depth as a result, but the models were not biased high or low. Variance with depth occurs in measured snow data because the density of deep snowdrifts varies as a result of interactions between slope, aspect and storm wind direction.

Histograms of snow depth, SWE, and density by year (Figure 26 - Figure 28) show distributions, despite value shifts, from year to year. The strong positive skew in snow depth and SWE data are typical. A square root or logarithmic transform of snow data has been demonstrated to reduce skew and reduce the leverage of outliers, and prevent violations of the regression assumptions. When this was tested, however, various transformations were found to affect each year's data differently. Furthermore, when reverse transforming predicted values, the uncertainty due to heteroscedasticity would be restored. Since these models were intended to predict SWE from depth, and to preserve interpretability of relationships between years, linear models were retained as the best compromise between fit, interpretability, and physical relevance.

The modeled relationships showed little error (indexed by $\mathrm{R}^{2}$ and RMSD) and extremely low bias. A more complex model would thus have little impact on the models' 
predictive capacity, so a simple linear relationship was deemed an acceptable simplification.

Theoretically, these models should have an intercept of 0 , as a depth of $0 \mathrm{~cm}$ corresponds to a SWE of 0 . In reality, however, some sites with a non-zero average depth had no SWE at their central location -this may have been bare ground, or SWE below the instrumental detection limit (snow thinner than $2-3 \mathrm{~cm}$ is often not cohesive enough to be cored, and the spring scale does not respond reliably to extremely low weights). Thus, a negative intercept represents the lower sampling threshold. If negative SWE values were predicted from low depth, they were truncated to 0 . For comparison, means and standard deviations of field-measured and regression-modeled SWE are given in Table 13.

Outliers were found in the regression diagnostics. Closer examination of these outliers suggested that they were not the result of sampling error, but rather, occurred where a site's central depth differed substantially from the mean of its supporting depths. Such cases occurred near sharp topographic boundaries, such as ridgelines, lake edges, or in boulderfields where the depth probe had an equal probability of sampling on top of a boulder or between 2 boulders. Since the datasets were small to begin with, and the cumulative outlier effects were small, all outliers were retained.

Table 13: Mean and standard deviation of field-measured SWE (F-SWE) and regressionmodeled SWE (R-SWE) in the NRW over both study years.

\begin{tabular}{ccc}
\hline Year & $\begin{array}{c}\text { F-SWE }[ \pm \boldsymbol{\sigma}] \\
(\mathbf{m m})\end{array}$ & $\begin{array}{c}\text { R-SWE }[ \pm \boldsymbol{\sigma}] \\
(\mathbf{m m})\end{array}$ \\
\hline 2015 & $166[155]$ & $182[154]$ \\
2016 & $241[241]$ & $242[232]$
\end{tabular}



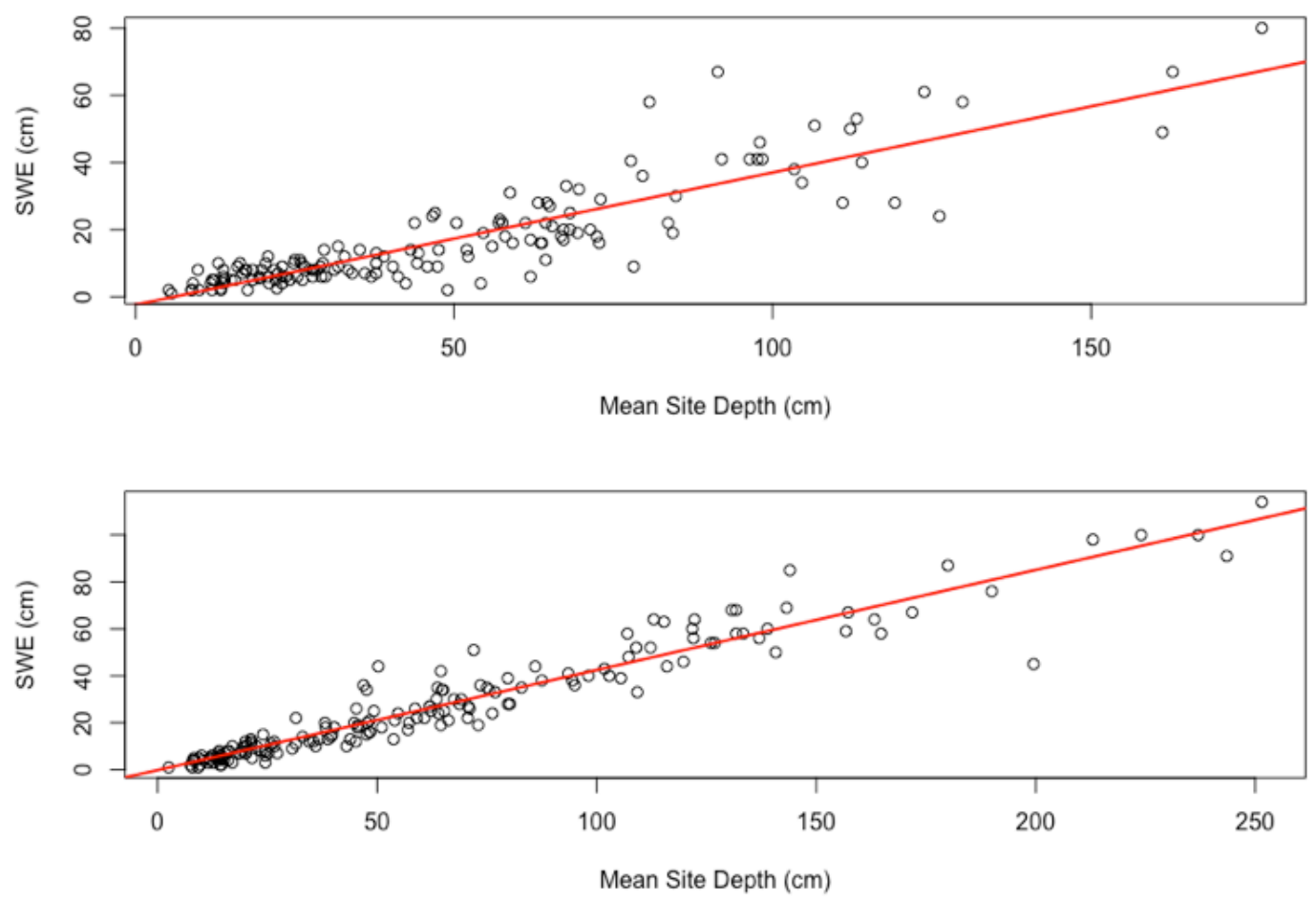

Figure 25: Snow water equivalent (SWE, cm) vs snow depth (cm) for 2015 (top panel, $\mathrm{n}$ $=149$ ) and 2016 (bottom panel, $\mathrm{n}=169$ ). The linear regression models are plotted in red.
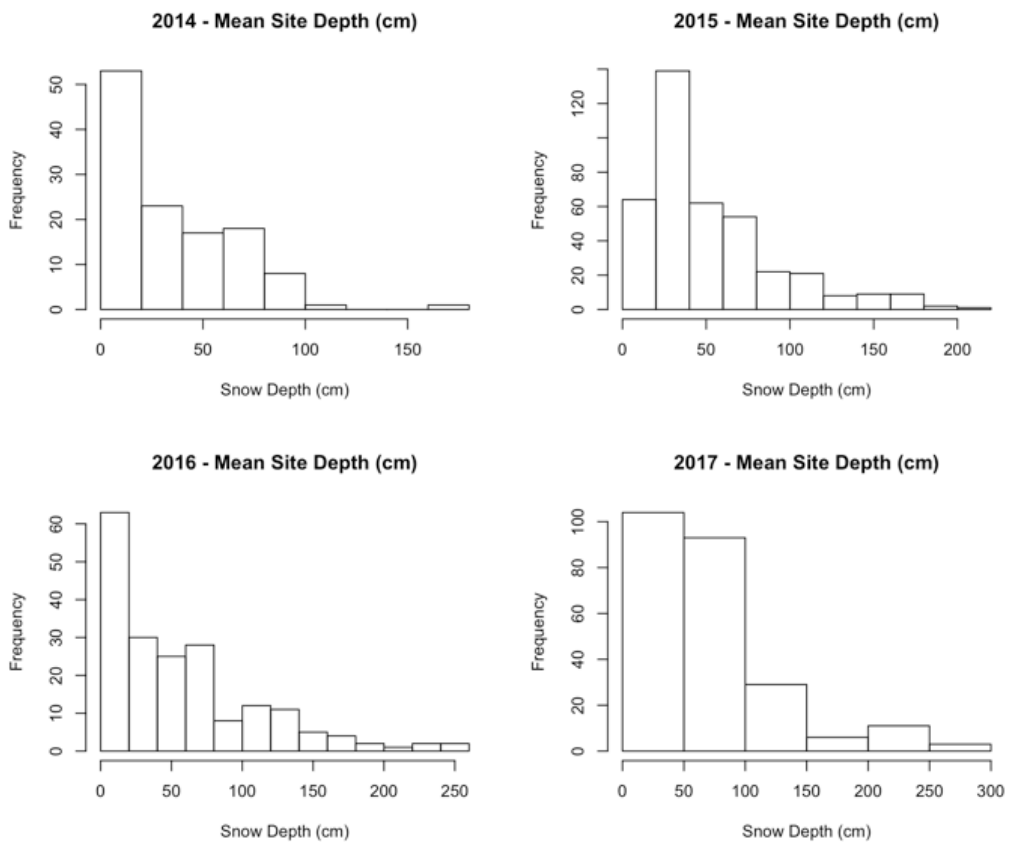

Figure 26: Mean site depth - histograms by year. 

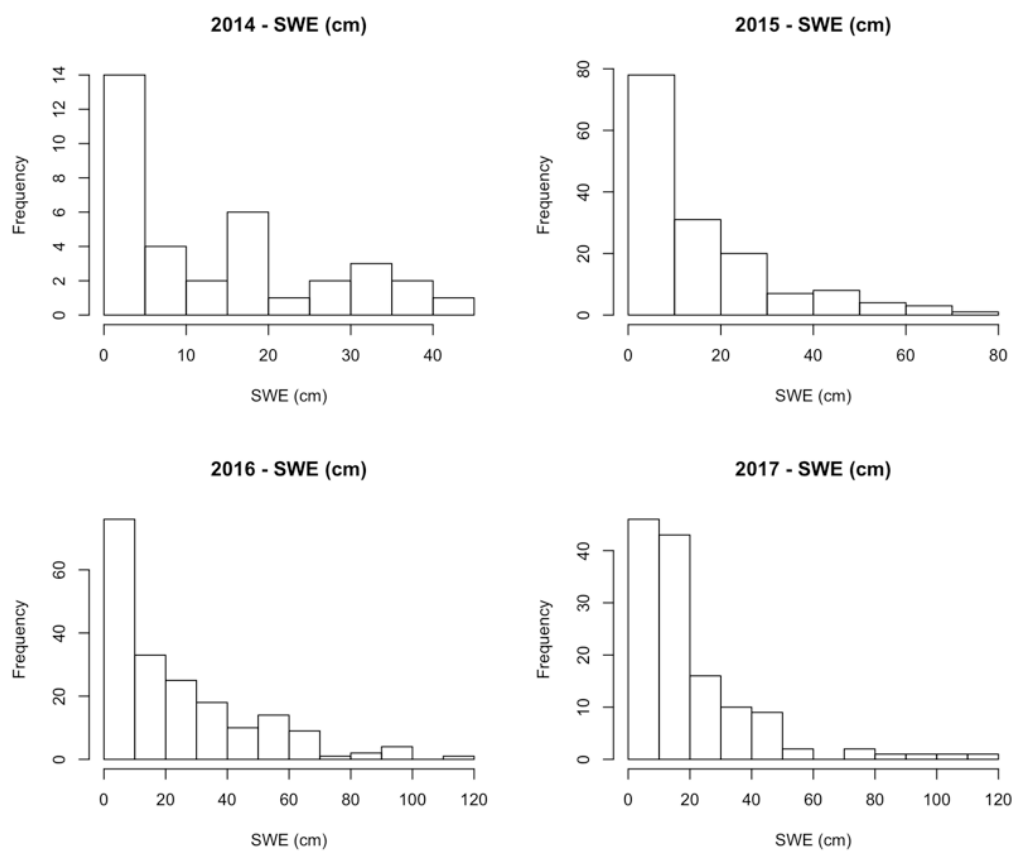

Figure 27: Snow Water Equivalent (SWE) from survey data - histograms by year.
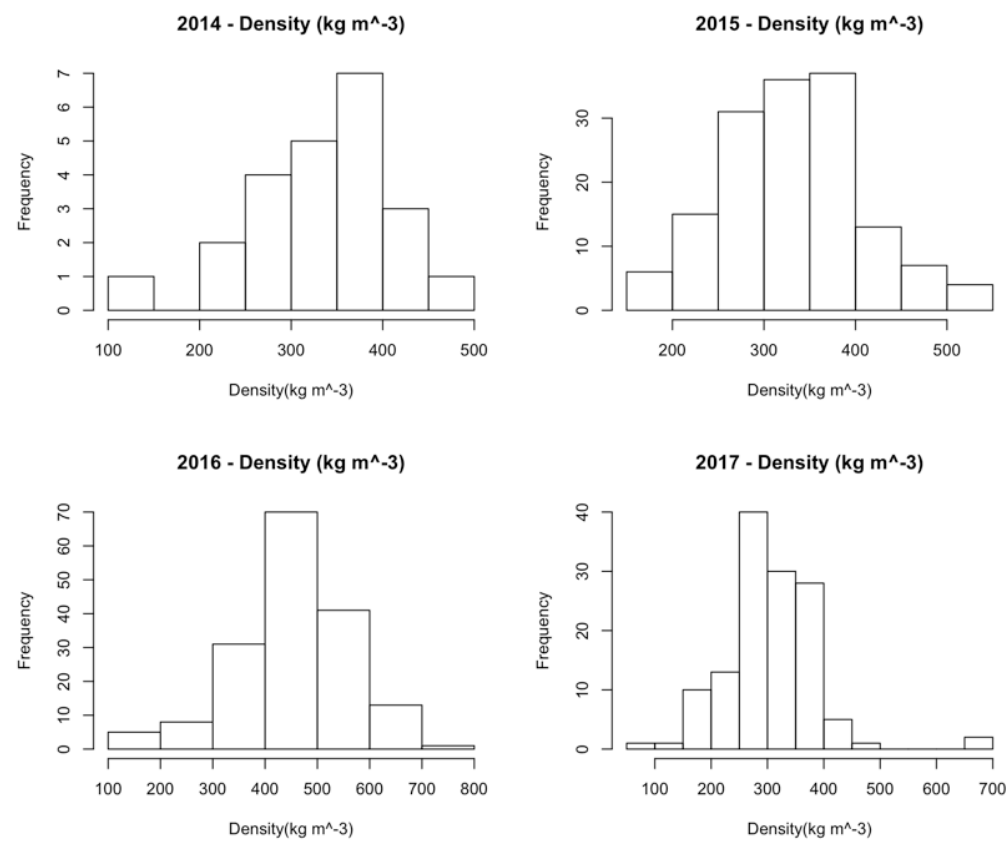

Figure 28: Snowpack bulk density - histograms by year 


\section{Appendix D- Inuktitut Terminology}

The following is a subset of Inuktitut terminology the author learned over several seasons of fieldwork in Iqaluit. These come from many dialects, and variations will exist across Inuit Nunangat. For the most part, their spelling here follows Roman orthographic conventions of the South Qikiqtaaluq dialect.

\begin{tabular}{|c|c|c|c|}
\hline Word & Definition & Notes & Source \\
\hline alluiqaniq & $\begin{array}{l}\text { "Snow drift which forms on } \\
\text { the side of a hill, sloping } \\
\text { outward at the top and } \\
\text { forming a huge concave at } \\
\text { the bottom." }\end{array}$ & $\begin{array}{l}\text { The tallest and most } \\
\text { dramatic drifts. Due to } \\
\text { their depth and density, } \\
\text { they are impossible to } \\
\text { conventionally survey, } \\
\text { but they may store } \\
\text { millions of } \mathrm{m}^{3} \text { of snow } \\
\text { water. }\end{array}$ & $\begin{array}{l}\text { Spalding and } \\
\text { Kusugaq, } 1998\end{array}$ \\
\hline aputi & $\begin{array}{l}\text { "Snow on the ground" (i.e., } \\
\text { snow that has fallen already) }\end{array}$ & - & $\begin{array}{l}\text { A. Pedersen, } \\
\text { pers. comm., } \\
2015\end{array}$ \\
\hline aniuvaq & $\begin{array}{l}\text { "Snow lying on slopes of } \\
\text { hills." }\end{array}$ & $\begin{array}{l}\text { Long drifts, which } \\
\text { "smooth" winter } \\
\text { topography. The last } \\
\text { drifts to melt due to their } \\
\text { large storage. }\end{array}$ & $\begin{array}{l}\text { Spalding and } \\
\text { Kusugaq, } 1998\end{array}$ \\
\hline iglusaq & $\begin{array}{l}\text { "Snow that can become an } \\
\text { iglu" (i.e., hard snow that } \\
\text { can be cut into blocks for } \\
\text { building) } \\
\text { English term (wind slab) } \\
\text { refers to formation, rather } \\
\text { than function. }\end{array}$ & $\begin{array}{l}\text { Small, closely-bonded } \\
\text { grains that have been } \\
\text { broken in the wind and } \\
\text { deposited at the end of a } \\
\text { snow storm. Very strong. } \\
\text { Density }>350 \mathrm{~kg} \mathrm{~m}^{-3} \text {, } \\
\text { though "good" iglusaq } \\
\text { seems to be }>400 \text {. }\end{array}$ & $\begin{array}{l}\text { Original } \\
\text { source not } \\
\text { noted in field } \\
\text { journal. }\end{array}$ \\
\hline mangusait & $\begin{array}{l}\text { "Snow that melts snow." } \\
\text { Refers to snow that comes } \\
\text { down warm in the spring, } \\
\text { with a high liquid water } \\
\text { content. Freezes at the snow }\end{array}$ & $\begin{array}{l}\text { Most significant when } \\
\text { the weather is coming } \\
\text { from the sea (SSE at } \\
\text { Iqaluit), as this air will be } \\
\text { warmer, more humid, }\end{array}$ & $\begin{array}{l}\text { D. Taukie, } \\
\text { pers. comm., } \\
2016 \text { (concept) } \\
\text { D. Tikvik, }\end{array}$ \\
\hline
\end{tabular}


surface, releasing latent heat and richer in salts which and warming the snowpack. depress the freezing point.

"Not completely thawed" snow in the shoulder season that is becoming slushy and hard to travel in

"Snow drift forming in the

qimukjuk

uluarnaq

uqaluraq lee of a projection, which tapers gradually to the ground."
May re-harden during evening travel

Often found on the lee side of rocks after wind storms. These can be very hard and dense, formed from tumbling crystals. Indicate direction of storm winds.

Form in open areas with singular prevailing winds, such as sea or lake ice in wide fjords or valleys.

"woman's knife".

"Tongue-shaped snowdrift, aligned to the prevailing

"Cheek-shaped snowdrift, rounded." Might be alternatively called barchan dunes. Resemble the crescent-shaped $u l u$ or night-time cooling early Spalding and in the spring, allowing Kusugaq, 1998

Spalding and Kusugaq, 1998 wind, useful for

navigation."

pers. comm., 2017
Often teardrop-shaped (with "tail" pointing away from the prevailing wind).

\author{
Spalding and \\ Kusugaq, 1998 \\ R. Qitsualik, \\ pers. comm., \\ 2016
}




\section{Appendix E - Terrain Variables Used For Snow Modeling}

\section{E.1 Terrain Curvature}

Terrain curvature is a well-established topographic parameter (e.g. Hengl and Reuter, 2008, Wood, 1996, Zevenbergen and Thorne, 1987, Evans, 1972), and is commonly described as the second derivative of elevation, or as the radius of a curve defined by the intersection of the terrain surface with a plane. Measured in units of $1 / M$, where $M$ is the map unit, negative curvatures indicate a concave surface, whereas positive values indicate a convex surface. The essential topographic curvatures defined by Zevenbergen and Thorne (1987) are profile and planform (also referred to as "contour") curvature, which intersect with the $(x, z)$ and $(x, y)$ planes, respectively, where $x$ is the aspect direction and $y$ the horizontal perpendicular to $x$.

Profile curvature represents the rate of change of slope, and is commonly used as an index of gravitational potential, for example when modeling soil wetness or mass wasting. Planform curvature indicates the inflection of a slope's cross-section through the $(x, y)$ plane, and is commonly used to as a convergence/divergence index for overland flow and wetness modeling. The other forms of curvature calculated for this study were: longitudinal curvature (Wood, 1996), which intersects with the plane defined by $x$ and the slope normal, and tangential curvature (Schmidt et al., 2003, Krcho, 1991), which intersects the plane defined by $y$ and the slope normal.

\section{E.2 Normalized Height}


Normalized height $(\mathrm{NH})$ is a hydrologically oriented metric indicating a location's position between the local altitude of drain culmination $\left(z_{d}\right.$, the lowest point, assigned a value of 0$)$ and the altitude of summit culmination $\left(z_{s}\right.$, the highest point, assigned a value of 1), defined by determining the weighted mean upslope altitude:

$$
\mathrm{z}_{\mathrm{s}}=\frac{\sum_{\mathrm{i}}^{\mathrm{n}} \frac{\mathrm{z}_{0}}{\sqrt{\mathrm{A}_{\mathrm{Ci}}}}}{\sum_{\mathrm{i}}^{\mathrm{n}} \frac{1}{\sqrt{\mathrm{A}_{\mathrm{Ci}}}}}-\mathrm{z}_{0}
$$

Where $z_{0}$ is the target grid cell's altitude, $z_{0 i}$ is the altitude of the $i$ 'th grid cell upslope of $z_{0}$, and $A_{C i}$ is the target grid cell's catchment area. To calculate $z_{d}$, inverted altitudes are used in the same formula, and altitudes are then normalized by Equation 30. The $N H$ metric was developed by Böhner and Selige (2006) for predicting soil attributes, but has been successfully applied for airflow modeling in gentle terrain in Germany (Dietrich and Böhner, 2008).

Large snowdrifts typically occur in the lower portion of windward slopes and the middle portion of leeward slopes, and $\mathrm{NH}$ might improve a classification model's ability to differentiate between these distinct depositional environments. Furthermore, since $\mathrm{NH}$ is defined from hydrological analysis rather than an a priori scale specification, it was an appealing alternative to the explicitly user-scaled metrics used elsewhere in this study.

\section{E.3 Topographic Openness}

Topographic openness $(\mathrm{O})$ is an angular measure of the relation between surface relief and horizontal distance from a given point (Yokoyama et al., 2002). There are 2 "perspectives"; positive openness $\left(\mathrm{O}_{+}\right)$represents a point's dominance above the surrounding terrain, whereas negative openness (O_) represents its enclosure within the 
terrain. For a target point $A, \mathrm{O}$ is calculated by defining a radius $L$, and finding the highest and lowest points for the 8 primary directions $D_{1: 8}$.

Along the line defined by $D$ and $L$, elevation angle $\beta_{D, L}$ from $A$ to any distant point $B$, defined relative to the horizon, is given by:

$$
\beta_{D, L}=\tan ^{-1}\left[\frac{\left(z_{B}-z_{A}\right)}{\sqrt{\left(x_{A}-x_{B}\right)^{2}+\left(y_{A}-y_{B}\right)^{2}}}\right]
$$

Where $x, y$, and $z$ are the horizontal and vertical axes, $B$ is either the highest (for $\mathrm{O}_{+}$) or lowest (for $\mathrm{O}_{-}$) point along the $D-L$ line, and $\beta_{D, L}$ is in degrees. The zenith angle $\left({ }_{D} \phi_{L}\right)$ from $A$ to $B$ is then calculated by subtracting $\beta_{D, L}$ from $90^{\circ}$, whereas the nadir $\left({ }_{D} \psi_{L}\right)$ is calculated by adding it to $90^{\circ}$. At $\mathrm{A}, \mathrm{O}_{+}$is then the average zenith $\left(\phi_{L}\right)$ for radius $L$, whereas $\mathrm{O}_{-}$is the average nadir $\left(\psi_{L}\right)$. Thus conceptually, $\mathrm{O}_{+}$is $A$ 's "openness to the sky", and $\mathrm{O}_{-}$is it's "enclosure within the earth".

As noted by Yokoyama et al. (2002), O. may initially seem redundant; for a 1-D profile, $\mathrm{O}_{-}$is the exact inverse of $\mathrm{O}_{+}$. However, when calculated from multiple azimuths over an irregular 2-D surface, the 2 perspectives can differ strongly. For a perfectly planar surface, $\mathrm{O}_{+}=\mathrm{O}_{-}=90^{\circ}$. By comparison, a summit takes $\mathrm{O}_{+}>\mathrm{O}_{\text {, }}$, whereas a depression, or "inverted summit", takes $\mathrm{O}_{-}>\mathrm{O}_{+}$. Given an appropriately chosen $L$, a summit (depression) will take $\mathrm{O}_{+}\left(\mathrm{O}_{-}\right)>90^{\circ}$, indicating an obtuse angle between the vertical and the horizon. For irregular surfaces, the 2 values will vary freely, but whichever is larger defines that point's "predominant" condition, exposed or enclosed.

Though topographic openness was originally developed as an aspect-independent alternative to hillshading for topographic visualization (Yokoyama et al., 2002), it has received increasing attention in the geomorphological literature in the past decade. Openness has proven useful in automated landform classifications (e.g. Anders et al, 
2011(a) and (b), Prima and Yoshida, 2010, Anders et al 2009, Prima et al, 2006), but has seen more limited usage in geophysical process research.

To my knowledge, only one other study has incorporated openness in a snow distribution model: Hanzer et al (2016) employed negative openness in a glacierized Alpine watershed in Austria, calculating O. at a radius of 50 and $5000 \mathrm{~m}$ for a $50 \mathrm{~m}$ DEM, and a study area covering $558 \mathrm{~km}^{2}$. They used these to define a "snow redistribution factor", where O. was clipped between upper and lower thresholds to define the amount of precipitation that could be retained on surfaces ranging from steep and highly exposed to strongly wind-sheltered (indexed by small and large O. values, respectively). They found that this parameterization significantly improved their snow distribution model relative to adjustment for elevation and snowfall undercatch, as only the simulations parameterized with the $\mathrm{O}$ - redistribution factor were able to reproduce the observed temporal variations in SWE.

\section{E.4 Wind Shelter Index}

Wind flow is accelerated over windward slopes, and decelerated over leeward slopes. If slope transitions are gentle, flow modification is minor, but where slope breaks occur, flow separation causes rapid deceleration. The accompanying drop in fluid shear stress in the leeward eddy zone reduces the wind's transport capacity, and a fraction of transported snow crystals may be deposited. This drives the formation of large, impressive snowdrifts in the lee of dramatic topographic obstacles, such as cliffs.

To index a location's topographic sheltering by upwind slope breaks, Winstral et al (2002) devised the wind shelter index $(W)$. The algorithm works by specifying a wind direction, $A$, and a search distance, $d$. Then, for a given $A$, slope between the target grid 
node $x_{0}$ and each upwind grid node $x_{1}, x_{2} \ldots x_{n}$ is determined, and the maximum value retained, such that:

$$
\mathrm{W}(\mathrm{x})=\tan ^{-1}\left[\max \left(\frac{\mathrm{z}_{0}-\mathrm{z}_{\mathrm{i}}}{\left|\mathrm{x}_{0}-\mathrm{x}_{\mathrm{i}}\right|}\right)\right]
$$

Increasing positive values for $W$ indicate a greater degree of wind sheltering at $x_{0}$, whereas a value of 0 indicates that $z_{0}$ is equal to all upwind elevations - this might occur, for example, on a frozen lake. Negative values indicate increasing exposure to wind as $z_{0}$ 's dominance over the upwind landscape increases. Increasing the search distance increases the likelihood that a grid node will be considered "sheltered" by some point upwind, though $W$ for locations sheltered by a distant point will be small.

To account for lateral diversion of wind direction by terrain, Winstral et al calculated the mean $W$ for the target location from multiple azimuths within an angular tolerance. Plattner et al (2004) later extended this by determining $W$ from all cells within a specified angular region. During their study in the Austrian Alps, they found that wind redistribution overtook elevation as an important snow depth predictor at altitudes $>3050$ $\mathrm{m}$. Their 2 optimal parameter combinations were $d=60 \mathrm{~m}$ and $250 \mathrm{~m}$, with tolerances of 10 and $15^{\circ}$, respectively. The Plattner et al algorithm was coded into the RSAGA geocomputing package (Brenning, 2008), and employed in this study.

Winstral et al (2002) found that $W$ was a significant snow depth predictor for a small watershed in the Colorado Rockies; in testing $d$ between 50 and $2000 \mathrm{~m}$, an optimal distance was found at $100 \mathrm{~m}$. Studies at Reynolds Creek Experimental Watershed in the Idaho Rockies (Winstral et al, 2013, Winstral and Marks, 2002) used $W$ to provide windfield scaling for the ISNOBAL distributed snow model, and delineated potential drift zones by finding the difference between a location's WSI at $d=60 \mathrm{~m}$ and $d=1000 \mathrm{~m}$. 
The conceptual basis for this delineation originated with the equilibrium fetch concept of Takeuchi (1980) and Pomeroy et al (1993); exposure at long range indicates greater potential mass transport from the upwind fetch, while shelter at a short range indicates greater deceleration and thus drift potential. Overall, $W$ was found to be a powerful predictor for wind speeds, and replicated observed drift patterns very well.

Further alpine studies have indicated similarly strong performance; Erickson et al (2005) found that $W$ was a statistically significant predictor for snow depth in every year of their study, and Schirmer et al (2011) used $W$ to generate wind fields for a numerical simulation in an alpine study. Schirmer et al selected $d=300 \mathrm{~m}$ from observed variations in wind speed at exposed and sheltered meteorological stations, and a $30^{\circ}$ tolerance, to calculate $W$ for a $10 \mathrm{~m}$ DEM.

For this study, field experience suggested that wind diversion around a topographic obstruction in the NRW is minimal with increasing distance, so an angular tolerance of $\pm 10^{\circ}$ was specified around a search azimuth of $340^{\circ}$ (the prevailing wind direction). To investigate the role of topography at varying scales, multiple search distances from $15 \mathrm{~m}$ (on the order of reported wind-snow variance ranges from Mott et al, 2011) to $1000 \mathrm{~m}$ (the long-distance used by Winstral et al, 2002) were tested. 


\section{Appendix F-Terrain Unit Model: Supplementary Statistics}

Correlations between SWE depth and the terrain variables used are given in Table 14. In 2015, only $\mathrm{C}_{\mathrm{L}}$ and $\mathrm{O}_{+10 \mathrm{~K}}$ were statistically significant at the Bonferroni-adjusted $\alpha$ level. All correlations were stronger in 2016 , with only $O_{-10 K}$ being statistically insignificant in both years. In both years, $W_{30}$ was highly significant, especially in 2015.

Table 14: Spearman correlations between measured SWE and the terrain variables used for cluster analysis. Bonferroni-corrected $\alpha=7.1 \times 10^{-3}(0.05 / 7)$.

\begin{tabular}{lcc}
\hline & $\mathbf{2 0 1 5}$ & $\mathbf{2 0 1 6}$ \\
Parameter & Spearman's $\boldsymbol{\rho}(\boldsymbol{p}$-val $)$ & Spearman's $\boldsymbol{\rho}(\boldsymbol{p}$-val $)$ \\
\hline $\mathrm{NH}$ & $-0.176\left(2.7 * 10^{-3}\right)$ & $-0.419\left(1.3 * 10^{-9}\right)$ \\
Slope & $-0.089\left(1.3 * 10^{-1}\right)$ & $0.276\left(1 * 10^{-4}\right)$ \\
$\mathrm{C}_{\mathrm{T}}$ & $-0.097\left(1.0 * 10^{-1}\right)$ & $-0.370\left(1.1 * 10^{-7}\right)$ \\
$\mathrm{C}_{\mathrm{L}}$ & $-0.232\left(6.6 * 10^{-5}\right)$ & $-0.450\left(5.0 * 10^{-11}\right)$ \\
$\mathrm{O}_{+10 \mathrm{~K}}$ & $-0.250\left(1.7 * 10^{-5}\right)$ & $-0.483\left(1.1 * 10^{-12}\right)$ \\
$\mathrm{O}_{-10 \mathrm{~K}}$ & $0.102\left(8.2 * 10^{-2}\right)$ & $0.117\left(1.03 * 10^{-1}\right)$ \\
$\mathrm{W}_{30}$ & $0.373\left(5.5 * 10^{-11}\right)$ & $0.393\left(1.6 * 10^{-8}\right)$ \\
\hline
\end{tabular}




\section{Appendix G - Heuristics in Snow and Soil Science}

Heuristics are informal approaches to problem solving, encompassing a variety of techniques, such as trial-and-error, "rules of thumb”, or approximation. Koen's (1985) definition of heuristics includes 4 key points: (1) Heuristics do not guarantee a solution, (2) they may contradict one another and still be useful, (3) they may reduce the search time in solving a problem, and (4) their standard of validity can be taken from immediate context, rather than absolute truth.

Heuristics are commonly employed where resources are limited in some way; e.g., the system is poorly understood, it cannot be effectively modeled with existing methods, or an optimal solution is difficult to define. Koen (1985) states that the role of heuristics is "to cause the best change in a poorly understood situation within the available resources". Explicitly heuristic methods are uncommon in snow science, so the following section is devoted to (1) justifying their use in this study, and (2) exploring their use in soil science and geomorphometry, as proxies for the snow mapping problem.

The processes driving snow transport are relatively well understood, but major gaps remain; for example, the processes controlling a snowpack's threshold shear stress and the initiation of saltation, have yet to be fully elucidated. These gaps persist in part because they occur at spatial and temporal scales that cannot be adequately captured by current modeling techniques. For routine measurements, deficiencies are at their worst in the Arctic; the Arctic meteorological network is sparse and remote stations often have uncertainties or extended gaps (Mekis and Hogg, 1999). In particular, winter snowfall measurements are prone to massive errors (Liston and Sturm, 2004, 2002, Goodison et 
al., 1998), and these are exacerbated by Arctic winter cold and high wind speeds (Wolff et al., 2015).

For the more obscure variables required for detailed snow transport modeling, such as crystal morphology at snowfall (which affects a crystal's aerodynamic drag, Theriault et al., 2012, Rasmussen et al., 1999), blowing snow particle density (a direct measure of saltation, Mann et al., 2000, see Pomeroy et al., 1997 for a brief discussion of particle counters at a remote Arctic station) or snowpack metamorphic processes (which affect threshold shear stress, Liston et al., 2007, Li and Pomeroy, 1997), measurements may not even be possible at dedicated research stations. Even when the governing equations can be resolved at appropriate scales, matching measurements may not be available; for example, empirical saltation equations are often based on 7.5 or $15 \mathrm{~min}$ intervals (e.g., Pomeroy and Gray, 1990), but standard meteorological measurements are reported on an hourly or daily time step.

A heuristic (or "knowledge-based") approach may in fact be a reasonable alternative to providing a physically-based model with poor inputs and uncertain parameterizations. In Koen's (1985) engineering context, heuristics are useful for problem solving, and their contextual solutions are acceptable; when the context changes, new engineering heuristics can be developed. In contrast, the general objective of scientific research is to abstract natural principles from empirical observations (Chalmers, 1999). Heuristics cannot always be easily extended in this way, given their focus on a given context. Another problem for scientific applications is Koen's $2^{\text {nd }}$ point, that contradicting heuristics can each be "valid". Under a traditional scientific hypothetical- 
deductive framework, the most accurate and parsimonious theory should be retained, and others discarded.

Despite this apparent disagreement, heuristics are commonly employed in science to provide a decision framework where data is insufficient, optimization is impossible, or an approximation is needed (Gigerenzer, 2008). This is done at various levels of abstraction; from research program design (Chalmers, 1999) down to process design and measurement theory. Indeed, Kuhn (1970) argued that heuristic or intuitive approaches were essential to defining a discipline's research "paradigm", a broad theoretical framework that facilitates methodological progression and ordered knowledge development within a scientific research program.

As noted above, heuristic approaches to snow distribution mapping are uncommon (but see Mizukami et al., 2003, or Purves et al., 1998, for examples). Instead, proxies can be found elsewhere in the geosciences, where heuristic or "knowledge-based" classification of complex continuous variables is needed, often where data is limited. As stated by Valentine and Kalnins (2016): "this kind of task is straightforward to an experienced human eye", but "simple rules break down in the face of the complexities inherent to real data from the natural world".

In soil science, classification and mapping at a landscape scale often relies on expert field knowledge to generate accurate maps, so heuristic approaches are commonplace (Bui, 2004, Hudson, 1992, Skidmore, 1989). Hudson (1992) states that soil surveying and mapping are poster-children for Kuhn's (1970) scientific paradigm, arguing that the soil survey requires tacit (experiential) knowledge to identify natural groupings in the landscape. Thus, the heuristic is essential for accurate soil mapping. The 
caveat is that this knowledge can be difficult to thoroughly and clearly express; "we can know more than we can tell" (Polanyi, 1966). Hudson (1992) argues that reliance on tacit knowledge and maps alone is inefficient for the soil-mapping paradigm, stating the clear need for sophisticated linguistic communication techniques.

Likewise, Bui (2004) argues that the various heuristics in soil surveying and mapping constitute a structured knowledge system capable of generating large amounts of useful information. The soil mapper's logic must be explicitly presented in order to make this information accessible to the non-expert. Bui reviews techniques to formalize and express a heuristic soil model's logic, and like Hudson (1992), she identifies a clear need for vocabulary as distinct from a map or diagram. For our purposes, it is worth noting that this is also required under the scientific requirements of transparency and repeatability.

One of the most effective linguistic communication approaches is the use of Boolean decision rules. These are conceptually approachable, and lend themselves to computation, such as within a geographic information system (GIS). This application is rapidly growing; heuristics are often integrated into GIS-based object-oriented classification and machine-learning techniques for landform identification (Valentine and Kalnins, 2016, Podobnikar and Szekely, 2015, Qin et al., 2013, Hengl and Reuters, 2008).

Macmillan et al. (2007) applied a "hybrid" approach to soil and landform classification for spatial ecological modeling in central British Columbia. Relevant landscape entities were identified from existing field guides and classification schemes for the study area. Once these entities were "translated" into definitive and mutually 
exclusive groups, Boolean rules could be used for automated classification from multiple data sources. These rules for were iteratively defined, and validated against fieldclassifications performed by local knowledge-holders who were "blind" to the authors' predictions. Their map accuracy was $66-70 \%$, roughly equivalent to the typical agreements between multiple knowledge-holders classifying the same area on the ground ( $65 \%$ on average, for a given traverse). In keeping with the recommendations of authors such as Bui and Hudson, MacMillan et al. supplied explicit linguistic/mathematical definitions for their decision rules and the fuzzy logic used to resolve potential class membership conflicts. 


\section{Appendix H - Decision Rule Model: Supplementary Statistics}

The Spearman correlations between SWE accumulation and the terrain variables used in the decision rules are shown in Table 15. The correlations with $\beta$ and $W_{30}$ are the same as those in the cluster analysis method, but the $O_{+}$and $O_{-}$radii are $25 \mathrm{~m}$ rather than the $10 \mathrm{~km}$ radii employed in the cluster analysis method. The general trend of stronger and more statistically significant correlations in 2016 than in 2015 was observed for the TU models, and is also observed for the short-radius openness calculated for DR, further suggesting that the role of terrain was somehow more important for snow distribution in 2016 than in 2015. Neither correlation with slope nor negative openness is statistically significant in 2015, but as discussed above for the TU models, these correlations fail to account for interactions with wind direction and sheltering.

Table 15: Spearman correlations between the measured SWE and the terrain variables used in the decision rules. Bonferroni-corrected $\alpha=1.25 * 10^{-2}(0.05 / 4)$.

\begin{tabular}{lcc}
\hline & $\mathbf{2 0 1 5}$ & $\mathbf{2 0 1 6}$ \\
Parameter & Spearman's $\boldsymbol{\rho}(\boldsymbol{p}$-val $)$ & Spearman's $\boldsymbol{\rho}(\boldsymbol{p}$-val $)$ \\
\hline$\beta$ & $-0.089\left(1.3 * 10^{-1}\right)$ & $0.276\left(1.0 * 10^{-4}\right)$ \\
$O_{+25}$ & $-0.358\left(5.3 * 10^{-10}\right)$ & $-0.576(p<<<\alpha)$ \\
$O_{-25}$ & $0.143\left(1.56 * 10^{-2}\right)$ & $0.336\left(8.2 * 10^{-6}\right)$ \\
$W_{30}$ & $0.373\left(5.5 * 10^{-11}\right)$ & $0.393\left(1.6 * 10^{-8}\right)$ \\
\hline
\end{tabular}




\section{Appendix I - Meteorological forcing data for 2015 and 2016}

SnowModel's required forcings are air temperature $\left(T_{a}\right)$, relative humidity $(R H)$, wind speed $(u)$, wind direction $(\theta)$, and precipitation $(P)$, at an hourly-to-daily interval. These are typically drawn from one or more station observations, spatially distributed by the MicroMet submodel (Liston and Elder, 2006b). The transformation follows 3 broad steps:

1. The 1-D station data is read by the "MicroMet preprocessor" (MMPP), which checks data quality and fills missing periods.

2. The checked, gap-filled 1-D series is then passed to MicroMet, which spatially-distributes the inputs over the 2-D domain at every time step.

3. For each time step, MicroMet then uses established meteorologicaltopographic relationships to:

a. Modify the distributed input forcings based on spatial context.

b. Simulate distributions of shortwave and longwave radiation, as well as barometric pressure, from the input forcings.

c. If observations for the simulated variables are available, they can be incorporated using a data-assimilation routine.

Missing data cause errors during spatial interpolation, so the MMPP is used to identify gaps or erroneous values (following Meek and Hatfield, 1994). Single missing values are filled by linear interpolation, whereas longer gaps are filled with an autoregressive integrated moving average (ARIMA; Walton, 1996, Box and Jenkins, 1976). The ARIMA uses the data preceding and following the gap to create an average forecast to fill the gap. 
For observations from northern meteorological stations, especially during winter, data quality checks are essential. Power outages, anemometer icing, datalogger failures, and snow capping of snowfall gauges are a subset of the potential problems that may be caught by the MMPP. Liston and Elder (2006b) provide assessment results for the MMPP, suggesting that for periods of less than 3 days, it shows strong performance (Nash-Sutcliffe coefficient $>0.79$ ), but longer periods are less reliably handled.

For this study, outside of MMPP, a circular-interpolation function was written to gap-fill wind-direction data. This was done by first determining the clockwise (CW) distance between known angles $\theta_{0}$ and $\theta_{\mathrm{n}+1}$ over a gap of $n$ hours, as:

$$
\delta \theta=\left(\theta_{0}-\theta_{n+1}\right) \bmod 360
$$

Where $\bmod$ is the modulo operator. If $\delta \theta$ is greater than $180^{\circ}$, then its inverse must be the shortest angular distance over the gap, $\delta \theta_{s}$, determined by:

$$
\delta \theta_{s}=[(2 \delta \theta) \bmod 360]-\delta \theta
$$

If $\delta \theta>180^{\circ}$, then $\delta \theta=\delta \theta_{s}$. The final step is the familiar interpolation, whereby $\delta \theta_{s}$ is divided evenly over the gap:

$$
\theta_{i}=\theta_{0}+\delta \theta_{s}\left(\frac{i}{n}\right) \bmod 360
$$

Where $i$ is the number of hours into the gap.

MicroMet then distributes the pre-processed forcings from a single station over the grid. Given forcings from multiple stations, MicroMet spatially interpolates them to the grid using a Barnes objective analysis interpolation scheme (Barnes, 1964, 1973). Once the variables are spatially interpolated to the domain grid, they are modified according to their terrain context. Each of the 5 input variables is distributed, and the 
inputs are also used to simulate a barometric pressure surface, as well as gridded incoming solar and longwave radiative fluxes.

By default, MicroMet provides an adjustment by increasing precipitation at higher elevations - however, this created an unnaturally strong correlation between simulated snow depth and elevation, whereas surveyed snow depth showed no correlation at all. The adjustment factor was therefore set to 0 , and the station value was applied uniformly over the grid. With the exception of the wind field, other data distributed with the default routines appear reasonable, and their details can be found in Liston and Elder (2006b). These routines are generally well established, though the wind model requires closer examination. 
Air Temperature $\left({ }^{\circ} \mathrm{C}\right)$ - 2014-15

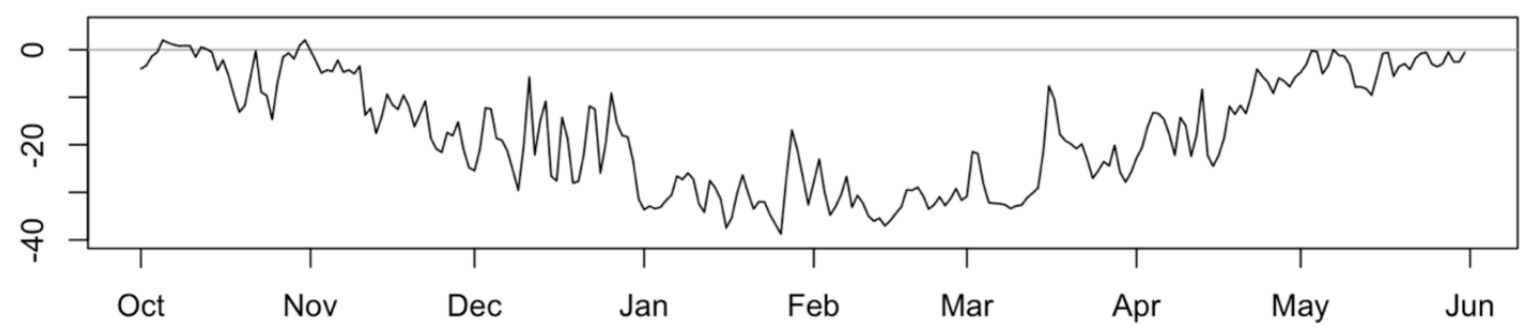

Relative Humidity (\%) - 2014-15

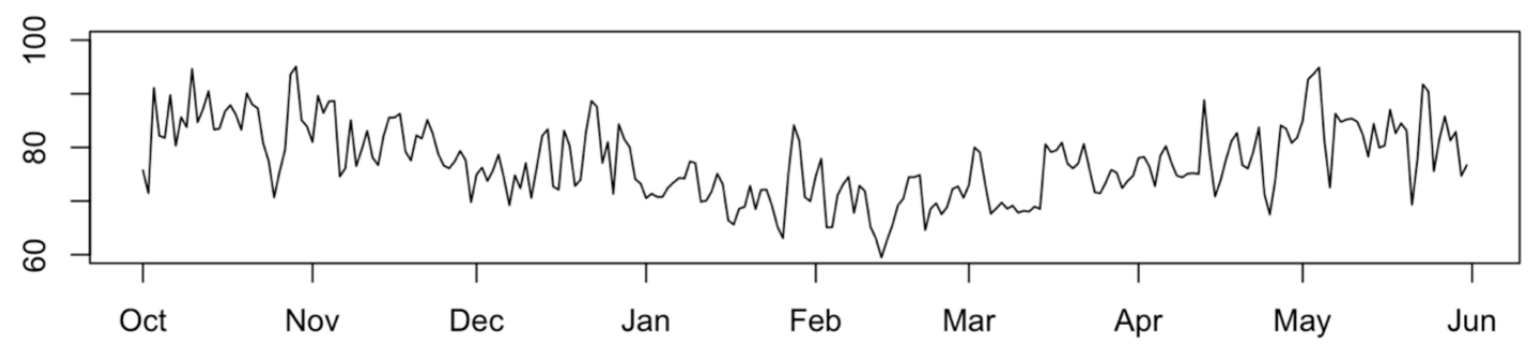

Wind Speed $(\mathrm{m} / \mathrm{s})$ - 2014-15

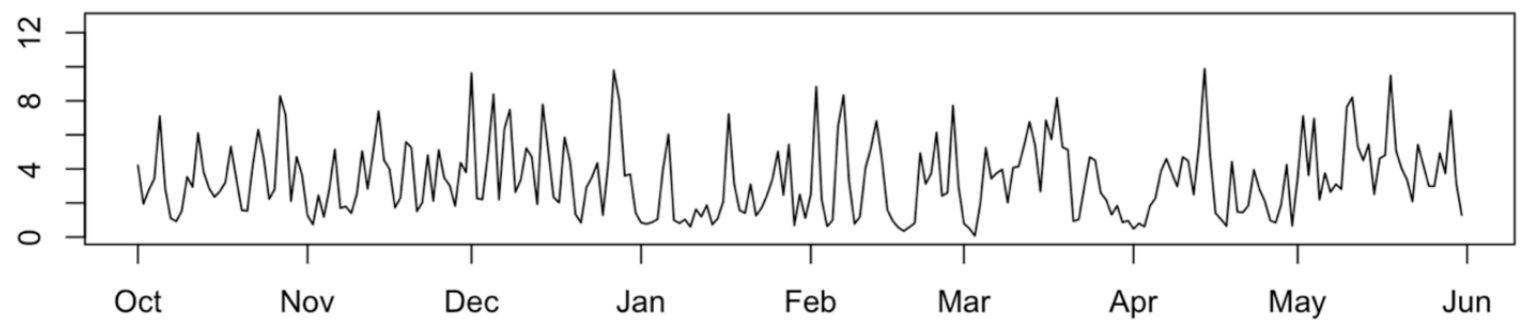

Wind Direction $\left({ }^{\circ}\right)$ - 2014-15

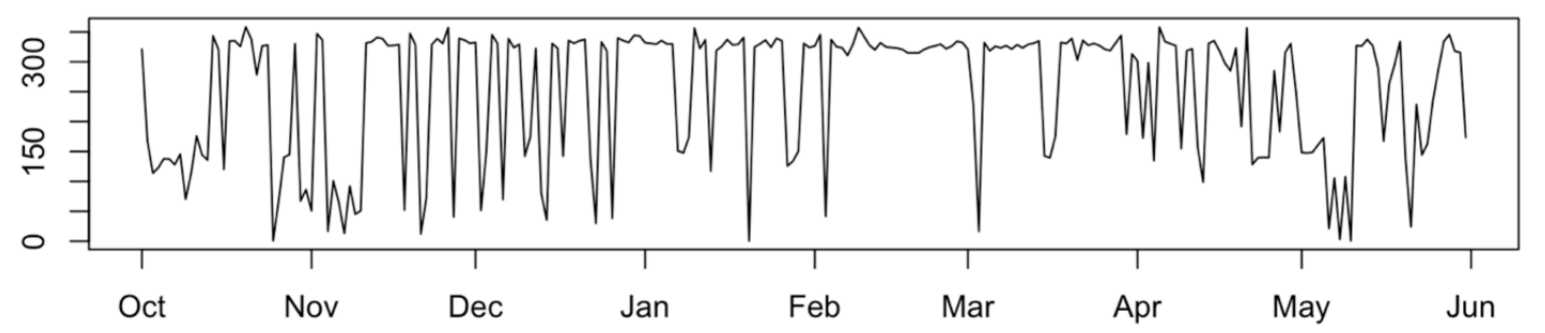

Figure 29: Daily mean meteorological data during the 2015 study winter. Top to bottom:

$T_{a}, R H, u, \theta$. Note common y-axis with plots for 2016. 


\section{Air Temperature $\left({ }^{\circ} \mathrm{C}\right)-\mathbf{2 0 1 5 - 1 6}$}
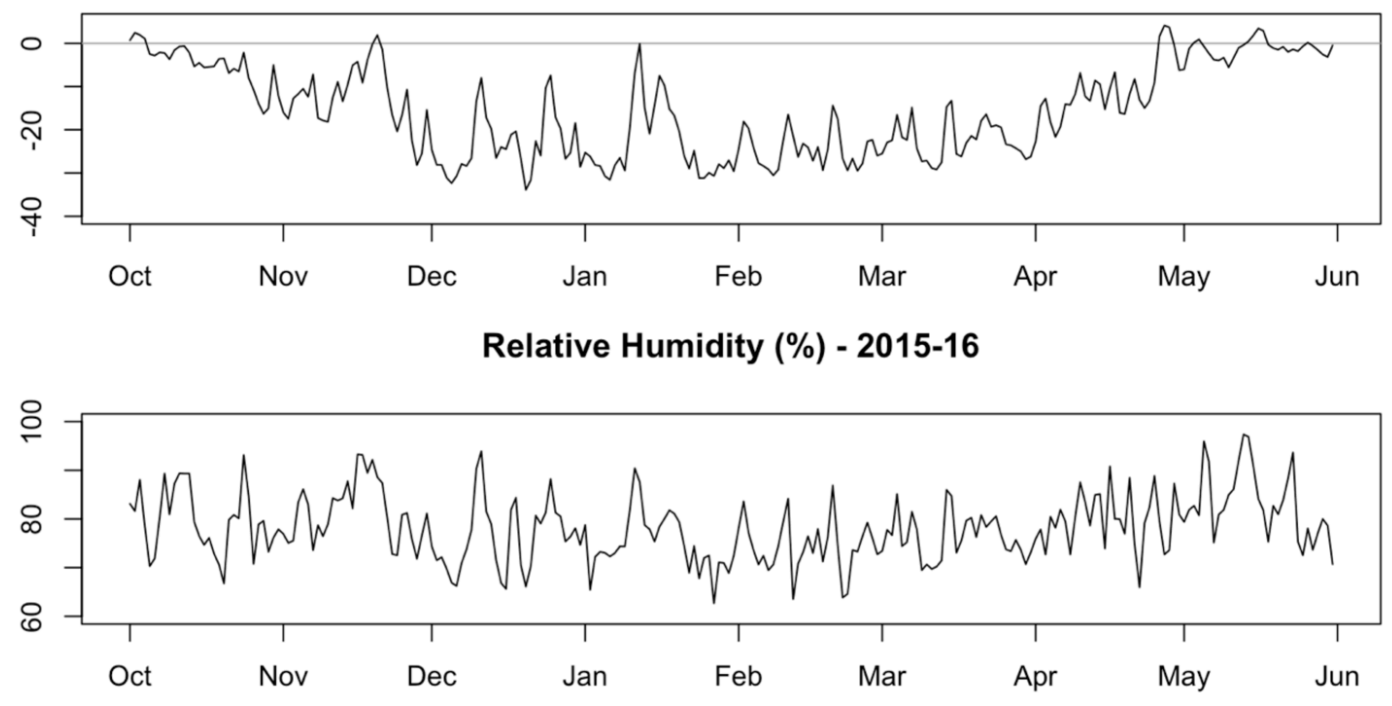

Wind Speed $(\mathrm{m} / \mathrm{s})$ - 2015-16
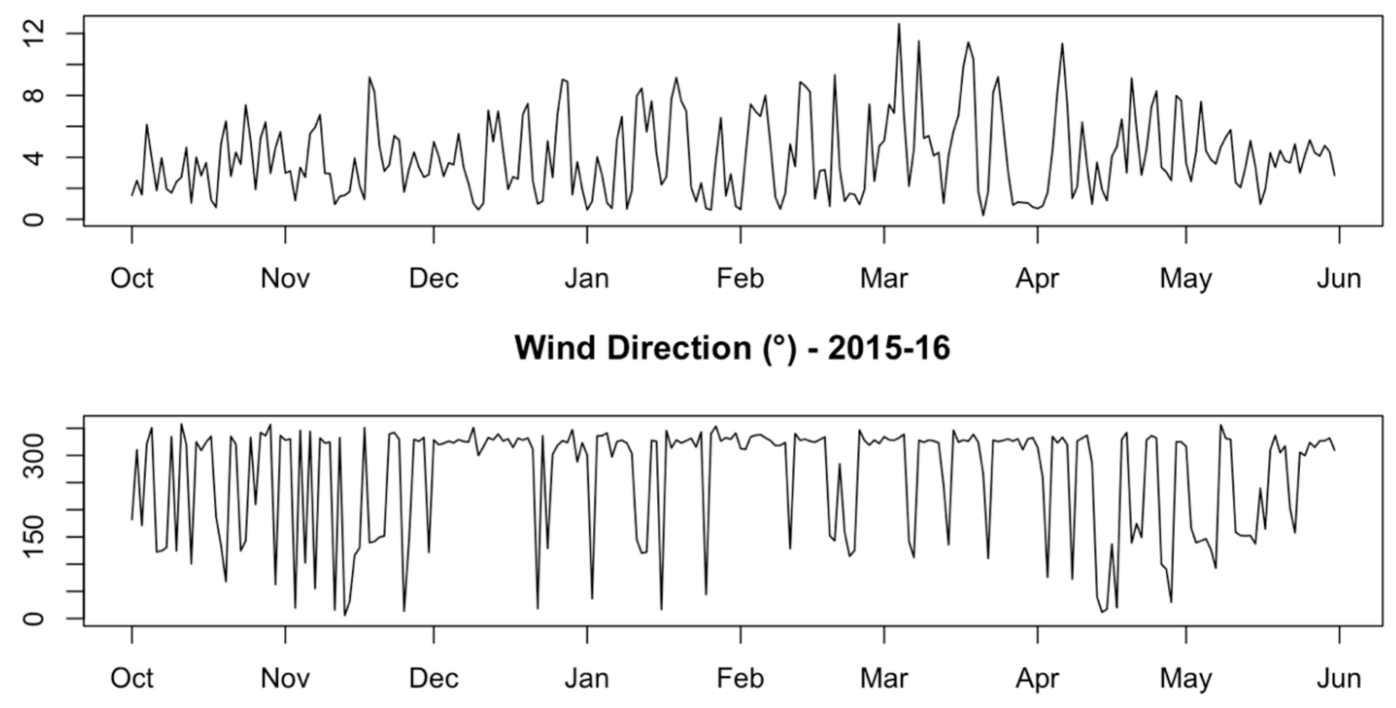

Figure 30: Daily mean meteorological data during the 2016 study winter. Top to bottom: $T_{a}, R H, u, \theta$. Note common y-axis with plots for 2015 . 
WE Precipitation (mm) - DFAR 2014-15

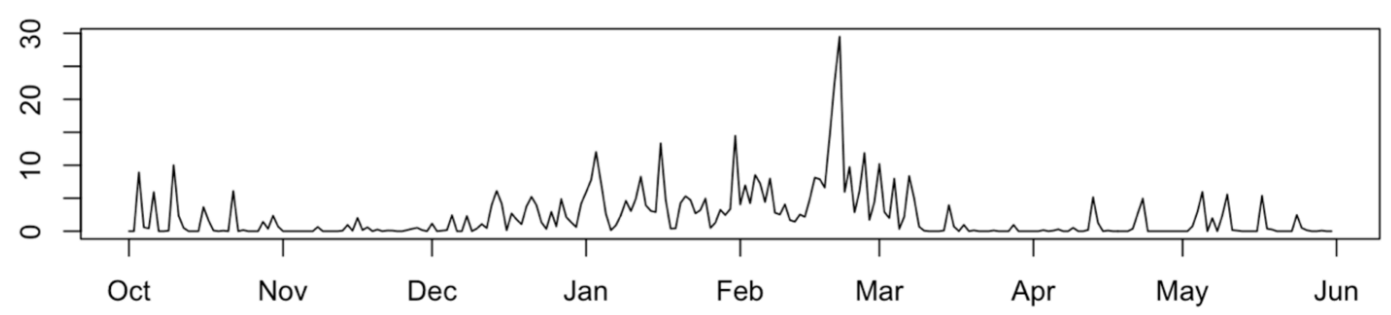

WE Precipitation (mm) - SAGE 2014-15

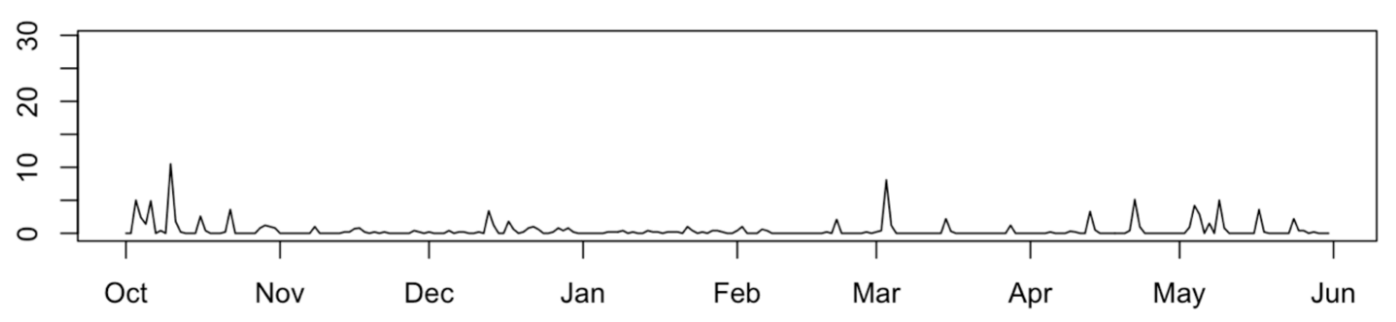

WE Precipitation (mm) - DFAR 2015-16
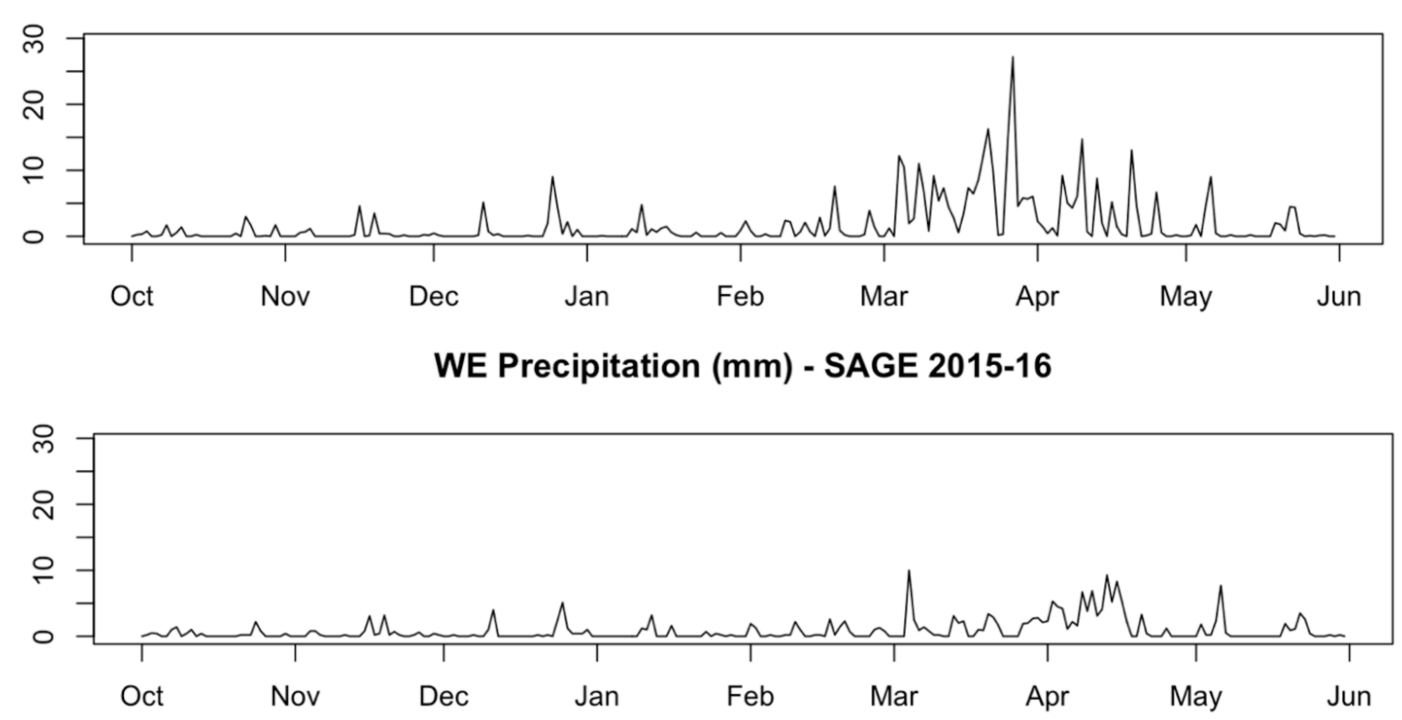

Figure 31:Daily total water-equivalent precipitation for the 2014 and 2015 study winters.

"DFAR" indicates the double-fence gauge, whereas "SAGE" indicates the single-shield gauge, both at XFB. 

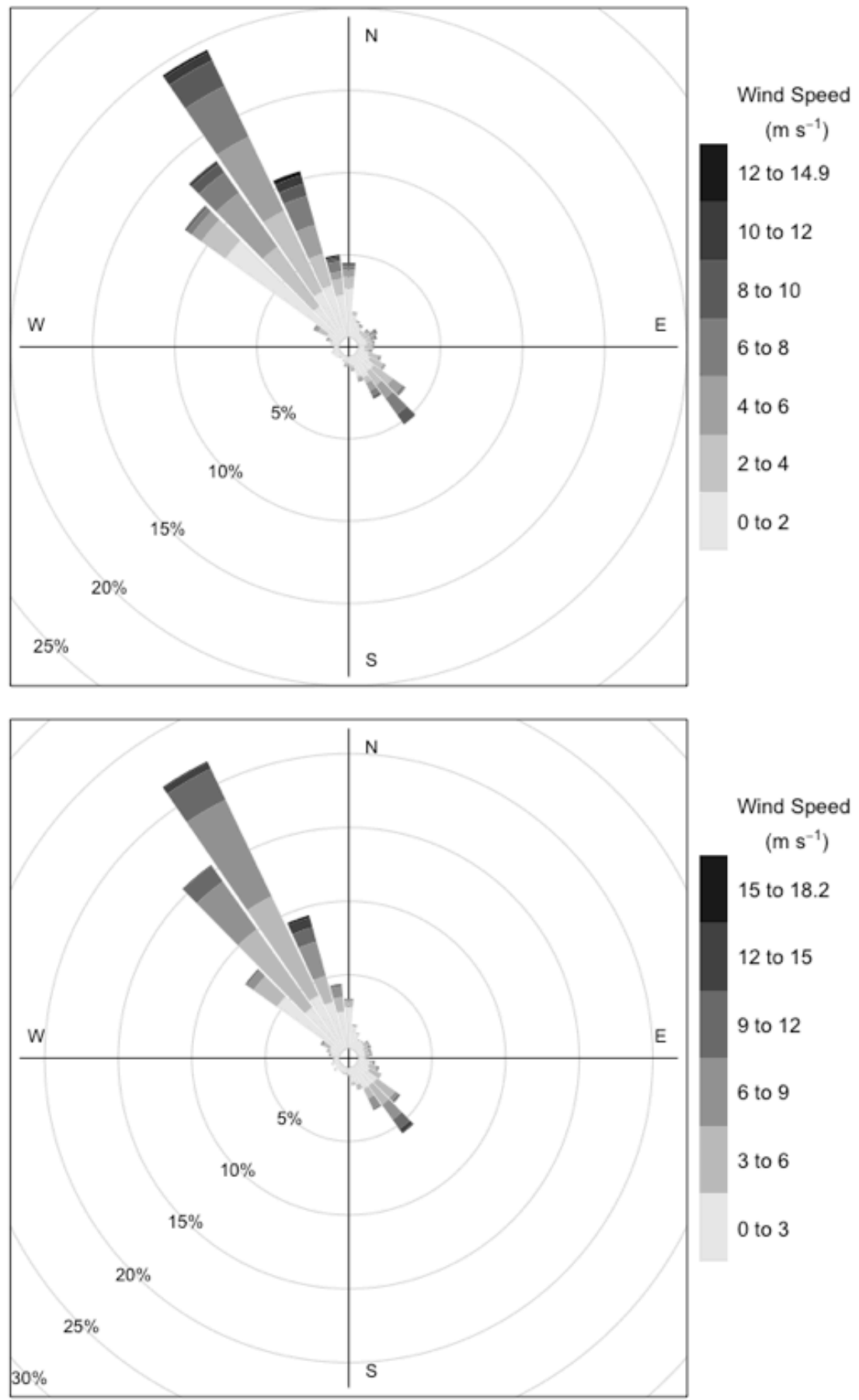

Figure 32: Wind roses for the 2014 (above) and 2015 (below) study winters. 


\section{Appendix J - Errors in Arctic Winter Snowfall Measurements}

Accurate precipitation measurement is one of the most significant challenges in hydrology. The difficulties inherent in the measurement of solid precipitation and snow on the ground (SoG) measurement have been extensively discussed (e.g., Smith et al., 2017, Rasmussen et al., 2012, Doesken and Leffler, 2000, Goodison et al., 1998, Peck, 1972), but lasting solutions have yet to be developed. This is an important hydrological problem at high latitudes; uncertainties in the precipitation term of the water balance are the most significant cause of failure in water-budget closures for Canadian basins (Wang, 2015).

At regional and larger scales, this uncertainty is driven by the limited spatial density of the meteorological station network, requiring hydrologists to interpolate their measurements to provide continuous precipitation data. This is important in the sparsely populated Canadian Arctic, where measurements from a limited number of monitoring stations established since the 1940's, must be used to represent large and heterogeneous areas (Mekis and Hogg, 1999). North of $60^{\circ} \mathrm{N}$ in Canada, the 1999 average density was 1 station per $100,000 \mathrm{~km}^{2}$, with inconsistent recording periods, further reducing the effective useful density (Vincent and Gullett, 1999).

At the site-scale, further uncertainties arise from stochasticity in hydrometeor number density, causing errors between gauges at a single measurement site (Goodison et $a l ., 1998)$. Furthermore, the choice of site instrumentation can strongly affect the measurements taken, with gauge-specific errors such as wind-induced under-catch, gauge wetting, evaporative loss, snow capping and dumping, and temperature-driven gauge drift each accumulating systematic biases in the record (Goodison et al., 1998, Benson, 1982, 
Larson and Peck, 1974). Most of these errors are small, especially when using an automated weighing-gauge, and they often cancel one another out. Moreover, universal corrections are often not available, requiring specific correction factors for every gauge (Duchon et al., 2008, Forland et al., 1996).

By contrast, wind-bias is an important problem in high-latitude or high-altitude climates, where solid precipitation comprises an important part of the water budget. Solid precipitation is far more susceptible to wind bias than rain, due to the low fall velocity and high aerodynamic drag of snow crystals (Theriault et al., 2012, Rasmussen et al., 1999). During high winds, airflow distortion around a precipitation gauge accelerates crystals over the gauge orifice, preventing them from falling into the gauge for measurement. Snowfall gauges in the Arctic can under-report seasonal P estimates by up to $75 \%$ (Liston and Sturm, 2004, Goodison et al., 1998), and can completely miss individual events. The Arctic is also impacted by the high frequency of small events (Mekis, 2005), which are disproportionately affected by gauge errors, and require special attention (Fortin et al., 2008).

Wind also induces SWE measurement errors through blowing-snow events, which can actually cause shielded gauges to overestimate, by catching laterally transported snow originating at the surface in addition to true snowfall. Moreover, blowing snow events cause lateral redistribution and extensive sublimation of snowfall, making it impossible to accurately benchmark gauge measurements with survey measurements. At Trail Valley Creek (TVC), a small shrub-tundra watershed in the Northwest Territory, Pomeroy et al. (1997) observed that $18 \%$ of the annual snowfall was redistributed to drift catchments, while $28 \%$ was sublimated during transport. Snow accumulation estimates 
for Arctic catchments can thus comprise anywhere from 54 to $419 \%$ of snowfall gauge measurements (Pomeroy et al., 1997). Clearly, bias at the snowfall gauge is not the only source of error in Arctic winter precipitation measurements, but adjusting for it is critical to improving northern water budgets.

Sevruk (in Goodison et al., 1998, Annex 1.A) states that gauge design geometry is the most important factor in gauge measurement error, with 4 categories of precipitation gauge accuracy assessment developing since the $18^{\text {th }}$ century:

1. Passive observation and deduction

2. Field intercomparisons of differing installation designs

3. Controlled wind tunnel experiments

4. Simulations employing computational fluid dynamics (CFD)

These latter categories are increasingly common, though expense and difficulty have delayed their implementation.

Modeling with CFD from physical first principles has provided important insights, demonstrating flow patterns around the commonly used Tretyakov (Bolshakov, 1974) and Alter (Theriault et al., 2012) gauge shields. Similarly, wind tunnel experimentation allows for controlled tests of theory and gauge designs, such as the Nipher shield (Goodison et al., 1983). Nešpor (1993) used both wind tunnels and CFD to show that wind is directed upwards against the windward face of a cylindrical gauge, accelerating to its greatest speed over top of the gauge orifice, before slowing and forming turbulent eddies past the gauge's leeward face. Acceleration over the orifice causes a low-velocity circulation inside of the gauge, which can cause solid precipitation to blow back out of the gauge given sufficiently high wind speeds. 
To adjust gauge data for the effects of wind-bias, researchers in the $20^{\text {th }}$ century developed transfer functions - mathematical representations of a system's input/output characteristics. For precipitation gauges, transfer functions are fit by determining an optimal mathematical solution for "catch efficiency" (CE) - the ratio of precipitation measured at the target gauge to the precipitation measured at the reference gauge - as a function of wind speed. Recently, transfer functions have included other environmental variables, such as air temperature, to account for interaction effects such as hydrometeor structure and density. The adjusted, or "true", precipitation is the product of the measured precipitation and the CE's reciprocal (the "gauge adjustment factor" or GAF):

$$
P_{T}=P_{M} * G A F=P_{M} *\left(\frac{1}{C E}\right)
$$

Research into the development of improved transfer functions, based on large datasets, is ongoing, and often involves international collaboration between meteorologists, who can each provide a dataset from a physiographically and/or climatically distinct region. Unfortunately, data from Arctic regions remain limited, so the performance of these functions in regions like the Canadian Eastern Arctic is unknown.

The WMO standard for "true" snowfall is the so-called "bush gauge" at Valdai hydrological research station in Russia. This consists of a Tretyakov gauge in the centre of a 3-hectare shrub field. Full details of the bush gauge's layout can be found in Yang (2014). While bush gauges have been established at other sites internationally (Canada's bush gauge at Caribou Creek, north of Prince Albert, Saskatchewan, began collecting data in February 2013), the WMO recognized that bush gauges were not feasible for most 
contributing members. For example, establishing a bush gauge at sites north of the shrubline (such as Iqaluit, NU), where wind-bias is most severe, would be impossible.

Accordingly, the double-fence intercomparison reference (DFIR) was designated as the WMO standard, and is described in the section below on gauge shielding. Since the bush gauge is the "universal reference", transfer functions to adjust DFIR measurements to match it were developed by Golubev (1986), Yang et al. (1993), and Yang (2014). To avoid error propagation, and because fewer bush-gauge references are available, many authors choose not to employ these functions, instead calling the DFIR their "true" snowfall reference. Modern double-fence gauges incorporate an automated weighing gauge, and are thus referred to as a "DFAR". 


\section{Appendix K - Pre-Processing for the Iqaluit DFAR}

Iqaluit has been the site of multiple ECCC monitoring stations since the 1940's (Table 16). As the only station reporting precipitation measurements during the entirety of the study period, the XFB station was the only logical choice as a precipitation data source. Hourly reports of weather conditions and visibility were provided by the Iqaluit YFB airport's “A (2)” station, which reports incidences of blowing snow.

There are also a number of experimental meteorological instruments co-located with the XFB station, including a high-precision DFAR-shielded precipitation gauge, which provided sub-hourly precipitation data for this study. Data from these "test-bed" instruments are not operationally quality-controlled, and are not widely available.

Table 16: Inventory of currently and historically active ECCC monitoring stations at Iqaluit

\begin{tabular}{|c|c|c|c|c|c|c|}
\hline Name & $\begin{array}{c}\text { Climate } \\
\text { ID \# }\end{array}$ & $\begin{array}{c}\text { Station } \\
\text { ID \# }\end{array}$ & $1^{\text {st }}$ HLY & $\mathrm{n}^{\text {th }}$ HLY & $1^{\text {st }}$ DLY & $n^{\text {th }}$ DLY \\
\hline \multicolumn{7}{|c|}{ Active Stations } \\
\hline Iqaluit Climate & 2402592 & 42503 & 2004 & $2017+$ & 2004 & $2017+$ \\
\hline Iqaluit A (2) & 2402596 & 52079 & 2014 & $2017+$ & - & - \\
\hline \multicolumn{7}{|c|}{ Retired Stations } \\
\hline Iqaluit AWOS & 2402591 & 47388 & 2008 & 2015 & 2008 & 2015 \\
\hline Iqaluit A & 2402590 & 1758 & 1953 & 2014 & 1946 & 2008 \\
\hline Iqaluit UA & 2402594 & 10082 & - & - & 1997 & 2016 \\
\hline \multicolumn{7}{|c|}{$\begin{array}{l}\text { HLY }=\text { hourly data } \\
\text { DLY = daily data } \\
1^{\text {st }} \text { indicates first year recording at this interval } \\
\mathrm{n}^{\text {th }} \text { indicates final year recording at this interval }(2017+\text { indicates an active station })\end{array}$} \\
\hline \multicolumn{7}{|c|}{ Precipitation measurements at XFB are made using a Geonor T-200B (Duchon, } \\
\hline
\end{tabular}


averaging the transducers outputs a stable measurement. This is especially important in high winds, when airflow over the bucket orifice creates a pocket of low pressure via the Bernoulli effect, causing apparent bucket weight to change as it is "pumped" vertically, leading to potentially erroneous accumulation or precipitation intensity estimates. The Geonor transducer response shows a slight temperature-dependence (Duchon, 2008), but due to its limited magnitude $\left(0.005-0.02 \mathrm{~mm}^{\circ} \mathrm{C}^{-1}\right.$, depending on bucket weight) and the difficulty of calibrating a drift relationship for any given transducer, site operators often ignore this effect. Given the Geonor's reliability and accuracy when measuring solid or liquid precipitation, it is one of the primary automatic precipitation gauges in operational use in Canada.

The other gauge type at Iqaluit is the OTT Pluvio ${ }^{2}$ 200-RH (henceforth: Pluvio, OTT Hydromet, 2017), which is installed in the DFAR. The Pluvio records the weight of precipitation in its collecting bucket to the nearest $0.001 \mathrm{~mm}$, by use of a high-precision load cell. An on-board processor automatically filters precipitation accumulation and intensity over the $6 \mathrm{~s}$ intervals, and keeps a running total of accumulation since the instrument's last power-up. The instrument's lower measurement threshold is $0.05 \mathrm{~mm} \mathrm{~h}^{-}$ ; for an hourly total less than $0.05 \mathrm{~mm}$, all $6 \mathrm{~s}$ accumulations are reset to 0 (OTT Hydromet, 2017).

The stability of the load cell, together with the on-board filtering, reduces highfrequency noise, such as that commonly observed in the vibrating-wire transducers used in Geonor gauges. Consequently, the data often doesn't require a post-hoc smoothing filter (such as the Gaussian filter commonly employed to reduce "jitter" in Geonor data). The Pluvio's on-board processor is also capable of diagnosing basic error conditions in 
the gauge or rim heater, providing additional redundancy for quality control. The Pluvio reports 2 categories of error: (a) "Status" errors indicate a problem with the instrument itself, while (b) "Heater" errors indicate a problem with the rim heater. Multiple simultaneous errors are reported by assigning each error a single bit in a 10-bit binary number. Decomposing these binaries gives the full set of errors for each category for each interval.

The Pluvio's orifice rim heater is designed to prevent snow “capping” (building up) on the rim. This is commonly observed in unheated gauges, where the cap can significantly reduce the gauge's catchment area and thus the measurement of event snowfall. The cap can then slough into the bucket at some later point, possibly when precipitation is not occurring, giving a false measurement.

For any weighing gauge, a site technician must empty the bucket before it reaches capacity. When re-installing the bucket, a small amount of oil is added; this creates a "film" at the surface to prevent evaporation. For deployment at subzero temperatures, the bucket will also require some volume of an antifreeze mixture, the composition and volume of which will vary with the anticipated air temperature. For Geonor gauges deployed at $-51^{\circ} \mathrm{C}$ (e.g. Iqaluit, NU), Campbell Scientific (2016) recommends that the bucket be filled to $60 \%$ capacity with a $2: 3$ mixture of propylene glycol and methanol. This oil/antifreeze mixture reduces the bucket's total capacity, requiring more frequent site visits, and requires some special disposal method for the bucket contents when the gauge is emptied. A user must be aware of bucket-emptying events, which can cause an erroneous signal in the data (such as an apparent large, negative accumulation). 
A variety of shielding options have been developed to reduce wind-bias at gauge height. Since bias-adjustment transfer functions are developed for specific gauge geometries, a user must know the shielding system used at their site, and must be aware of the system's shortcomings. National meteorological offices often designate a small number of configurations to be standard, but variation exists, and these details should be verified with a measurement site manager.

The most popular shield choices in the $20^{\text {th }}$ century were the Nipher shield (Nipher, 1878) and the Russian Tretyakov shield (Goodison et al., 1998). The Nipher, a conical, trumpet-shaped shield, is the Canadian national shield for manual snowfall gauges. The Canadian Nipher showed the best performance in the $3^{\text {rd }} \mathrm{WMO}$ intercomparison, which Sevruk (in Goodison et al., 1998) attributes to the conical shield's ability to deflect airflow downwards and away from the gauge orifice. The Tretyakov shield was the second-best performer after the Nipher, is the national shield for manual gauges in former USSR states, and is the shield used inside the original DFIR.

The bulky geometry of automatic gauges precludes the use of shielding systems like the Nipher. The Alter shield (Alter, 1937) has thus become increasingly important, and is the standard shield for the Geonor weighing gauge at automated stations in Canada. Alter recognized that a taller gauge was subject to greater wind speeds, but his tests of baffle systems at ground level caught drifting snow (the snow saltation flux follows a logarithmic profile, decreasing exponentially with height above the surface). His design arose from the requirement for uniform eddy control around the gauge; a metal ring suspending aluminum lathe plates, whose angle of deflection varies with wind 
speed as the lathes are pushed increasingly to the horizontal. The ring itself is held just above the height of the gauge orifice by arms attached to the gauge pedestal.

The Alter shield is effective at low wind speeds, but its performance degrades rapidly with increasing wind speed (Smith 2007, 2009). This is partly due to the shield's dynamic nature - the lathes are allowed to swing freely, creating chaotic secondary turbulence patterns - and partly because flow deflection around the supporting ring still occurs, leading to flow acceleration above the shield - though this is greatly decreased over the gauge orifice relative to an unshielded gauge (Colli et al., 2015). Errors are also induced at high winds by the shield's attachment to the gauge pedestal, as wind stress is conveyed to the pedestal and subsequently the gauge weighing mechanisms, which can cause high frequency amplitude, commonly referred to as "jitter", in precipitation measurements (Smith, 2007, Lamb and Durocher, 2004). Despite the Alter shield's shortcomings, it is the standard for many nations, including Canada.

The best estimate of "true" snowfall is derived from the double-fence shielding configuration. This consists of an octagonal wooden slat fence of radius $6 \mathrm{~m}$, surrounding a second fence of radius $2 \mathrm{~m}$, surrounding a central shielded gauge, whose orifice is held at $3 \mathrm{~m}$ above the ground surface (Figure 33). A full description of the double fence can be found in Goodison et al. (1998). Gauge height is a trade-off between increasing wind speed with gauge height, and increasing errors from being close to the ground (splash for rain gauges, drifting for snow gauges). In the case of the DFAR, the $3 \mathrm{~m}$ height reduces the influx of blowing snow, which was observed at the $2 \mathrm{~m}$ bush gauge (Yang, 2014).

Unprocessed data from the Iqaluit DFAR for the period from October 1, 2014, to June 30, 2016, was supplied by Environment and Climate Change Canada in late 2016 
(H. Mouradian, 2016, personal communication). This data was collected in $6 \mathrm{~s}$ intervals on an OTT Pluvio² 200-RH weighing-bucket gauge (henceforth: Pluvio).
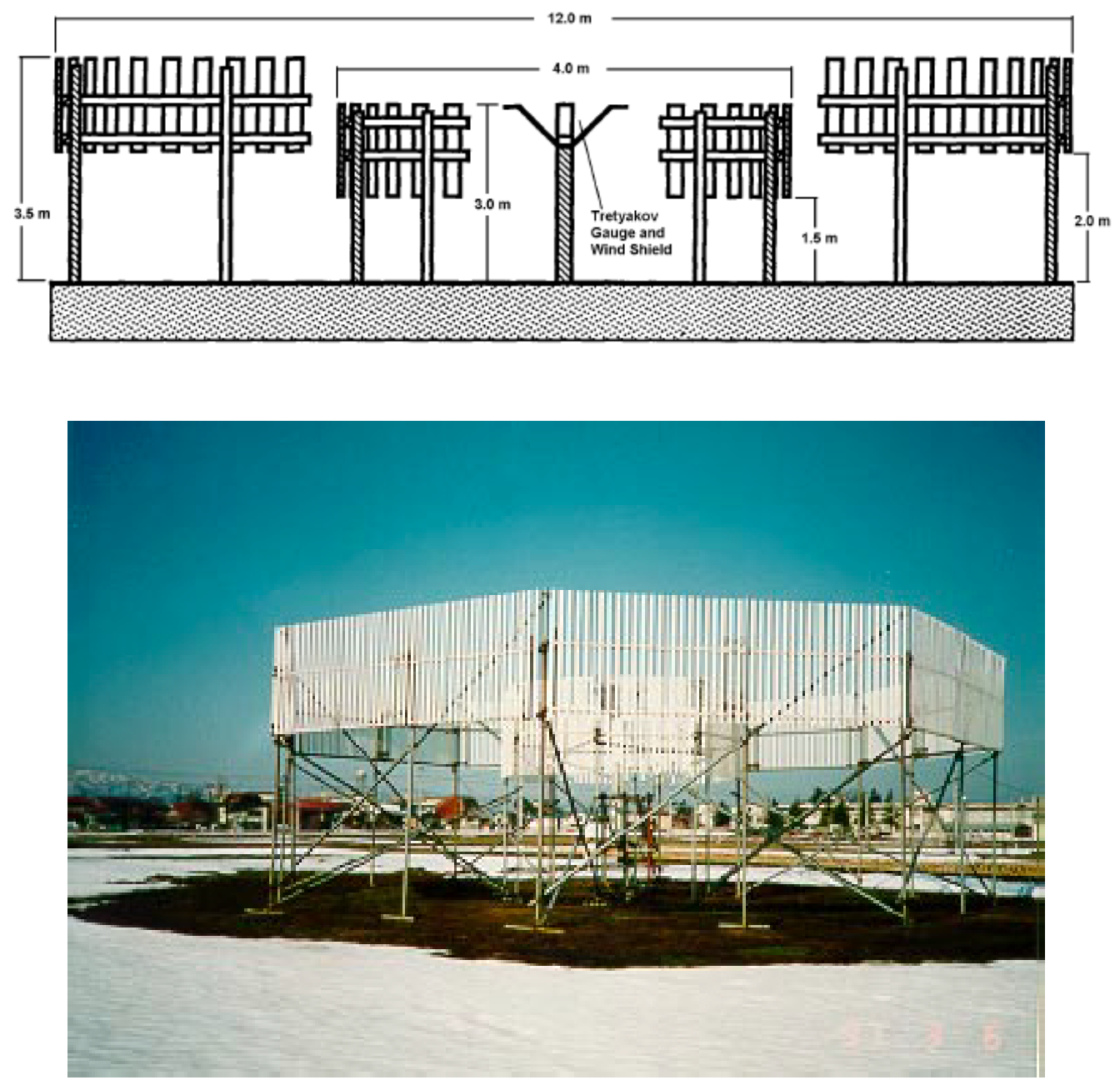

Figure 33: Schematic of the double-fence shielding configuration used in the DFIR/DFAR, and photograph of the DFIR at Hokoriku National Agricultural Experimental Station (Japan). Images from Goodison et al. (1998).

This gauge was installed in the Iqaluit double-fence assembly in September 2013, replacing the Geonor T-200B (henceforth: Geonor) that had been recording there since the double-fence's construction in 2007 (H. Mouradian, 2016, personal communication). 
The gauge showed no evidence of capping and sloughing, indicating that the rim heater worked well, even in the harsh conditions of Arctic winter.

A pre-processing procedure was scripted in $\mathrm{R}$ ( $\mathrm{R}$ Development Core Team, 2013) based on the quality control procedures used in the WMO-SPICE project (Reverdin et al., 2016). A flowchart for this procedure is presented in Figure 34.

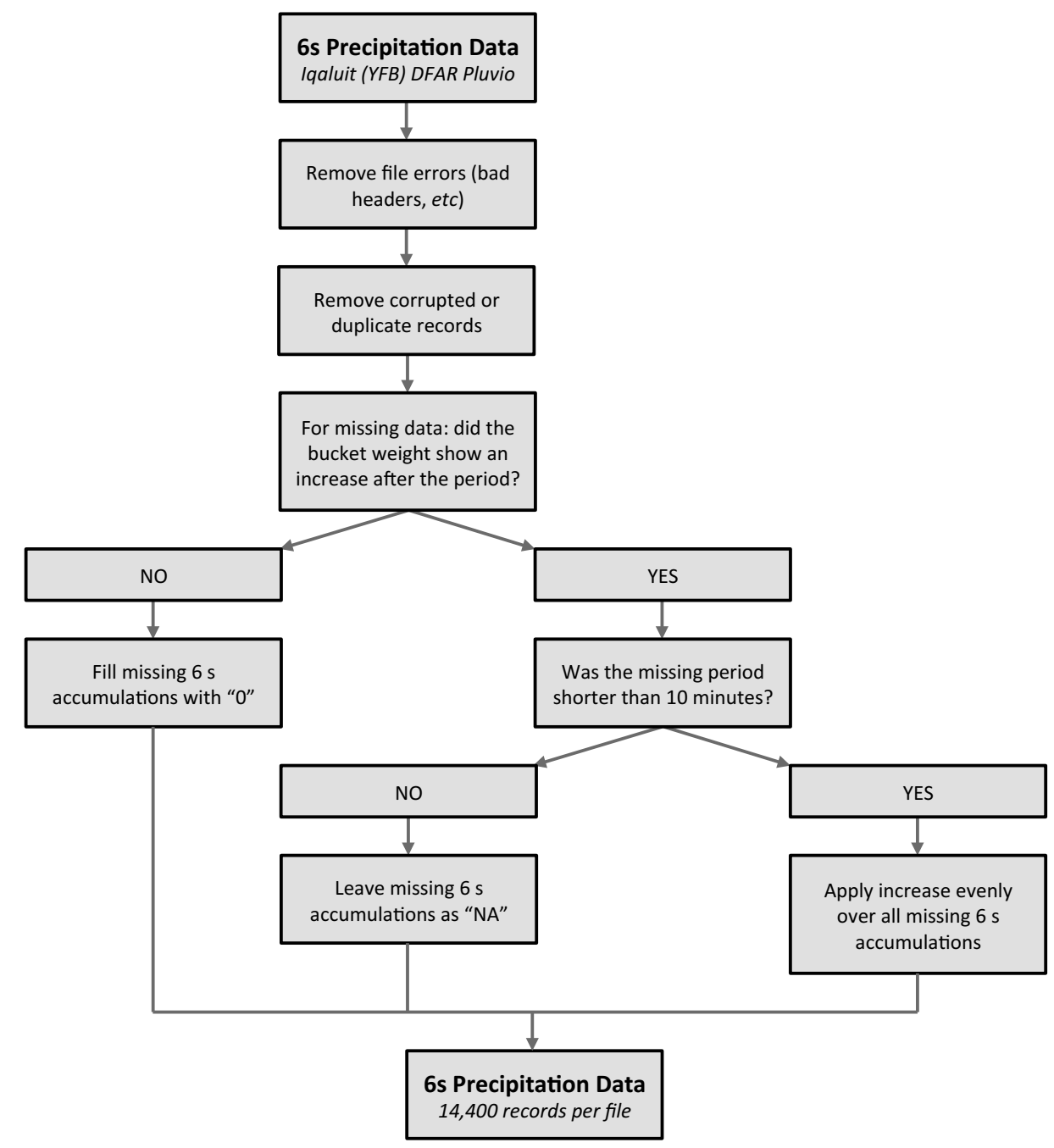

Figure 34: Algorithm for pre-processing of Iqaluit DFAR Pluvio data (Part 1). 


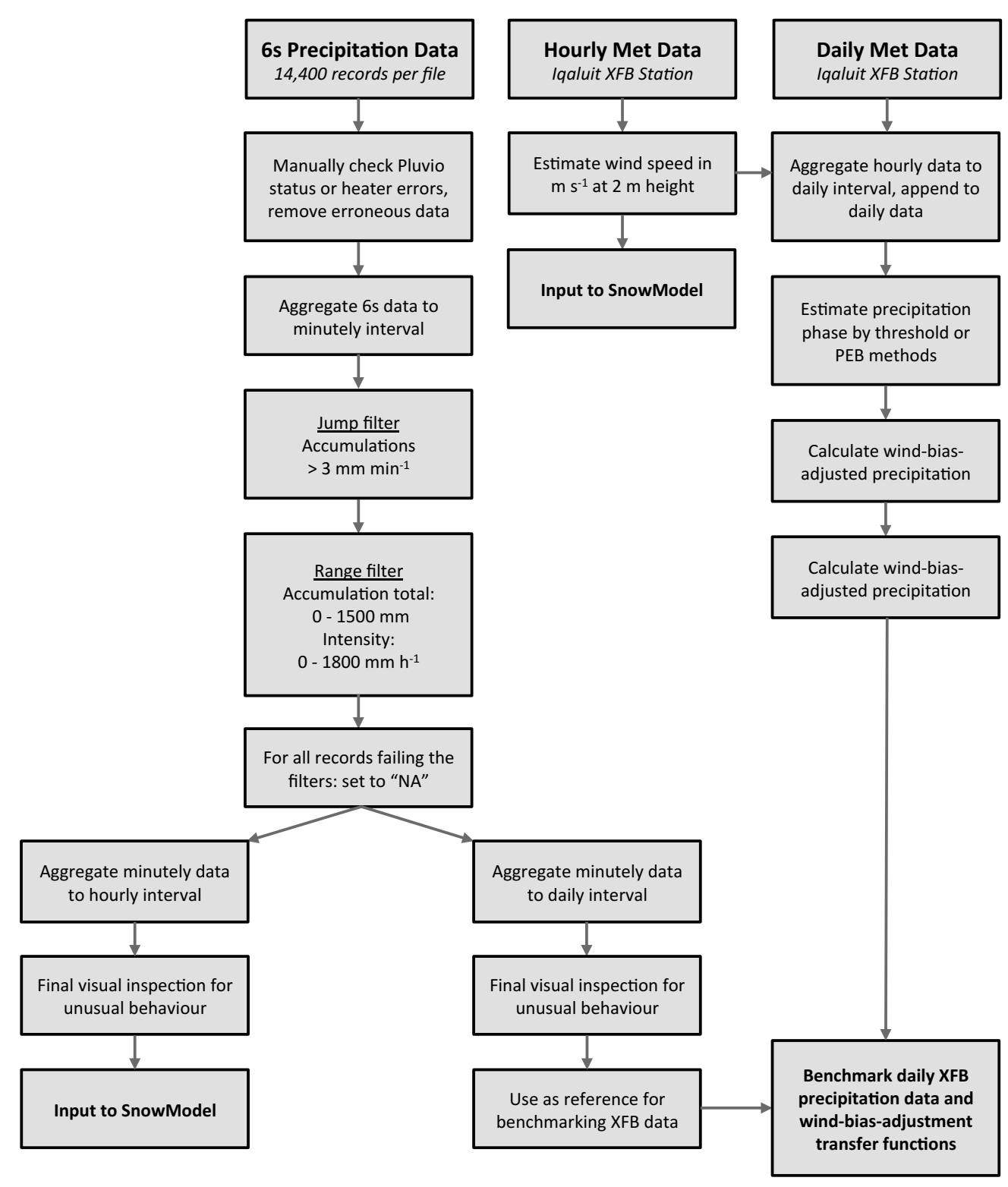

Figure 35: Algorithm for pre-processing of Iqaluit DFAR Pluvio data (Part 2), and processing Iqaluit XFB data to force SnowModel, and for benchmarking XFB precipitation with the final DFAR data.

For each of the 639 raw Pluvio files: 
1. File structure anomalies were removed, including corrupted data lines, erroneous file headers, and inconsistent spacing or character separation.

2. Missing data in the $6 \mathrm{~s}$ accumulations were filled as accurately as possible:

a. Any corrupted or duplicate records were deleted, leaving small $(<1 \mathrm{~min})$ gaps in the record where they had been.

b. All missing data (both from gaps in the original record, and from the removal of faulty records) were filled with "NA" to bring each file to 14,400 records in length.

c. For all "NA" records, the Pluvio's bucket weights before and after the missing period were compared. If these were identical, no precipitation had occurred, so every $6 \mathrm{~s}$ accumulation in the period was set to 0 .

d. If bucket weight increased during a missing period, precipitation had occurred.

i. If the missing period was less than 10 minutes' duration, the difference was applied linearly over the period's length.

ii. If the missing period was longer than 10 minutes, there was insufficient data to determine the timing of the precipitation event, so the $6 \mathrm{~s}$ accumulations were left as NA.

iii. A 10-minute interval was chosen to buffer gaps caused by external communication with the Pluvio, which can delay data collection by up to 5 minutes (OTT Hydromet, 2017).

e. Bucket weight decrease during a missing period indicated that an instrument reset occurred, deleting the cumulative precipitation record. 
Accumulation during the period could not be estimated, so the missing $6 \mathrm{~s}$ accumulations were left as "NA".

3. Error codes were examined for evidence of a malfunction.

a. "Status" errors, indicating faulty and/or unstable measurements, only occurred briefly during instrument resets or communication with the gauge. These events reset the running accumulation total to 0 , but are discarded by the Pluvio's internal filters, so the $6 \mathrm{~s}$ accumulations used when aggregating the data are unaffected.

b. The only "Heater" error was: "a functional check of orifice rim heating was defective".

i. These occurred during instrument resets; functional checks are "successful" if an increase in rim temperature of $0.5{ }^{\circ} \mathrm{C}$ is detected after a short period of heating. Detection is interrupted by external communications, so this is not a "true" error when associated with communication events.

ii. These also occurred sporadically throughout the winter record, rarely lasting more than 3 hours. The most likely explanation for these errors is the extreme cold (most occurred below $-25^{\circ} \mathrm{C}$ ), which may have dissipated the heater's energy through turbulent and radiative fluxes quickly enough to prevent the "functional check" from succeeding. 
iii. There was no evidence of snow capping onto (and subsequent sloughing off of) the gauge rim, suggesting that the heater kept the rim free of snow and ice over the entire winter.

4. After the error codes were manually determined to have no effect on the $6 \mathrm{~s}$ accumulation data, the data were aggregated by summing all accumulations over a 1 minute period.

5. This 1-minute accumulation data was then examined for "jumps" - any event exceeding $3 \mathrm{~mm} \mathrm{~min}^{-1}$. None were detected.

a. Apparent "negative" jumps can also occur when the site technician empties the collecting bucket and refills the antifreeze/oil mixture. Due to the low annual precipitation depths in Iqaluit, this is infrequently needed (D. Coulombe, 2016, personal communication). In any case, such decreases only occur during instrument resets, and do not affect the $6 \mathrm{~s}$ accumulations.

6. A range filter then checks that the accumulation total and precipitation intensity values are within the operating ranges $(0-1500 \mathrm{~mm}$ for accumulation, and 0-1800 $\mathrm{mm} \mathrm{h}^{-1}$ for intensity). The only measurements out of range were during instrument resets, and do not affect the $6 \mathrm{~s}$ accumulations.

7. After performing all QC checks, the 1-min data were then aggregated by summing all accumulations in each hour, or in each day. As a result of the filling procedure, any missing data must occur in blocks of 10 minutes or more, representing an accumulation of potentially unknown magnitude over that period. If an hour or day were found to contain such a block of missing data, the entire 
hour or day was marked missing ("NA"). There were no missing hours in the 2016 winter, and only 2 days in the 2015 winter were marked missing, with only 3 missing hours in each:
a. 2014-11-08, from 12:00-15:00
b. 2015-03-22, from 04:00-07:00

8. In both of the missing data cases above, the missing period occurred in the original record, and seems to have been the result of an undiagnosed instrumental error. Since the bucket weight over these periods increased by $0.3 \mathrm{~mm}$ and 0.06 $\mathrm{mm}$, respectively, it was decided that their contributions were negligible in the larger record, and precipitation for these periods was set to $0 \mathrm{~mm}$.

9. The resulting daily and hourly datasets were examined for unusual or unexpected behaviour. None was observed. 


\section{Appendix L- Potential Errors in Iqaluit XFB Measured Data}

Measurements of $T_{a}$ and $R H$ from the field micrometeorological tower (henceforth, FT), established by the author in southern Niaqunguk River Watershed (NRW) in spring 2015, closely matched those from the Iqaluit XFB station (Table 17).

The measurements were taken by comparable instruments, within $6 \mathrm{~km}$ distance and 200 m elevation of one another, so synoptic conditions between the two sites will be similar. Frobisher Bay remains open until mid-winter, but due to the proximity of both measurement sites to the Bay, any regime shift caused by sea-ice formation should have affected both locations similarly.

Table 17: Comparison of winter meteorological variables at Iqaluit XFB and the field tower (FT). Due to an error in the datalogger's averaging procedure, wind direction data is not available for 2016 .

\begin{tabular}{|c|c|c|c|c|}
\hline & $\begin{array}{c}\text { Mean } T_{a} \\
\quad\left({ }^{\circ} \mathrm{C}\right)\end{array}$ & $\begin{array}{c}\text { Mean } R H \\
(\%)\end{array}$ & $\begin{array}{c}\operatorname{Mean} u \\
\left(\mathrm{~m} \mathrm{~s}^{-1}\right)\end{array}$ & $\begin{array}{c}\text { Mean } \theta \\
\left({ }^{\circ}\right)\end{array}$ \\
\hline & \multicolumn{4}{|c|}{2016} \\
\hline XFB & -17.4 & 77.6 & 4.1 & 340 \\
\hline \multirow[t]{2}{*}{ FT } & -17.6 & NA & 5.1 & NA \\
\hline & \multicolumn{4}{|c|}{2017} \\
\hline XFB & -18 & 77.8 & 3.7 & 340 \\
\hline FT & -17.3 & 78.0 & 4.7 & 36 \\
\hline
\end{tabular}

The greatest difference in these records is in $u$ and $\theta$, which were found to vary significantly more at FT than at XFB (Table 17). Wind speeds at FT were generally greater $-1 \mathrm{~m} \mathrm{~s}^{-1}$ greater than XFB on average in both years. For the single year of available winter data, mean $\theta$ at FT was from the NNE, whereas NNW winds were observed at XFB. These data suggest that the wind measurements at XFB may not be ideally representative of winds on the open tundra of the NRW, underestimating $u$ and 
the variability in $\theta$. The extent to which uncertainties in these input will affect SnowModel is unclear but potentially large.

SnowModel requires accurate $u$ to solve for aerodynamic shear stress, which in turn determines whether snow will be eroded, transported, or deposited at a grid cell in a given time step. In addition to mass fluxes of solid snow, $u$ also determines the extent of blowing snow sublimation, where large vapour fluxes to the atmosphere from wellventilated crystals in suspension have been observed. Underestimating $u$ could thus cause the model to underestimate these fluxes, resulting in a large cumulative overestimation of terrestrial SWE by the end of winter. The importance of $\theta$ is in determining the transport direction, and thus the position and orientation of drifts.

These differences may arise as an artefact of measurement and data aggregation techniques. The open, flat terrain at the airport (relative to the complex topography around FT) reduces lateral flow variance relative to the complex terrain of the NRW. Similar prevailing winds are observed at both sites, though wind exposure at FT was partly blocked by a hill to the SW, and the shelter effect of this hill is clearly visible in the wind rose (Figure 36). If the site had not been blocked to the SW, this side of the tower's exposure would likely have matched the NE side, resulting in higher overall variability in wind direction, and reducing bias in the mean, such that the prevailing wind direction would be NNE. 


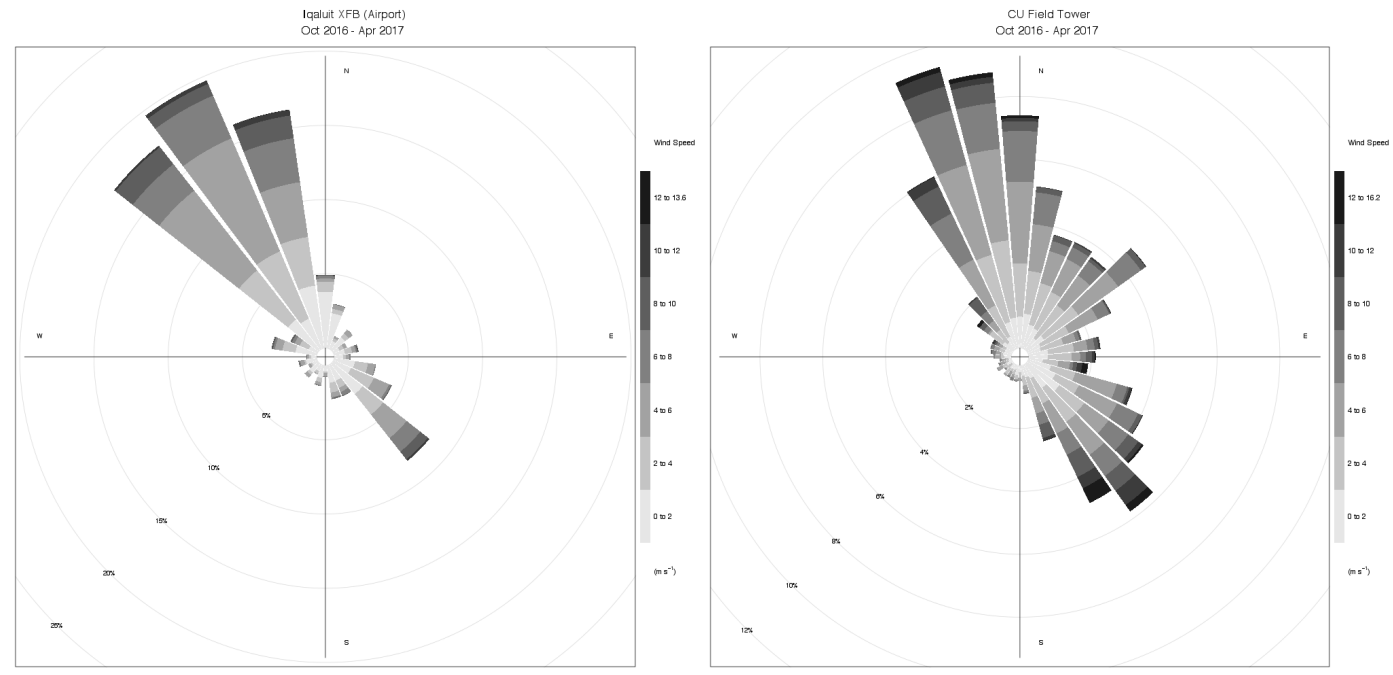

Figure 36: Wind roses for the 2016-17 winter at Iqaluit XFB (left, measured at $10 \mathrm{~m}$ height at Iqaluit airport) and the field tower (right).

Differences in $u$ could arise due to flow acceleration around terrain at many locations in the NRW. Alternatively, this could arise from another artefact: ECCC reports hourly $u$ as the average of the last $120 \mathrm{~s}$ on the hour. This introduces sampling bias relative to a regular schedule (such as the $5 \mathrm{~s}$ measurement routine at FT), as $u$ tends to follow a positively skewed Weibull distribution (Justus et al., 1978, Davenport, 1964). Since a far larger number of samples are taken under the FT measurement scheme, the FT mean should tend more closely to the true mean (per the Law of Large Numbers), whereas it is possible that XFB will tend to underestimate the true mean due to the much smaller sample size per hour and skewed population probability density function.

The difference in $u$ and $\theta$ between XFB and FT may have arisen from differences in instrumentation and sampling technique. While there is some evidence that this may be a true difference between the sites, this cannot be declared with certainty. More importantly, the record from FT is incomplete (with no observations in 2015, and no $\theta$ in 
2016). Thus, while XFB may somewhat misrepresent wind in the NRW, it remains the best choice for input to SnowModel. 